\title{
Integrated Watershed-Scale Response to Climate Change for Selected Basins Across the United States
}

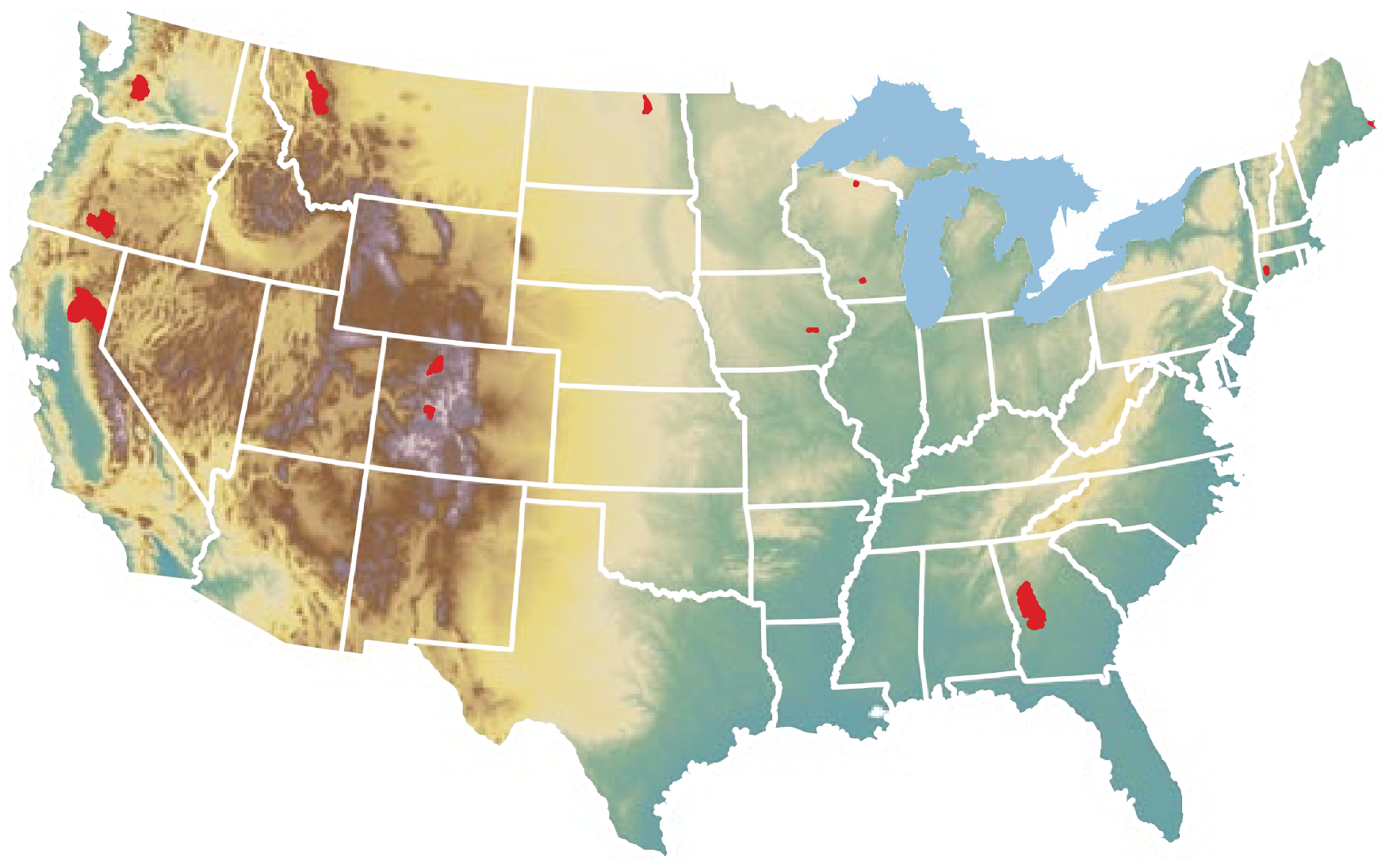

Scientific Investigations Report 2011-5077 
Cover. Output from the General Circulation Model used to simulate the response of the Earth's atmosphere to all important driving forces, especially greenhouse gases, and are used for projecting changes in climate globally. 


\section{Integrated Watershed-Scale Response to Climate Change for Selected Basins Across the United States}

By Steven L. Markstrom, Lauren E. Hay, Christian D. Ward-Garrison, John C. Risley, William A. Battaglin, David M. Bjerklie, Katherine J. Chase, Daniel E. Christiansen, Robert W. Dudley, Randall J. Hunt, Kathryn M. Koczot, Mark C. Mastin, R. Steven Regan, Roland J. Viger, Kevin C. Vining, and John F. Walker

Scientific Investigations Report 2011-5077 


\title{
U.S. Department of the Interior \\ KEN SALAZAR, Secretary \\ U.S. Geological Survey \\ Marcia K. McNutt, Director
}

\author{
U.S. Geological Survey, Reston, Virginia: 2012
}

For more information on the USGS - the Federal source for science about the Earth, its natural and living resources, natural hazards, and the environment, visit http://www.usgs.gov or call 1-888-ASK-USGS.

For an overview of USGS information products, including maps, imagery, and publications, visit http://www.usgs.gov/pubprod

To order this and other USGS information products, visit http://store.usgs.gov

Any use of trade, product, or firm names is for descriptive purposes only and does not imply endorsement by the U.S. Government.

Although this report is in the public domain, permission must be secured from the individual copyright owners to reproduce any copyrighted materials contained within this report.

Suggested citation:

Markstrom, S.L., Hay, L.E., Ward-Garrison, C.D., Risley, J.C., Battaglin, W.A., Bjerklie, D.M., Chase, K.J., Christiansen, D.E., Dudley, R.W., Hunt, R.J., Koczot, K.M., Mastin, M.C., Regan, R.S., Viger, R.J., Vining, K.C., and Walker, J.F., 2012, Integrated watershed-scale response to climate change for selected basins across the United States: U.S. Geological Survey Scientific Investigations Report 2011-5077, 143 p. 


\section{Contents}

Abstract

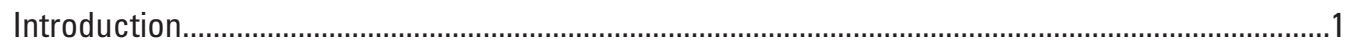

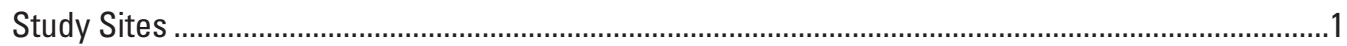

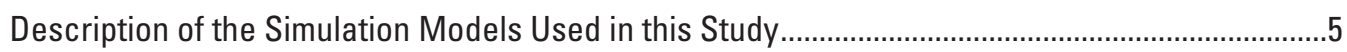

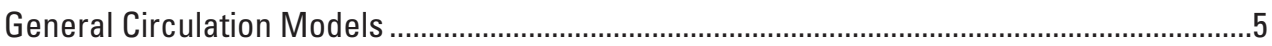

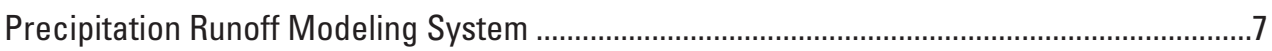

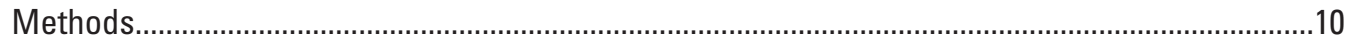

Step 1: Evaluate Precipitation Runoff Modeling System Applications for Baseline

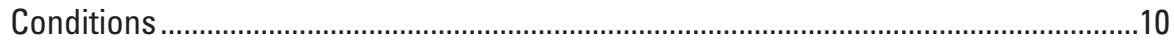

Step 2: Select and Acquire General Circulation Model Projections......................................15

Step 3: Downscale General Circulation Model Projections ...................................................15

Step 4: Generate the Precipitation Runoff Modeling System Projections ..............................18

Step 5: Analyze the Precipitation Runoff Modeling System Projections..................................18

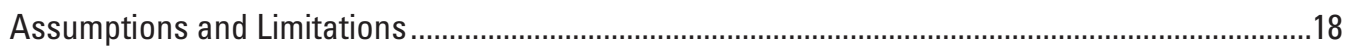

Spatial and Temporal Resolution.................................................................................... 19

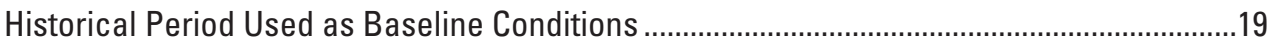

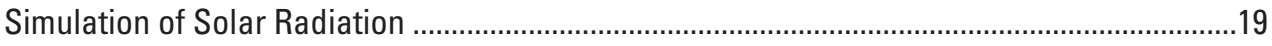

Simulation of Snowmelt and Rainfall on Snowpacks ..........................................................19

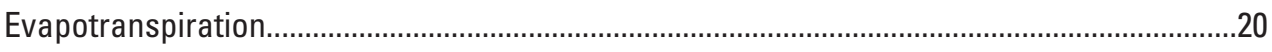

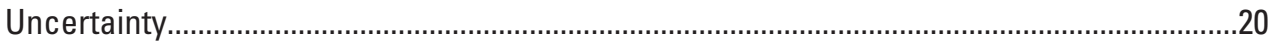

Precipitation Runoff Modeling System Projections by Application ..................................................21

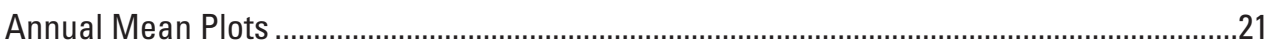

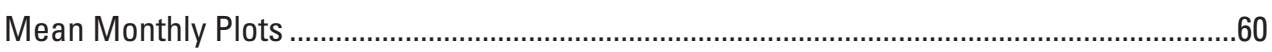

Precipitation Runoff Modeling System Projections for Black Earth Creek, Wisconsin..........60

Black Earth Creek Input Variables .................................................................................60

Black Earth Creek Streamflow Variables.................................................................60

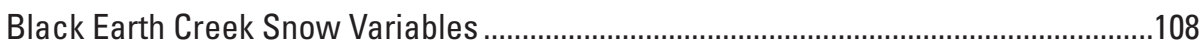

Black Earth Creek Soil Moisture Variables ....................................................................108

Discussion of Black Earth Creek Projections ................................................................108

Precipitation Runoff Modeling System Projections for Cathance Stream, Maine ................108

Cathance Stream Input Variables .................................................................................109

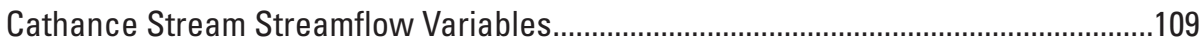

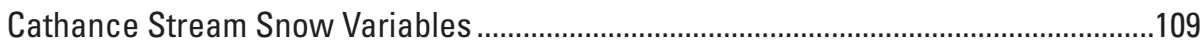

Cathance Stream Soil Moisture Variables .................................................................109

Discussion of Cathance Stream Projections .................................................................109

Precipitation Runoff Modeling System Projections for Clear Creek, lowa ............................110

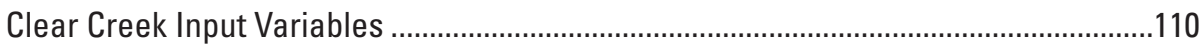

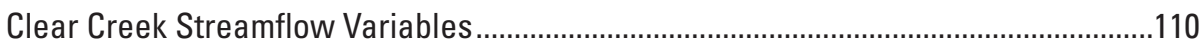

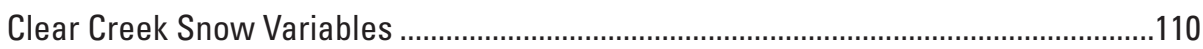

Clear Creek Soil Moisture Variables.......................................................................111

Discussion of Clear Creek Projections...........................................................................111

Precipitation Runoff Modeling System Projections for East River, Colorado ........................111

East River Input Variables ..................................................................................111

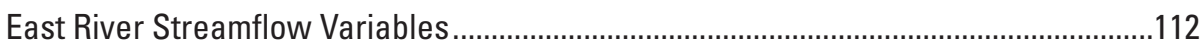


East River Snow Variables .........................................................................................112

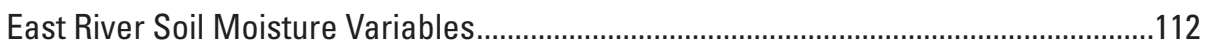

Discussion of East River Projections........................................................................112

Precipitation Runoff Modeling System Projections for Feather River, California ..................112

Feather River Input Variables ...................................................................................113

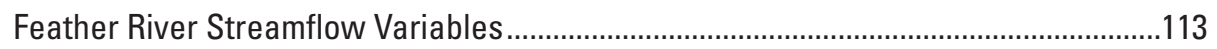

Feather River Snow Variables ....................................................................................114

Feather River Soil Moisture Variables........................................................................114

Discussion of Feather River Projections.....................................................................114

Precipitation Runoff Modeling System Projections for South Fork Flathead River,

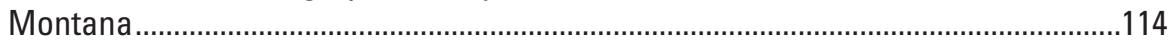

Flathead River Input Variables.................................................................................115

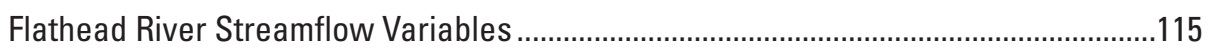

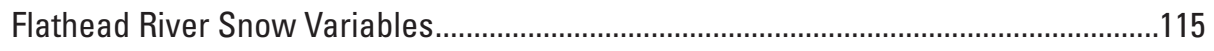

Flathead River Soil Moisture Variables.................................................................115

Discussion of Flathead River Results .........................................................................116

Precipitation Runoff Modeling System Projections for Flint River, Georgia ..........................116

Flint River Input Variables.......................................................................................116

Flint River Streamflow Variables .............................................................................116

Flint River Snow Variables......................................................................................116

Flint River Soil Moisture Variables..........................................................................117

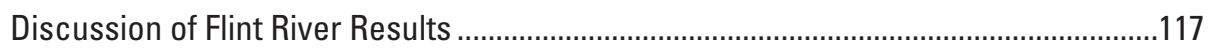

Precipitation Runoff Modeling System Projections for Naches River, Washington .............117

Naches River Input Variables .................................................................................117

Naches River Streamflow Variables...........................................................................118

Naches River Snow Variables .....................................................................................118

Naches River Soil Moisture Variables ........................................................................118

Discussion of Naches River Results...........................................................................118

Precipitation Runoff Modeling System Projections for Pomperaug River, Connecticut ......119

Pomperaug River Input Variables .............................................................................119

Pomperaug River Streamflow Variables......................................................................119

Pomperaug River Snow Variables ...............................................................................119

Pomperaug River Soil Moisture Variables................................................................120

Discussion of Pomperaug River Results ................................................................120

Precipitation Runoff Modeling System Projections for Sagehen Creek, California ..............120

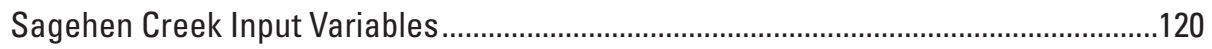

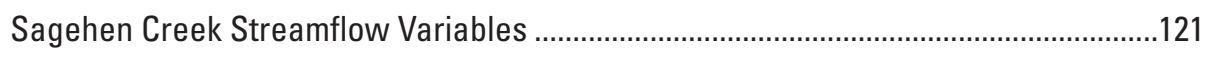

Sagehen Creek Snow Variables .............................................................................121

Sagehen Creek Soil Moisture Variables ..................................................................121

Discussion of Sagehen Creek Results ..................................................................121

Precipitation Runoff Modeling System Projections for Sprague River, Oregon ...................121

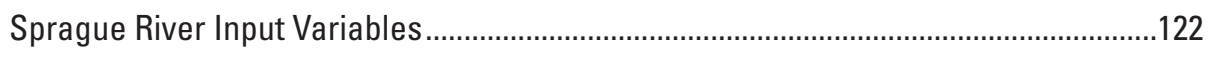

Sprague River Streamflow Variables .....................................................................122

Sprague River Snow Variables...............................................................................122

Sprague River Soil Moisture Variables ...................................................................122

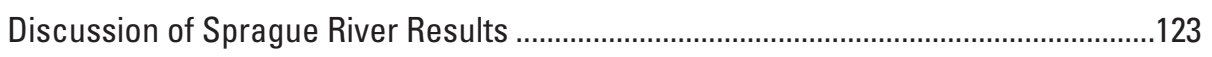


Precipitation Runoff Modeling System Projections for Starkweather Coulee, North Dakota. 123

Starkweather Coulee Input Variables .......................................................................123

Starkweather Coulee Streamflow Variables............................................................123

Starkweather Coulee Snow Variables ........................................................................124

Starkweather Coulee Soil Moisture Variables..........................................................124

Discussion of Starkweather Coulee Results..............................................................124

Precipitation Runoff Modeling System Projections for Trout Lake, Wisconsin ....................124

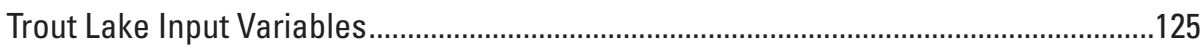

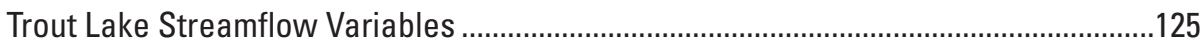

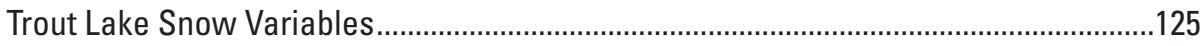

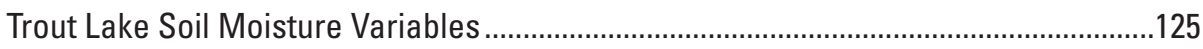

Discussion of Trout Lake Results ............................................................................125

Precipitation Runoff Modeling System Projections for Yampa River, Colorado.....................126

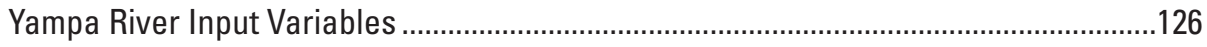

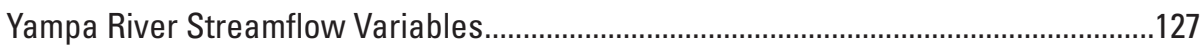

Yampa River Snow Variables ......................................................................................127

Yampa River Soil Moisture Variables .......................................................................127

Discussion of Yampa River Results............................................................................127

Integrated Watershed Scale Response to Climate Change for Selected Basins Across

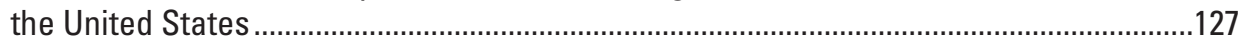

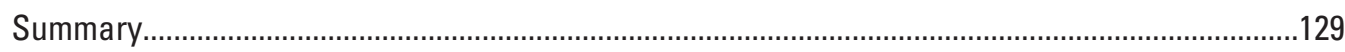

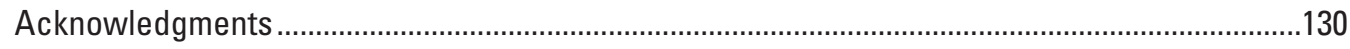

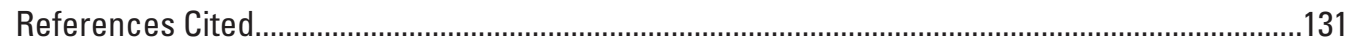

Appendix

\section{Figures}

1. Map showing Precipitation Runoff Modeling System application sites for selected basins across the United States......................................................................2

2. Modeling sequence: output from coarse General Circulation Models used as input to fine scale Precipitation Runoff Modeling System applications across the United States.

3. Components of the snowpack energy balance, accumulation, snowmelt, and sublimation............................................................................................................

4. Watershed and inputs simulated by the Precipitation Runoff Modeling System

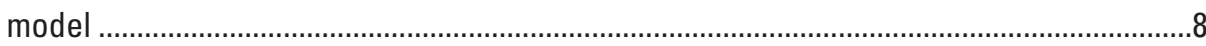

5. Graph showing basin mean monthly (1989-1999): $(A)$ maximum temperature $(B)$ minimum temperature, and $(C)$ precipitation for the 14 basins.

6. Graph showing alibration results by basin (1989-1999): mean monthly measured (gray) and Precipitation Runoff Modeling System-simulated (black) solar radiation, potential evapotranspiration, and streamflow.

7. Schematic diagram showing the climate change factor method as applied in this study. 
8. Screen capture showing SHODAN user interface used to create Precipitation Runoff Modeling System input data files for future climatic conditions:

(A) Setup Parameters; $(B)$ Setup Input; $(C)$ Setup Output; and (D) Run windows............17

9. An example of the tasmax_xyz file of station point locations used by Shodan ...............18

10-47. Graphs showing:

10. Projected range in 11 -year moving mean daily precipitation values by emission scenarios for the 14 basins

11. Projected range in 11-year moving mean daily maximum temperature values by emission scenarios for the 14 basins

12. Projected range in 11 -year moving mean daily minimum temperature values by emission scenarios for the 14 basins.

13. Projected range in 11-year moving mean daily evapotransipration values by emission scenarios for the 14 basins

14. Projected range in 11-year moving mean growing season length by emission scenarios for the 14 basins

15. Projected range in 11-year moving mean daily streamflow values by emission scenarios for the 14 basins

16. Projected range in 11-year moving mean daily surface runoff values by emission scenarios for the 14 basins

17. Projected range in 11-year moving mean daily subsurface flow values by emission scenarios for the 14 basins

18. Projected range in 11-year moving mean daily groundwater flow values by emission scenarios for the 14 basins

19. Projected range in 11-year moving mean daily percent of precipitation that falls as snow by emission scenarios for the 14 basins

20. Projected range in 11-year moving mean daily percent of area covered by snow by emission scenarios for the 14 basins

21. Projected range in 11-year moving mean daily snowpack water equivalent by emission scenarios for the 14 basins

22. Projected range in 11-year moving mean daily snowmelt values by emission scenarios for the 14 basins

23. Projected range in 11-year moving mean daily infiltration values by emission scenarios for the 14 basins

24. Projected range in 11-year moving mean daily subsurface reservoir inflow values by emission scenarios for the 14 basins

25. Projected range in 11-year moving mean daily groundwater reservoir recharge values by emission scenarios for the 14 basins

26. Projected range in 11-year moving mean daily soil moisture storage values by emission scenarios for the 14 basins

27. Projected range in 11-year moving mean daily subsurface reservoir storage values by emission scenarios for the 14 basins

28. Projected range in 11-year moving mean daily groundwater reservoir storage values by emission scenarios for the 14 basins 
29. Mean daily precipitation values by month for baseline conditions and projected range $(2030,2060$, and 2090) using the 5 general circulation models and 3 emission scenarios for the 14 basins

30. Mean daily maximum temperature values by month for baseline conditions and projected range $(2030,2060$, and 2090) using the 5 general circulation models and 3 emission scenarios for the 14 basins

31. Mean daily minimum temperature values by month for baseline conditions and projected range $(2030,2060$, and 2090) using the 5 general circulation models and 3 emission scenarios for the 14 basins

32. Mean daily evapotransipration values by month for baseline conditions and projected range $(2030,2060$, and 2090) using the 5 general circulation models and 3 emission scenarios for the 14 basins

33. Mean daily streamflow values by month for baseline conditions and projected range $(2030,2060$, and 2090) using the 5 general circulation models and 3 emission scenarios for the 14 basins

34. Mean daily surface runoff values by month for baseline conditions and projected range $(2030,2060$, and 2090) using the 5 general circulation models and 3 emission scenarios for the 14 basins .

35. Mean daily subsurface flow values by month for baseline conditions and projected range $(2030,2060$, and 2090) using the 5 general circulation models and 3 emission scenarios for the 14 basins

36. Mean daily groundwater flow values by month for baseline conditions and projected range $(2030,2060$, and 2090) using the 5 general circulation models and 3 emission scenarios for the 14 basins

37. Mean daily percent of precipitation that falls as snow by month for baseline conditions and projected range $(2030,2060$, and 2090) using the 5 general circulation models and 3 emission scenarios for the 14 basins

38. Mean daily percent of area covered by snow by month for baseline conditions and projected range $(2030,2060$, and 2090) using the 5 general circulation models and 3 emission scenarios for the 14 basins

39. Mean daily snowpack water equivalent by month for baseline conditions and projected range $(2030,2060$, and 2090) using the 5 general circulation models and 3 emission scenarios for the 14 basins

40. Mean daily snowmelt values by month for baseline conditions and projected range $(2030,2060$, and 2090) using the 5 general circulation models and 3 emission scenarios for the 14 basins

41. Mean daily infiltration values by month for baseline conditions and projected range $(2030,2060$, and 2090) using the 5 general circulation models and 3 emission scenarios for the 14 basins.

42. Mean daily subsurface reservoir inflow values by month for baseline conditions and projected range $(2030,2060$, and 2090) using the 5 general circulation models and 3 emission scenarios for the 14 basins.

43. Mean daily groundwater reservoir recharge values by month for baseline conditions and projected range $(2030,2060$, and 2090) using the 5 general circulation models and 3 emission scenarios for the 14 basins 
44. Mean daily soil moisture storage values by month for baseline conditions and projected range $(2030,2060$, and 2090) using the 5 general circulation models and 3 emission scenarios for the 14 basins

45. Mean daily subsurface reservoir storage values by month for baseline conditions and projected range $(2030,2060$, and 2090) using the 5 general circulation models and 3 emission scenarios for the 14 basins

46. Mean daily groundwater reservoir storage values by month for baseline conditions and projected range $(2030,2060$, and 2090) using the 5 general circulation models and 3 emission scenarios for the 14 basins

47. Mean monthly hydrographs for baseline conditions and projected conditions (2030, 2060, and 2090) using 5 general circulation models and 3 emission scenarios for the 14 basins

\section{Tables}

1. Drainage area, number of hydrologic response units, and elevation ranges for selected basins across the United States...

2. General Circulation Model projections used in this study

3. Description of Precipitation Runoff Modeling System variables analyzed in the climate change study

4. Carbon emission scenarios simulated by the General Circulation Models in this study

5. Projected change by year (slope) and adjusted $R^{2}\left(R^{2}\right)$ based on the central tendencies of the five General Circulation Models for the three carbon emission scenarios by basin for selected Precipitation Runoff Modeling System output variables.

\section{Appendix Tables}

A1-1. Input parameters to module transp_frost_prms ................................................................136

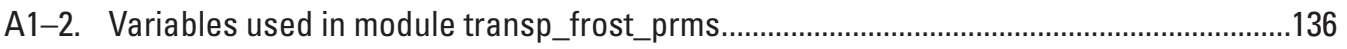

A1-3. Input parameters to module transp_frost_prms .............................................................137

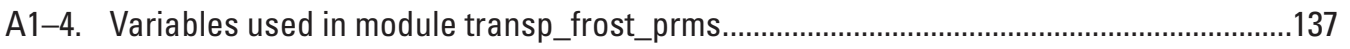

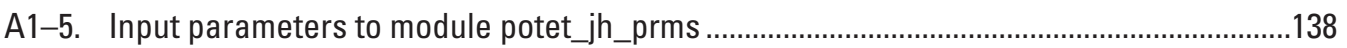

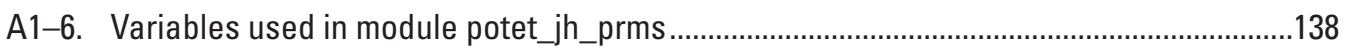

A1-7. Input parameters to module potet_hamon_hru_prms .....................................................139

A1-8. Variables used in module potet_hamon_hru_prms..........................................................140

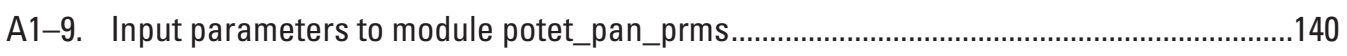

A1-10. Variables used in module potet_pan_prms ....................................................................141

A1-11. Input parameters to module frost_date_prms ……….................................................... 141

A1-12. Variables used in module frost_date_prms .....................................................................142 


\section{Conversion Factors}

SI to Inch/Pound

\begin{tabular}{|c|c|c|}
\hline Multiply & By & To obtain \\
\hline \multicolumn{3}{|c|}{ Length } \\
\hline millimeter (mm) & 0.03937 & inch (in.) \\
\hline meter $(\mathrm{m})$ & 3.281 & foot $(\mathrm{ft})$ \\
\hline kilometer $(\mathrm{km})$ & 0.6214 & mile (mi) \\
\hline \multicolumn{3}{|c|}{ Area } \\
\hline square kilometer $\left(\mathrm{km}^{2}\right)$ & 247.1 & acre \\
\hline square meter $\left(\mathrm{m}^{2}\right)$ & 10.76 & square foot $\left(\mathrm{ft}^{2}\right)$ \\
\hline square kilometer $\left(\mathrm{km}^{2}\right)$ & 0.3861 & square mile $\left(\mathrm{mi}^{2}\right)$ \\
\hline \multicolumn{3}{|c|}{ Volume } \\
\hline liter $(\mathrm{L})$ & 0.2642 & gallon (gal) \\
\hline cubic meter $\left(\mathrm{m}^{3}\right)$ & 264.2 & gallon (gal) \\
\hline cubic meter $\left(\mathrm{m}^{3}\right)$ & 35.31 & cubic foot $\left(\mathrm{ft}^{3}\right)$ \\
\hline \multicolumn{3}{|c|}{ Flow rate } \\
\hline cubic meter per second $\left(\mathrm{m}^{3} / \mathrm{s}\right)$ & 70.07 & acre-foot per day (acre-ft/d) \\
\hline meter per second $(\mathrm{m} / \mathrm{s})$ & 3.281 & foot per second (ft/s) \\
\hline meter per day $(\mathrm{m} / \mathrm{d})$ & 3.281 & foot per day (ft/d) \\
\hline cubic meter per second $\left(\mathrm{m}^{3} / \mathrm{s}\right)$ & 35.31 & cubic foot per second $\left(\mathrm{ft}^{3} / \mathrm{s}\right)$ \\
\hline cubic meter per day $\left(\mathrm{m}^{3} / \mathrm{d}\right)$ & 35.31 & cubic foot per day $\left(\mathrm{ft}^{3} / \mathrm{d}\right)$ \\
\hline cubic meter per day $\left(\mathrm{m}^{3} / \mathrm{d}\right)$ & 264.2 & gallon per day (gal/d) \\
\hline \multicolumn{3}{|c|}{ Mass } \\
\hline $\operatorname{gram}(\mathrm{g})$ & 0.03527 & ounce, avoirdupois (oz) \\
\hline kilogram $(\mathrm{kg})$ & 2.205 & pound avoirdupois (lb) \\
\hline \multicolumn{3}{|c|}{ Pressure } \\
\hline kilopascal (kPa) & 0.2961 & inch of mercury at $60^{\circ} \mathrm{F}$ (in $\mathrm{Hg}$ ) \\
\hline kilopascal $(\mathrm{kPa})$ & 0.1450 & pound per square inch $\left(\mathrm{lb} / \mathrm{ft}^{2}\right)$ \\
\hline \multicolumn{3}{|c|}{ Density } \\
\hline $\begin{array}{l}\text { gram per cubic centimeter } \\
\left(\mathrm{g} / \mathrm{cm}^{3}\right)\end{array}$ & 62.4220 & pound per cubic foot $\left(\mathrm{lb} / \mathrm{ft}^{3}\right)$ \\
\hline \multicolumn{3}{|c|}{ Hydraulic conductivity } \\
\hline meter per day $(\mathrm{m} / \mathrm{d})$ & 3.281 & foot per day (ft/d) \\
\hline millimeter per day $(\mathrm{mm} / \mathrm{d})$ & 0.03937 & inch per day (in/d) \\
\hline \multicolumn{3}{|c|}{ Hydraulic gradient } \\
\hline meter per kilometer $(\mathrm{m} / \mathrm{km})$ & 5.27983 & foot per mile ( $\mathrm{ft} / \mathrm{mi})$ \\
\hline \multicolumn{3}{|c|}{ Transmissivity* } \\
\hline meter squared per day $\left(\mathrm{m}^{2} / \mathrm{d}\right)$ & 10.76 & foot squared per day $\left(\mathrm{ft}^{2} / \mathrm{d}\right)$ \\
\hline
\end{tabular}

Temperature in degrees Celsius $\left({ }^{\circ} \mathrm{C}\right)$ may be converted to degrees Fahrenheit $\left({ }^{\circ} \mathrm{F}\right)$ as follows:

${ }^{\circ} \mathrm{F}=\left(1.8 \times^{\circ} \mathrm{C}\right)+32$

Temperature in degrees Fahrenheit $\left({ }^{\circ} \mathrm{F}\right)$ may be converted to degrees Celsius $\left({ }^{\circ} \mathrm{C}\right)$ as follows:

${ }^{\circ} \mathrm{C}=\left({ }^{\circ} \mathrm{F}-32\right) / 1.8$

Vertical coordinate information is referenced to North American Vertical Datum of 1988 (NAVD 88).

Altitude, as used in this report, refers to distance above the vertical datum. 
*Transmissivity: The standard unit for transmissivity is cubic foot per day per square foot times foot of aquifer thickness [(ft $\left.\left.\mathrm{ft}^{3} / \mathrm{d}\right) / \mathrm{ft}^{2}\right] \mathrm{ft}$. In this report, the mathematically reduced form, foot squared per day $\left(\mathrm{ft}^{2} / \mathrm{d}\right)$, is used for convenience.

\section{Abbreviations and Acronyms}

$\begin{array}{ll}\text { 20C3M } & \text { 20th century climate emission scenario } \\ \text { A1B } & \text { 21st century A1B climate emission scenario } \\ \text { A2 } & \text { 21st century A2 climate emission scenario } \\ \text { R }^{2} & \text { Adjusted R }{ }^{2} \text { (see Helsel and Hirsh, 2002) } \\ \text { AET } & \text { Actual Evapotranspiration } \\ \text { B1 } & \text { 21st century B1 climate emission scenario } \\ \text { CMIP3 } & \text { World Climate Research Programme's Coupled Model Intercomparison } \\ & \text { Project phase 3 } \\ \text { COOP } & \text { Cooperative Observer Program } \\ \text { GCM } & \text { General Circulation Models or Global Climate Model } \\ \text { GSFLW } & \text { Groundwater and Surface-Water Flow Model } \\ \text { HRU } & \text { Hydrologicl Response Unit } \\ \text { IPCC } & \text { Intergovernmental Panel on Climate Change } \\ \text { NOAA } & \text { National Oceanic and Atmospheric Administration } \\ \text { NRCS } & \text { Natural Resources Conservation Service } \\ \text { NWIS } & \text { National Water Information System } \\ \text { PET } & \text { Potential Evapotranspiration } \\ \text { PRMS } & \text { Precipitation Runoff Modeling System } \\ \text { SNOTEL } & \text { Snow Telemetry } \\ \text { SR } & \text { Solar Radiation } \\ \text { SRES } & \text { IPCC Fourth Assessment Special Report on Emission Scenarios } \\ \text { USGS } & \text { U.S. Geological Survey } \\ \text { WY } & \text { Water Year }\end{array}$




\title{
Integrated Watershed-Scale Response to Climate Change for Selected Basins Across the United States
}

\author{
By Steven L. Markstrom, Lauren E. Hay, Christian D. Ward-Garrison, John C. Risley, William A. Battaglin, \\ David M. Bjerklie, Katherine J. Chase, Daniel E. Christiansen, Robert W. Dudley, Randall J. Hunt, Kathryn M. \\ Koczot, Mark C. Mastin, R. Steven Regan, Roland J. Viger, Kevin C. Vining, and John F. Walker
}

\section{Abstract}

A study by the U.S. Geological Survey (USGS) evaluated the hydrologic response to different projected carbon emission scenarios of the 21 st century using a hydrologic simulation model. This study involved five major steps: (1) setup, calibrate and evaluated the Precipitation Runoff Modeling System (PRMS) model in 14 basins across the United States by local USGS personnel; (2) acquire selected simulated carbon emission scenarios from the World Climate Research Programme's Coupled Model Intercomparison Project; (3) statistical downscaling of these scenarios to create PRMS input files which reflect the future climatic conditions of these scenarios; (4) generate PRMS projections for the carbon emission scenarios for the 14 basins; and (5) analyze the modeled hydrologic response. This report presents an overview of this study, details of the methodology, results from the 14 basin simulations, and interpretation of these results.

A key finding is that the hydrological response of the different geographical regions of the United States to potential climate change may be different, depending on the dominant physical processes of that particular region. Also considered is the tremendous amount of uncertainty present in the carbon emission scenarios and how this uncertainty propagates through the hydrologic simulations.

\section{Introduction}

To evaluate the effects of long-term climate change on the freshwater resources of the United States, the U.S. Geological Survey (USGS) Global Change Research and Development Program initiated a study in 2008 (Markstrom and Hay, 2009). A long-term goal of the study was to provide a foundation to analyze the effects of climate change on hydrology across the nation. This work was a collaborative effort between the USGS National Research Program, eight USGS Water Science Centers, and a team of USGS scientists from the hydrology, hydroclimatology, biology, geography, and natural hazards disciplines.

In this study (fig. 1), 14 basins from different hydroclimatic regions of the United States were selected as systems to be modeled. These 14 basins were all the subject of previous watershed modeling studies using the USGS Precipitation Runoff Modeling System (PRMS, Leavesley and others, 1983). Carbon emission scenarios (Intergovenrmental Panel on Climate Change, 2007), hereafter referred to as the scenarios, were simulated by several different General Circulation Models or Global Climate Models (GCMs). The results of the GCM simulations of the scenarios are hereafter referred to as the GCM projections. The GCM projections contain a wide range of climatic conditions, each of which is used by PRMS to simulate hydrologic response for each of the 14 basins. The results of the PRMS simulations of the GCM projections are hereafter referred to as the PRMS projections. The PRMS projections are used to assess the hydrologic effects of climate change on each of the 14 basins.

This report presents an overview of this study, details of the methodology, results from the 14 basin simulations, and interpretation of the results.

\section{Study Sites}

The 14 basins (fig. 1) selected as modeling sites in this study have all been modeled previously (table 1) with PRMS by the USGS; these are hereafter referred to as the PRMS applications. The output from a specific run of a PRMS application is hereafter referred to as a PRMS simulation. Once a PRMS application has been successfully calibrated, a PRMS simulation is made using the available historical climate data. This PRMS simulation is hereafter referred to as the baseline condition. These PRMS applications were developed for different reasons, such as evaluation of water supply or ecological habitat. Whenever possible, the original developers of the PRMS applications were engaged in this study to provide local expertise and insight for validation and interpretation of the PRMS projections. 


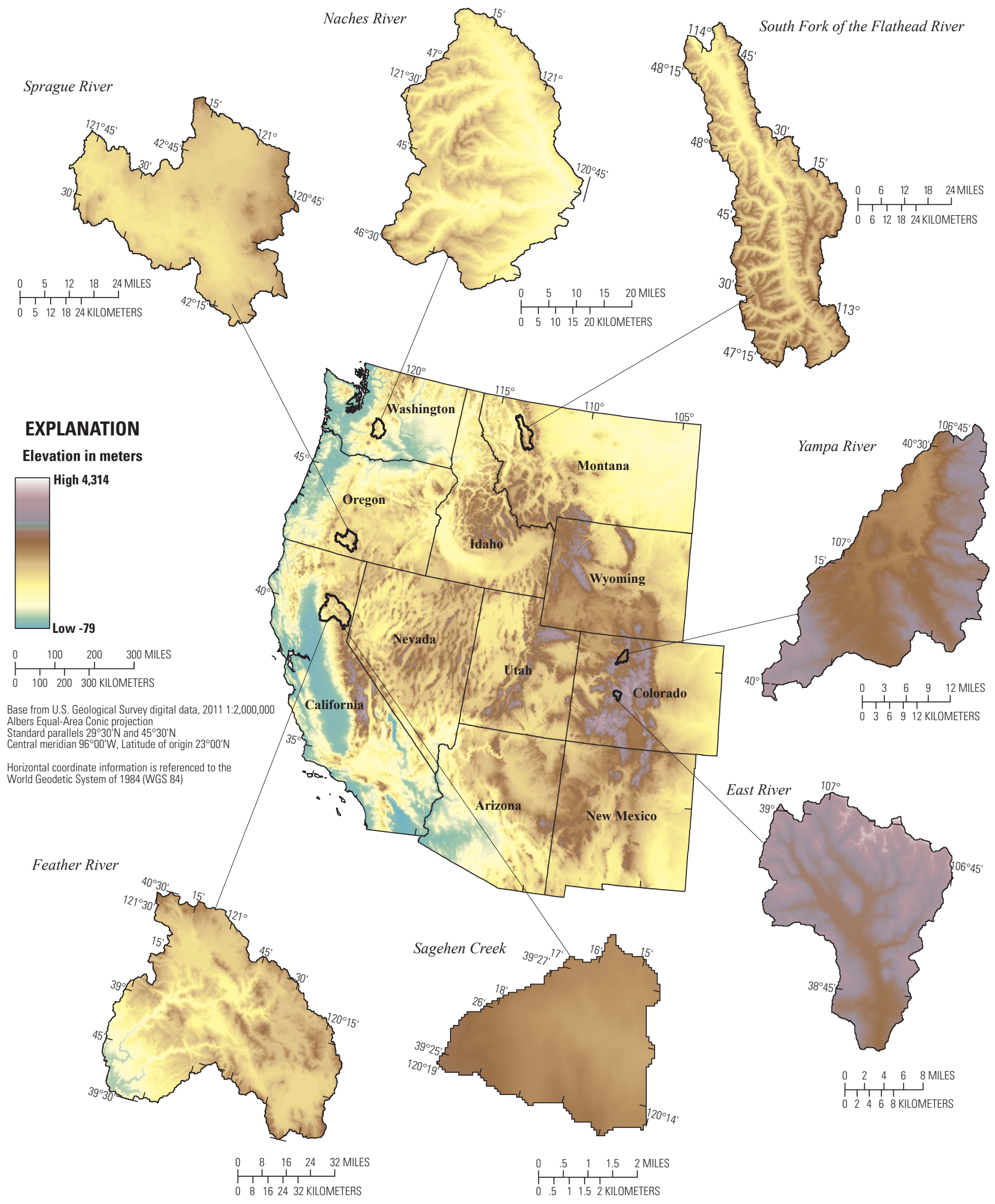

Figure 1. Precipitation Runoff Modeling System application sites for selected basins across the United States. Streamflow-gaging station locations used for model calibration. 


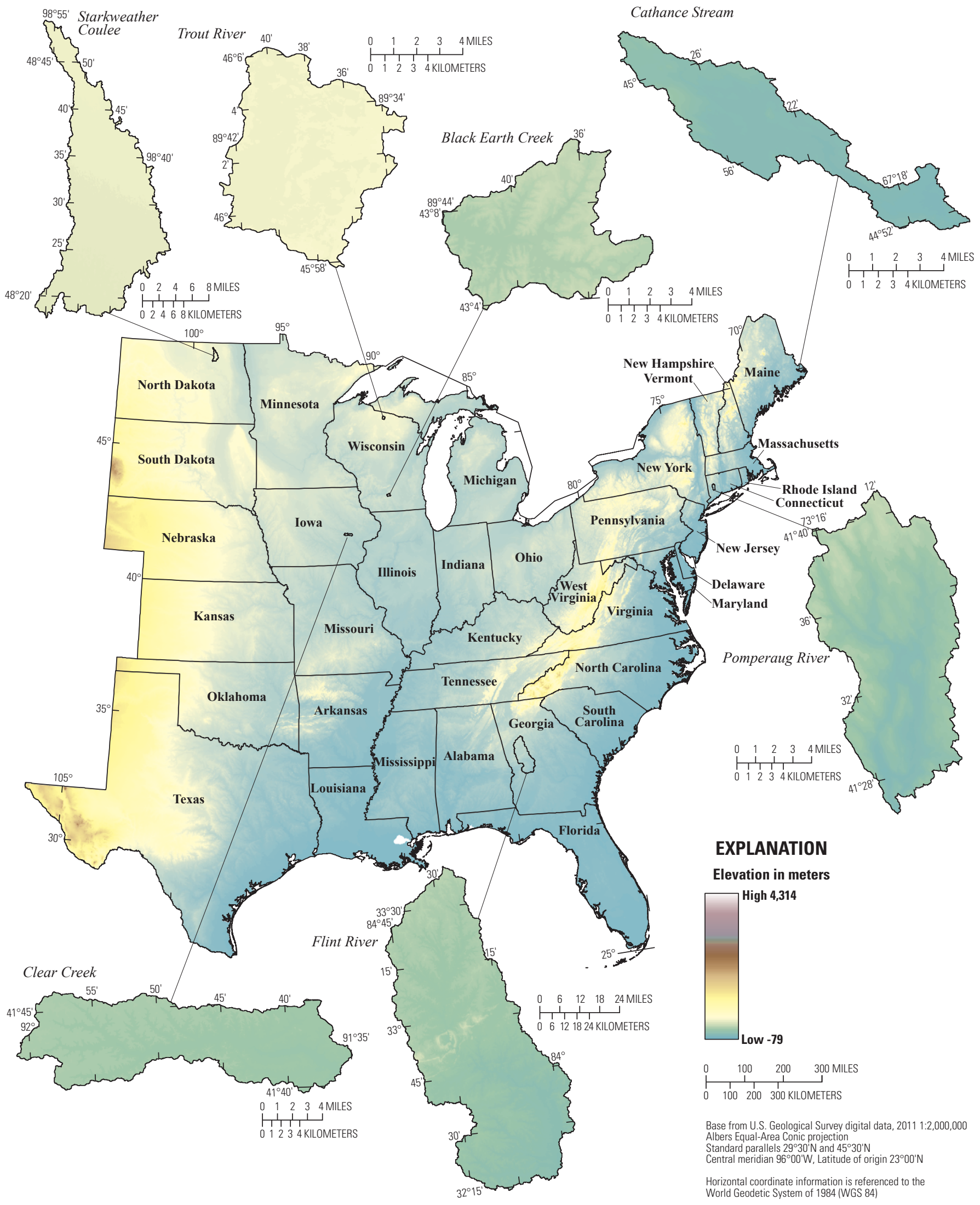

Figure 1. Precipitation Runoff Modeling System application sites for selected basins across the United States. Streamflow-gaging station locations used for model calibration.-Continued 
Table 1. Drainage area, number of hydrologic response units, and elevation ranges for selected basins across the United States.

[USGS, U.S. Geological Survey; NAVD88, North American Vertical Datum of 1988]

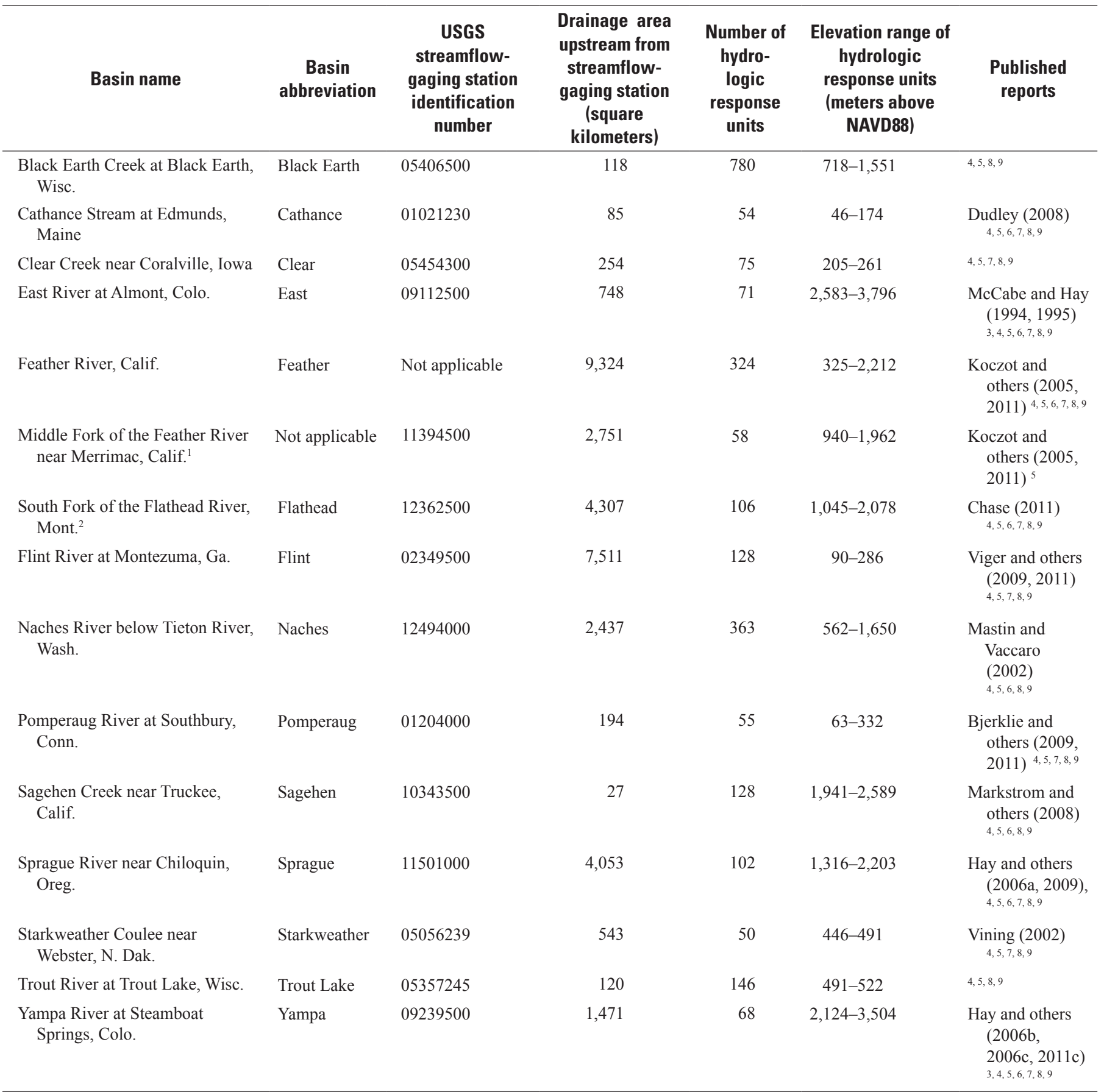

${ }^{1}$ Middle Fork is a gaged interior basin of the Feather River Basin.

${ }^{2}$ For the South Fork of the Flathead River, natural daily mean streamflow values calculated by the Bureau of Reclamation were used for calibration.

${ }^{3}$ Included in analysis by Battaglin and others (2011).

${ }^{4}$ Included in analysis by Christiansen and others (2011).

${ }^{5}$ Included in analysis by Hay and others (2011).

${ }^{6}$ Included in analysis by Mastin and others (2011).

${ }^{7}$ Included in analysis by Milly and Dunne (2011).

${ }^{8}$ Included in analysis by Risley and others (2011).

${ }^{9}$ Included in analysis by Walker and others (2011). 
The 14 basins can be grouped into 6 geographical regions of the United States; these regions are:

- The Naches and Sprague River Basins in the Cascade Mountains of the Pacific Northwest region of the United States.

- The Feather River and Sagehen Creek Basins in the Sierra Nevada region of the United States.

- The South Fork of the Flathead, East, and Yampa River Basins in the Rocky Mountain region of the United States.

- The Starkweather Coulee, Clear Creek, Black Earth Creek, and Trout Lake Basins in the Midwestern region of the United States.

- The Cathance Stream and Pomperaug River Basins in the Northeastern region of the United States.

- The Flint River Basin in the Southeastern region of the United States.

\section{Description of the Simulation Models Used in this Study}

This study uses two different types of simulation models. The first type is the GCM models, which simulate the response of the Earth's atmosphere to all the important driving forces, especially greenhouse gases, and are used for projecting changes in climate globally. These models have been run by members of the Intergovernmental Panel on Climate Change (IPCC) and their output was made available for download, as described below in section "Step 1: Select and Acquire General Circulation Model Projections." The second type of model is the watershed hydrology model PRMS, hereafter referred to as the PRMS model. The PRMS model is applied at a much finer spatial resolution and can generate detailed hydrologic output which typically is not produced by the GCMs. Specifically, the average resolution used in the 14 PRMS applications is less than 14 square kilometers $\left(\mathrm{km}^{2}\right)$, whereas the resolution of grid cells used by the GCM models are larger than one degree of latitude and longitude (table 2). For mid-latitude basins, this could represent resolutions as large as $18,000 \mathrm{~km}^{2}$ per grid cell. The PRMS model was coupled to the GCMs through a downscaling procedure (fig. 2). The GCM models, PRMS model, and downscaling procedure, as applied in this study, are described below in the section "Methods."

\section{General Circulation Models}

GCMs are numerical models that represent all components of the Earth system including the atmosphere, oceans, cryosphere, and land surface. The climate-change signal from individual GCMs (that is, the difference between simulated future climate and simulated historical climate) can vary in direction and magnitude because of the uncertainties associated with each GCM parameterization, initial forcings, emission scenarios, and representation of the Earth system components (Fealy and Sweeney, 2008). The same forcings can produce different GCM responses because of differences in the method for modeling climate system and feedbacks and the initial conditions used for the climate simulations. Given this parametric and structural uncertainty in climate modeling, it is desirable to use output from more than one GCM to obtain a range of potential future climatic conditions. Ensembles of multiple GCM outputs provide an envelope of possible regional changes and their accompanying uncertainties (Murphy and others, 2004; Boorman and Sefton, 1997; Intergovenrmental Panel on Climate Change, 2007).

Representing GCM uncertainties using multiple GCM outputs is now feasible because of the large data archives available at the GCM modeling centers. The World Climate Research Programme's Coupled Model Intercomparison Project phase 3 (CMIP3) multimodel dataset archive, which was used in the IPCC Fourth Assessment Special Report on Emission Scenarios (SRES) (Intergovernmental Panel on Climate Change, 2007) contains 28 archived GCMs with multiple emission scenarios. The emission scenarios describe how greenhouse gas emissions could evolve between 2000 and 2100 , depending on various hypotheses on what the state of the future world may be. The range in results from the various GCMs can then be compared by emission scenario.

Table 2. General Circulation Model projections used in this study.

\begin{tabular}{lll}
\hline GCM & \multicolumn{1}{c}{ Description } & $\begin{array}{c}\text { Cell size } \\
\text { (latitude } \times \text { longitude) }\end{array}$ \\
\hline BCC-BCM2.0 & Bjerknes Centre for Climate Research, Norway & $2.79^{\circ} \times 2.81^{\circ}$ \\
CSIRO-Mk3.0 & Commonwealth Scientific and Industrial Research Organization, & $1.865^{\circ} \times 1.875^{\circ}$ \\
& Australia & \\
CSIRO-Mk3.5 & Commonwealth Scientific and Industrial Research Organization, & $1.865^{\circ} \times 1.875^{\circ}$ \\
& Australia & \\
INM-CM3.0 & Institute for Numerical Mathematics, Russia & $4.0^{\circ} \times 5.0^{\circ}$ \\
MIROC3.2 & National Institute for Environmental Studies, Japan & $2.79^{\circ} \times 2.81^{\circ}$ \\
\hline
\end{tabular}




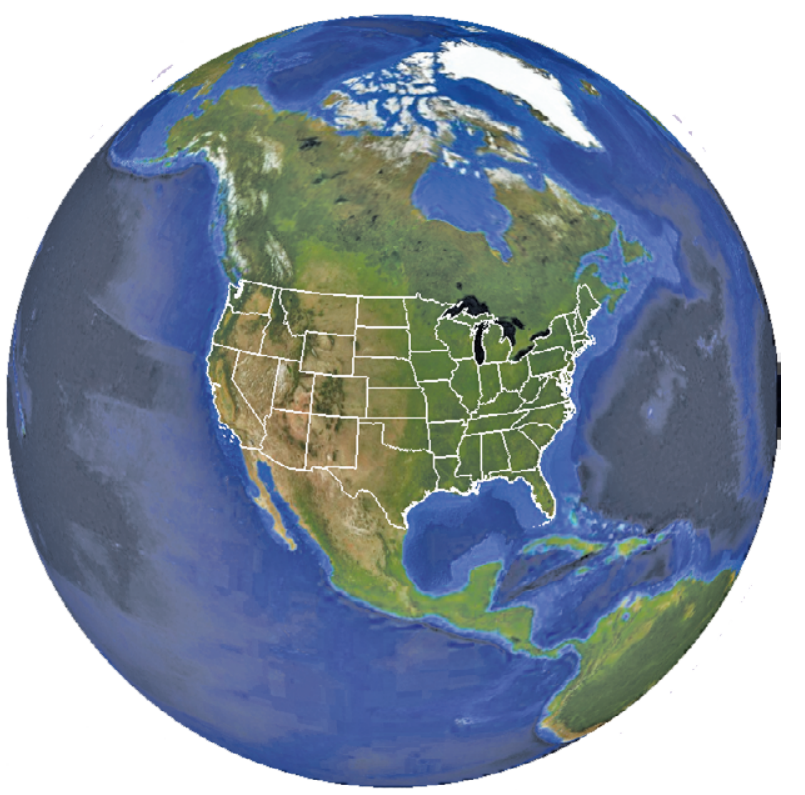

\section{General \\ Circulation Model scale}
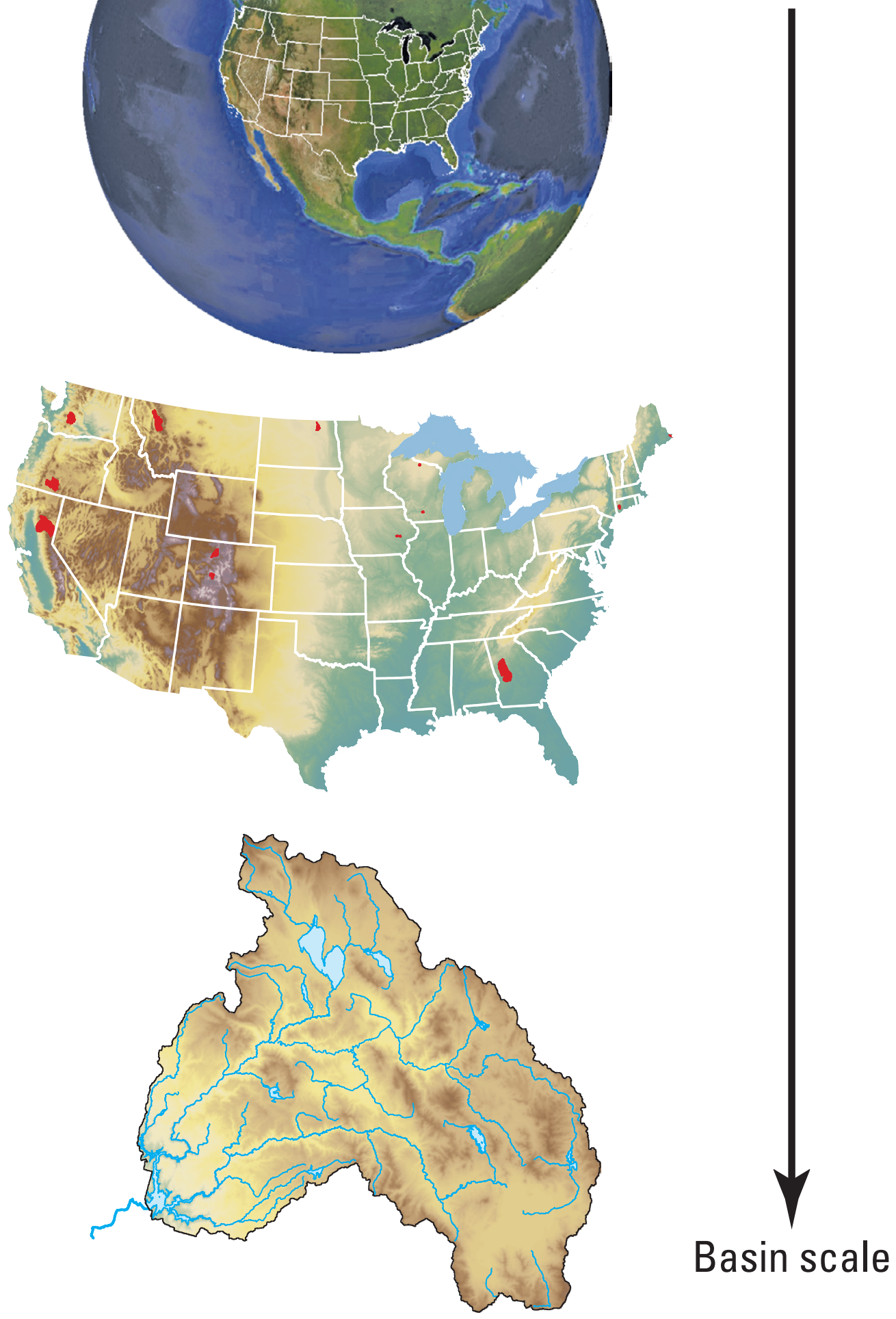

Figure 2. Modeling sequence: output from coarse General Circulation Models used as input to fine scale Precipitation Runoff Modeling System applications across the United States. 


\section{Precipitation Runoff Modeling System}

The PRMS model is a deterministic, distributedparameter, process-based watershed model. Each hydrologic component used for generation of streamflow is represented within the PRMS model by a process algorithm that is based on a physical law or an empirical relation with measured or estimated characteristics (see Leavesley and others, 1983; and Markstrom and others, 2008). PRMS is used to simulate and evaluate the effects of various combinations of climate (precipitation, air temperature, and solar radiation) and land use on basin hydrologic response. Response to normal and extreme rainfall and snowmelt can be simulated to evaluate changes in water-balance relations, streamflow regimes, soil-water relations, and groundwater recharge.

Distributed-parameter capabilities are provided by partitioning a basin into hydrologically similar units, using characteristics such as slope, aspect, elevation, vegetation type, soil type, and precipitation distribution. These units are called hydrologic response units (HRUs) and are assumed to be homogeneous with respect to hydrologic response. Water and energy balances are computed daily for each HRU. Although more sophisticated streamflow routing methods are available in PRMS, in this study, the sum of the responses of all HRUs, weighted on a unit-area basis, produced the daily time step basin hydrologic response.

Climate data consisting of daily measurements of precipitation, air temperature, and solar radiation are the driving variables used to compute evaporation, transpiration, sublimation, snowmelt, infiltration, and runoff in a PRMS simulation. The form of precipitation (rain, snow, or mixture of both) is determined from air temperature or can be specified as input. Precipitation can be intercepted by and evaporated from the plant canopy. Throughfall is precipitation that is not intercepted by the plant canopy and is distributed to the land surface. Throughfall can accumulate as part of the snowpack, be stored on impervious areas, infiltrate into the soil zone, be evaporated and transpired, or become surface-water runoff. Water and energy balances are computed for the snowpack to determine snow accumulation, snowmelt, or sublimation (fig. 3).

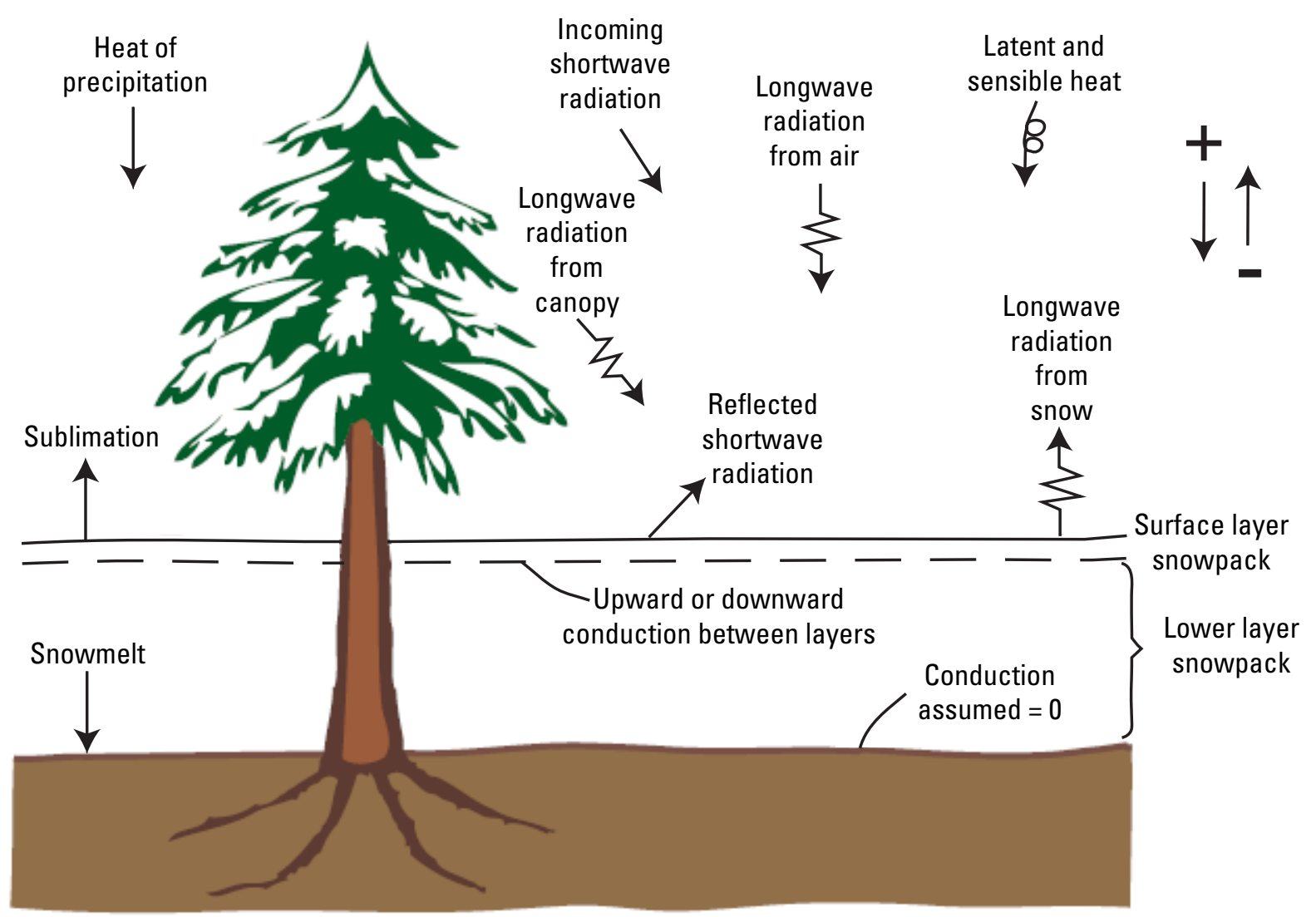

Figure 3. Components of the snowpack energy balance, accumulation, snowmelt, and sublimation (from Koczot and others, 2005). 
Precipitation that falls on each HRU is routed through the conceptual storage reservoirs (fig. 4), where water is added and subtracted according to the computational sequence. Each HRU simulates water stored in the plant canopy, snowpack, impervious-zone, capillary, gravity, and groundwater reservoirs. Reservoirs in the HRU are assumed to be homogeneous in hydrologic response and model parameterization. Water entering any HRU reservoir is considered to be instantaneously mixed with water previously in the reservoir.

Several input files are needed for a PRMS simulation (Markstrom and others, 2008, p. 139-150). This study was conducted by modifying two of the PRMS input files. These files are the PRMS Data File and the PRMS Parameter File. The PRMS Data File contains time-series climate data used to drive the PRMS simulation. These input data include daily values of precipitation and maximum and minimum air temperature. The different carbon emission scenarios were simulated using PRMS by creating an input PRMS Data File corresponding to each scenario. The PRMS Parameter File contains static values which characterize the physical and empirical aspects of the basin. Only the values of the "spring_frost" and "fall_frost" parameters (table A1-1) were changed in this file according to the information developed for each carbon emission scenario. These parameters are described in the description of the "transp_frost_prms" module in Appendix 1.

PRMS has the capability of producing more than 200 output variables which characterize the simulated hydrologic conditions for all HRUs on any day of the simulated time period (some are listed in Markstrom and others, 2008, p. 138, table A1-2). For this study, only 19 of these output variables were considered for analysis (table 3 ). These variables include streamflow, evapotranspiration, groundwater storage and inflow, soil moisture, and snowpack water equivalent and snowmelt. The results of running PRMS on 14 basins, four carbon emission scenarios from five GCMs for 100 years of the 21 st century, and outputting 35 variables at both HRU and basin-aggregated resolutions resulted in almost one terabyte of output data.

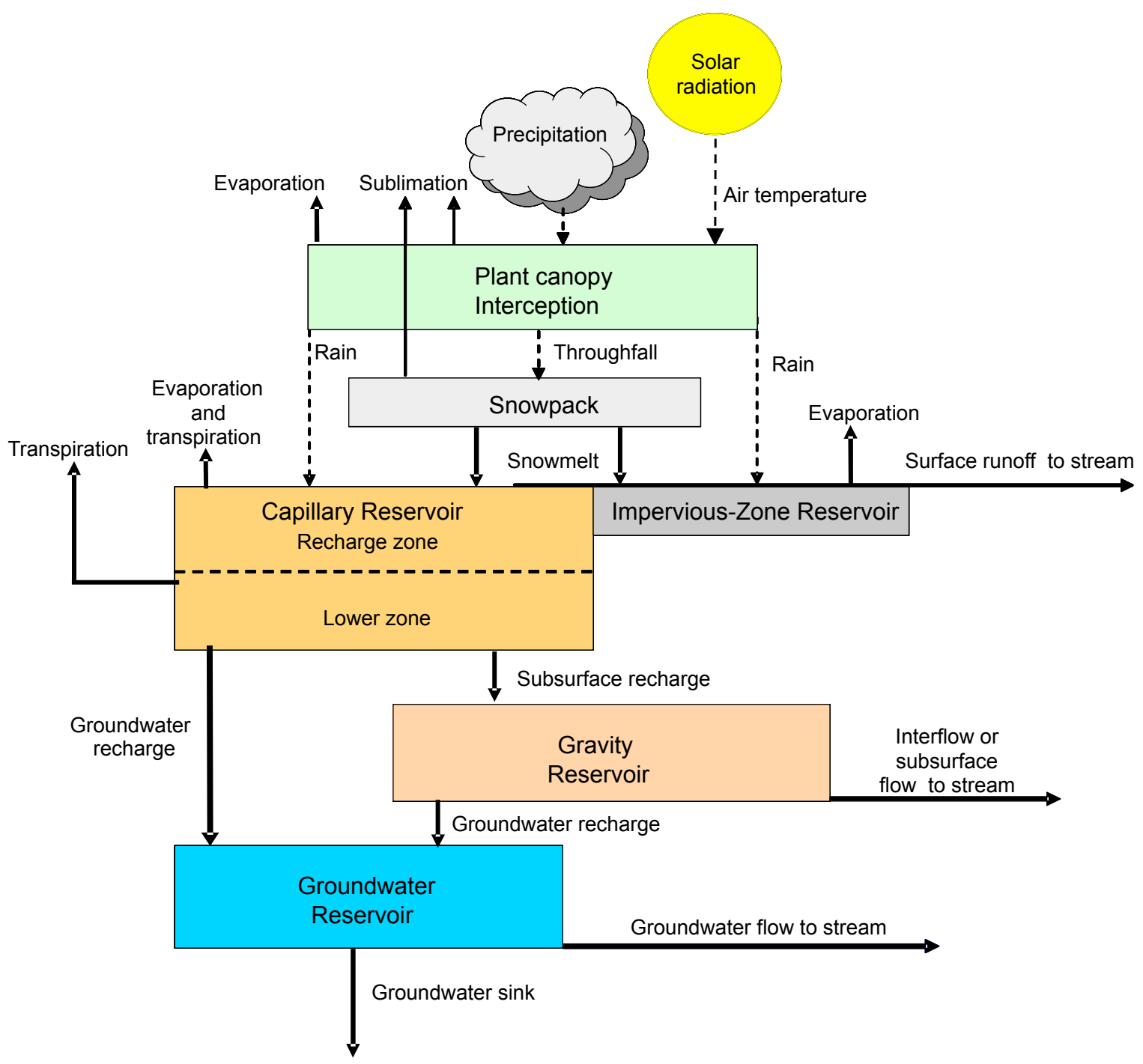

Figure 4. Schematic diagram of a watershed and inputs simulated by the Precipitation Runoff Modeling System model. 
Table 3. Description of Precipitation Runoff Modeling System variables analyzed in the climate change study.

[Units of "millimeters" are depth over the basin area per daily timestep]

\begin{tabular}{|c|c|c|c|}
\hline Variable type & Variable name & Units & Variable description \\
\hline \multirow[t]{5}{*}{ Input } & Precipitation & Millimeters & $\begin{array}{l}\text { Area-weighted adjusted } \\
\text { average precipitation for } \\
\text { basin }\end{array}$ \\
\hline & $\begin{array}{l}\text { Maximum } \\
\text { temperature }\end{array}$ & Degrees celsius & $\begin{array}{l}\text { Basin area-weighted daily } \\
\text { maximum temperature }\end{array}$ \\
\hline & $\begin{array}{l}\text { Minimum } \\
\text { temperature }\end{array}$ & Degrees celsius & $\begin{array}{l}\text { Basin area-weighted daily } \\
\text { minimum temperature }\end{array}$ \\
\hline & Evapotranspiration & Millimeters & Evapotranspiration on basin \\
\hline & $\begin{array}{l}\text { Growing season } \\
\text { length }\end{array}$ & Days & $\begin{array}{l}\text { Length of the growing } \\
\text { season derived from the } \\
\text { temperature data }\end{array}$ \\
\hline \multirow[t]{4}{*}{ Streamflow } & Streamflow & $\begin{array}{r}\text { Cubic meters } \\
\text { per second }\end{array}$ & Streamflow from basin \\
\hline & Surface runoff & $\begin{array}{r}\text { Cubic meters } \\
\text { per second }\end{array}$ & Basin surface runoff \\
\hline & Subsurface flow & $\begin{array}{r}\text { Cubic meters } \\
\text { per second }\end{array}$ & Basin subsurface flow \\
\hline & Groundwater flow & $\begin{array}{r}\text { Cubic meters } \\
\text { per second }\end{array}$ & Basin groundwater flow \\
\hline \multirow[t]{4}{*}{ Snow } & $\begin{array}{l}\text { Precipitation that } \\
\text { falls as snow }\end{array}$ & Percent & $\begin{array}{l}\text { Percent of precipitation that } \\
\text { falls as snow derived } \\
\text { from precipitation and } \\
\text { snow }\end{array}$ \\
\hline & Snow-covered area & Percent & $\begin{array}{l}\text { Average snow-covered area } \\
\text { for total basin }\end{array}$ \\
\hline & $\begin{array}{c}\text { Snowpack water } \\
\text { equivalent }\end{array}$ & Millimeters & $\begin{array}{l}\text { Average snowpack water } \\
\text { equivalent for total basin } \\
\text { area }\end{array}$ \\
\hline & Snowmelt & Millimeters & $\begin{array}{l}\text { Average snowmelt for total } \\
\text { basin area }\end{array}$ \\
\hline \multirow[t]{6}{*}{ Soil moisture } & Infiltration & Millimeters & $\begin{array}{l}\text { Basin area-weighted aver- } \\
\text { age for infiltration }\end{array}$ \\
\hline & $\begin{array}{l}\text { Inflow to subsurface } \\
\text { reservoirs }\end{array}$ & Millimeters & $\begin{array}{l}\text { Basin weighted average } \\
\text { for inflow to subsurface } \\
\text { reservoirs }\end{array}$ \\
\hline & $\begin{array}{l}\text { Inflow to ground- } \\
\text { water reservoirs }\end{array}$ & Millimeters & $\begin{array}{l}\text { Basin area-weighted aver- } \\
\text { age of inflow to ground- } \\
\text { water reservoir (recharge) }\end{array}$ \\
\hline & Soil moisture & Millimeters & $\begin{array}{l}\text { Basin area-weighted aver- } \\
\text { age soil moisture }\end{array}$ \\
\hline & $\begin{array}{l}\text { Subsurface reservoir } \\
\text { storage }\end{array}$ & Millimeters & $\begin{array}{l}\text { Basin weighted average } \\
\text { for subsurface reservoir } \\
\text { storage }\end{array}$ \\
\hline & Groundwater storage & Millimeters & $\begin{array}{l}\text { Basin area-weighted } \\
\text { average of groundwater } \\
\text { storage }\end{array}$ \\
\hline
\end{tabular}




\section{Methods}

Coupling the GCM projections to the PRMS applications required five major steps: (1) after evaluating a common baseline condition for all of the 14 PRMS applications and recalibrating if necessary; (2) the GCM projections, including precipitation and maximum and minimum temperature, for the baseline period and the period of the scenarios were acquired; (3) the GCM projections were downscaled to the climate stations used for each of the 14 PRMS applications; (4) the PRMS projections were generated from the GCM modified climate station record inputs by running the PRMS model; and (5) the PRMS projections were analyzed for the hydrologic effects of climate change. These steps are described in detail in the following sections.

\section{Step 1: Evaluate Precipitation Runoff Modeling System Applications for Baseline Conditions}

The PRMS applications used in this study have all been the subject of previous modeling studies (table 1). These applications were each calibrated for different purposes and for different baseline conditions. The first step in the evaluation of the previous PRMS applications was to find a common baseline period which could be used by all 14 of the applications. A common baseline period was found to start in 1987 because of the availability of measured temperature data from the U.S. Department of Agriculture, Natural Resources Conservation Service, National Water and Climate Center, Snow Survey and Water Supply Forecasting Program (NRCS SNOTEL, http://www.wcc.nrcs.usda.gov/snow, accessed July 2010). A common baseline period was found to end in 1999 because many of the 20th century scenarios end in calendar year 1999. These temperature data were used by many of the PRMS applications; consequently, water years (WYs) 1988-99 (October 1, 1987 to September 30, 1999) were chosen as the common baseline period.

Each of the 14 PRMS applications was evaluated for the common baseline period. Climate data from WY 1988 was reserved for initialization of all PRMS simulations. The evaluation was based on four criteria: (1) mean monthly streamflow, where the "mean monthly" is the arithmetic mean of all mean daily values that occurred during a particular month, across all years, resulting in 12 values; (2) monthly mean streamflow, where "monthly mean" is the arithmetic mean of all of the values that occurred in a particular month, resulting in a time series of values, one for each month of each year; (3) mean monthly solar radiation (SR); and (4) mean monthly potential evapotranspiration (PET). All daily values, both measured and simulated, were aggregated to monthly time steps for evaluation.

Measured streamflow data were obtained from the U.S. Geological Survey National Water Information System (USGS NWIS, http://waterdata.usgs.gov/nwis, accessed July 2010); however, these data were not always available for all of the PRMS applications during the common baseline period. In some cases, this was because of incomplete streamflow-gaging station information, or more commonly, because of anthropogenic causes. Natural streamflow (streamflow corrected for withdrawal or return flows or other measurable uses) data records were estimated when possible. If natural streamflow data records could not be estimated, they were not used as evaluation criterion.

Measured monthly SR values are available for 217 stations in the United States (http://rredc.nrel.gov/solar/old_data/ nsrdb/redbook/mon2/, accessed July 2010). A multiple linear regression (Helsel and Hirsh, 2002) was developed between these measured monthly SR values and daily climate statistics calculated using data from climate stations collocated with the measured solar radiation. For each month a separate multiple linear regression equation was developed using latitude, longitude, elevation, mean precipitation on days with temperatures greater than $0{ }^{\circ} \mathrm{C}$, mean precipitation, number of rain days, mean maximum temperature, and the difference between mean maximum and mean minimum temperature as possible independent variables. Adjusted $\mathrm{R}^{2}\left(\mathrm{R}_{\mathrm{a}}{ }_{\mathrm{a}}\right.$, Helsel and Hirsh, 2002) values ranged from $0.83-0.98$. Then, a dataset of mean monthly SR values at each of the climate stations in the National Oceanic and Atmospheric Administration Cooperative Observer Program (NOAA COOP, http://www.nws.noaa. gov/om/coop, accessed July 2010) and the NRCS SNOTEL sites was developed using the monthly multiple linear regression equations. The values used as measured mean monthly PET values were derived from the free-water evaporation atlas of Farnsworth and others (1982).

Initial evaluation of the PRMS applications to basin mean monthly values of SR, PET, and streamflow showed varied results. In order to ensure consistency, all PRMS applications were recalibrated to common baseline conditions using Luca (Hay and Umemoto, 2006; Hay and others, 2006b; 2006c), which is a multiple-objective, stepwise, automated procedure that uses the Shuffled Complex Evolution (Duan and others, 1992; 1993; 1994) global search algorithm to calibrate PRMS applications. For this study, SR, PET, and water balance were calibrated for each PRMS application. Luca assures that intermediate model fluxes as well as the water balance are simulated consistently with measured values (Hay and others, 2006c).

PRMS applications that are reliably calibrated for the baseline period are important because any biases are likely to transfer to the future simulations of flow (Prudhomme and Davies, 2009). PRMS simulation of maximum and minimum temperature and precipitation of baseline conditions for all applications are summarized in figure 5. Results from the Luca calibrations of each of the PRMS applications are shown in figure 6. The calibration results shown for the Feather River basin PRMS application are for the Middle Fork of the Feather River basin, the largest sub-basin modeled in the Feather River basin. After calibration, all PRMS applications are judged to produce reasonably accurate mean monthly results for SR, PET, and the water balance (when available) for the baseline period (fig. 6). 

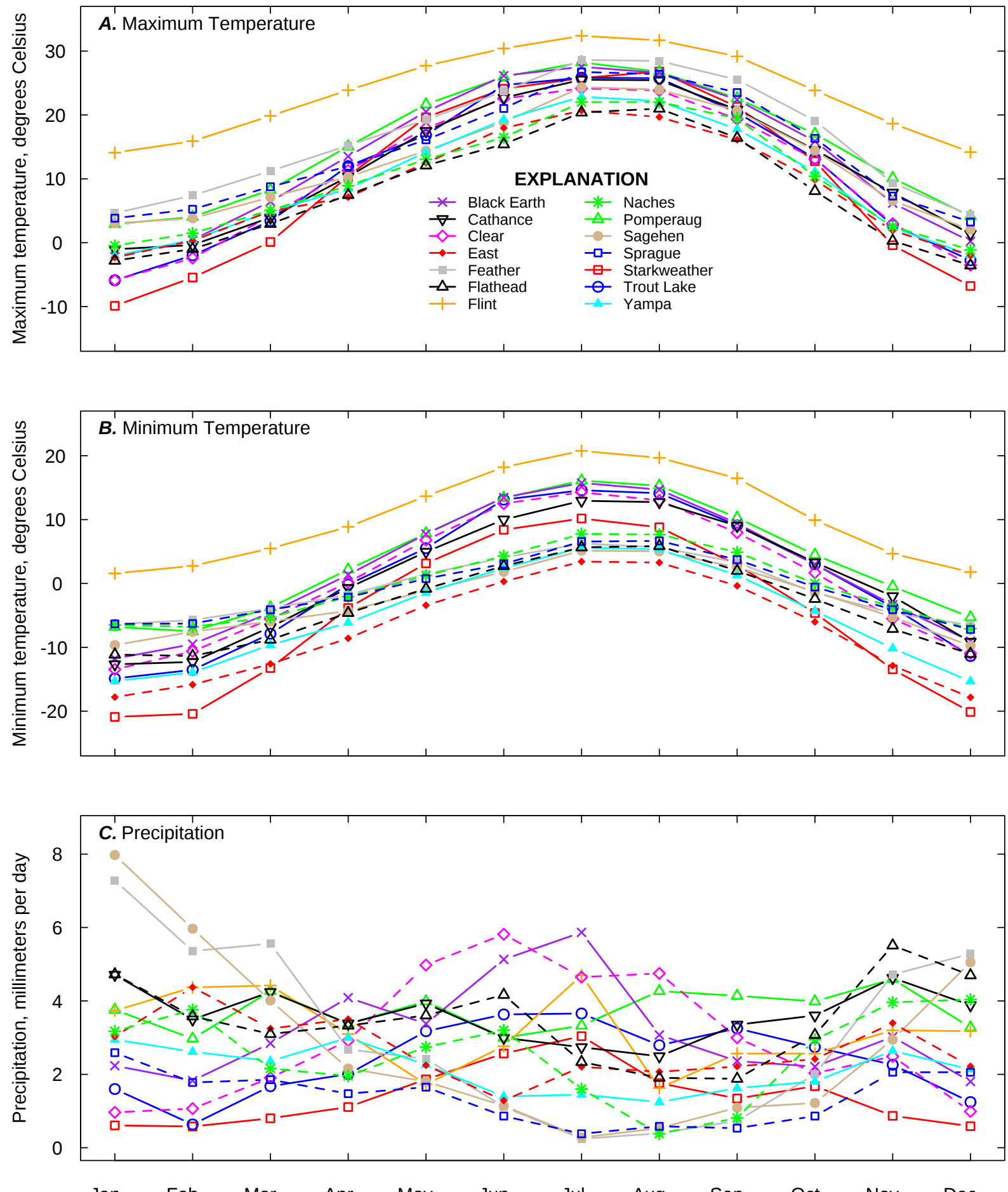

Figure 5. Basin mean monthly (1989-1999): (A) maximum temperature, $(B)$ minimum temperature, and $(C)$ precipitation for the 14 basins. 
Black Earth, Wisc.
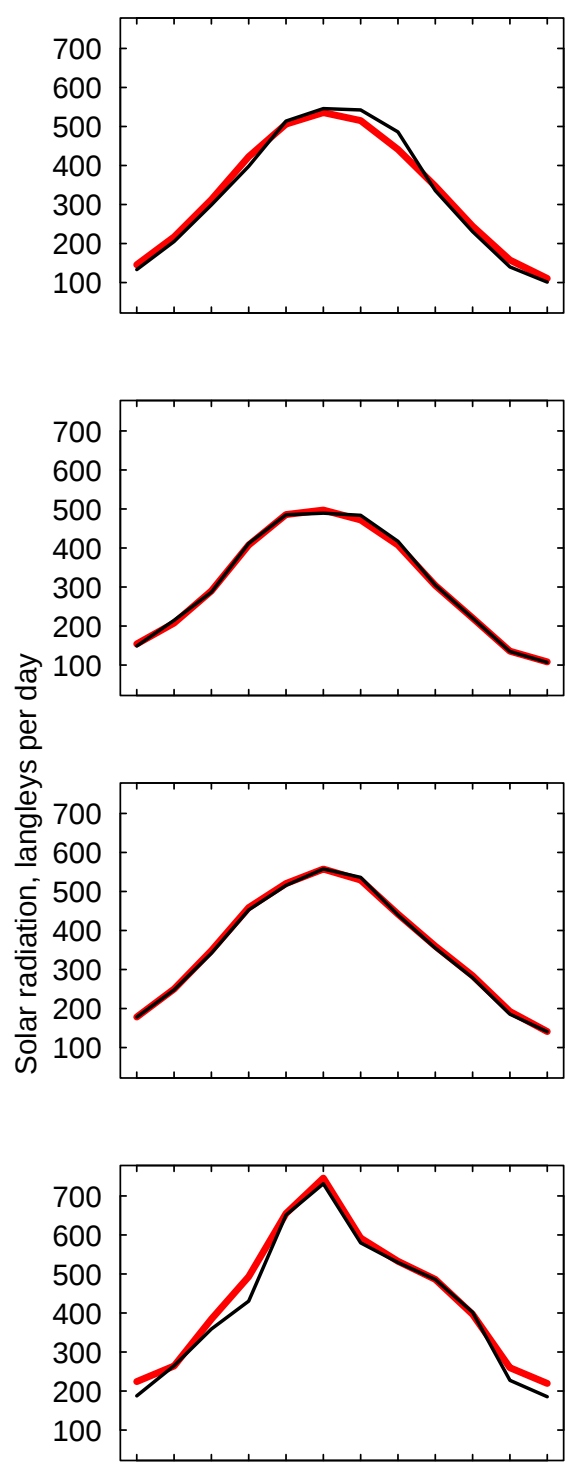

Jan. Apr. Jul. Oct.

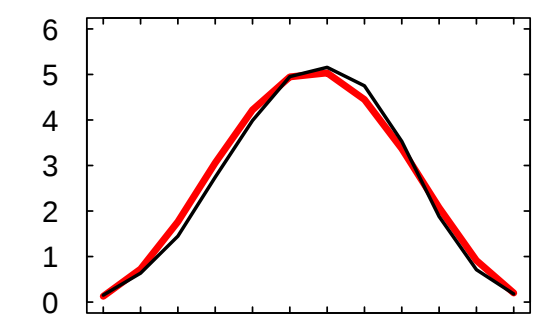

Cathance, Maine
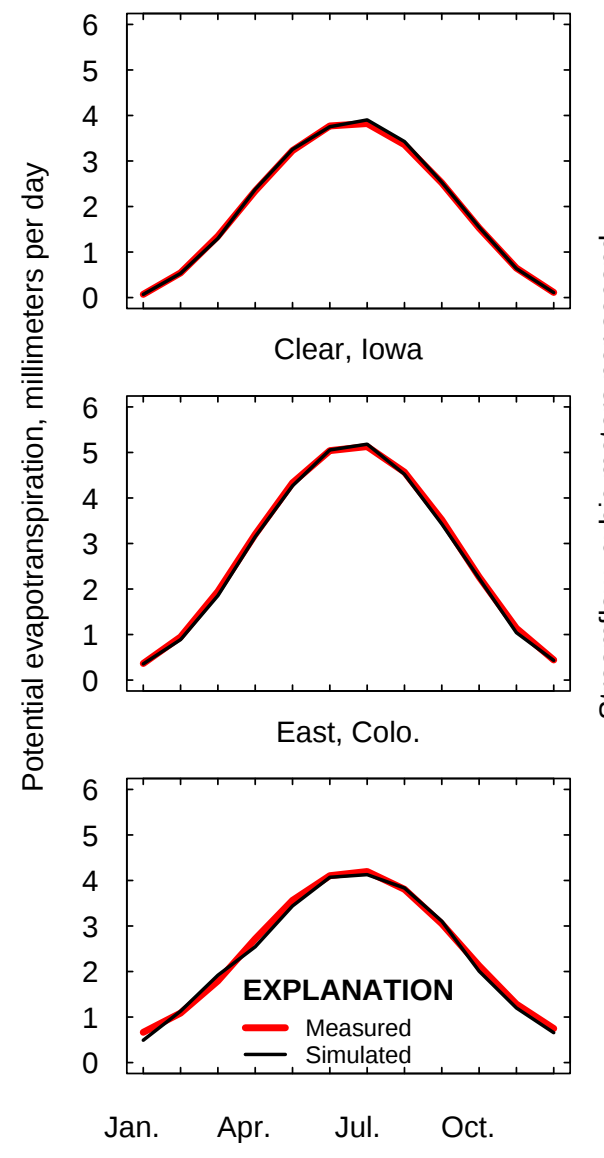

Month
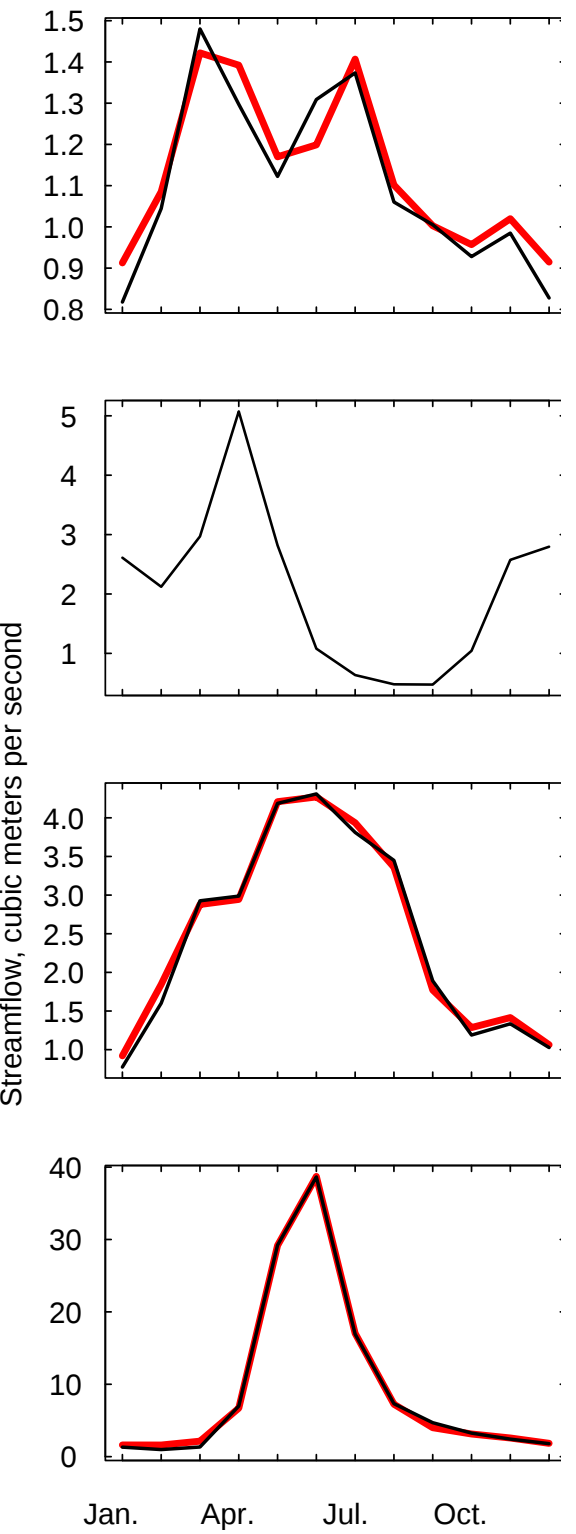

Figure 6. Calibration by basin (1989-1999): mean monthly measured (gray) and Precipitation Runoff Modeling System-simulated (black) solar radiation, potential evapotranspiration, and streamflow. 
Feather, Calif. (Middle Fork only)
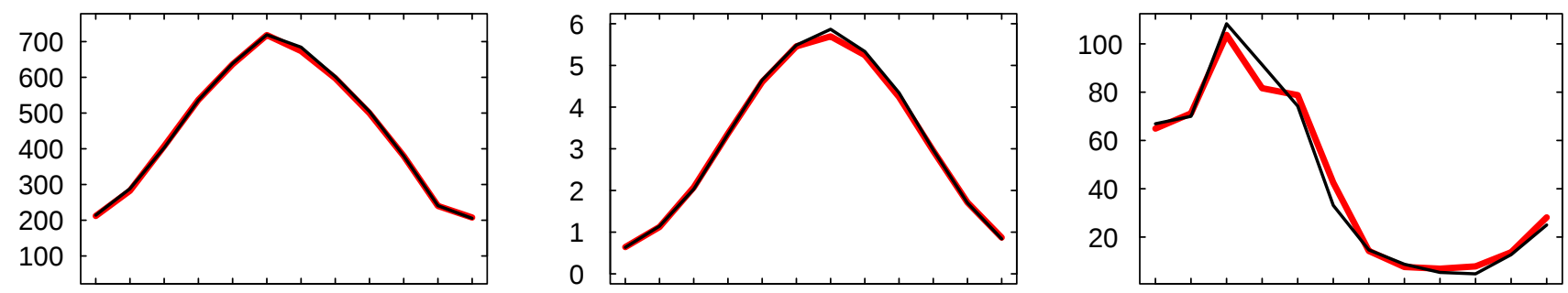

Flathead, Mont.
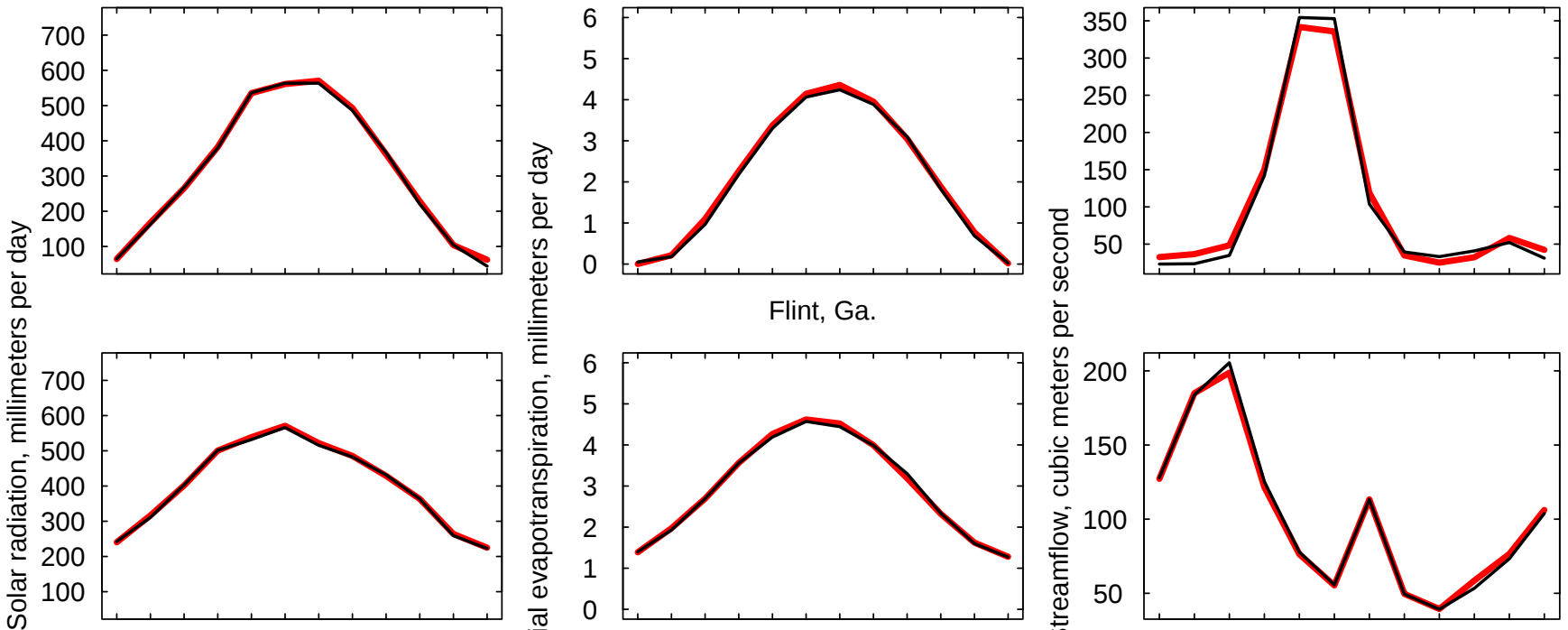

Flint, Ga.
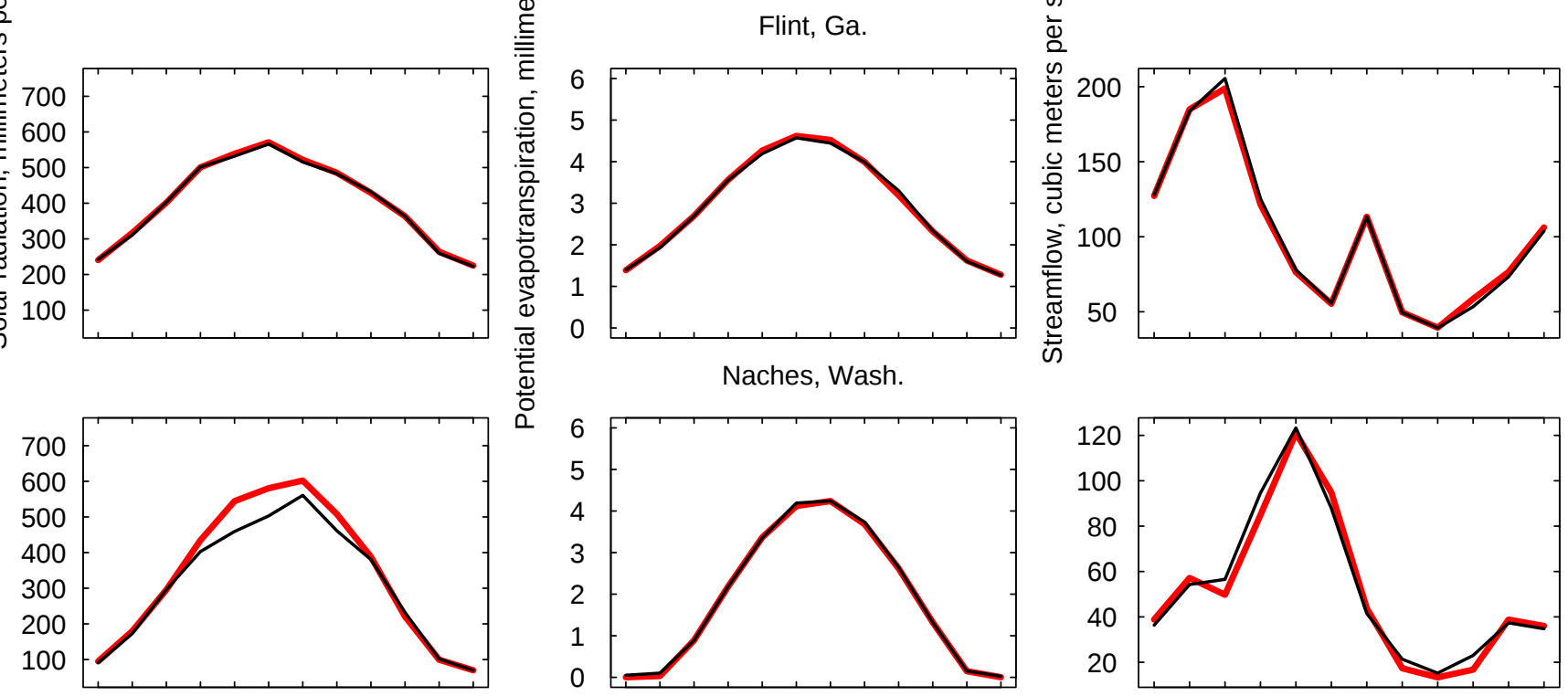

离

Naches, Wash.
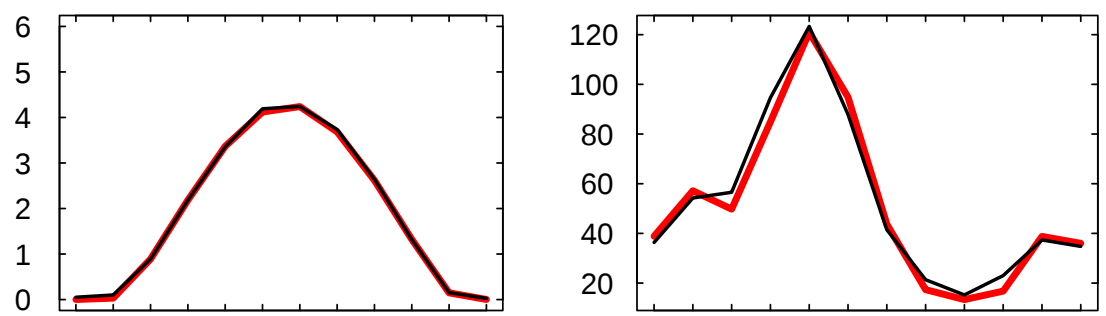

Pomperaug, Conn.

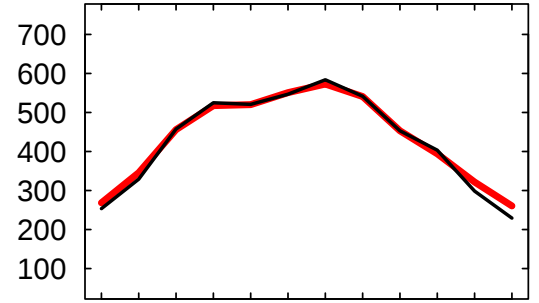

Jan. Apr. Jul. Oct.

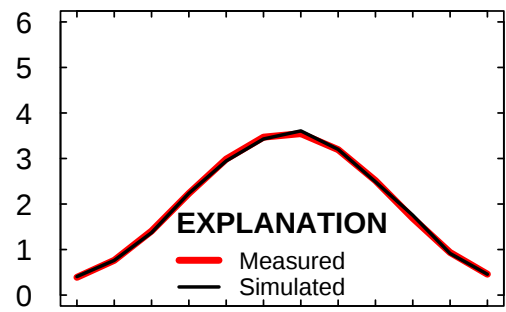

Jan. Apr. Jul. Oct.

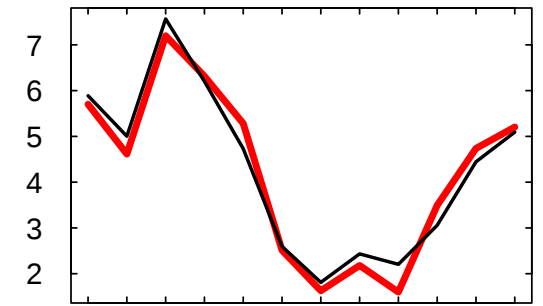

Jan. Apr. Jul. Oct.

Figure 6. Calibration by basin (1989-1999): mean monthly measured (gray) and Precipitation Runoff Modeling System-simulated (black) solar radiation, potential evapotranspiration, and streamflow.-Continued 
Sagehen, Calif.
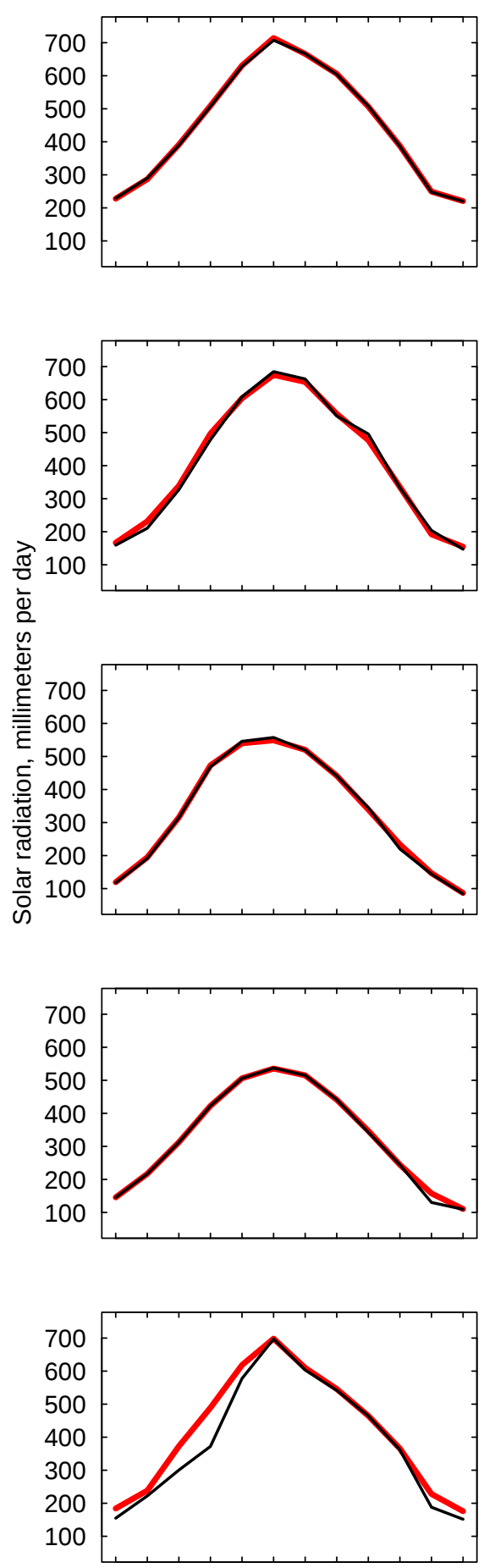

Jan. Apr. Jul. Oct.

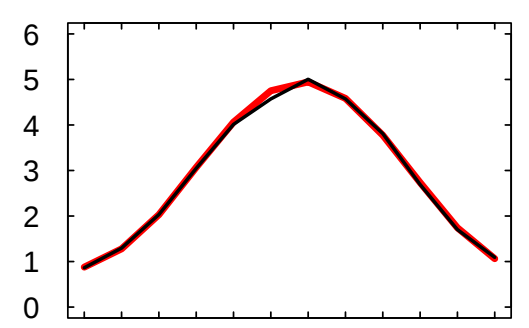

Sprague, Oreg.

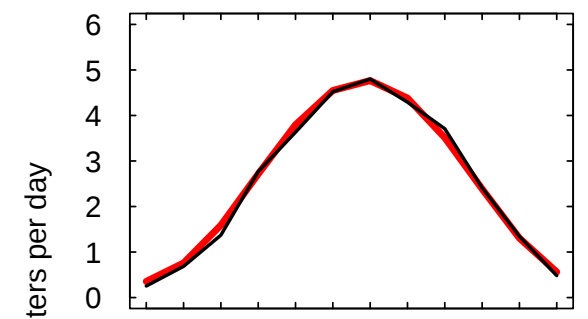

Starkweather, N. Dak.

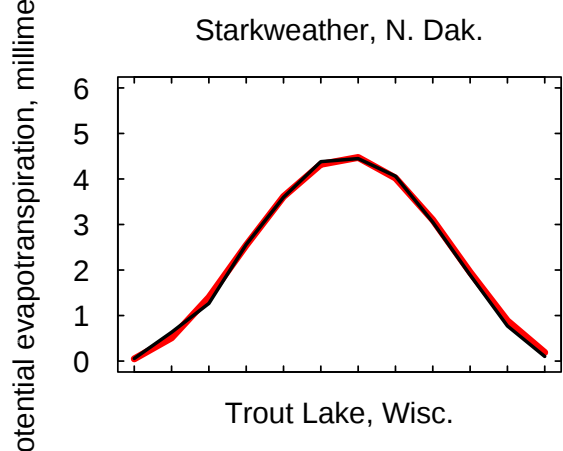

范

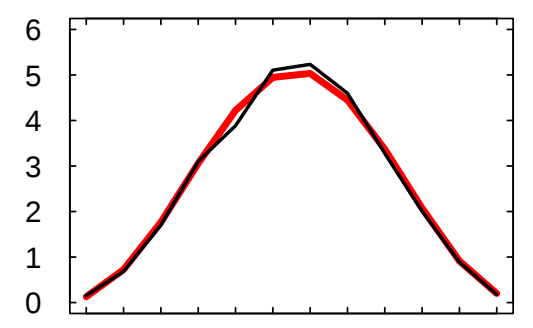

Yampa, Colo.

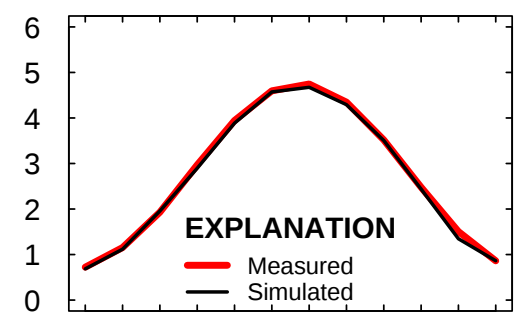

Jan. Apr. Jul. Oct.
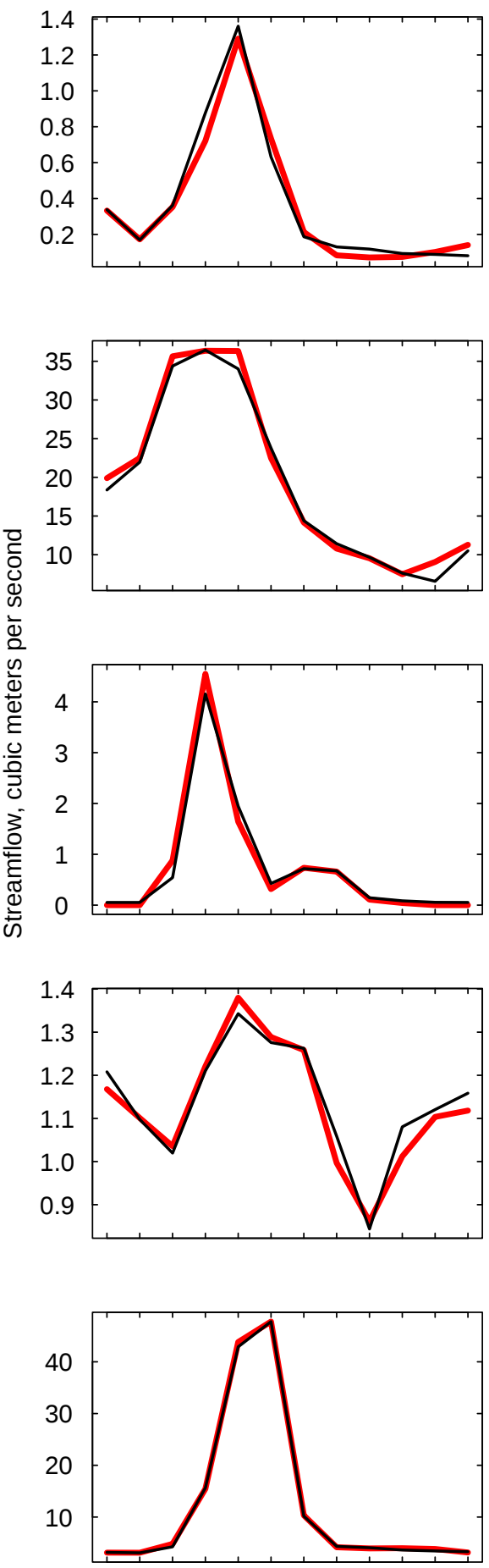

Jan. Apr. Jul. Oct.

Figure 6. Calibration by basin (1989-1999): mean monthly measured (gray) and Precipitation Runoff Modeling System-simulated (black) solar radiation, potential evapotranspiration, and streamflow.-Continued 


\section{Step 2: Select and Acquire General Circulation Model Projections}

Four scenarios developed by the IPCC were used in this study (table 4). One of these scenarios (20C3M) corresponds to the latter half of the 20th century. Only the period corresponding to PRMS baseline conditions was considered in this scenario. The other three scenarios represent different levels of carbon emission during the 21 st century. The three future emission scenarios lead to different patterns in greenhouse gas emissions and concentrations, from relatively low (B1), to medium (A1B), to high concentrations (A2) during the 21st century (Intergovernmental Panel on Climate Change, 2007). These three scenarios were selected as a representative subset of the other future emission scenarios developed by the IPCC. The total time period covered by these four scenarios was from October 1, 1988 to December 31, 2099.

Because of the uncertainty in any one GCM projection, an ensemble of projections was obtained from multiple GCMs to obtain a range of results. For a GCM projection to be suitable for this study, the World Climate Research Programme's CMIP3 multimodel dataset archive (Intergovenrmental Panel on Climate Change, 2007) had to contain monthly projections of precipitation and maximum and minimum temperature for the four scenarios (table 4) during the time period of the study. Only five GCM projections met these criteria (table 2).

\section{Step 3: Downscale General Circulation Model Projections}

PRMS projections, at a basin scale, require climatological information at resolutions that are much finer than the grid-size of the highest resolution GCM projections. The process of downscaling takes information produced at coarse spatial resolution and makes it available at finer spatial resolution. In this study, the GCM projections were necessarily downscaled because their resolution is not appropriate to make projections using the 14 PRMS applications. Downscaled GCM projections, at resolutions appropriate for the PRMS applications, have been made available by several research groups (for example, http://gdo-dcp.ucllnl.org/downscaled_cmip3_projections/dcpInterface.html, accessed July 2010 or http://www. gisclimatechange.org, accessed July 2010). These products were considered for this study, but were rejected because the downscaled gridded datasets were not compatible with the previous studies (table 1). All of the PRMS models used in this study distribute precipitation and maximum and minimum temperature data from a set of points (station locations) to HRUs defined for each basin. In order to apply these gridded products, each PRMS model would have to have been reconfigured to use gridded information, changing each model considerably from its original configuration. Therefore, a downscaling procedure that goes from coarse GCM grids to the climate stations used in each PRMS model was desired.

Either statistical or dynamical methods can be used to downscale coarse-resolution GCM projections to the basin scale for the PRMS applications. Statistical downscaling methods (Wilks, 1995; Wilby and others, 1999; Antolik, 2000; Intergovernmental Panel on Climate Change, 2001; Intergovernmental Panel on Climate Change, 2007) use empirical relations between features which are reliably simulated at GCM grid scales, and surface predictands at subgrid scales. Dynamic downscaling methods use finer-scale regional climate models, with initial and lateral boundary conditions determined by the GCM projections, which result in detailed climate simulations over a smaller region of interest (Hay and Clark, 2003; Leung and others, 2003; Giorgi and others, 2001).

Whereas considerable research and development has gone into these downscaling procedures, the most straightforward means of obtaining higher spatial resolution climate projections is to apply the statistical change factor method (Arnell, 2003a; 2003b; Arnell and Reynard, 1996; Hay and others, 2000; Diaz-Nieto and Wilby, 2004; Eckhardt and Ulbrich, 2003; Pilling and Jones, 1999; Prudhomme and others, 2002; Hay and McCabe, 2010). Fowler and others (2007) reviewed downscaling methods for their applicability for use in the evaluation of hydrological effects. They concluded that simple statistical downscaling methods, such as the "change factor' method, seem to perform as well as more sophisticated methods in reproducing mean climatic characteristics. One limitation of statistical downscaling is that the temporal

Table 4. Carbon emission scenarios simulated by the General Circulation Models in this study.

\begin{tabular}{ll}
\hline \multicolumn{1}{c}{ Emission scenario } & Description/Assumptions \\
\hline 20C3M & 20th century climate used to determine baseline (1989-1999) conditions \\
A1B & $\begin{array}{r}\text { Rapid economic growth, a global population that peaks in mid-21st century and rapid introduction of new and more efficient } \\
\text { technologies with a balanced emphasis on all energy sources } \\
\text { Convergent world, with the same global population as Emission scenario A1B, but with more rapid changes in economic struc- } \\
\text { B1 }\end{array}$ \\
& tures toward a service and information economy that is more ecologically friendly \\
A2 & Heterogeneous world with high population growth, slow economic development, and slow technological change \\
\hline
\end{tabular}


sequencing remains unchanged, limiting this method to studies examining changes in mean climatic conditions. For example, if changes in wet-/dry-spell lengths are important to the effects assessment, then another downscaling choice would be more appropriate (Wilby and others, 2004).

In this study, the change factor method was applied to the coarse-scale GCM projections and the PRMS baseline conditions to generate an ensemble of PRMS Data Files which were used to simulate the scenarios. The GCM simulations, of the 20C3M scenario, for the PRMS baseline period (WY 19881999) were used to compute the change factors (percentage changes in precipitation and degree changes in temperature). Change factors were computed for 12-year moving window periods (2001-2099) for the A2, B1, and A1B scenarios for each month. Figure 7 shows a schematic of the climate change factor method used in this study.

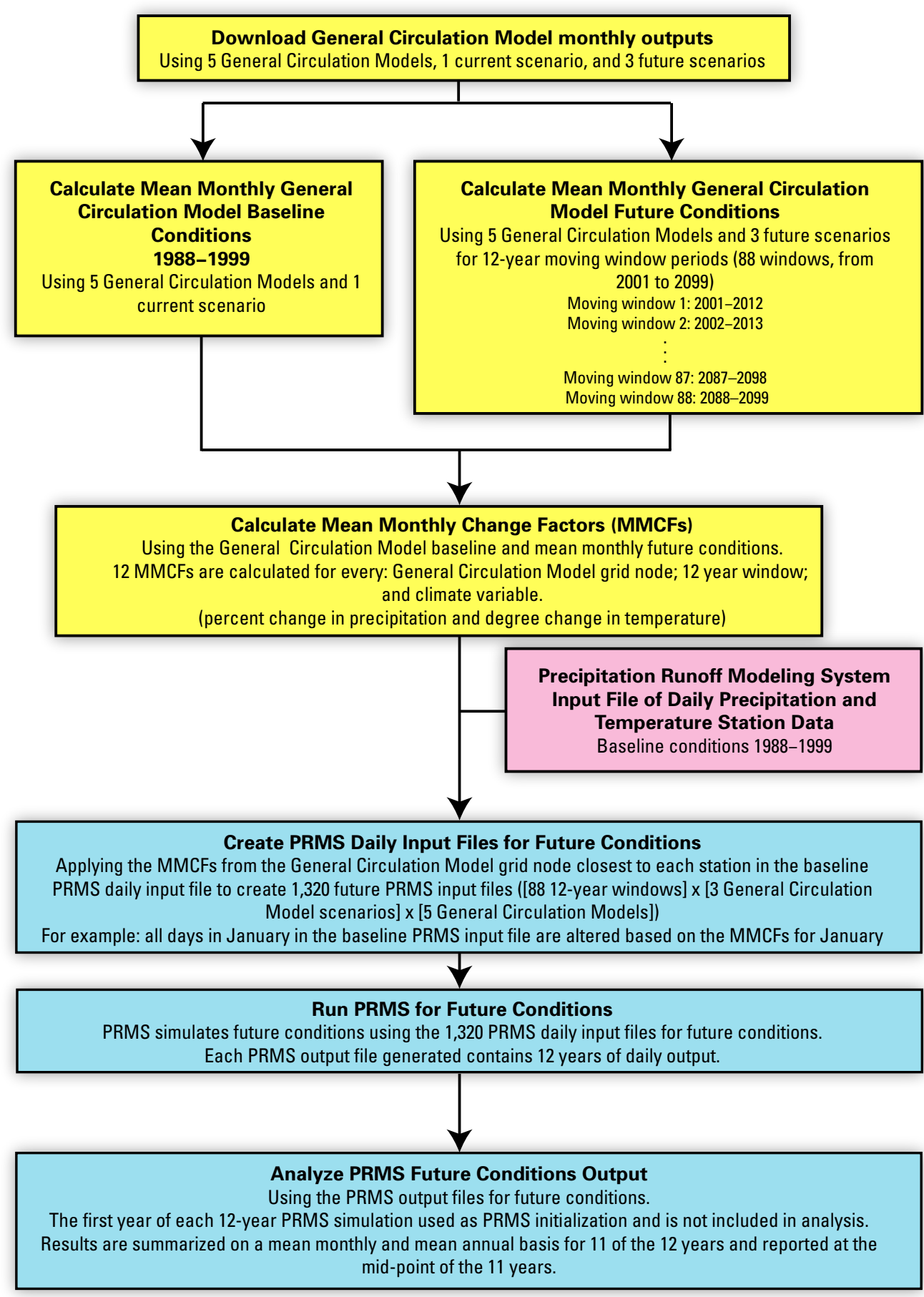

Figure 7. Schematic of the climate change factor method as applied in this study. 
A software tool, called Shodan, automates the calculation of change factors and applies them to the PRMS Data Files (fig. 8). The downscaling process, as described above (this section), results in 1,320 PRMS Data Files ([88, 12-year climatologies, 1 per year starting with water years 2001-2012 and ending with water years 2088-2099] x [3 scenarios] x [5 GCMs]). Four steps are required to run Shodan. Each step and the respective user interface screen are described below:

The Setup Parameters screen (fig. 8A) allows specification of: (1) the Start Year and End Year of the Baseline

\section{$A$}

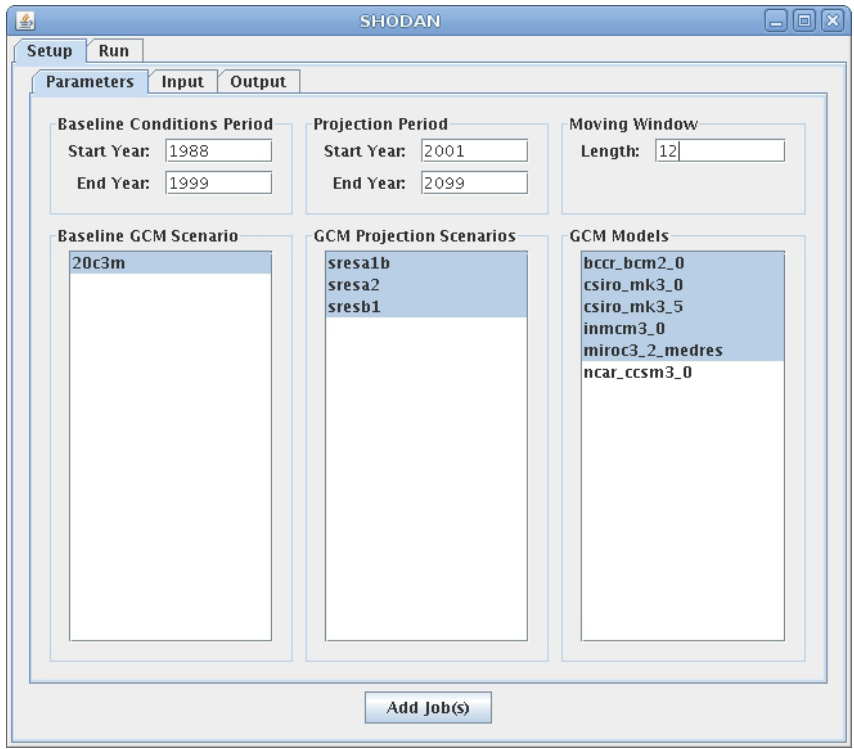

C

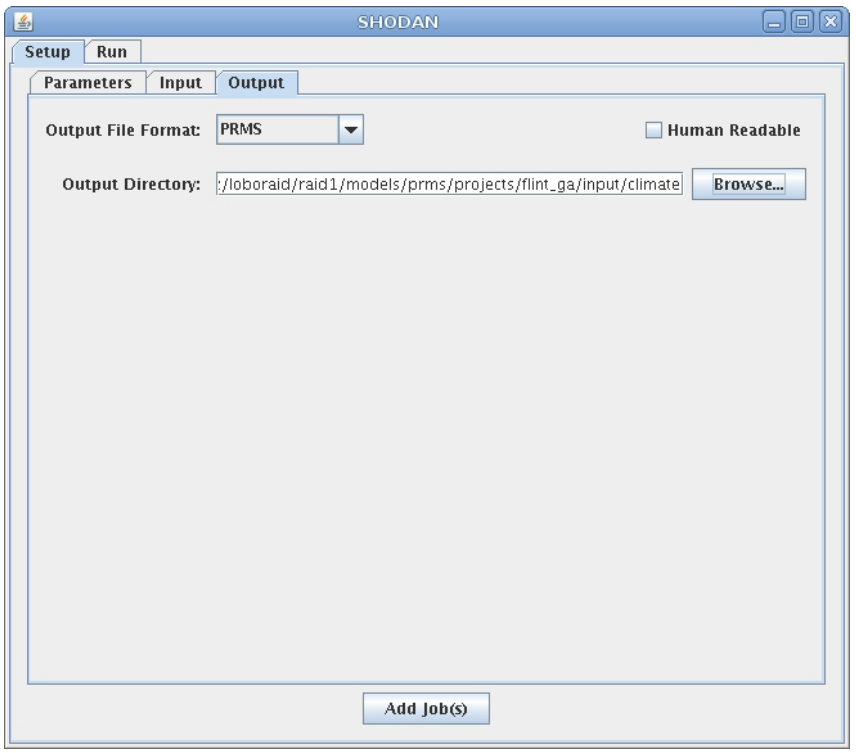

Conditions Period; (2) the Start Year and End Year of the Projection Period; (3) the Moving Window Length, which is the number of years for each projection; (4) the Baseline GCM Scenario; (5) the GCM Projection Scenarios; and (6) the GCM Models.

The Setup Input screen (fig. 8B) allows specification of: (1) the Input File Format; (2) the PRMS File name; and (3) the Meta Files, which contain information about the station point locations for the data (fig. 9).

\section{$B$}

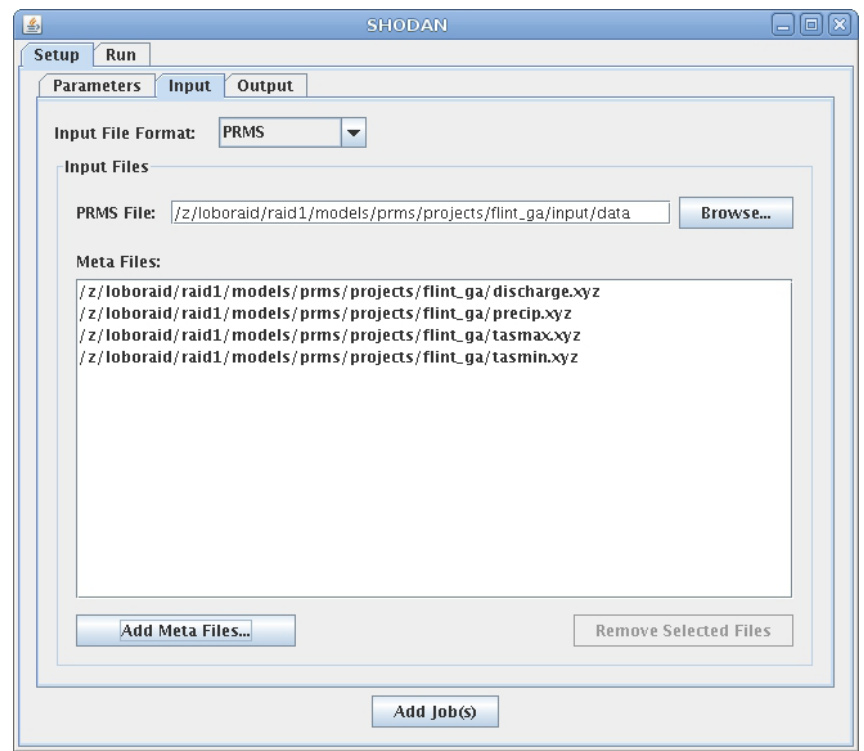

$D$

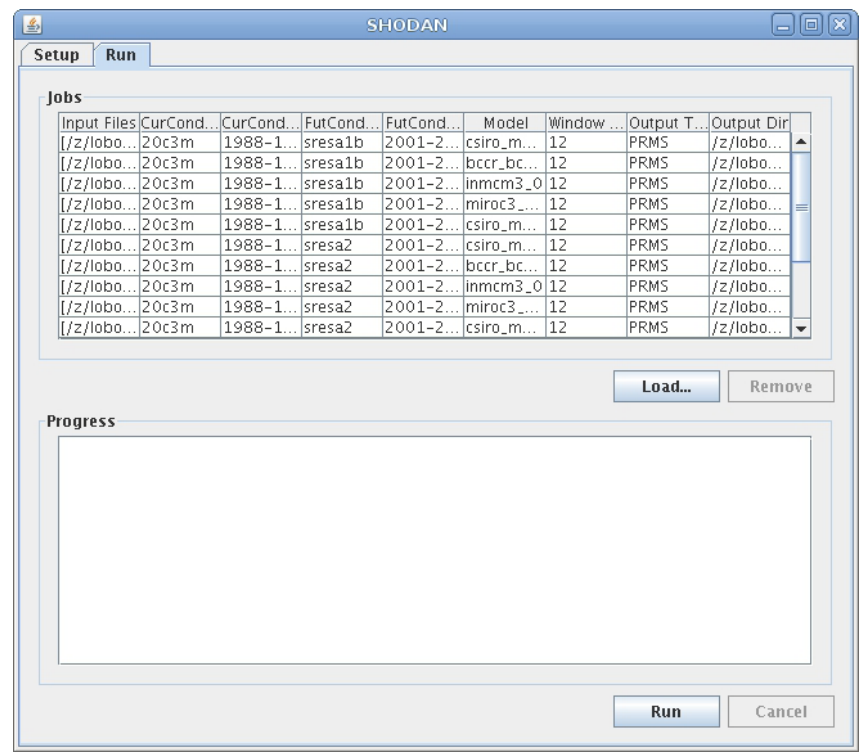

Figure 8. Shodan graphical user interface used to create Precipitation Runoff Modeling System input data files for future climatic conditions: $(A)$ Setup Parameters, $(B)$ Setup Input, $(C)$ Setup Output, and $(D)$ Run windows. 


\begin{tabular}{|c|c|c|c|c|c|}
\hline \multicolumn{6}{|c|}{ Number of stations: 5} \\
\hline \multicolumn{6}{|l|}{ Variable: tasmax } \\
\hline \multicolumn{6}{|l|}{ Unit: fahrenheit } \\
\hline ID: & 172620 & 174878 & 172426 & 176430 & 179891 \\
\hline Network: & COOP & COOP & COOP & $\mathrm{COOP}$ & COOP \\
\hline Name: & "ELLSWORTH" & "MACHIAS" & "EASTPORT" & "ORONO" & "WOODLAND" \\
\hline Latitude(degree_ & N): $\quad 44.5333$ & 44.7194 & 44.9067 & 44.8992 & 45.1572 \\
\hline Longitude(degree & e_E): -68.4333 & -67.4542 & -66.9919 & -68.6744 & -67.4044 \\
\hline Elevation(meter): & 6.096 & 6.096 & 25.908 & 35.052 & 42.672 \\
\hline
\end{tabular}

Figure 9. An example of the tasmax_xyz file of station point locations used by Shodan.

The Setup Output screen (fig. 8C) allows specification of: (1) the Output File Format; and (2) the Output Directory where the downscaled PRMS Data Files will be written.

The Run screen (fig. $8 D$ ) shows: (1) the downscaling Jobs that will be performed by Shodan. Each job consists of the creation of a set of PRMS Data Files, each containing the downscaled climate information; (2) the Run Jobs button which starts the creation of the PRMS Data File; and (3) the status of the jobs in the Progress window.

\section{Step 4: Generate the Precipitation Runoff Modeling System Projections}

For each of the 1,320 PRMS Data Files created by Shodan, as described in Step 3: Downscale General Circulation Model Projections of this report, the following procedure was executed:

- Modify the PRMS Control File so that the correct Shodan-produced PRMS Data File will be used.

- Modify the PRMS Control File so that the names of the four PRMS output files will be unique for each scenario. These output files are the PRMS statvar file, the HRU animation file, the Groundwater Reservoir animation file, and the Subsurface Reservoir animation file.

- Modify the PRMS Control File so that the starting and ending time step of the simulation is the appropriate 12-year time window.

- Determine the period of active transpiration for each HRU for the PRMS projection 12-year time window by executing the PRMS model in preprocess mode by specifying the "-preprocess" command line argument.
The period of active transpiration is computed by the new PRMS module "frost_date_prms" which processes the daily HRU temperatures and appends the parameters "fall_frost" and "spring_frost" directly to the PRMS Parameter File. These parameters are used by the new PRMS module "potet_jh_prms." Both new modules are documented in Appendix 1, "Documentation of New PRMS Modules."

- Simulate the 12-year time window by executing the PRMS model with the input and output files as specified above in section Step 3: Downscale General Circulation Model Projections.

\section{Step 5: Analyze the Precipitation Runoff Modeling System Projections}

This study is limited to "climate change;" therefore, projected changes in the 21 st century climate were analyzed on a basin mean monthly basis and on an annual basis for every PRMS model output variable in table 3 . The PRMS projections are summarized for each of the basins in the "PRMS Projections by Application" section below.

\section{Assumptions and Limitations}

Several assumptions and limitations related to the data and modeling aspects of this study are discussed. These are (1) the spatial and temporal resolution of the data and how it relates to the PRMS model, (2) the historical period used to represent the 20th century, (3) estimation of solar radiation by the PRMS model, (4) PRMS simulation and accounting of snowpacks, (5) PRMS simulation of evapotranspiration, and (6) a general discussion of the different sources of uncertainty. 


\section{Spatial and Temporal Resolution}

Because the PRMS model has a time step of one day, all flows and storages are mean daily values. In general, flows near land surface occur more rapidly than flows in the subsurface. Consequently, the daily time step may result in errors because of temporal averaging for near land-surface flows such as surface runoff, infiltration, and interflow. Simulation errors can occur when streamflow changes abruptly over time increments that are less than one day. For this study, simulating the subdaily behavior of these processes is not warranted because all output is analyzed on a mean monthly basis. Basically, it is assumed that the within day errors that might result do not significantly affect the monthly water budget analyses.

The delineation of the HRUs must be appropriate for the PRMS algorithms. In the PRMS model, each HRU is assumed to be homogeneous with respect to both input parameterization and computation of flows and storages. Because the 14 PRMS applications were developed by different modelers for different purposes, HRU delineation methodologies were not always consistent. Some of the 14 basins were set up as medium-tolong-term water-supply studies, which results in large HRUs, while others were set up as the basis for ecological and habitat studies, which results in much finer resolution HRUs. This problem was overcome by analyzing the output on an areaweighted average basis.

\section{Historical Period Used as Baseline Conditions}

The historical climate record chosen to represent baseline conditions may affect the PRMS projections. Koczot and others (2011) found when using the change-factor method for downscaling, several baseline conditions may need to be chosen to represent a range in historical climatic conditions. Ideally trends, variability, and extremes in the climate record could be considered. Koczot and others (2011) also found that not all hydrologic variables equally were sensitive to the selection of baseline conditions. Projections of PRMS variables which are not associated directly with long-term water storage in the model, like temperature, tend to be dominated by the climate trends introduced by the scenario. Variables associated with interannual water storage in the model, like content of the soil-zone reservoir, appear to be more sensitive to the selection of baseline conditions. In addition, the geographic location and dominant physical processes (in this case, influences from topography and multidecadal climatic cycles) may have a strong bearing on the sensitivity of PRMS projections to the selection of baseline conditions.

\section{Simulation of Solar Radiation}

The PRMS model simulates daily solar radiation for each HRU of the 14 applications in this study. Simulated solar radiation is used for snowpack energy balance calculations, and to simulate PET. These solar radiation values are simulated by one of two methods, depending on the geographical location of the basin, as described by Markstrom and others (2008, p. 41-43). Both of these methods heavily rely on an assumed positive relation between daily temperature and daily solar radiation. Neither method accounts for variations in solar activity or changes in atmospheric effects. Under conditions of changing climate, these assumptions may not hold. Roderick and others (2009) report that in some locations, despite a positive trend in daily air temperature, there may be a dimming of solar radiation. The PRMS model does not account for this. In future studies, the PRMS model could use solar radiation change factors computed from the GCM projections; however, uncertainty associated with this may not justify the additional effort.

Notwithstanding these issues related to simulation of solar radiation, analyses of the PRMS projections indicate that the simulated changes in solar radiation typically are less than 5 percent over the period of the study. Consequently, this small change in projected solar radiation has a minimal effect on projected basin runoff and other hydrologic variables.

\section{Simulation of Snowmelt and Rainfall on Snowpacks}

PRMS applications in cold weather and mountainous basins are sensitive to snowpack simulation. The PRMS model simulates temperature, melting, water content, and temporal and areal extent of the snowpack. It also determines phenological occurrences, such as the initiation of the snowpack and the onset of spring. Simulation of these processes is described in detail by Markstrom and others (2008), and the effects on this study are described below in the "PRMS Projections by Application" section.

Water storage within the snowpack is tracked in two states: ice (solid) and free water (liquid). The amount of free water in the snowpack is determined by freeze-thaw cycles, based on energy balance, and the physical capacity of the snowpack matrix to hold free water. The total amount of water storage in a snowpack is expressed as the volume of water equivalent, neglecting air space, if all the ice is melted to liquid form.

The PRMS model uses the freezing point of water (an all-ice isothermal snowpack at $0{ }^{\circ} \mathrm{C}$ ) as the condition to initiate melt in the snowpack. When the snowpack energy rises above this state, some ice melts and liquid free water results. The PRMS model reports snowmelt only when the free water in storage exceeds the pore space of the snowpack. This loss of free water from the snowpack represents an output of both water and latent energy.

Complications occur when falling rain enters the snowpack as free water in excess of the pore space. The PRMS model will report this excess water, which has never been frozen, as snowmelt. Another complication occurs when falling rain enters the snowpack as free water in deficit of the pore space and freezes to ice because of an energy deficit. In this 
case, the snowpack may contain more ice than the amount of precipitation that fell as snow, eventually causing the PRMS model to report more snowmelt than snowfall. Either of these cases may complicate the interpretation of simulations, particularly when the study basin straddles the seasonal snow line.

\section{Evapotranspiration}

A major component in the simulation of the water balance for any basin is the actual evapotranspiration (AET) rate. The PRMS model uses many factors to compute AET, including the simulated PET, vegetation type and cover density, land-use characteristics, soil type, simulated atmospheric conditions (available energy, precipitation, and cloud cover), and soil moisture availability (Markstrom and others, 2008).

An important source of uncertainty in hydrologic simulation modeling is the methodology and available data used to compute PET (Kingston and others, 2009). In the PRMS model, PET is the theoretical absolute upper limit of simulated AET and is not used directly in water balance computation. Measured, or surrogates for measured, PET data can be useful for calibration and evaluation of PRMS applications because they are independent of measured streamflow. Typically, this information is available either as an atlas of stationary mean monthly values (such as Farnsworth and others, 1982) or as time series of pan evaporation rates or corrected lake levels at sites in or nearby the study basin. Research suggests that the use of historical PET information must be considered carefully as rates have demonstratively changed over the latter half of the 20th century (Walter and others; 2004, Roderick and others, 2009; and Szilagyi and others, 2001). The physical process mechanism responsible for non-stationarity in PET is not well understood and PRMS provides no algorithmic simulation capability for it.

This study uses the Jensen-Haise method (Jensen and others, 1970; and Markstrom and others, 2008) to estimate PET. The method uses empirical constants to define a longterm climatic setting for simulating daily PET. The variability of daily PET is determined by the daily variation in solar radiation (as discussed in the "Simulation of Solar Radiation" section of this report) and temperature of the evaporation surfaces.

Two criticisms of the Jensen-Haise method are that it does not explicitly account for daily variation of relative humidity and assumes complete mixing of the atmosphere above the evaporation surface. Consequently, this method does not explicitly account for variation in the near-surface vapor pressure gradient and mass transfer of vapor into the atmosphere. In addition, because the method, as implemented in the PRMS model, relies on near surface air temperature as an index for both sensible heat and solar radiation, under warming conditions, it may overestimate the amount of energy available for PET. Milly and Dunne (2011) report, that for some of the applications in this study, the PRMS model overestimates PET. Conceptually, overestimation of PET may lead to unrealistically large decreases in projected streamflow; however, because AET, rather than PET is used in the water balance computations, decreases in streamflow are not nearly so severe (Kingston and other, 2009; and Donohue and others, 2010). In fact, all of the basins in this study, except one, are soil moisture limited (Hay and others, 2011).

Some researchers (Hall and others, 2008; Szilagyi, 2001; Walter and others, 2004; and Roderick and others, 2009) have observed that AET rates may be changing differently than PET rates. The "complementary hypothesis" (Szilagyi, 2001) describes how increases in AET may result in decreases in the vapor pressure deficit which consequently results in decreases in pan evaporation (PET). Roderick and others (2009) report that this phenomenon may not occur universally in all locations, as other physical processes, such as dimming of solar radiation and decreased wind speed may be dominate. Regardless, the PRMS model does not algorithmically account for any of these processes. Changes in the simulated AET rates, from the PRMS baseline simulations (Hay and others, 2011), are comparable to measured (or estimates of measured) values presented in the literature (Walter and others, 2004, p. 204; and Szilagyi and others, 2001). This may give an added degree of confidence that the PRMS projections are reasonable.

Under extreme changing climate conditions, the PRMS computational PET assumptions may not be adequate; however, the Jensen-Haise method has been successfully applied in widely varying environments under current and recent past conditions (later half of the 20th century), which suggests its applicability in the near future (Hay and others, 2011). Donohue and others (2010) believe that accurate simulation of PET is dependent on knowledge of net radiation, vapor pressure, wind speed, and air temperature. Ideally, accurate measurements (or projections) of these data and an appropriate PET simulation algorithm would result in improved simulation and reduction of uncertainty.

\section{Uncertainty}

Numerous sources of uncertainty have been identified in the steps of this study. Large uncertainties are associated with the representation of the physical processes, model structure, and feedbacks within the climate system as projected by the GCMs (Intergovenrnmental Panel on Climate Change, 2007). The scenarios chosen for this study (table 4) represent different economic, social, political, and technological development for the future, none of which may be the actual path. In this study, multiple GCM projections (table 2) were used to quantify these uncertainties. While some researchers prefer to weight or select specific GCMs based on their ability to reproduce current climate, others (Murphy and others, 2004; Tebaldi and others, 2005; Stainforth and others, 2007) argue that the entire ensemble of GCM projections can be used to produce a lower bound on the maximum range of uncertainty. 
Better quantification of uncertainty in GCM projections may be achieved by combining Bayesian approaches (Draper 1995; Tebaldi and others, 2005; Raftery and others, 2005) with earth models of intermediate complexity or energy balance models (Urban and Keller, 2009). This approach will allow detailed evaluation of the tails of the climate sensitivity distribution and can be used to derive probabilistic projections or posterior model weights, reducing the risk of overconfident projections that can result from truncated estimates of GCM model uncertainty within a finite ensemble of GCM projections.

The spatial scale of the GCM projections is an additional source of uncertainty. The change-factor method was used to downscale the coarse resolution GCM projections to the finer resolution input required by the PRMS model. In this approach, the changes in atmospheric processes at the GCM subgrid scale are not resolved, such as changing interactions between air masses and topography, and these subgrid interactions may be substantial in some cases (Ikeda and others, 2010). The uncertainty from the downscaling procedure may, however, be overwhelmed by the uncertainty of the driving GCM (Fowler and others, 2007; Khan and others, 2006), which has been shown to be consistently greater than uncertainty from the hydrologic model or natural variability (Prudhomme and Davies, 2009). Hydrologic model output was analyzed on a mean-monthly and annual basis. The uncertainty associated with this simple approach to downscaling is not directly addressed, but simple statistical downscaling methods seem to perform as well as more sophisticated methods in reproducing mean characteristics (Fowler and others, 2007).

The uncertainty going from the GCM projection to the hydrologic model projection can propagate in ways that may either be enhanced or compensated for depending on the structure and parameterization of the hydrologic model (Buytaert and others, 2009). There are many areas for hydrologic model improvement. Research towards improved process representation and methods to represent uncertainty in the choice of model structure and model parameters are needed. The approach used in this study ignores the important feedback mechanisms between the hydrology and the climate. The calibration of the hydrologic model assumes that the parameters for baseline conditions will hold under future conditions, but calibration to past data may not always fully represent the future (Blöschl and Montanari, 2010). The use of PRMS applications developed for other purposes, but used in an integrated assessment, leads to a bigger concern of model consistency in terms of formulation, parameterization, and calibration. As noted by Blöschl and Montanari (2010), when two groups examine the same watershed for effects of climate change the projections can be different. The same can be said for intercomparison using the same model (PRMS in this case) formulated for different reasons by different sets of researchers.

\section{Precipitation Runoff Modeling System Projections by Application}

The description of PRMS projections for each of the 14 application basins starts with a brief overview of the study area, an assessment of baseline conditions, and background on the previous PRMS application. This is followed by four sections: (1) Input: describes annual mean and mean monthly plot for precipitation, maximum temperature, and minimum temperature. Evapotranspiration and length of growing season (annual only) are also shown in this section; (2) Streamflow: describes annual mean and mean monthly plot for streamflow and the components of flow (surface, subsurface, and groundwater); (3) Snow: describes annual mean and mean monthly plot for the percent of precipitation that falls as snow, snowcovered area, snowpack water equivalent, and snowmelt; and (4) Soil Moisture: describes annual mean and mean monthly plot for the infiltration of rainfall and snowmelt, inflow to the capillary and gravity reservoirs, inflow to the groundwater reservoirs (recharge), soil moisture in the capillary reservoir (water stored by soil tension), subsurface storage reservoirs, and groundwater storage reservoirs. A description of all the variables can be found in table 3 .

\section{Annual Mean Plots}

All annual mean plots (figs. 10-28) show the range in the 11 -year moving mean daily values by scenario. The first year of each 12-year window (as described above in the "Step 3: Downscale General Circulation Model Projections" section of this report) was used for initialization of the PRMS projection and is not included in analysis of results. The three solid colored lines indicate the 11 -year moving mean daily values ( $\mathrm{x}$-axis indicates center of 11-year window) for the 3 scenarios (central tendencies of the $5 \mathrm{GCM}$ projections for A2, A1B, and B1). The mean-annual plots show the range in the 11-year moving mean daily values by scenario. The red, blue, and yellow represent the A2, A1B, and B1 scenarios, respectively. The shaded areas shown for each scenario indicates an envelope (or range) of PRMS projections. Each of these plots is described, basin by basin, in the following sections of this report. 


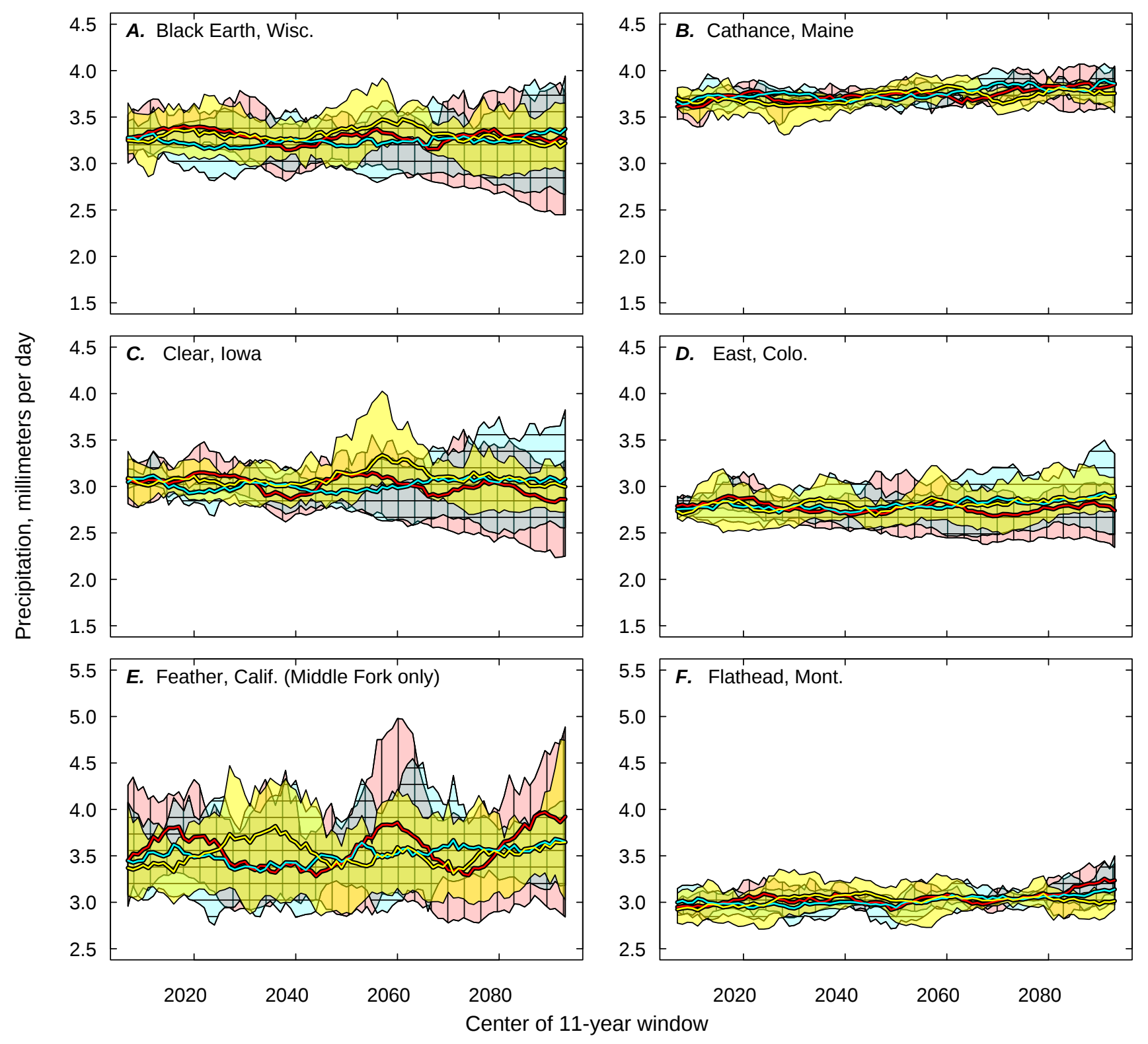

EXPLANATION

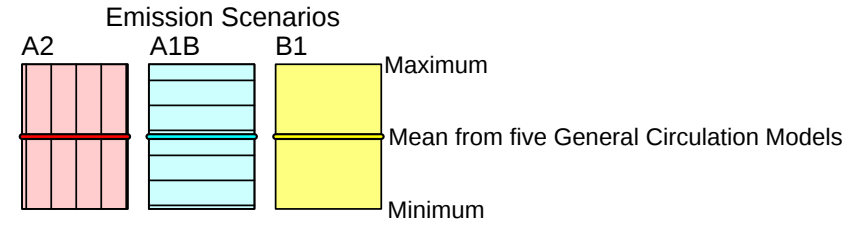

Figure 10. Projected range in 11-year moving mean daily precipitation values by emission scenarios for the 14 basins and means based on the 5 General Circulation Models (GCM). 


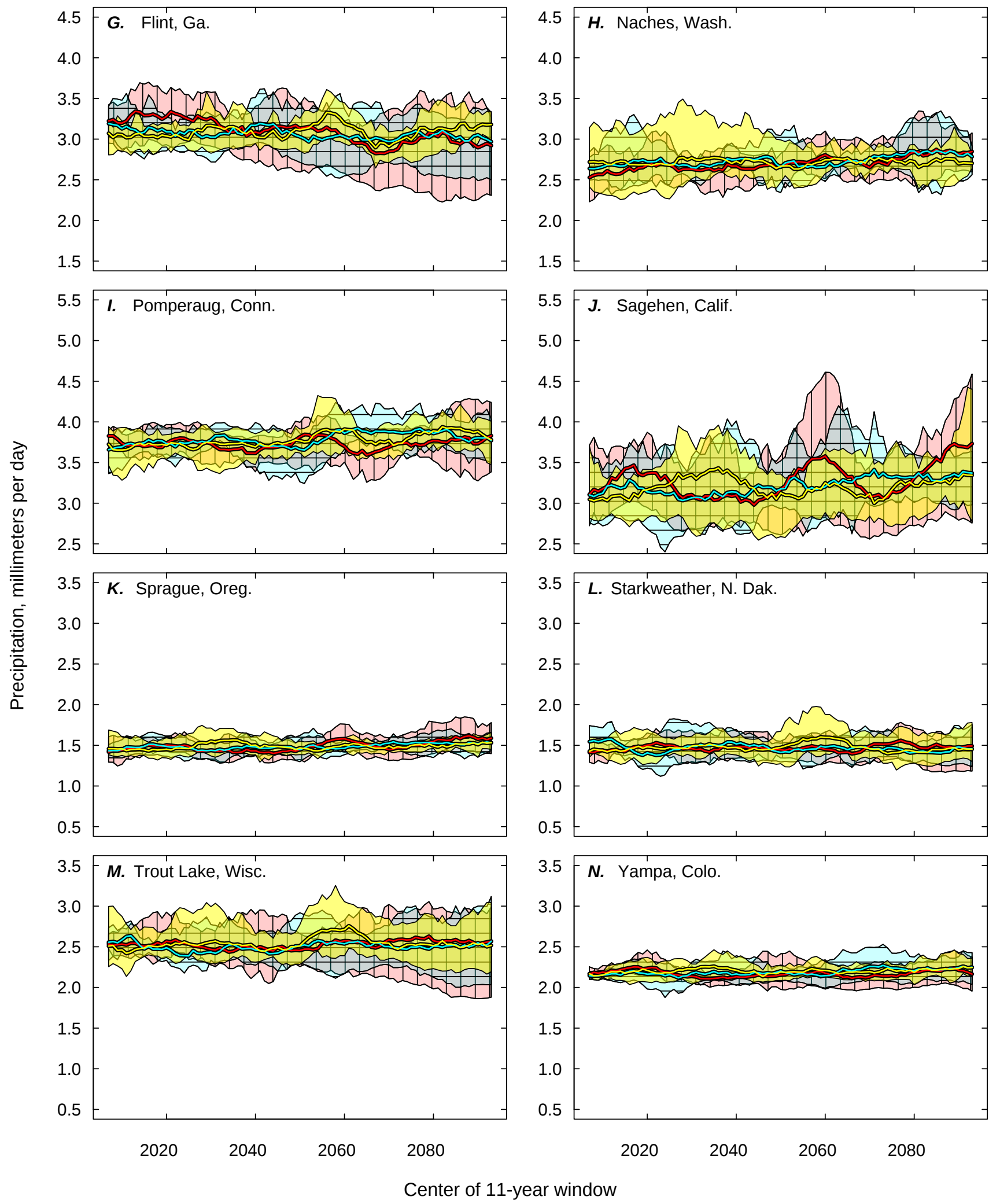

Figure 10. Projected range in 11-year moving mean daily precipitation values by emission scenarios for the 14 basins and means based on the 5 General Circulation Models (GCM).-Continued 

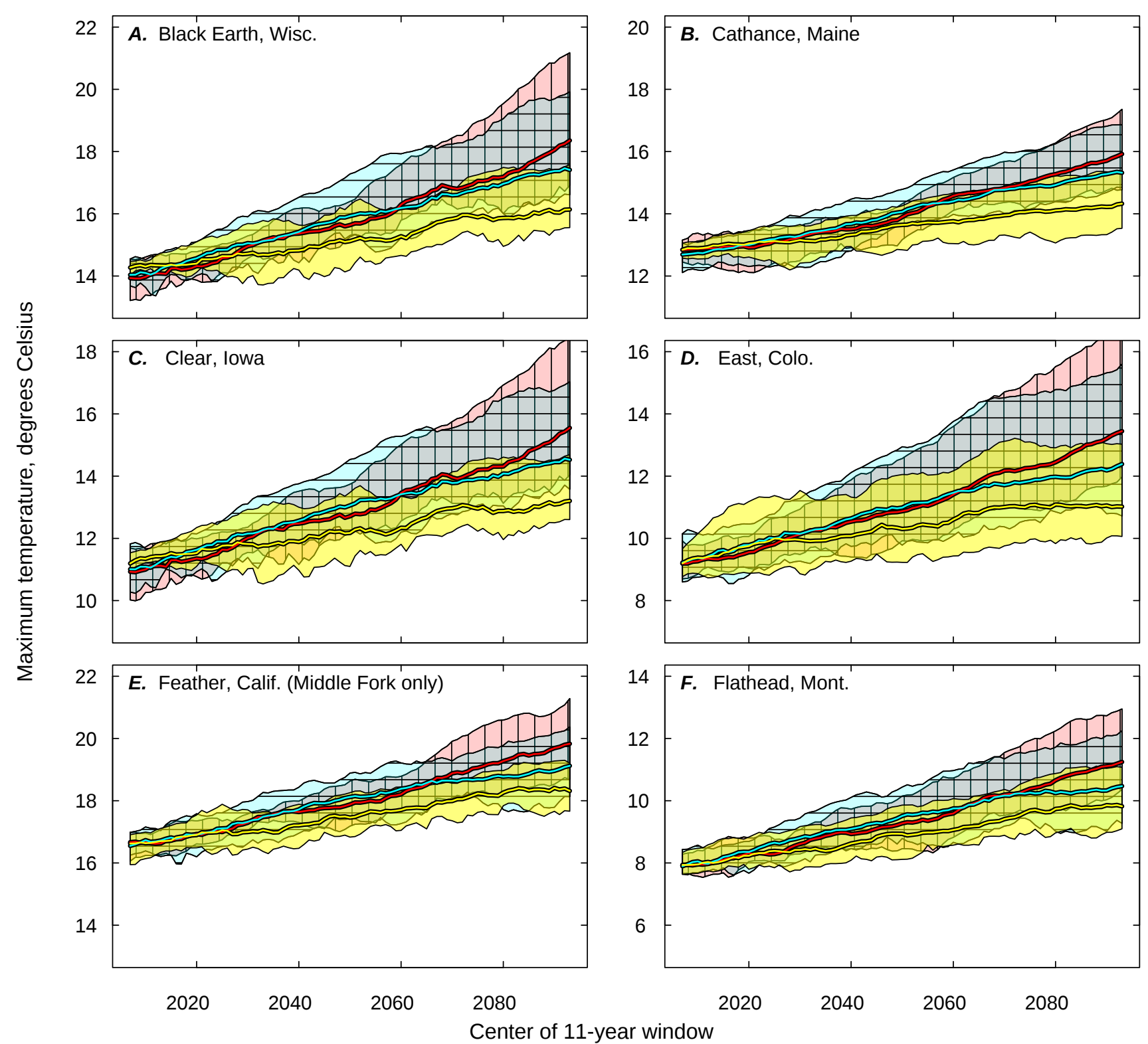

\section{EXPLANATION}

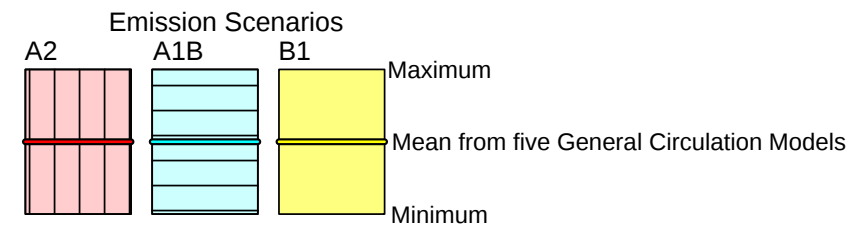

Figure 11. Projected range in 11-year moving mean daily maximum temperature values by emission scenarios for the 14 basins and means based on the 5 General Circulation Models (GCM). 

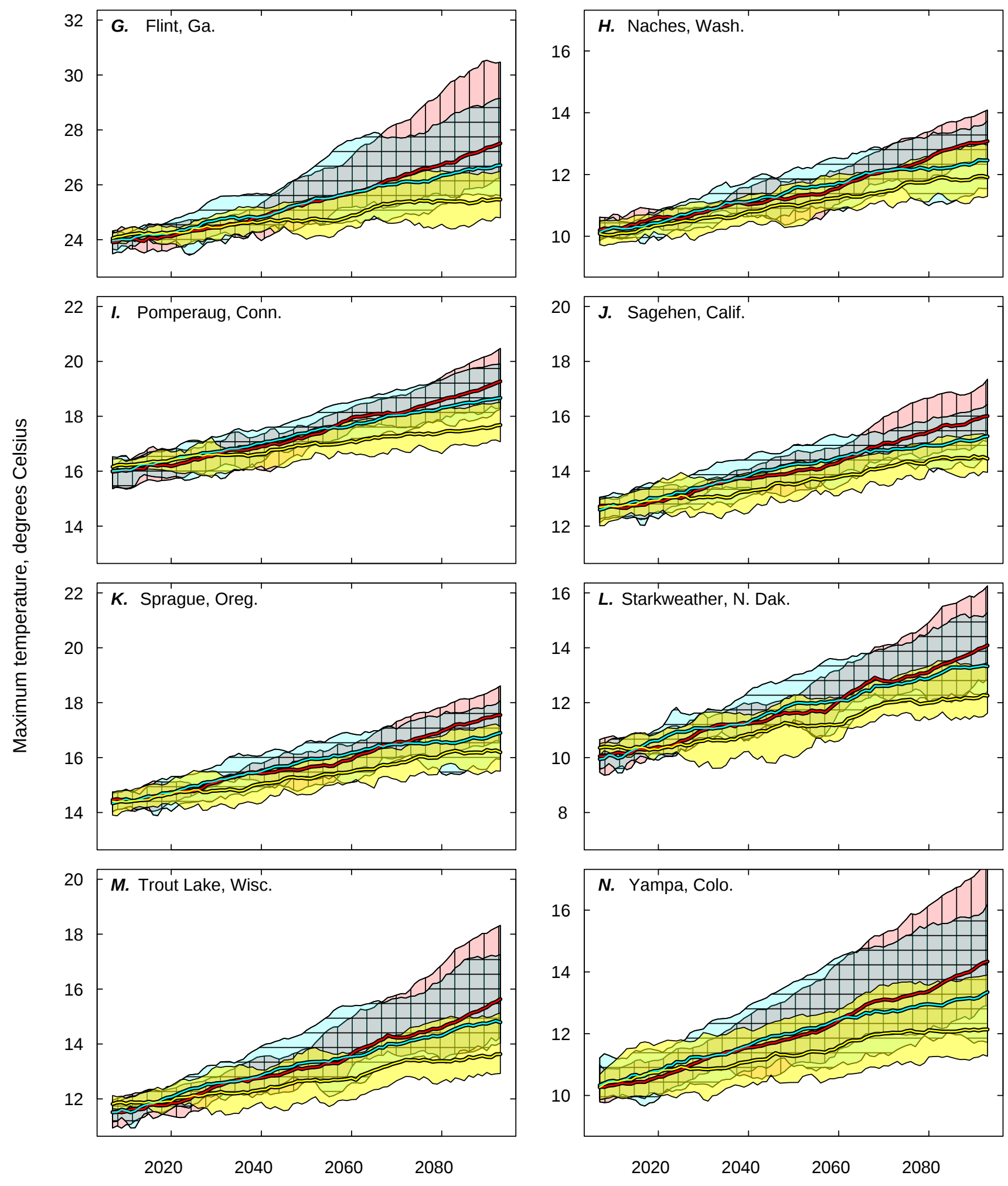

Center of 11-year window

Figure 11. Projected range in 11-year moving mean daily maximum temperature values by emission scenarios for the 14 basins and means based on the 5 General Circulation Models (GCM).-Continued 

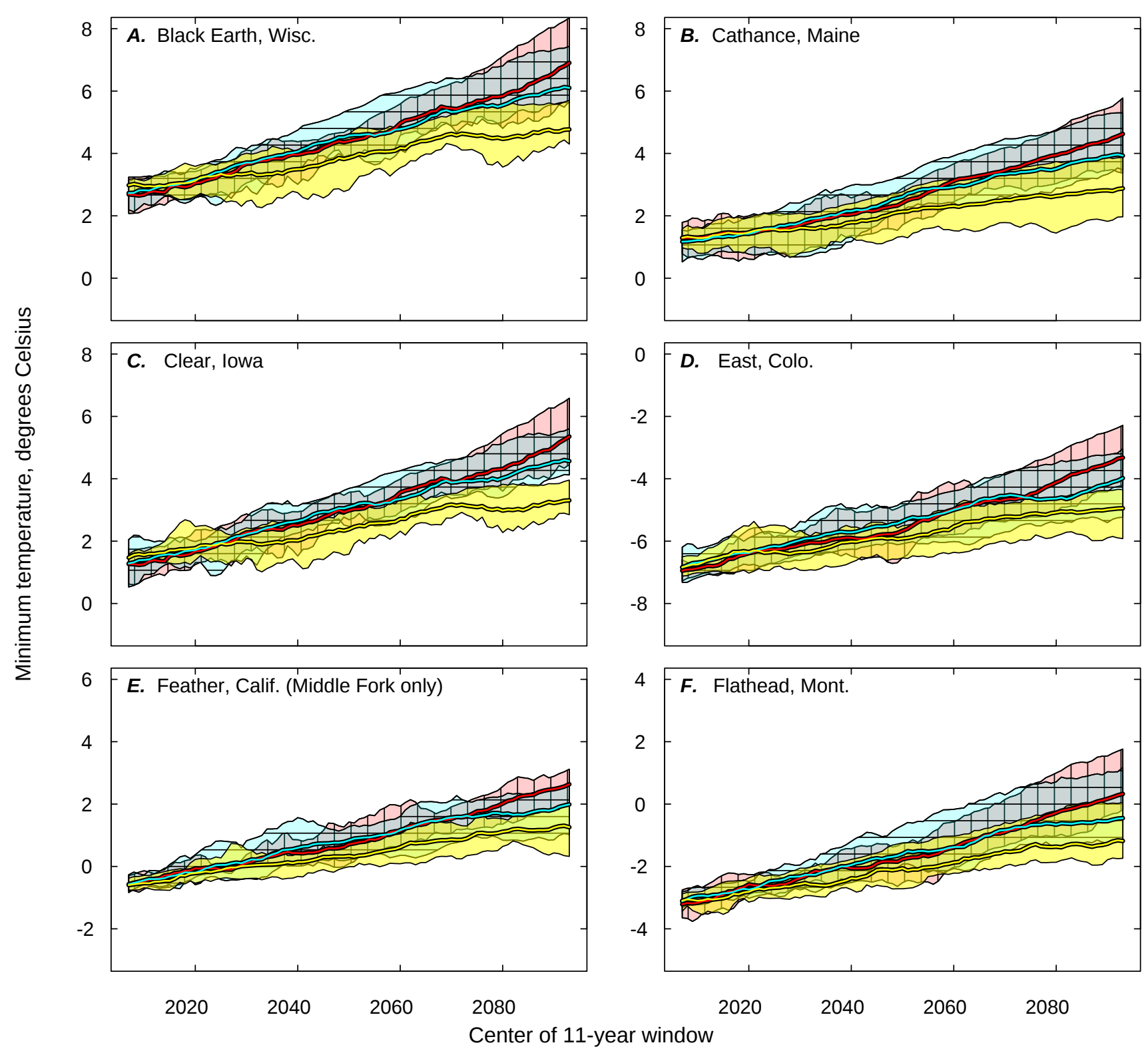

\section{EXPLANATION}

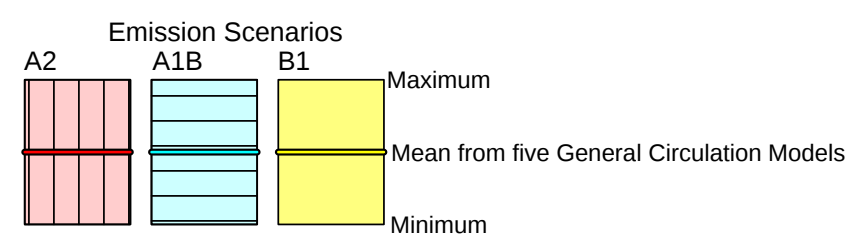

Figure 12. Projected range in 11-year moving mean daily minimum temperature values by emission scenarios for the 14 basins and means based on the 5 General Circulation Models (GCM). 

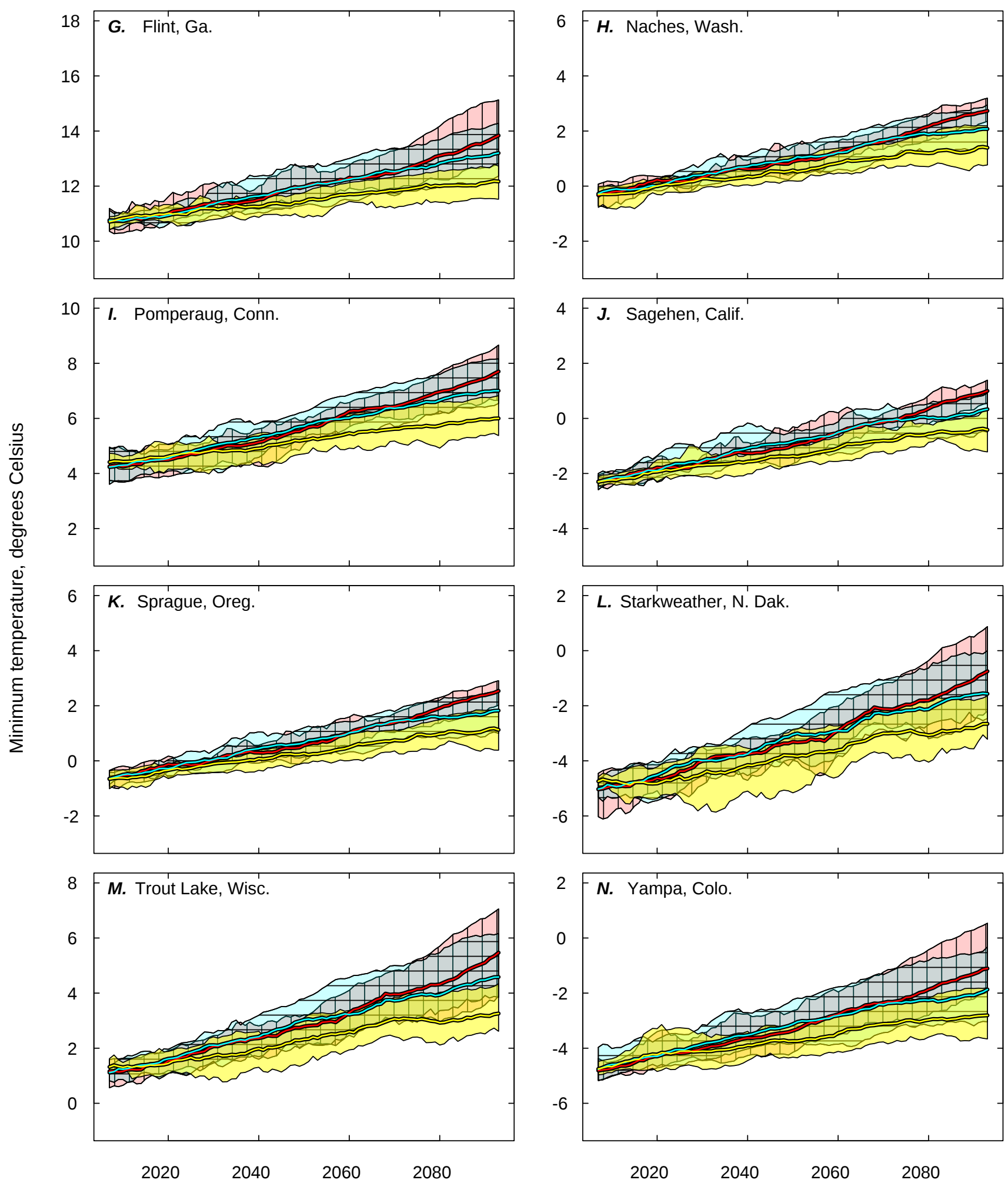

Center of 11-year window

Figure 12. Projected range in 11-year moving mean daily minimum temperature values by emission scenarios for the 14 basins and means based on the 5 General Circulation Models (GCM).-Continued 


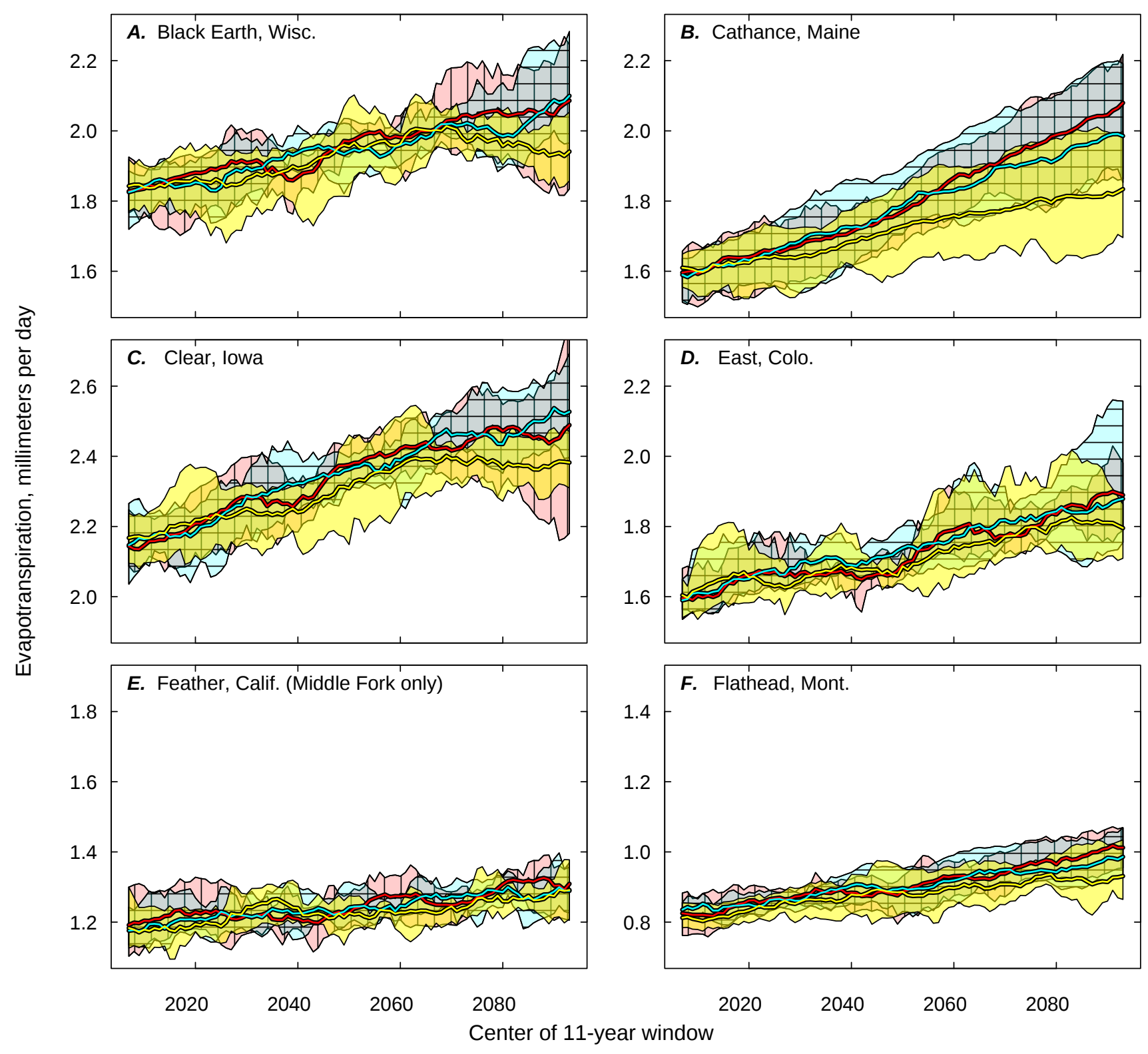

EXPLANATION

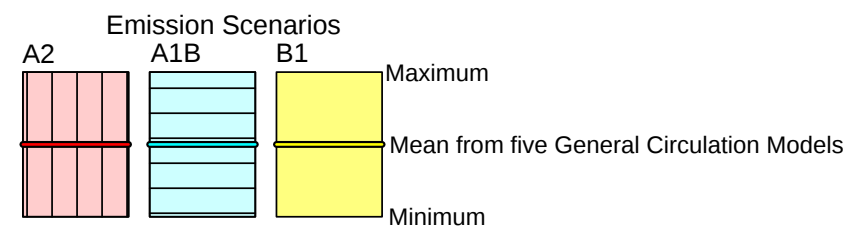

Figure 13. Projected range in 11-year moving mean evapotranspiration by emission scenarios for the 14 basins and means based on the 5 General Circulation Models (GCM). 

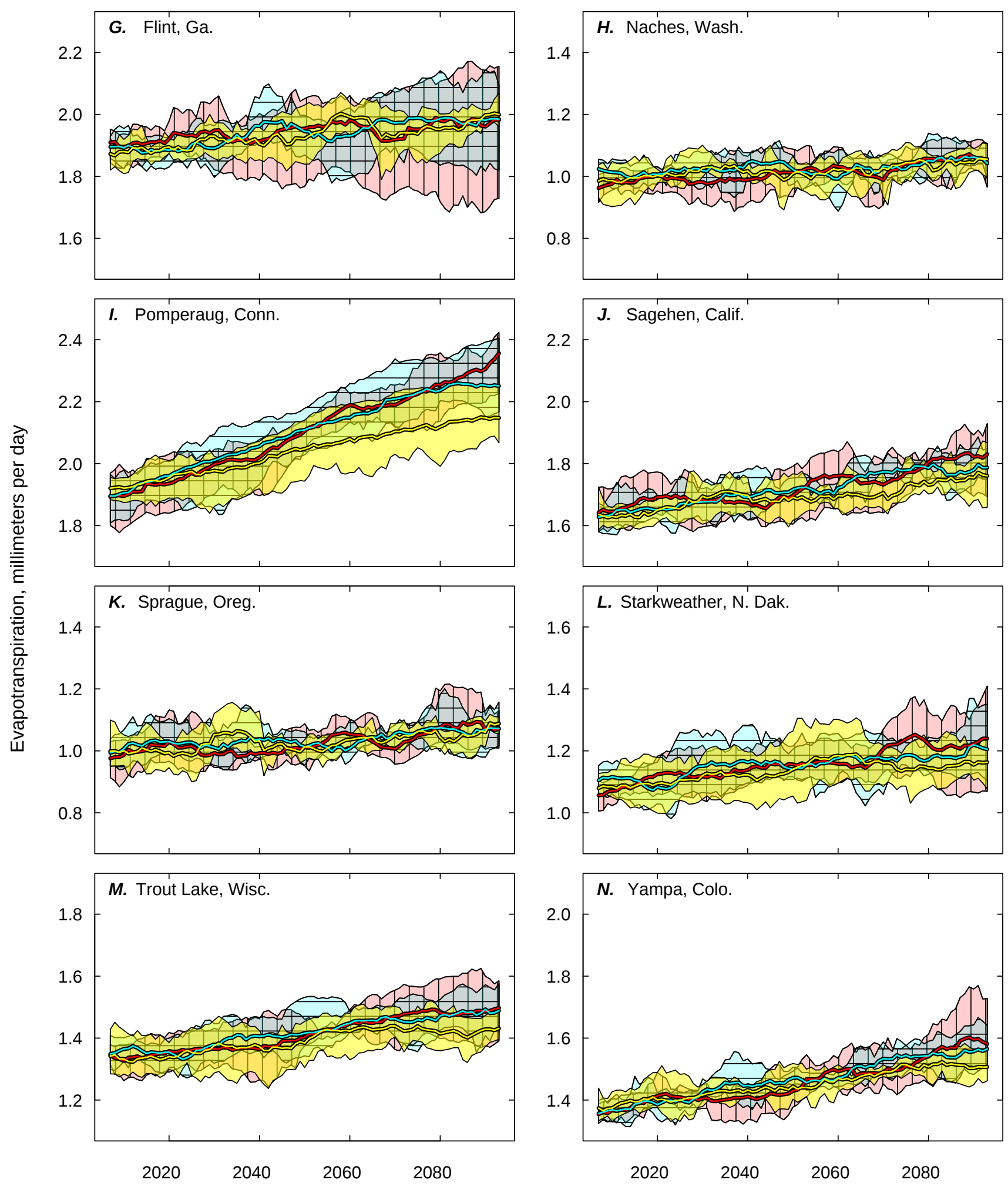

Center of 11-year window

Figure 13. Projected range in 11-year moving mean evapotranspiration by emission scenarios for the 14 basins and means based on the 5 General Circulation Models (GCM).-Continued 

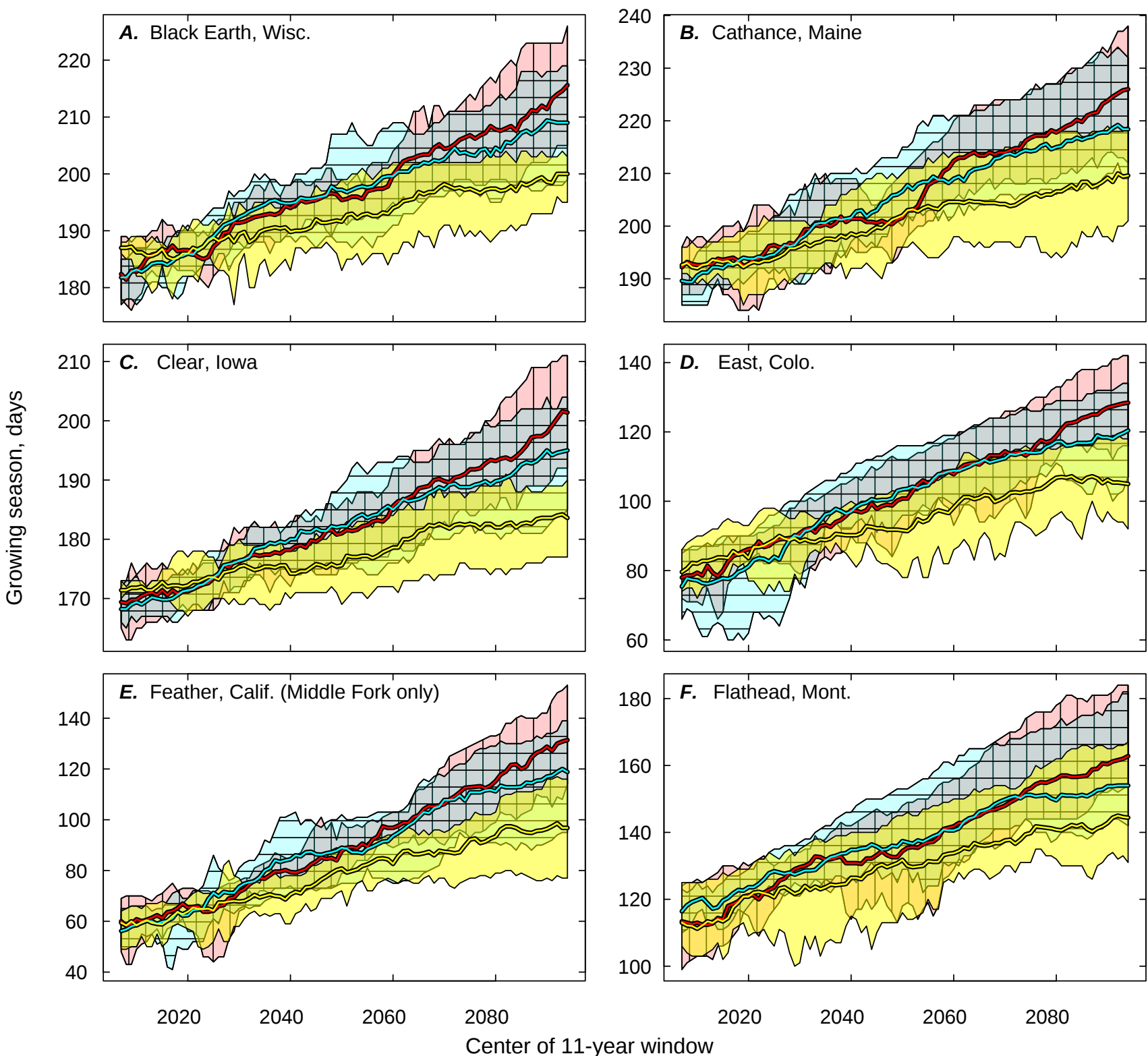

\section{EXPLANATION}

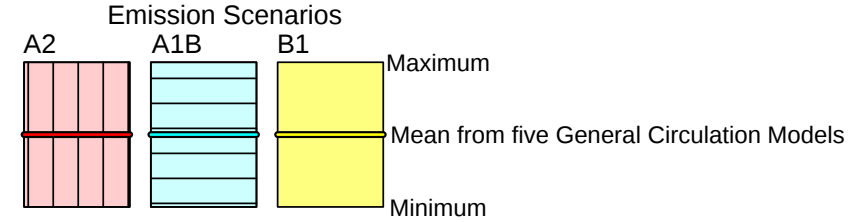

Figure 14. Projected range in 11-year moving mean growing season length by emission scenarios for the 14 basins and means based on the 5 General Circulation Models (GCM). 

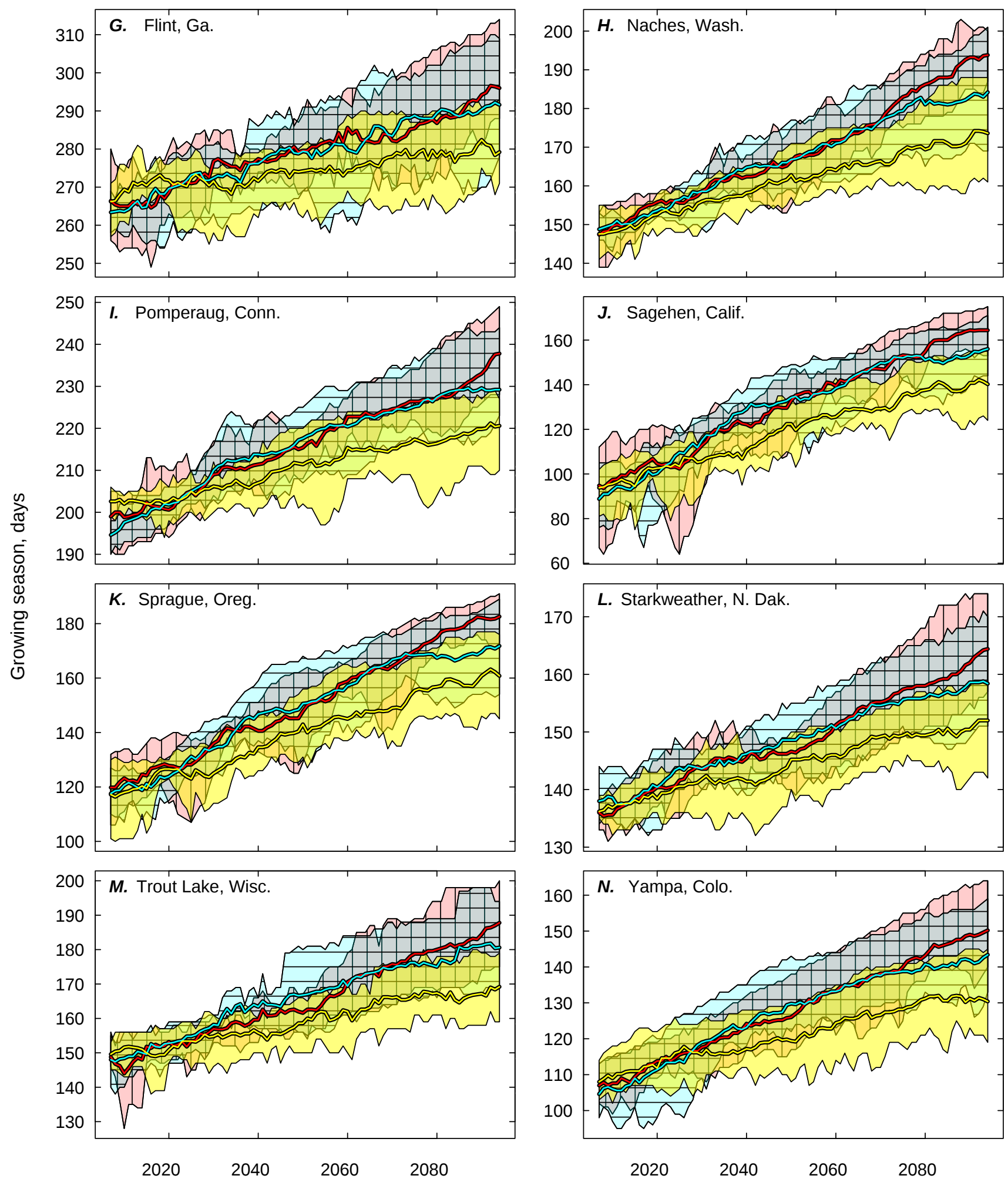

Center of 11-year window

Figure 14. Projected range in 11-year moving mean growing season length by emission scenarios for the 14 basins and means based on the 5 General Circulation Models (GCM).-Continued 

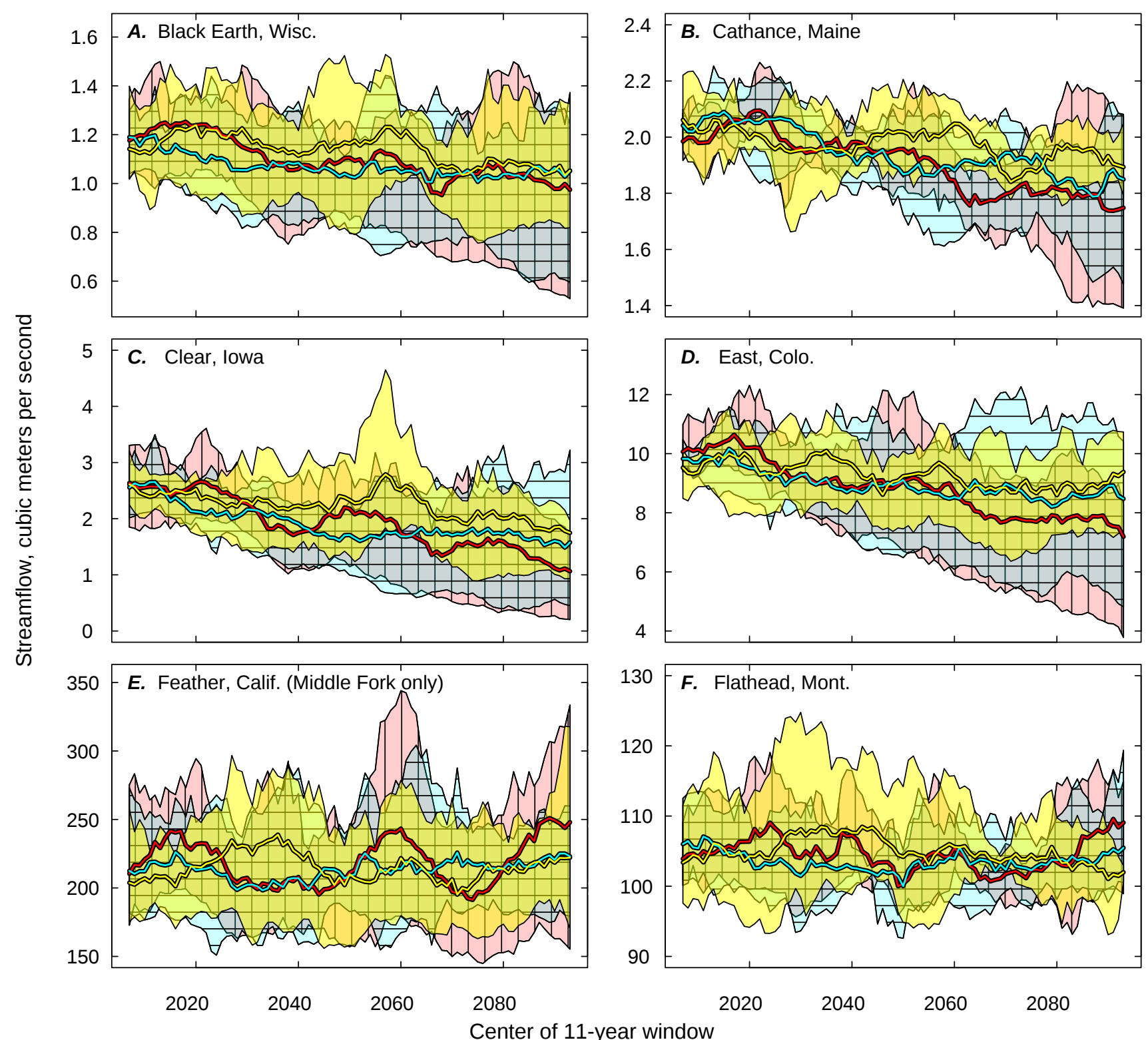

\section{EXPLANATION}

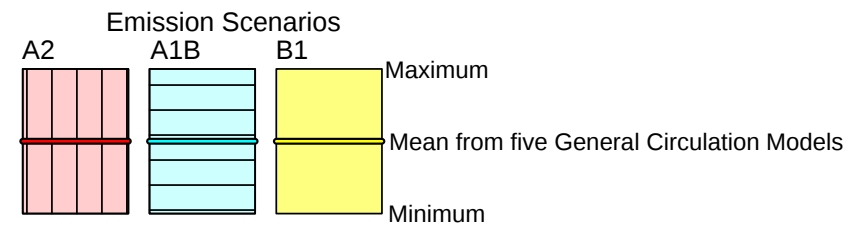

Figure 15. Projected range in 11-year moving mean daily streamflow values by emission scenarios for the 14 basins and means based on the 5 General Circulation Models (GCM). 

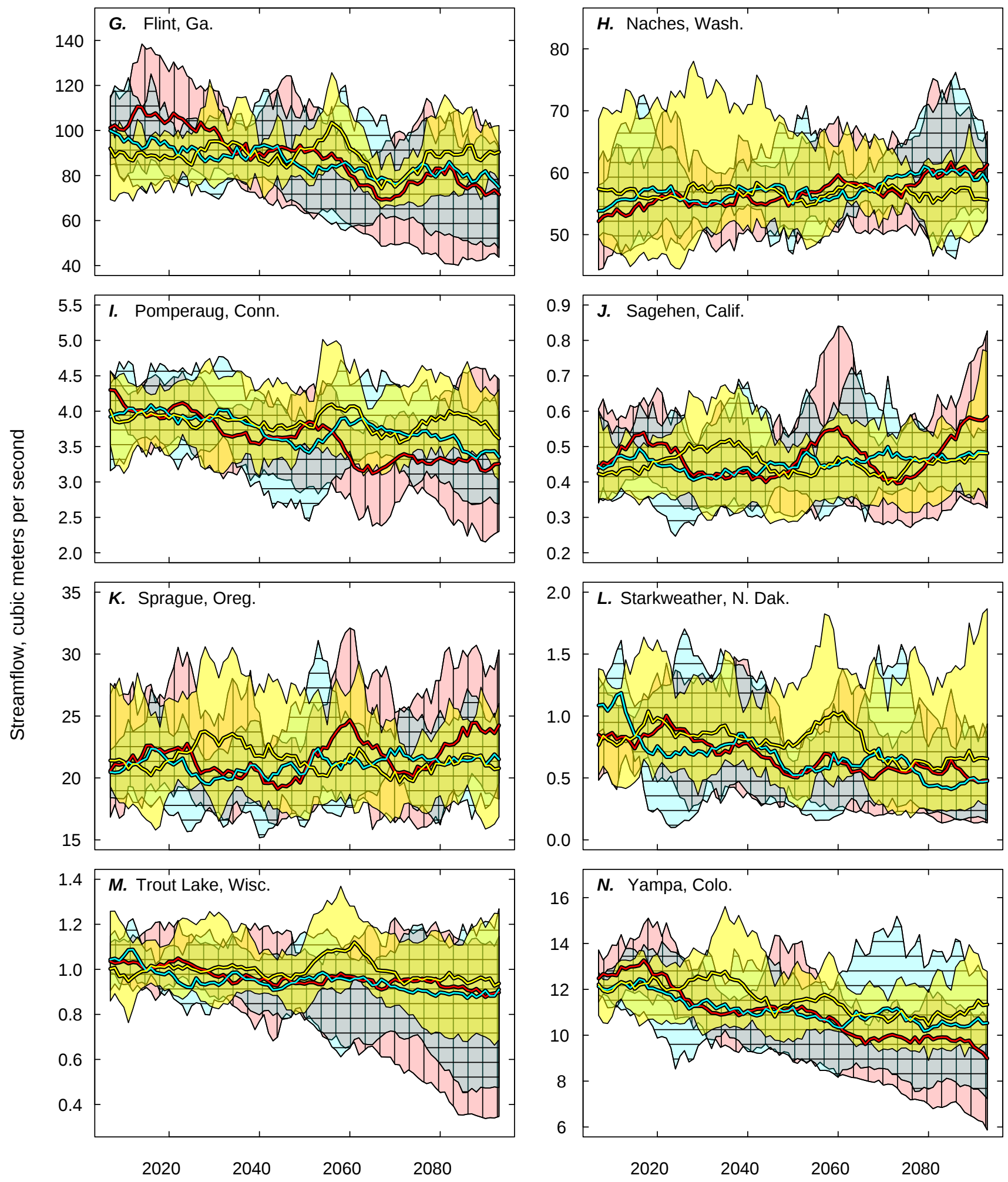

Center of 11-year window

Figure 15. Projected range in 11-year moving mean daily streamflow values by emission scenarios for the 14 basins and means based on the 5 General Circulation Models (GCM).-Continued 


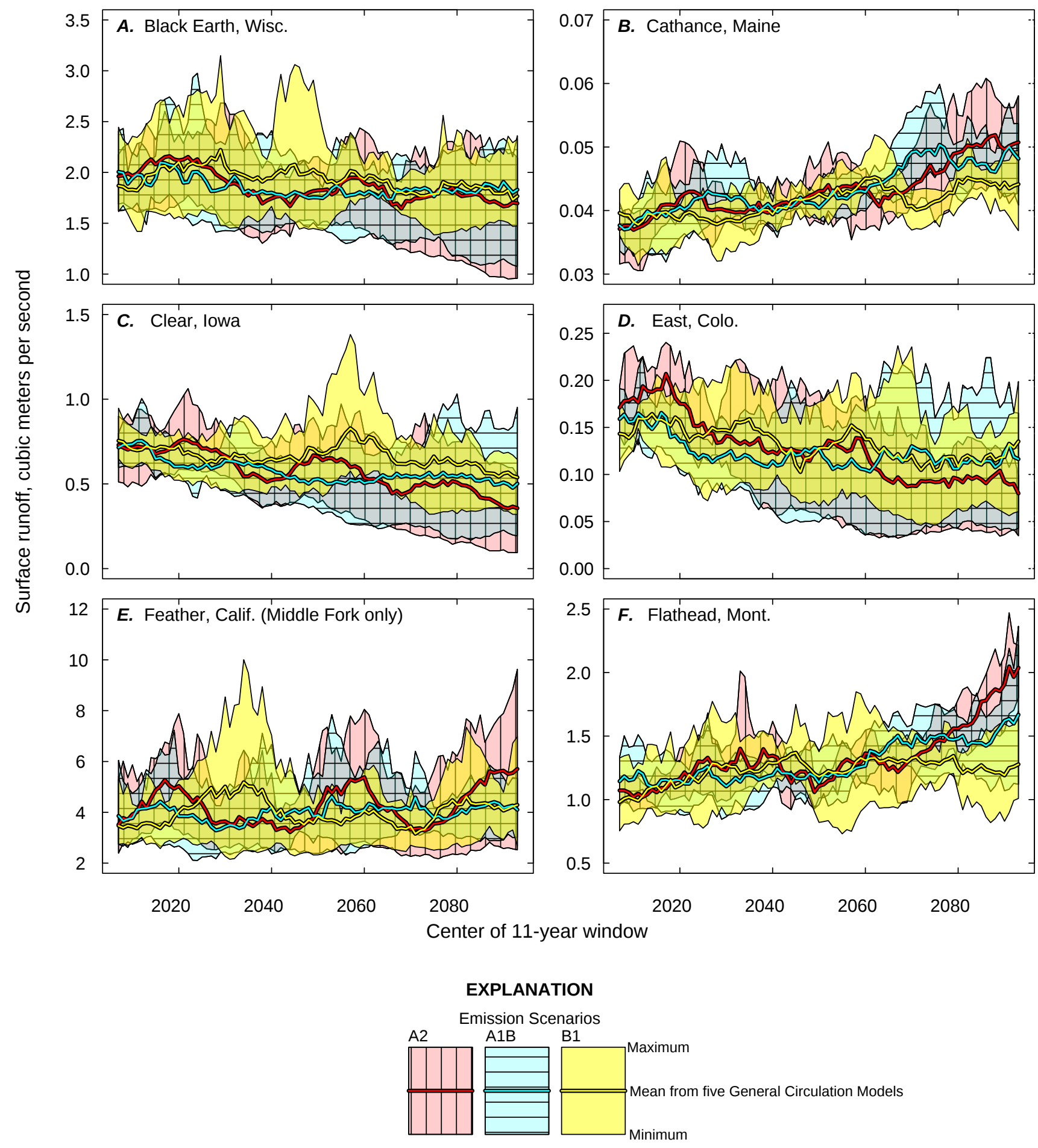

Figure 16. Projected range in 11-year moving mean daily surface runoff values by emission scenarios for the 14 basins. 

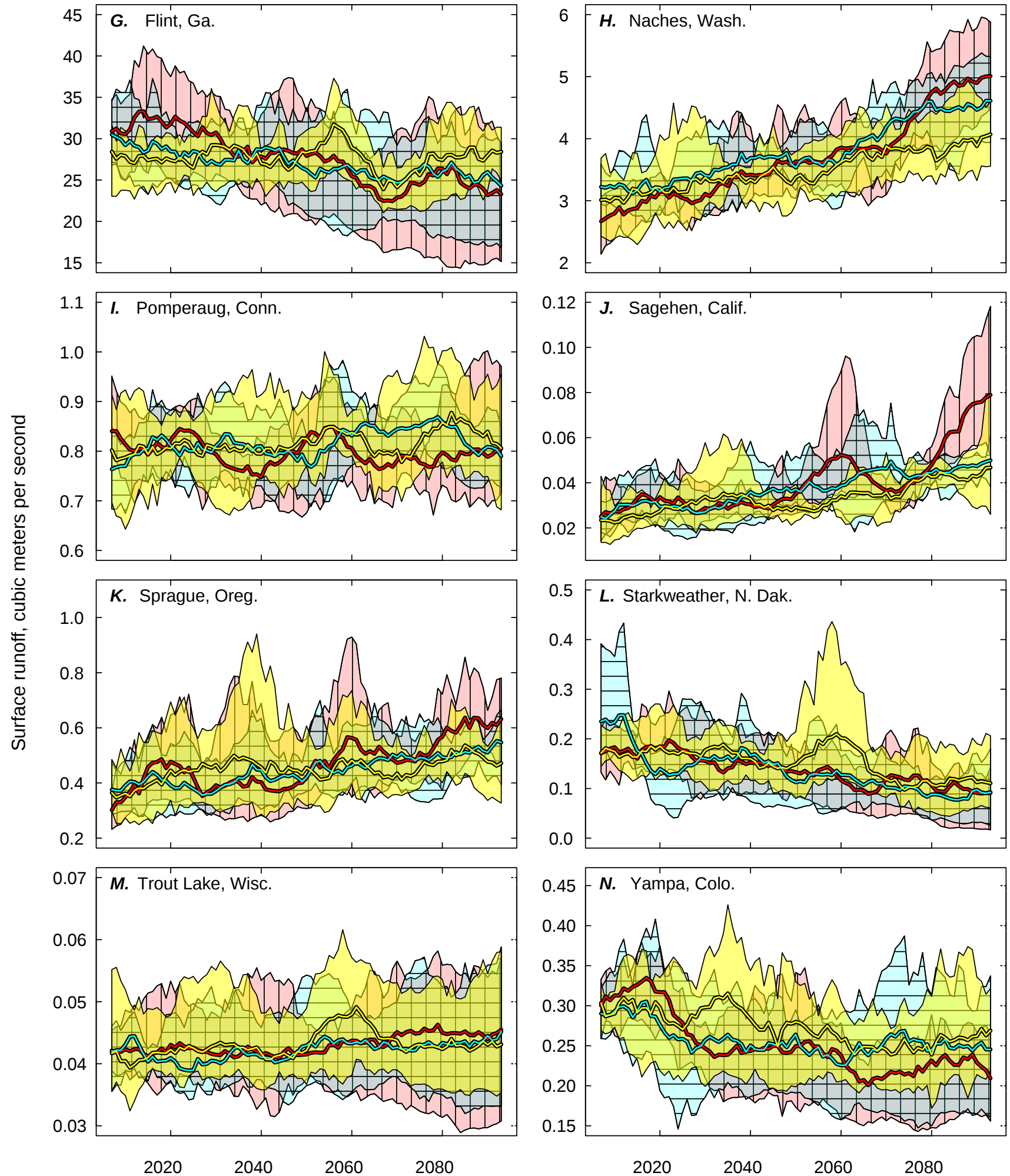

Center of 11-year window

Figure 16. Projected range in 11-year moving mean daily surface runoff values by emission scenarios for the 14 basins. -Continued 


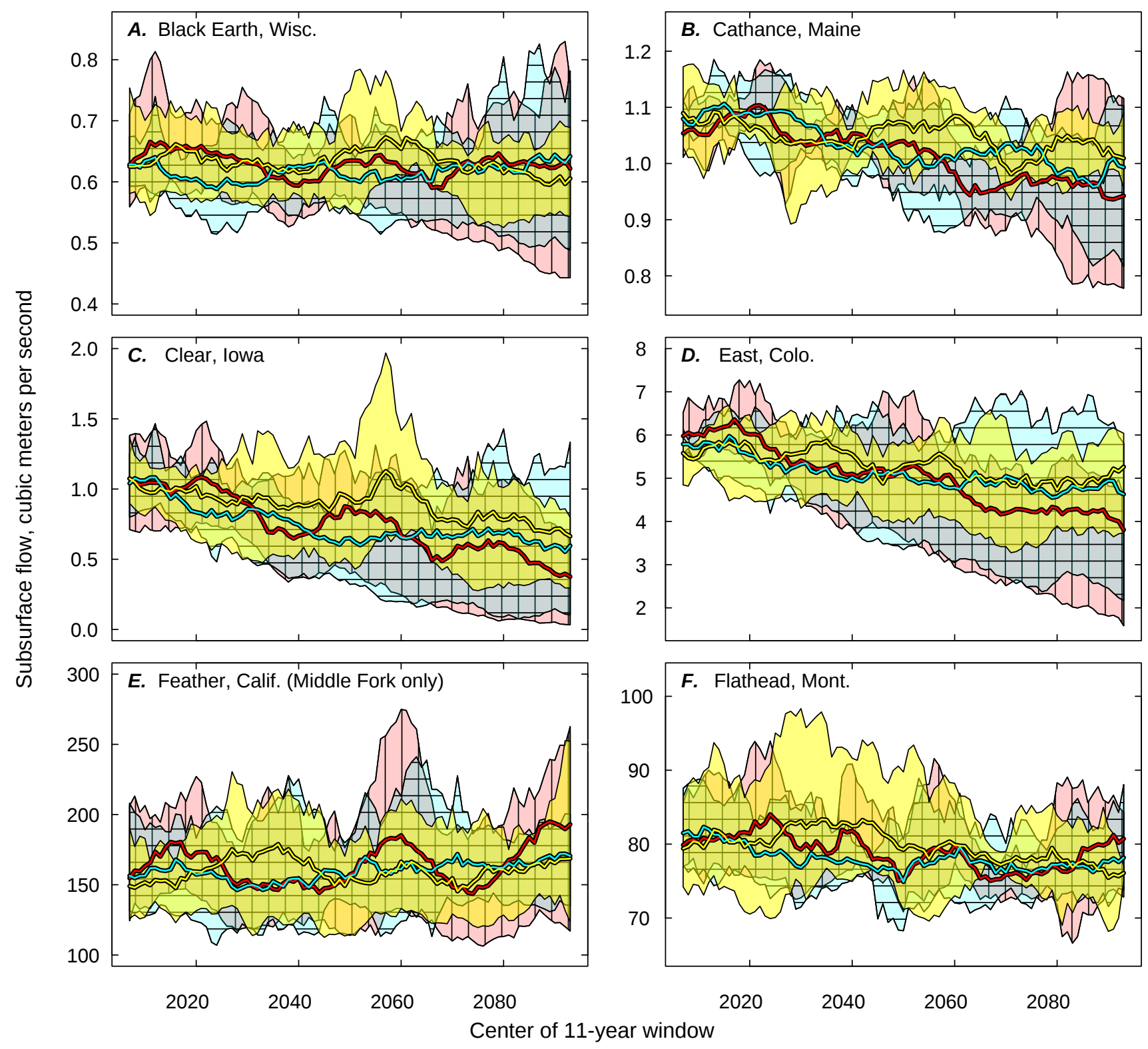

EXPLANATION

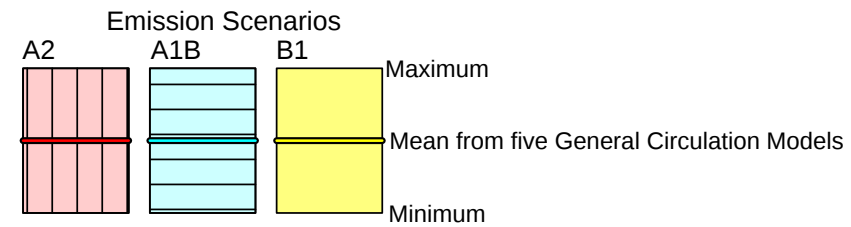

Figure 17. Projected range in 11-year moving mean daily subsurface flow values by emission scenarios for the 14 basins and means based on the $5 \mathrm{General} \mathrm{Circulation} \mathrm{Models} \mathrm{(GCM).}$ 

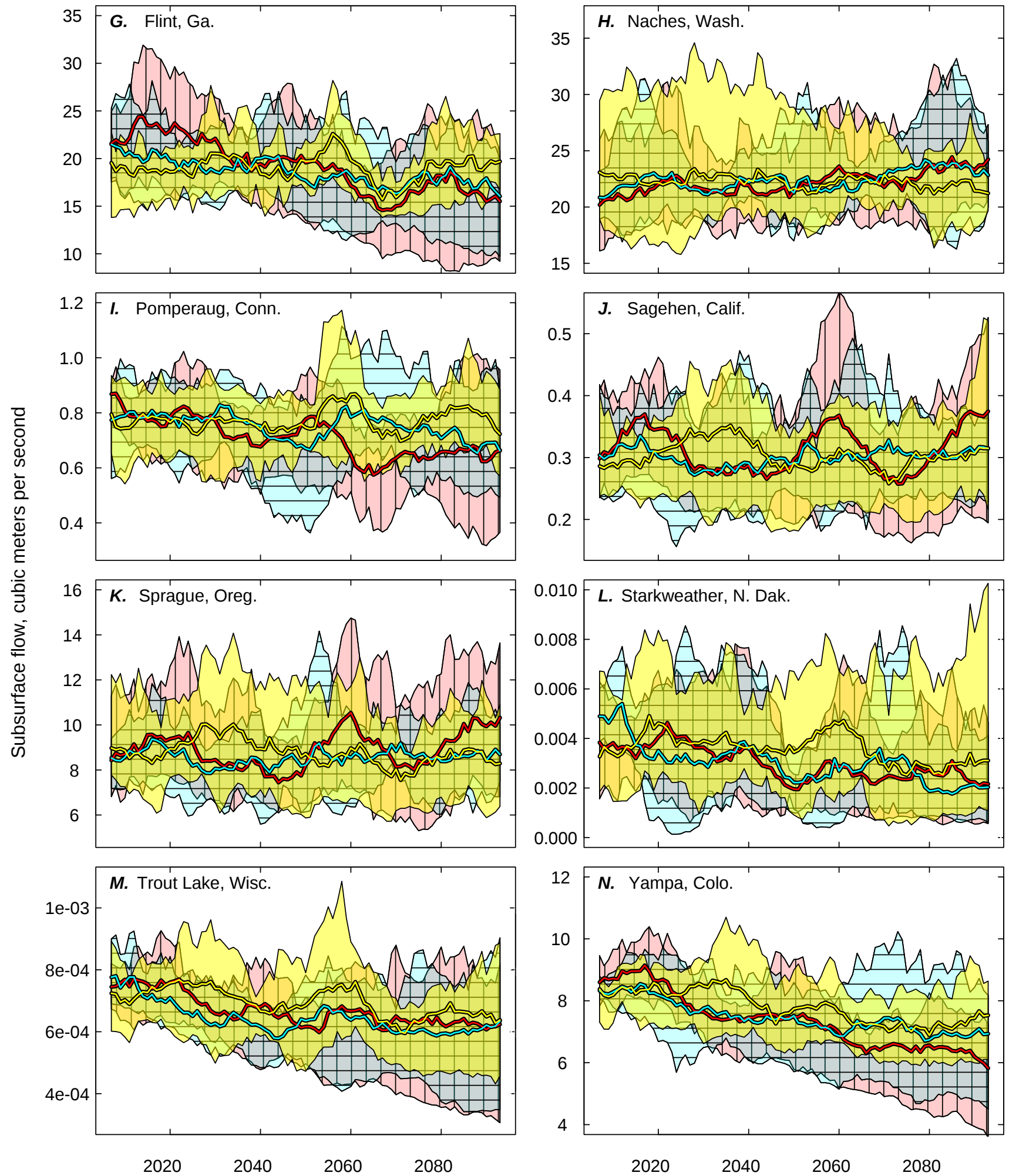

Center of 11-year window

Figure 17. Projected range in 11-year moving mean daily subsurface flow values by emission scenarios for the 14 basins and means based on the 5 General Circulation Models (GCM).-Continued 

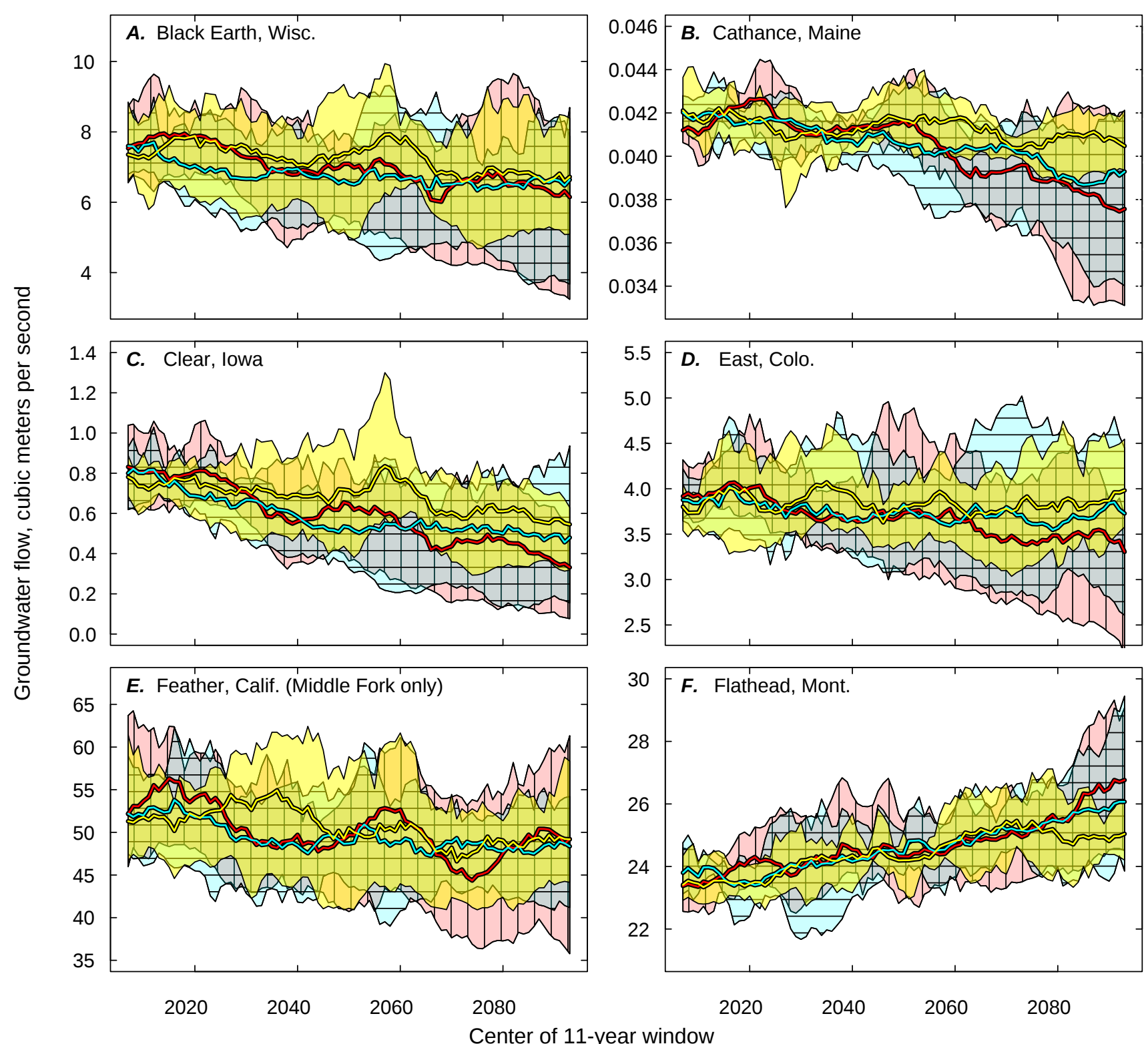

\section{EXPLANATION}

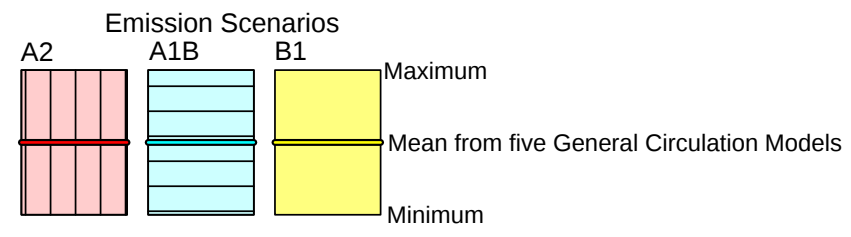

Figure 18. Projected range in 11-year moving mean daily groundwater flow values by emission scenarios for the 14 basins and means based on the 5 General Circulation Models (GCM). 

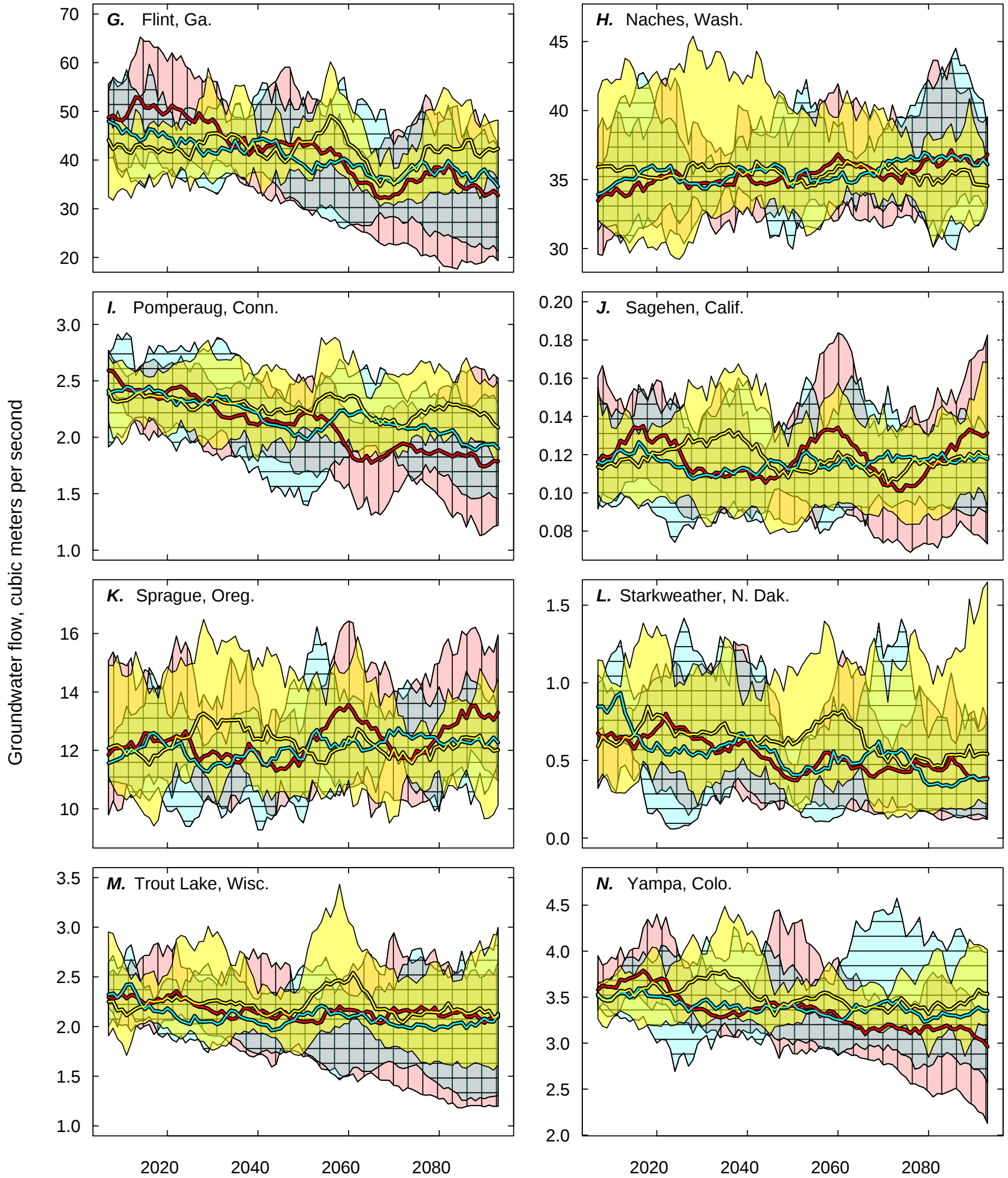

Center of 11-year window

Figure 18. Projected range in 11-year moving mean daily groundwater flow values by emission scenarios for the 14 basins and means based on the $5 \mathrm{General}$ Circulation Models (GCM).-Continued 

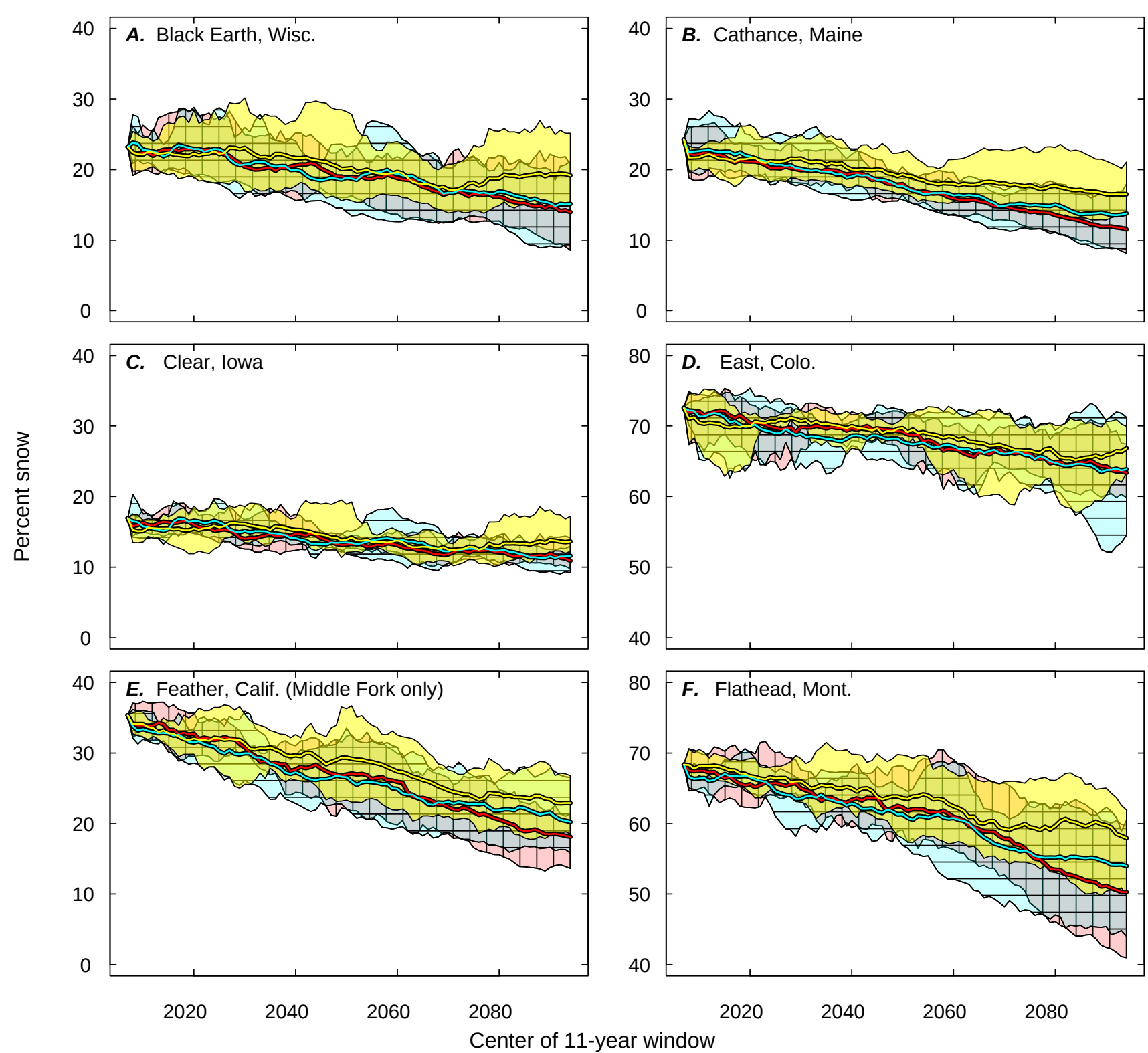

\section{EXPLANATION}

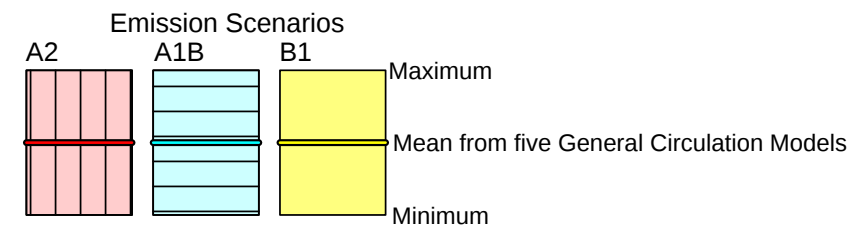

Figure 19. Projected range in 11-year moving mean daily percent of precipitation that falls as snow by emission scenarios for the 14 basins and means based on the 5 General Circulation Models (GCM). 

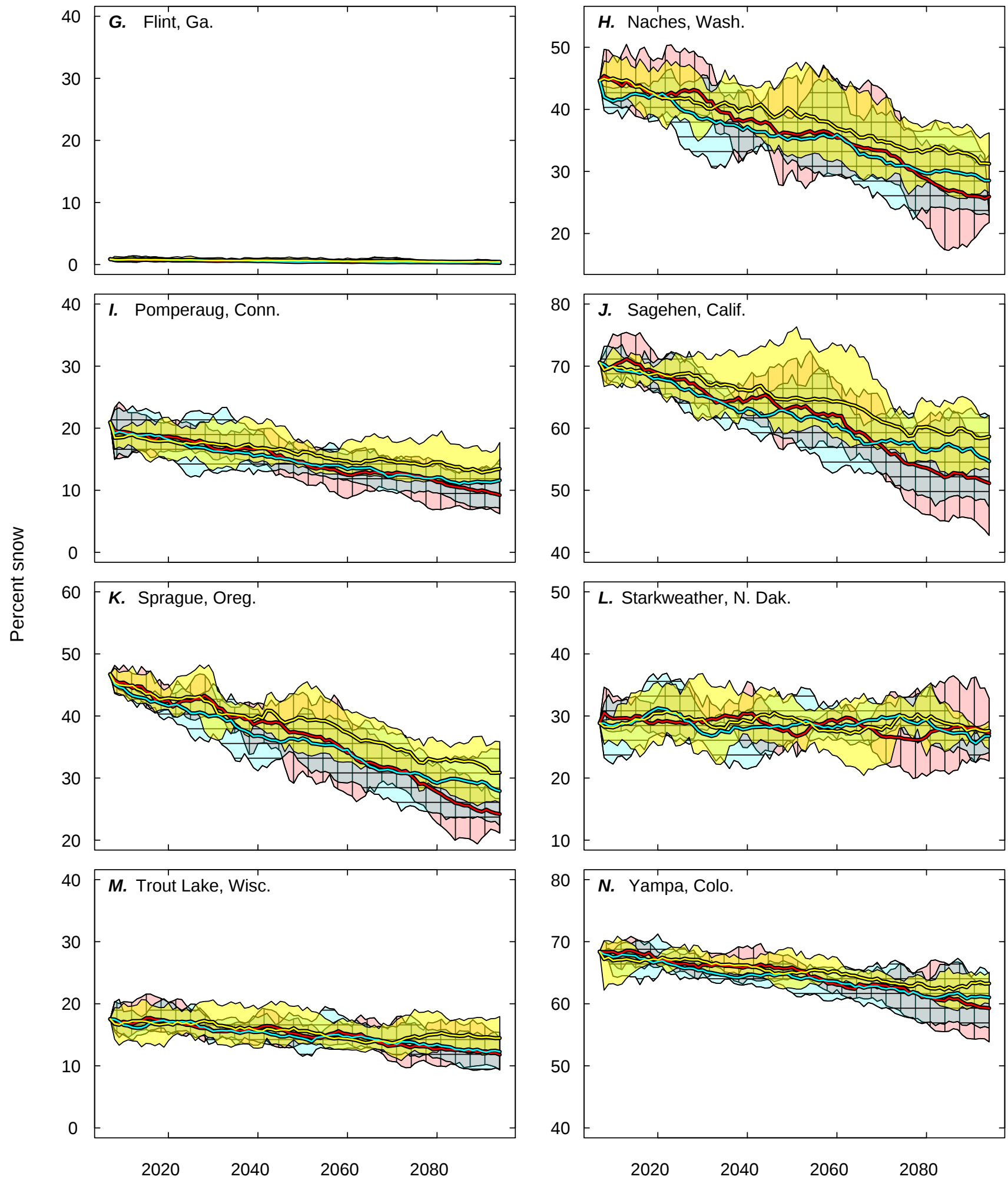

Center of 11-year window

Figure 19. Projected range in 11-year moving mean daily percent of precipitation that falls as snow by emission scenarios for the 14 basins and means based on the 5 General Circulation Models (GCM).-Continued 

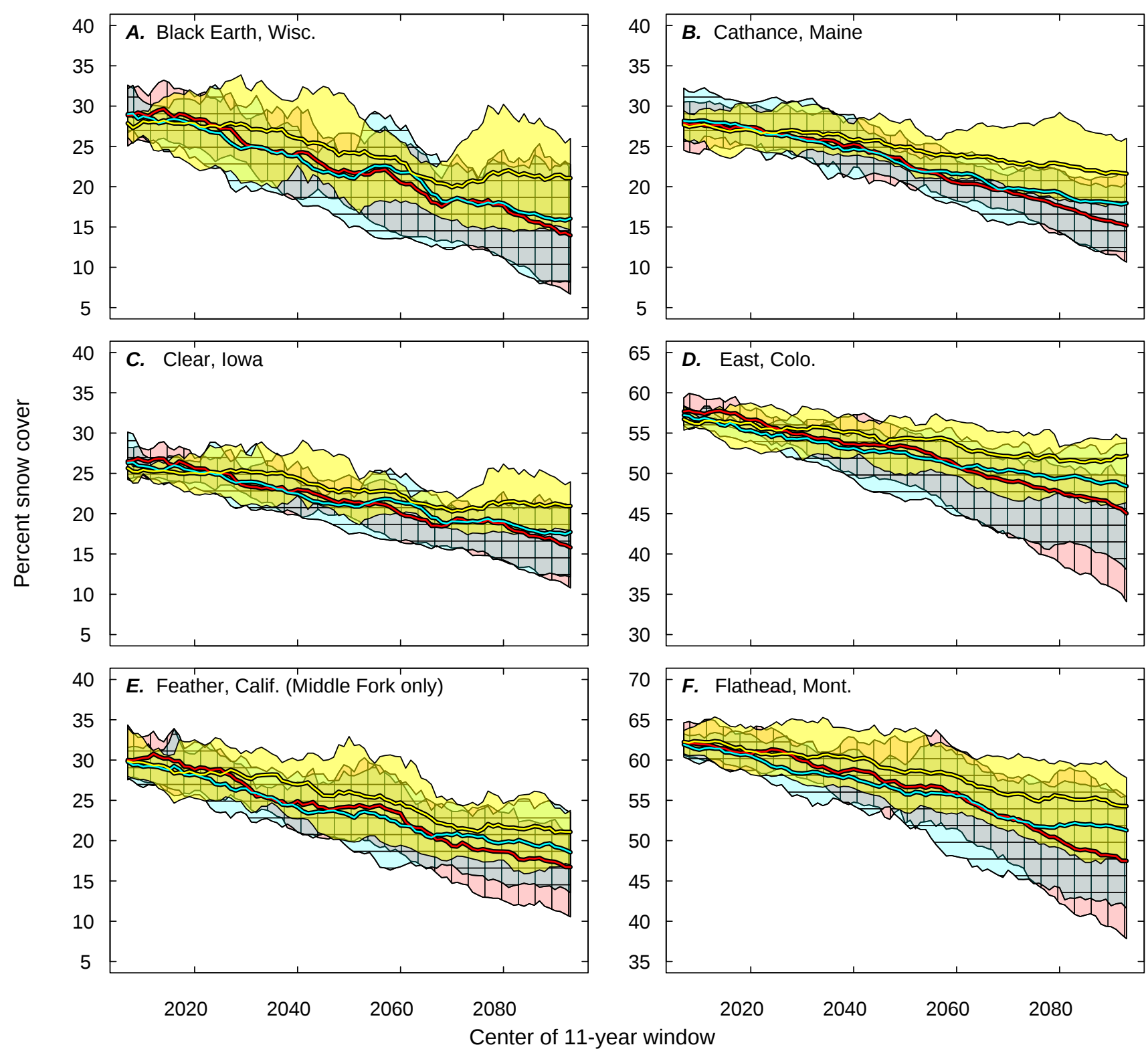

EXPLANATION

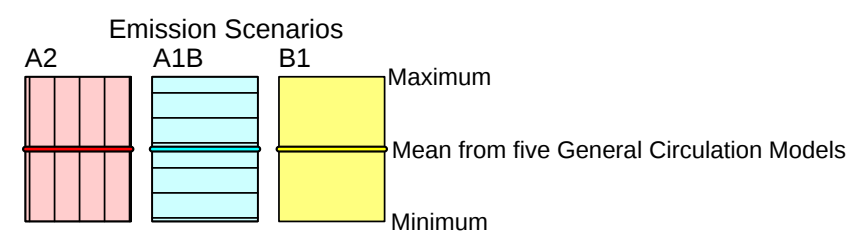

Figure 20. Projected range in 11-year moving mean daily percent of area covered by snow by emission scenarios for the 14 basins and means based on the 5 General Circulation Models (GCM). 

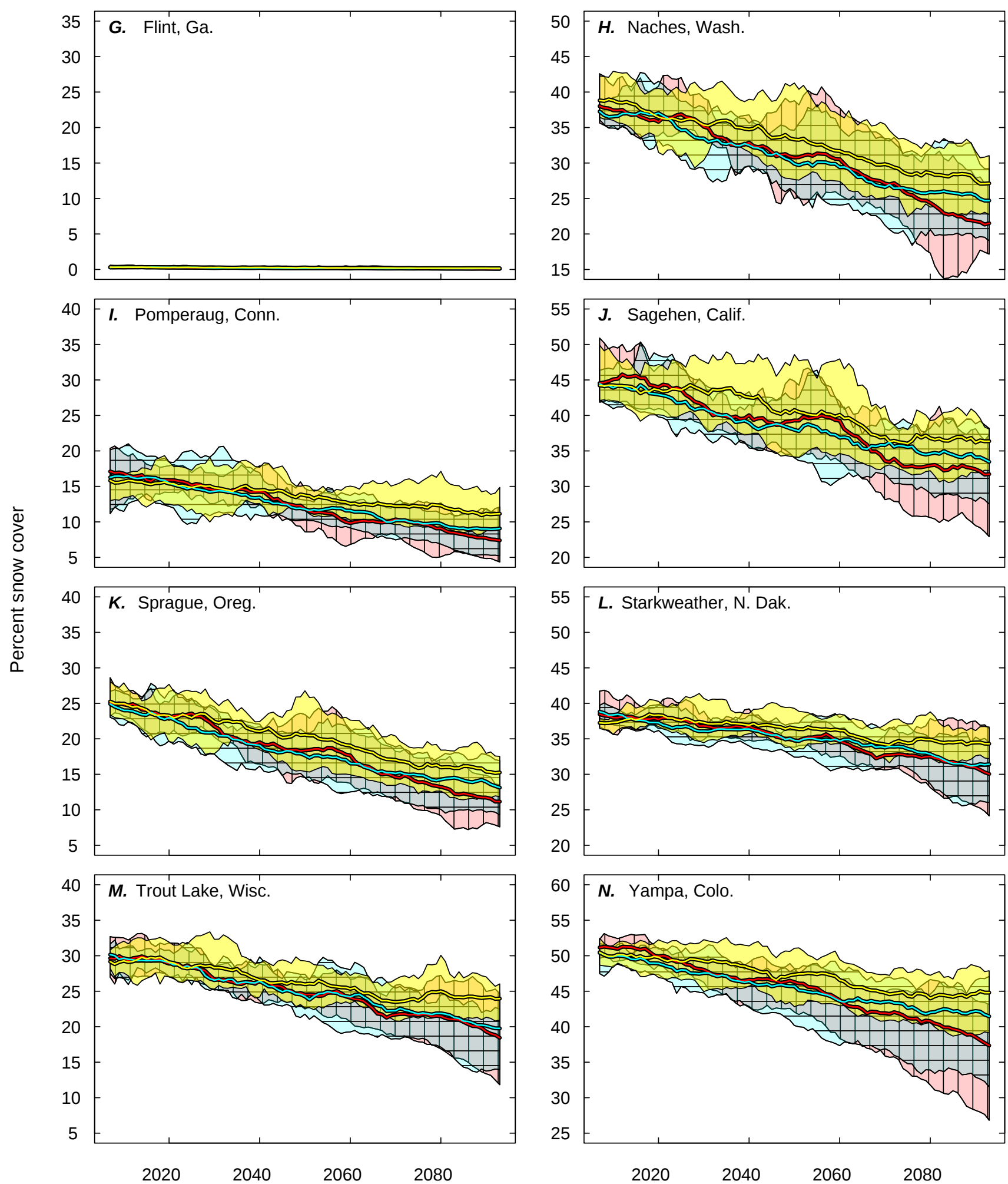

Center of 11-year window

Figure 20. Projected range in 11-year moving mean daily percent of area covered by snow by emission scenarios for the 14 basins and means based on the 5 General Circulation Models (GCM).-Continued 

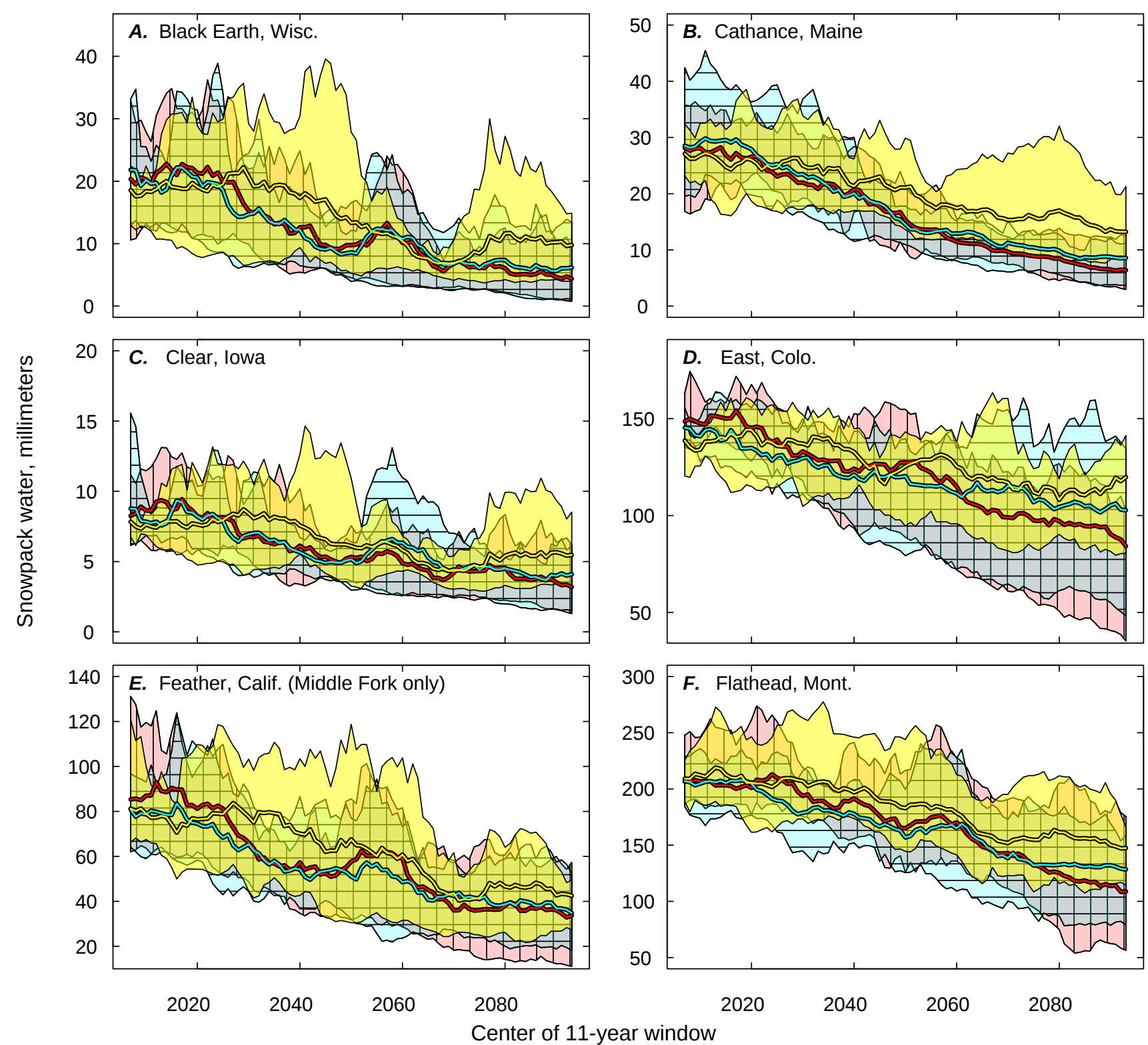

\section{EXPLANATION}

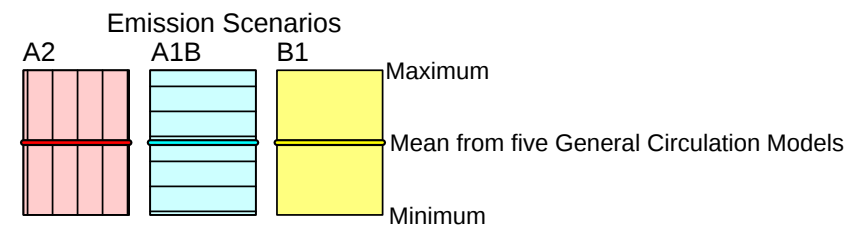

Figure 21. Projected range in 11-year moving mean daily snowpack water equivalent by emission scenarios for the 14 basins and means based on the 5 General Circulation Models (GCM). 

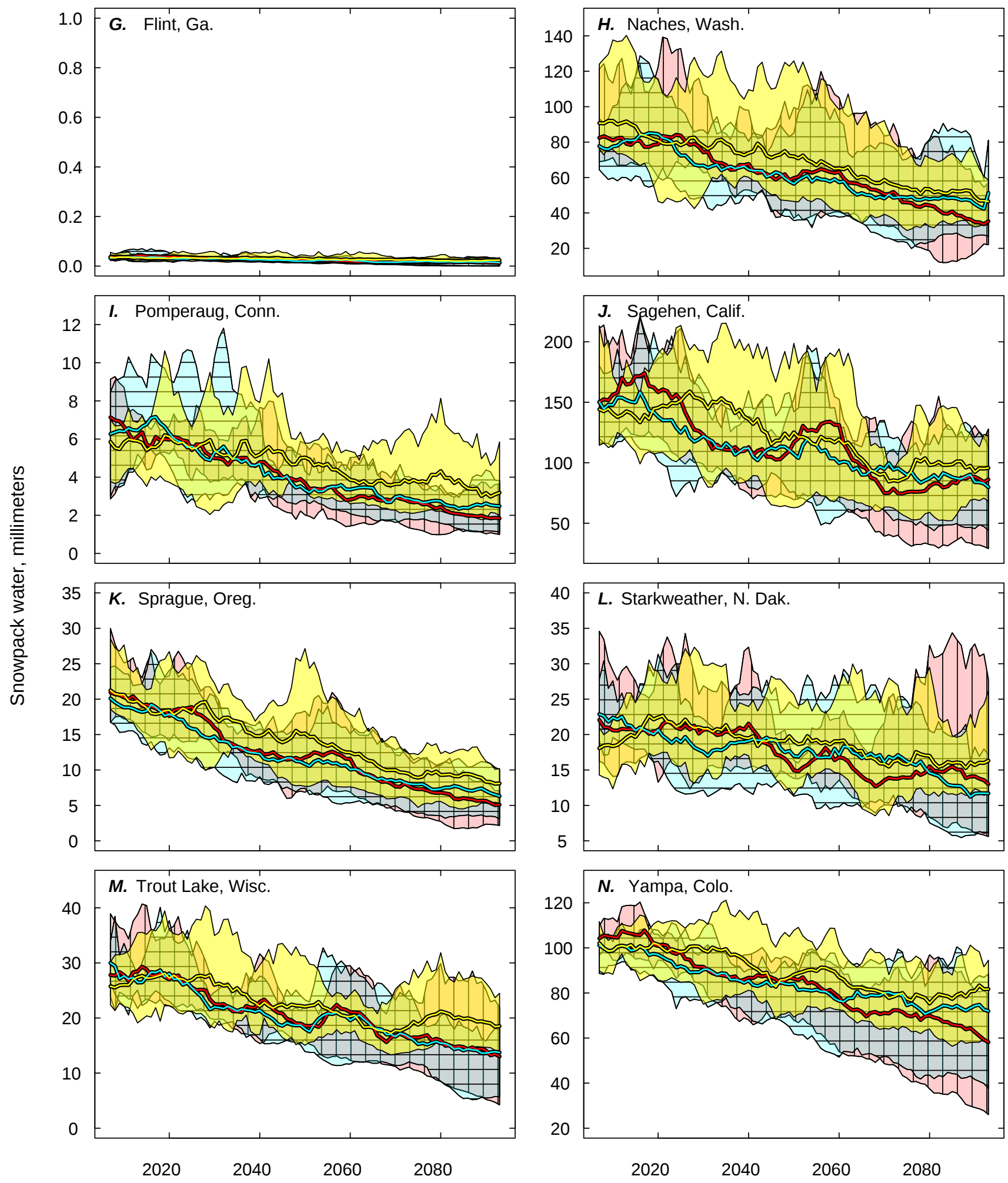

Center of 11-year window

Figure 21. Projected range in 11-year moving mean daily snowpack water equivalent by emission scenarios for the 14 basins and means based on the 5 General Circulation Models (GCM).-Continued 

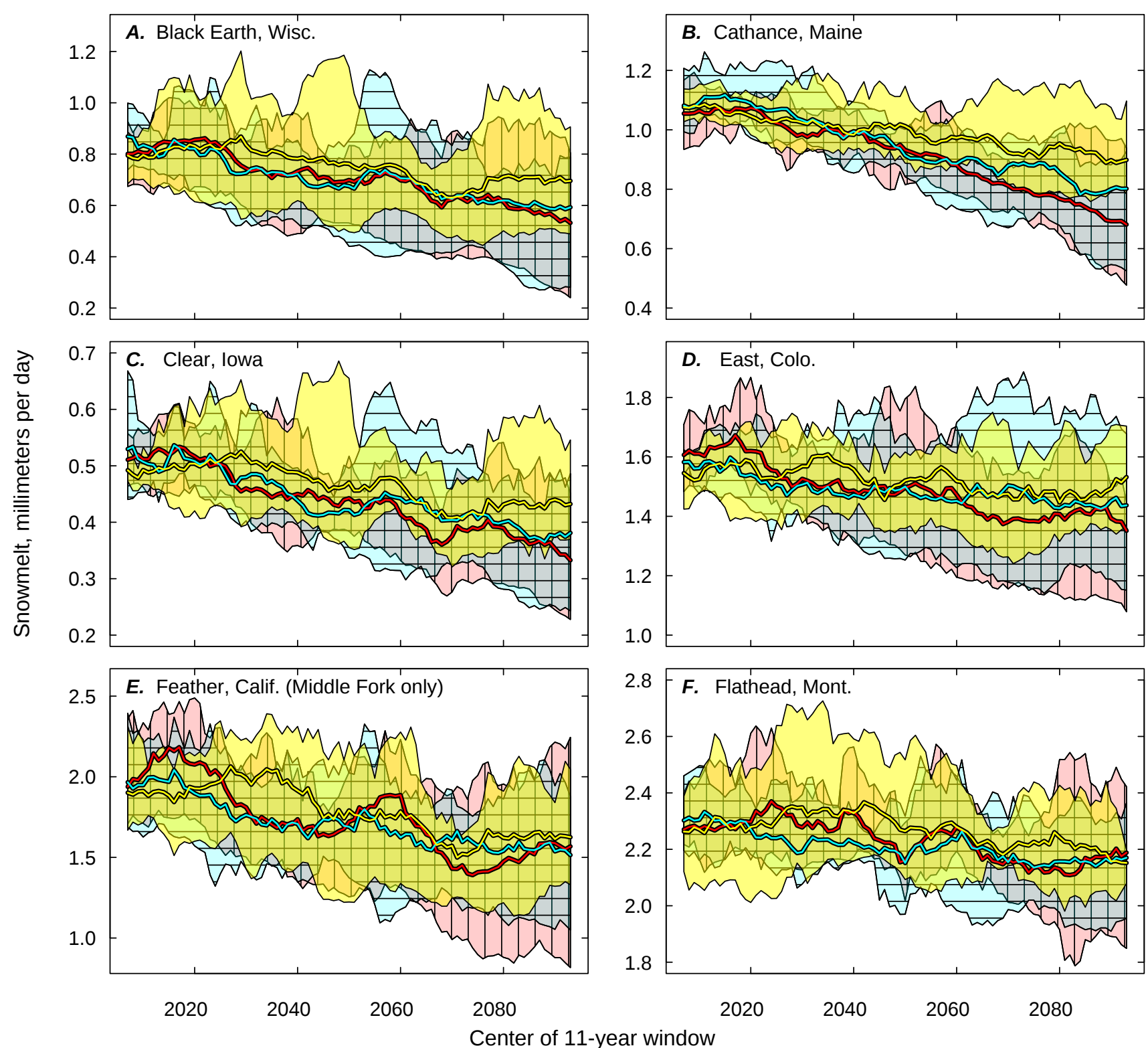

\section{EXPLANATION}

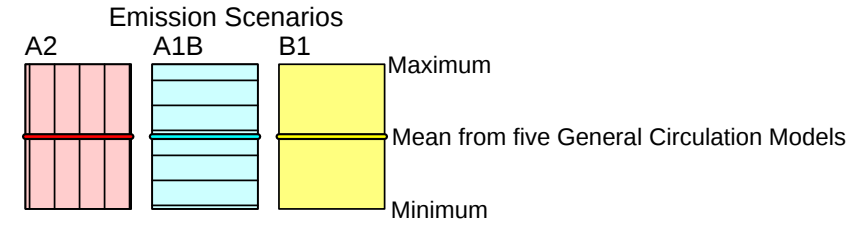

Figure 22. Projected range in 11-year moving mean daily snowmelt values by emission scenarios for the 14 basins and means based on the 5 General Circulation Models (GCM). 

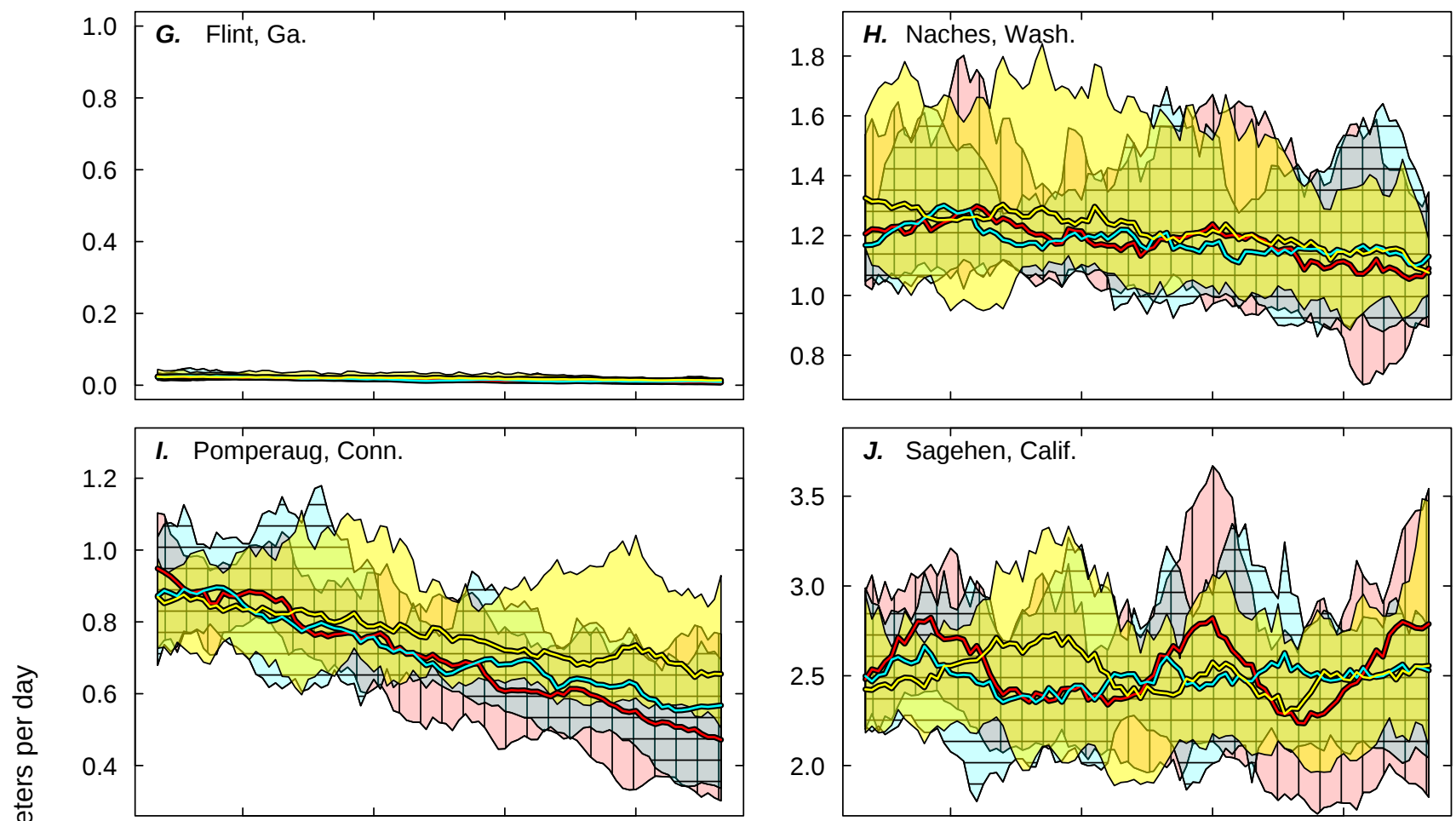

(
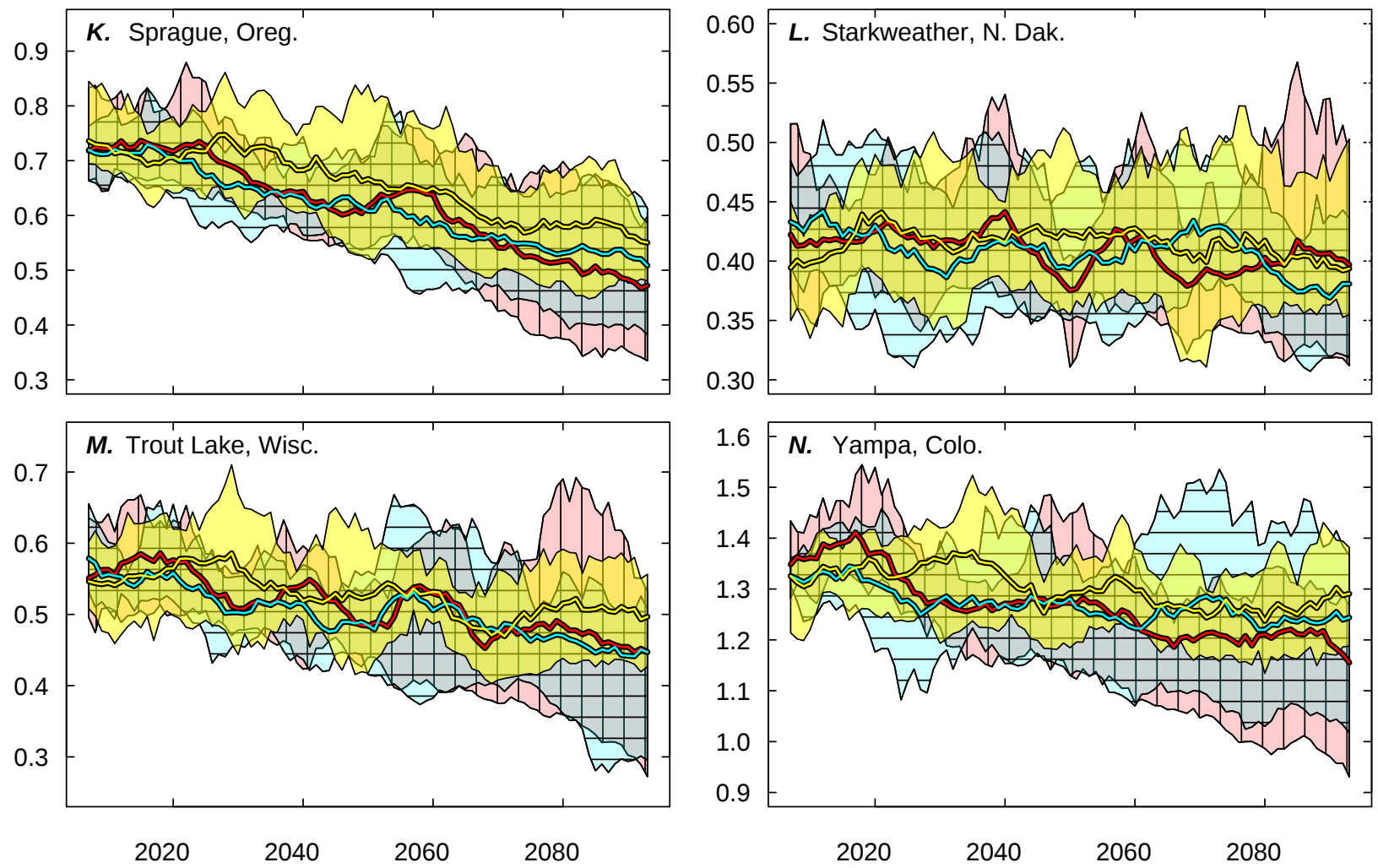

Center of 11-year window

Figure 22. Projected range in 11-year moving mean daily snowmelt values by emission scenarios for the 14 basins and means based on the 5 General Circulation Models (GCM).-Continued 

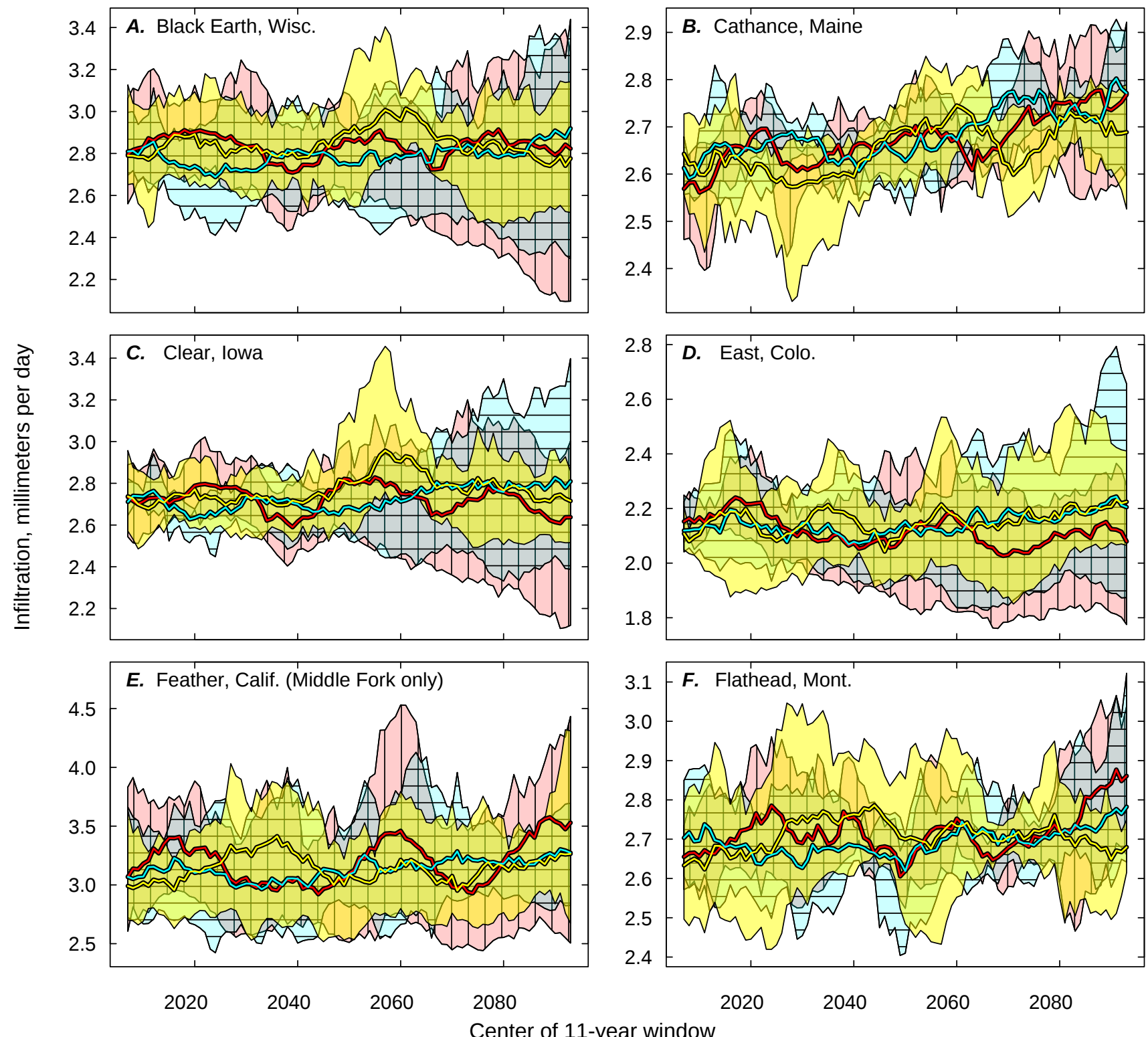

$20202040 \quad 2060 \quad 2080$

EXPLANATION

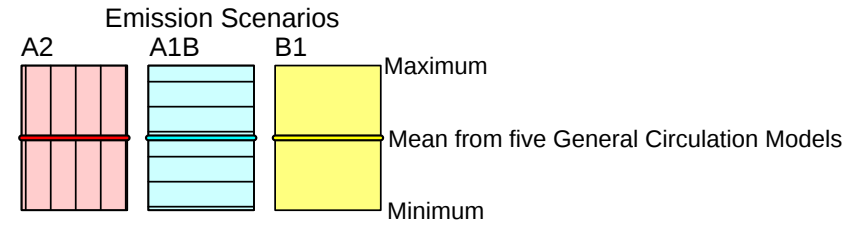

Figure 23. Projected range in 11-year moving mean daily infiltration values by emission scenarios for the 14 basins and means based on the 5 General Circulation Models (GCM). 

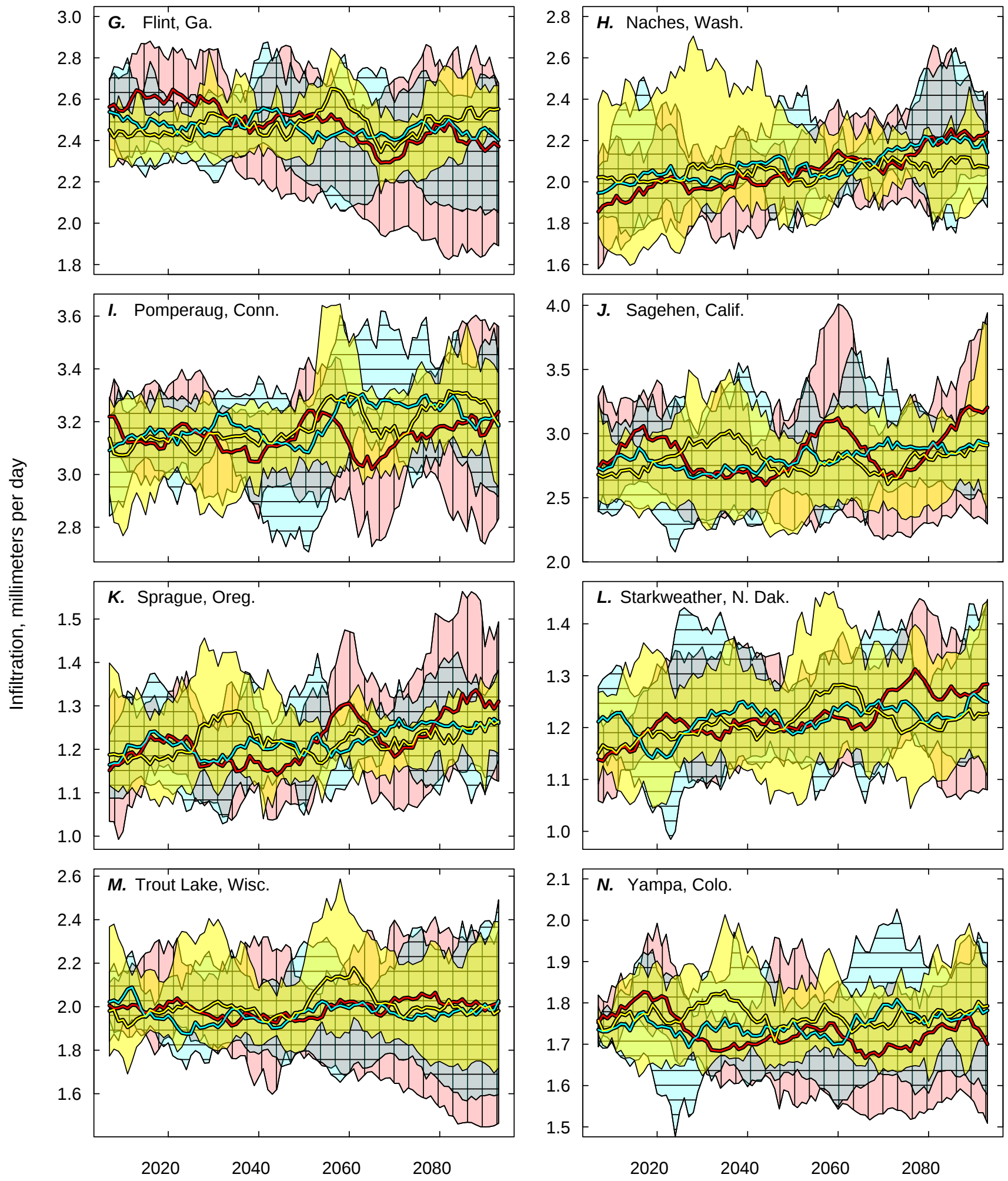

Center of 11-year window

Figure 23. Projected range in 11-year moving mean daily infiltration values by emission scenarios for the 14 basins and means based on the 5 General Circulation Models (GCM).-Continued 


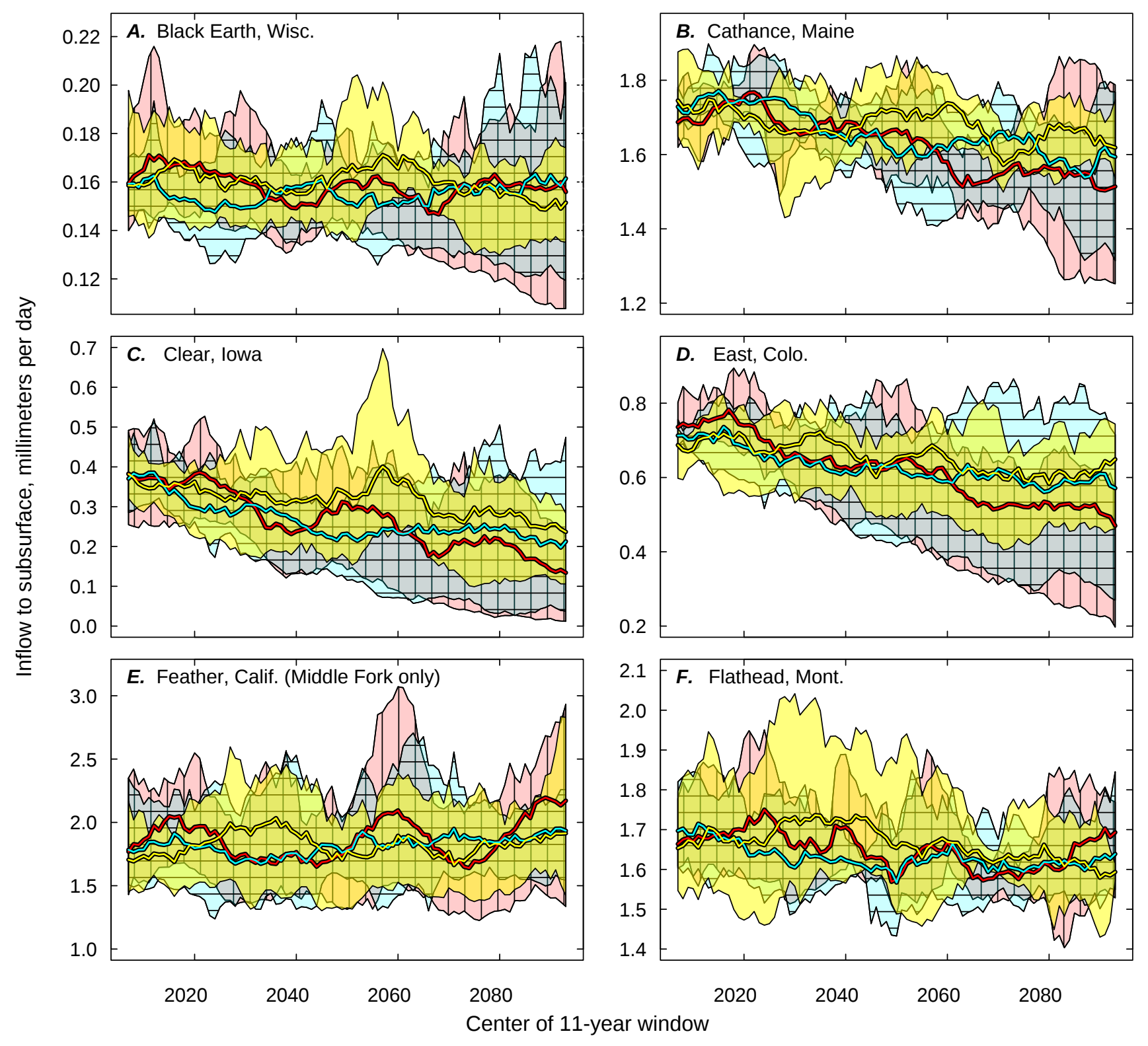

EXPLANATION

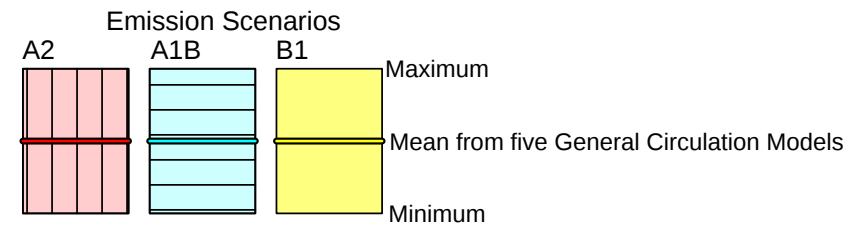

Figure 24. Projected range in 11-year moving mean daily subsurface reservoir inflow values by emission scenarios for the 14 basins and means based on the 5 General Circulation Models (GCM). 

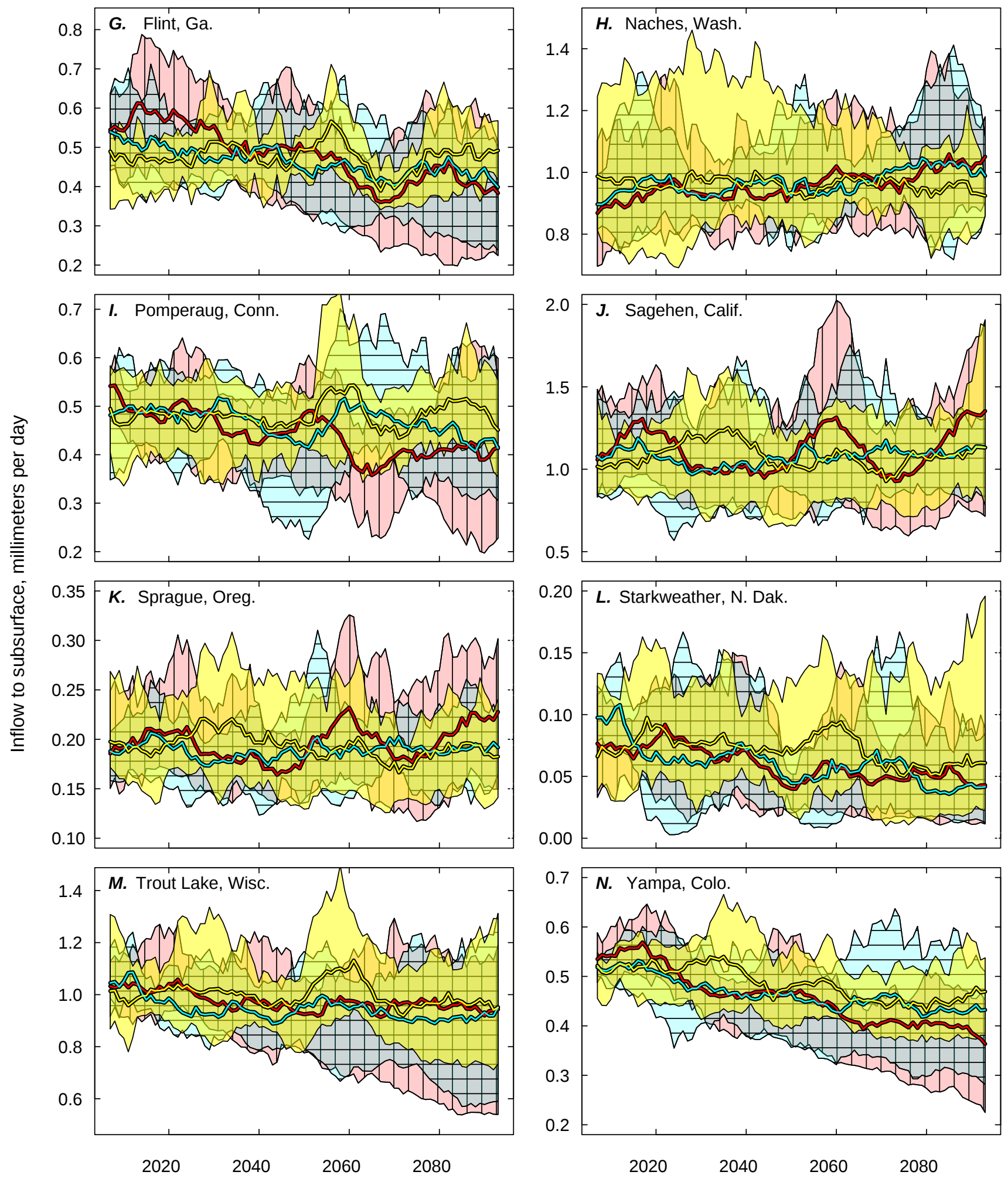

Center of 11-year window

Figure 24. Projected range in 11-year moving mean daily subsurface reservoir inflow values by emission scenarios for the 14 basins and means based on the 5 General Circulation Models (GCM).-Continued 

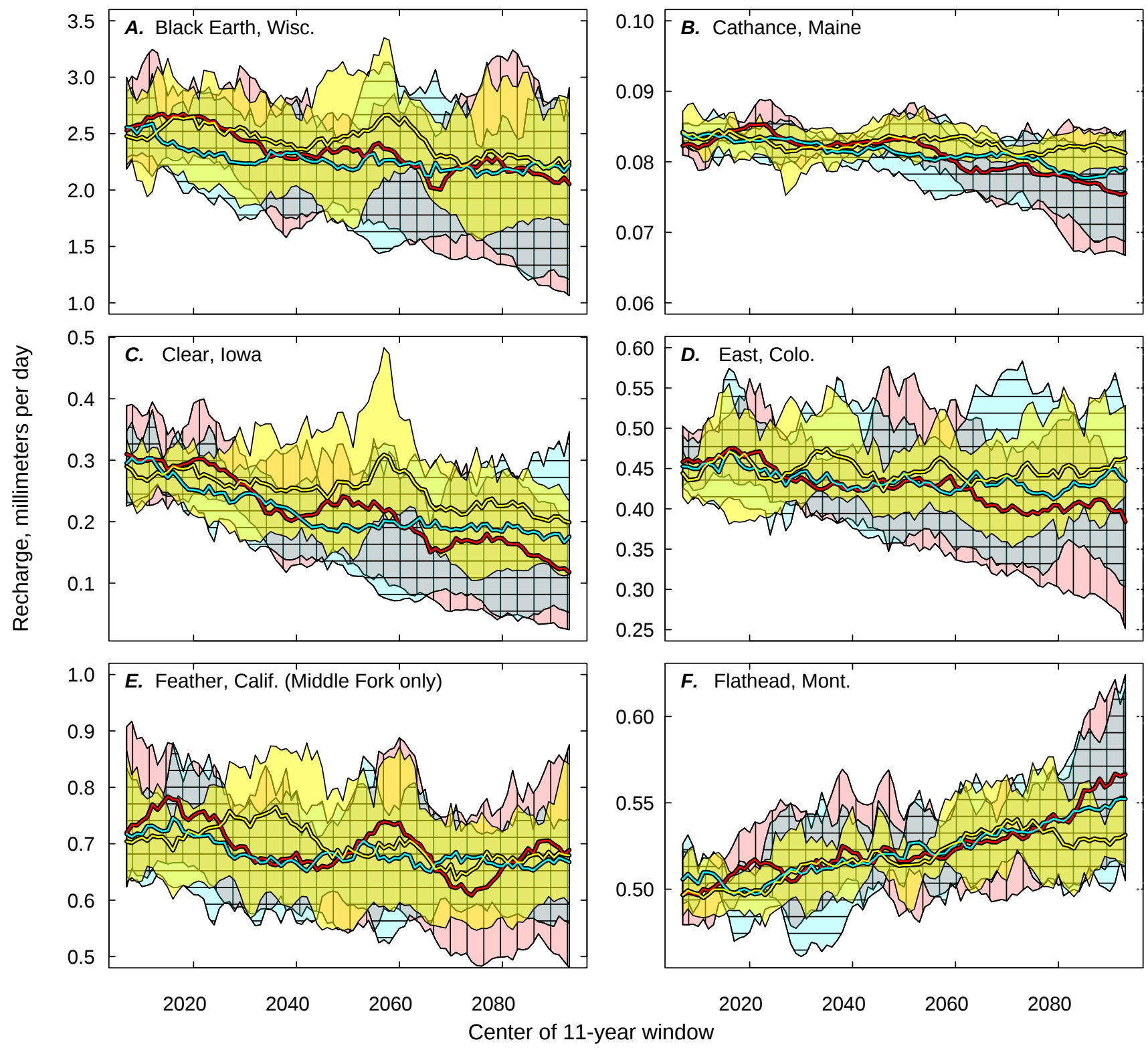

EXPLANATION

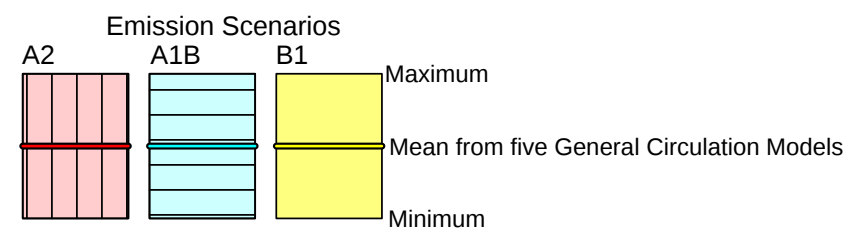

Figure 25. Projected range in 11-year moving mean daily groundwater reservoir recharge values by emission scenarios for the 14 basins and means based on the 5 General Circulation Models (GCM). 

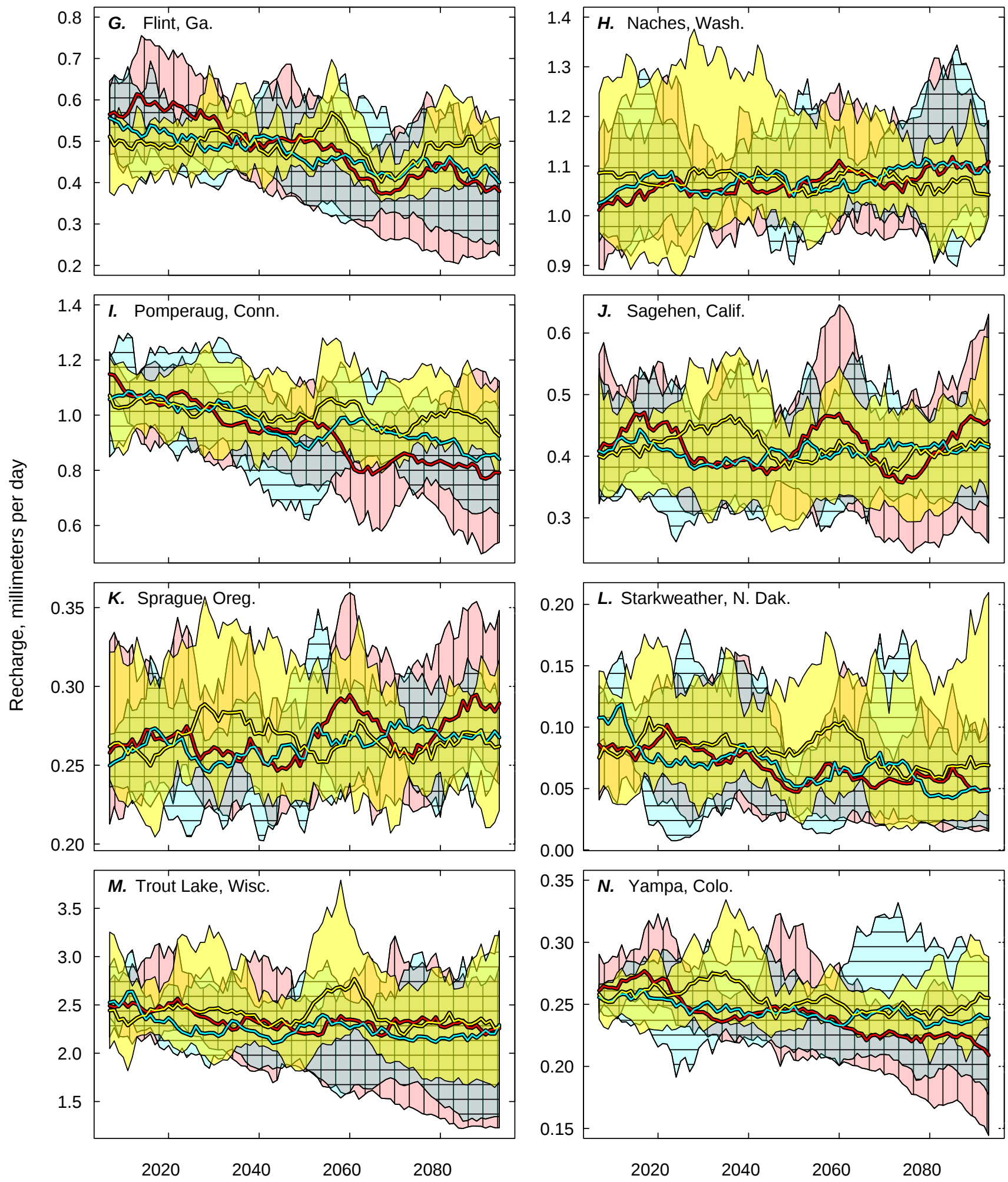

Center of 11-year window

Figure 25. Projected range in 11-year moving mean daily groundwater reservoir recharge values by emission scenarios for the 14 basins and means based on the 5 General Circulation Models (GCM).-Continued 

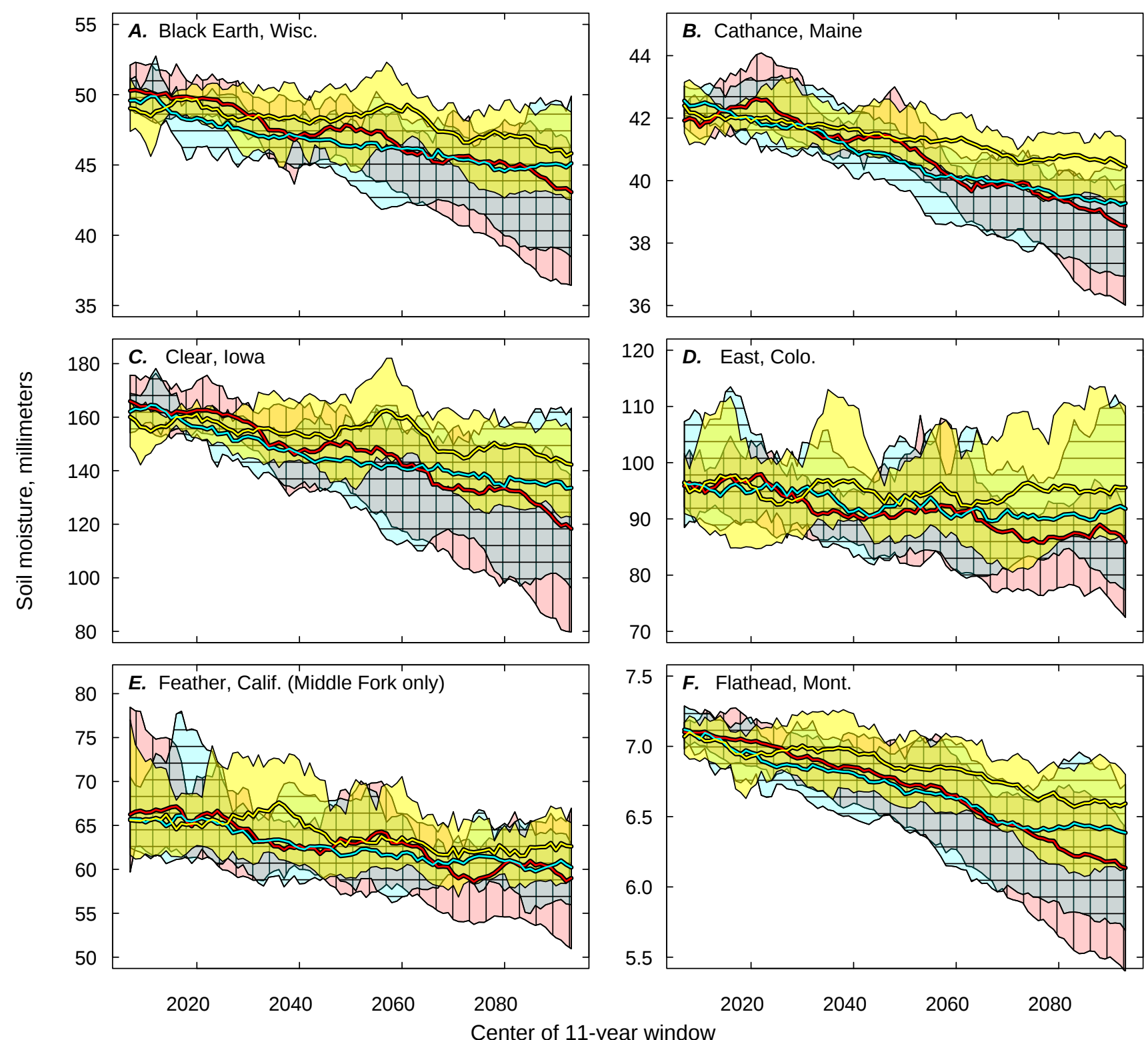

EXPLANATION

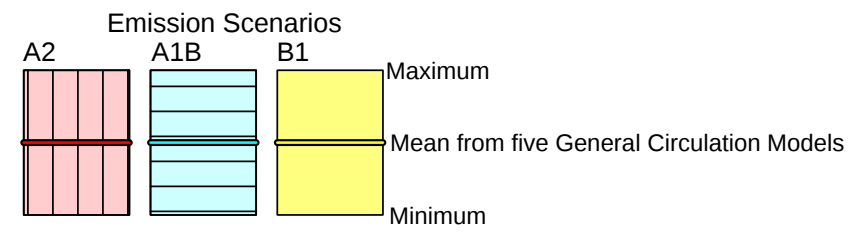

Figure 26. Projected range in 11-year moving mean daily soil moisture storage values by emission scenarios for the 14 basins and means based on the 5 General Circulation Models (GCM). 

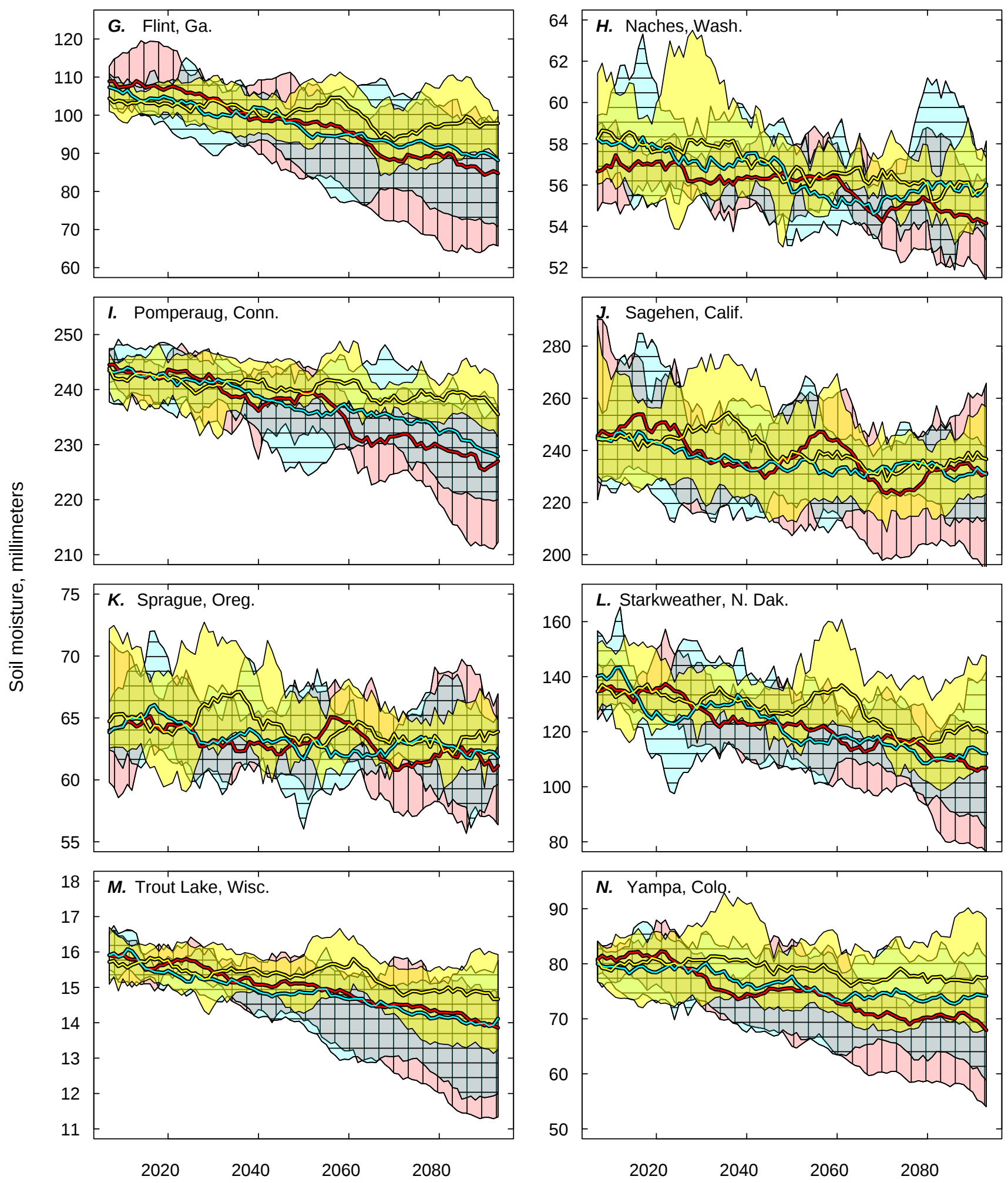

Center of 11-year window

Figure 26. Projected range in 11-year moving mean daily soil moisture storage values by emission scenarios for the 14 basins and means based on the 5 General Circulation Models (GCM).-Continued 

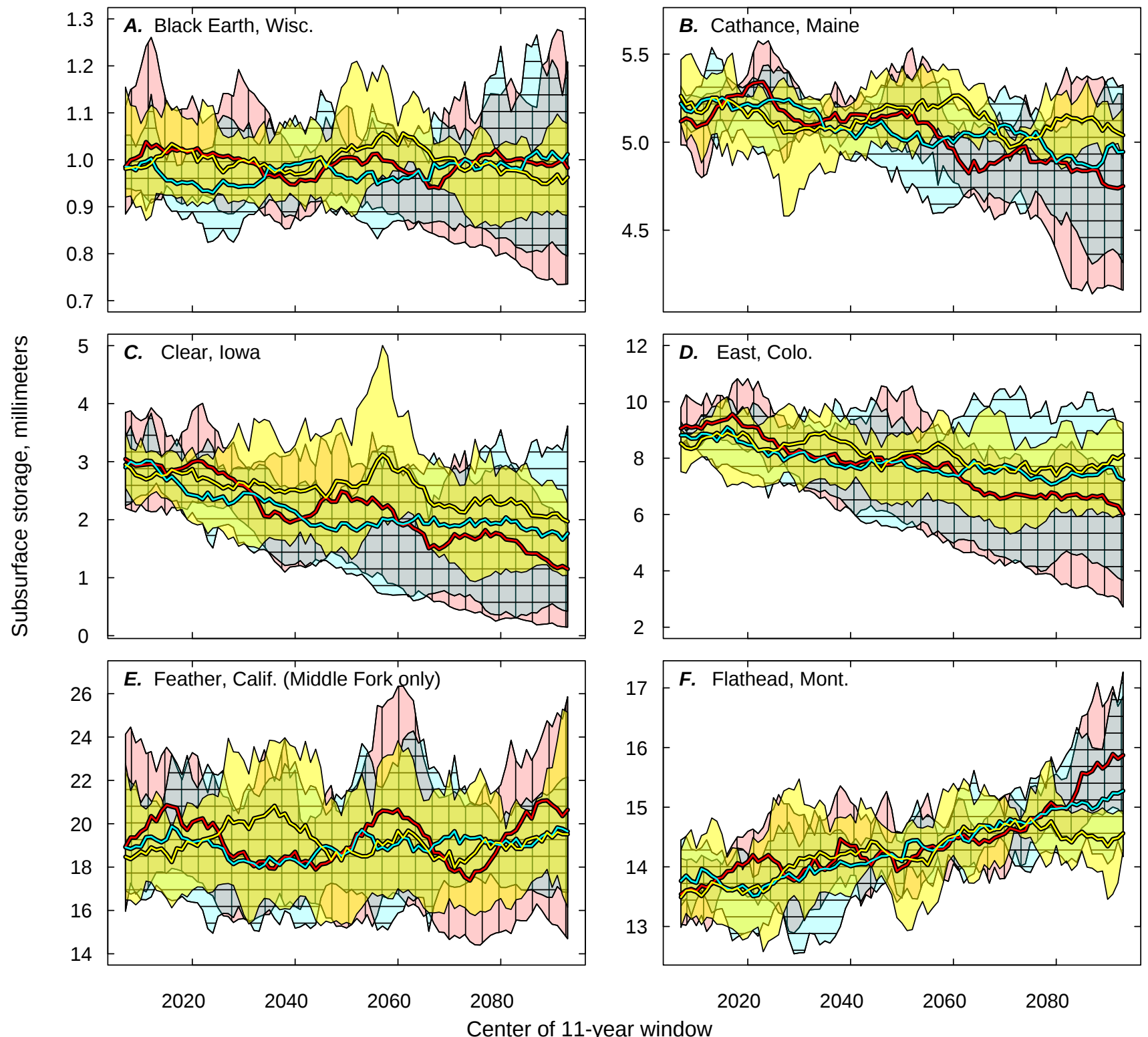

Center of 11-year window

EXPLANATION

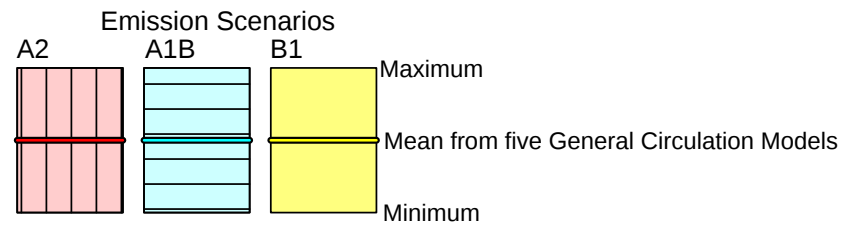

Figure 27. Projected range in 11-year moving mean daily subsurface reservoir storage values by emission scenarios for the 14 basins and means based on the 5 General Circulation Models (GCM). 

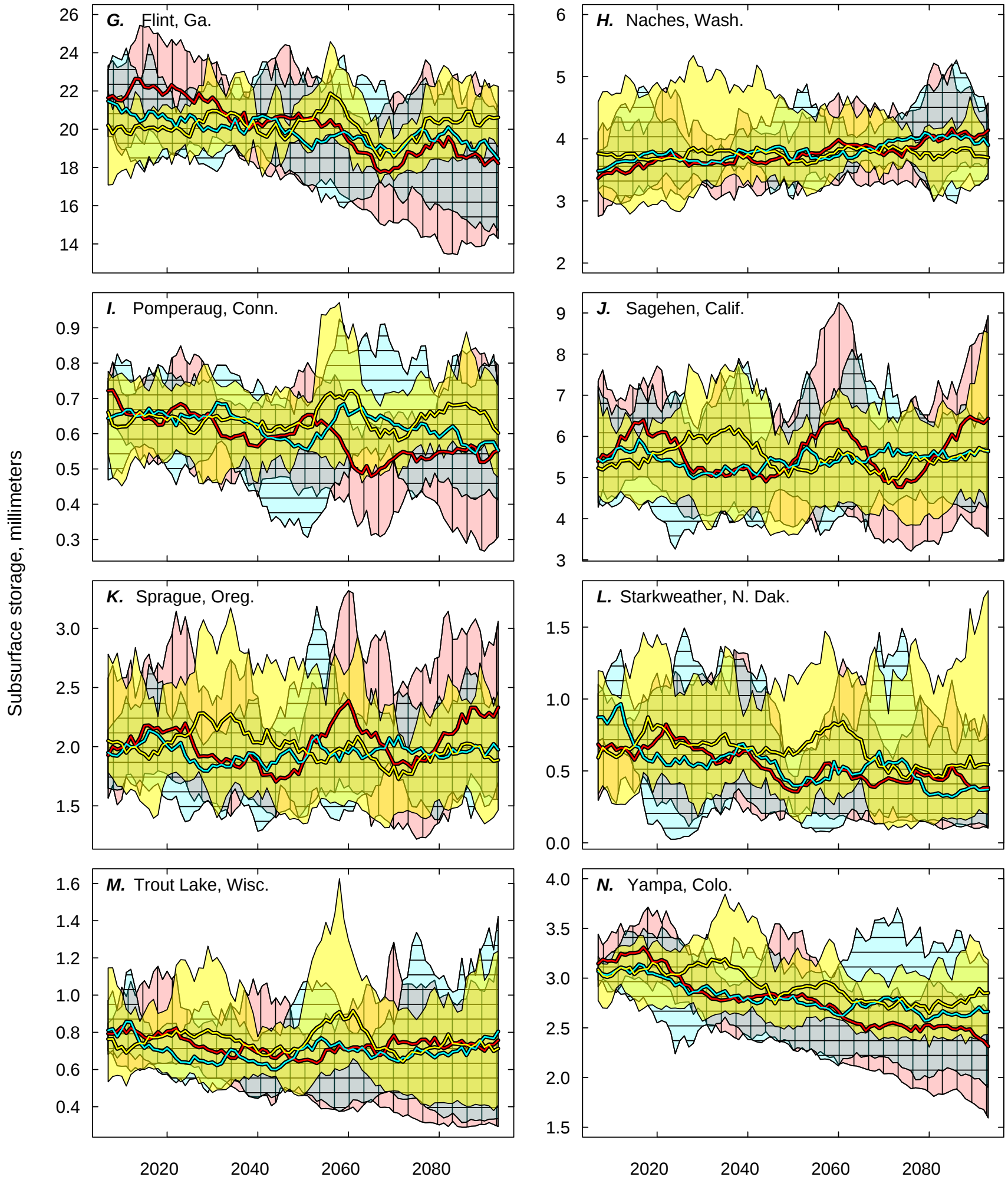

Center of 11-year window

Figure 27. Projected range in 11-year moving mean daily subsurface reservoir storage values by emission scenarios for the 14 basins and means based on the 5 General Circulation Models (GCM).-Continued 

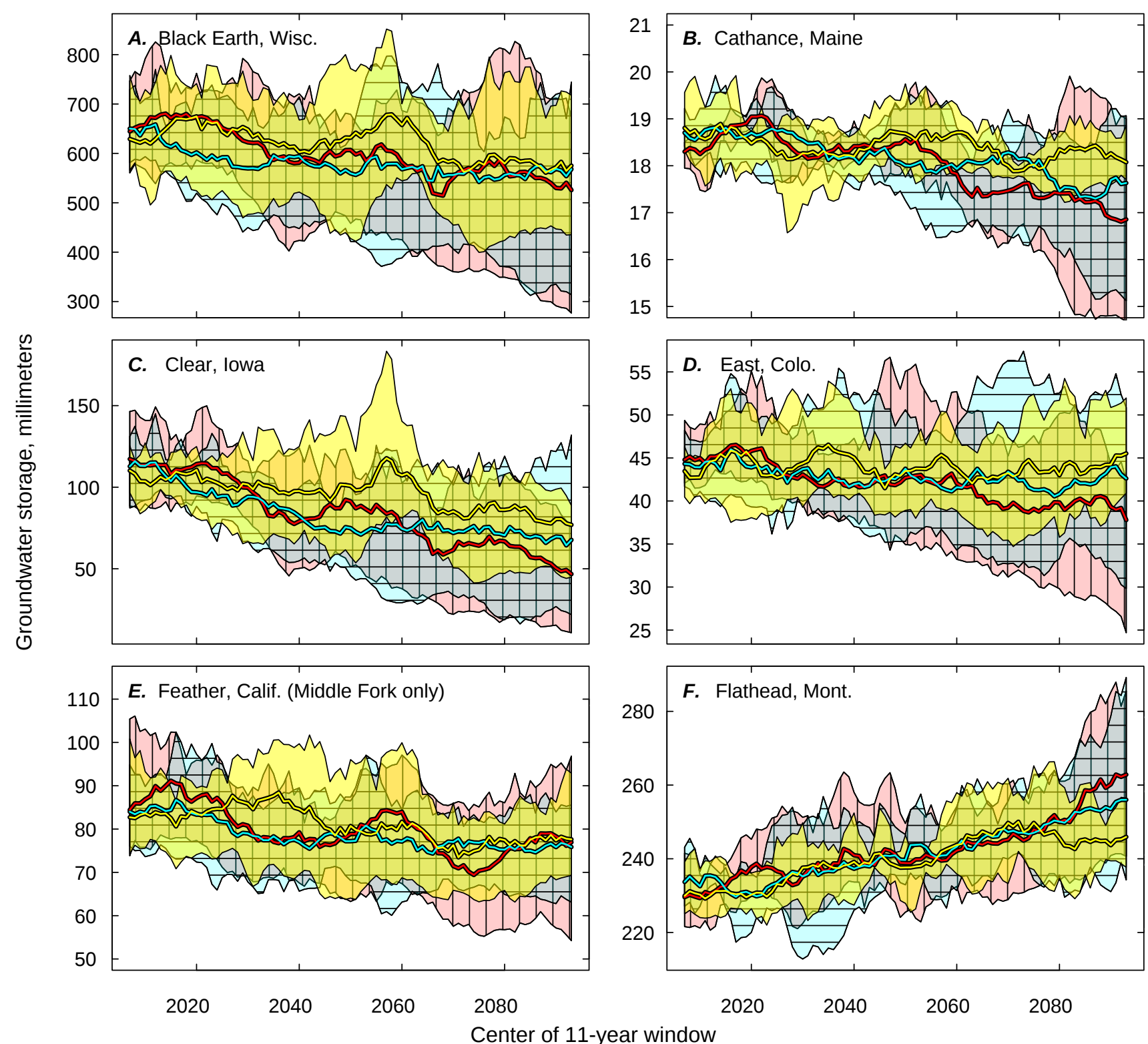

\section{EXPLANATION}

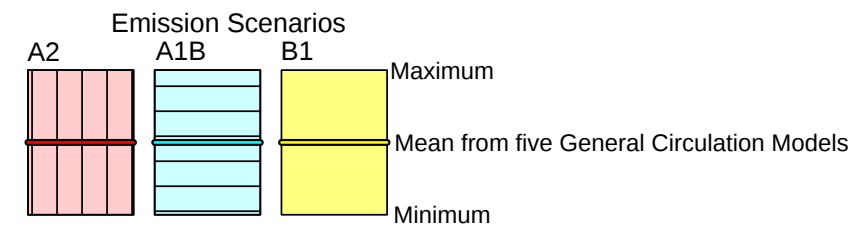

Figure 28. Projected range in 11-year moving mean daily groundwater reservoir storage values by emission scenarios for the 14 basins and means based on the 5 General Circulation Models (GCM). 

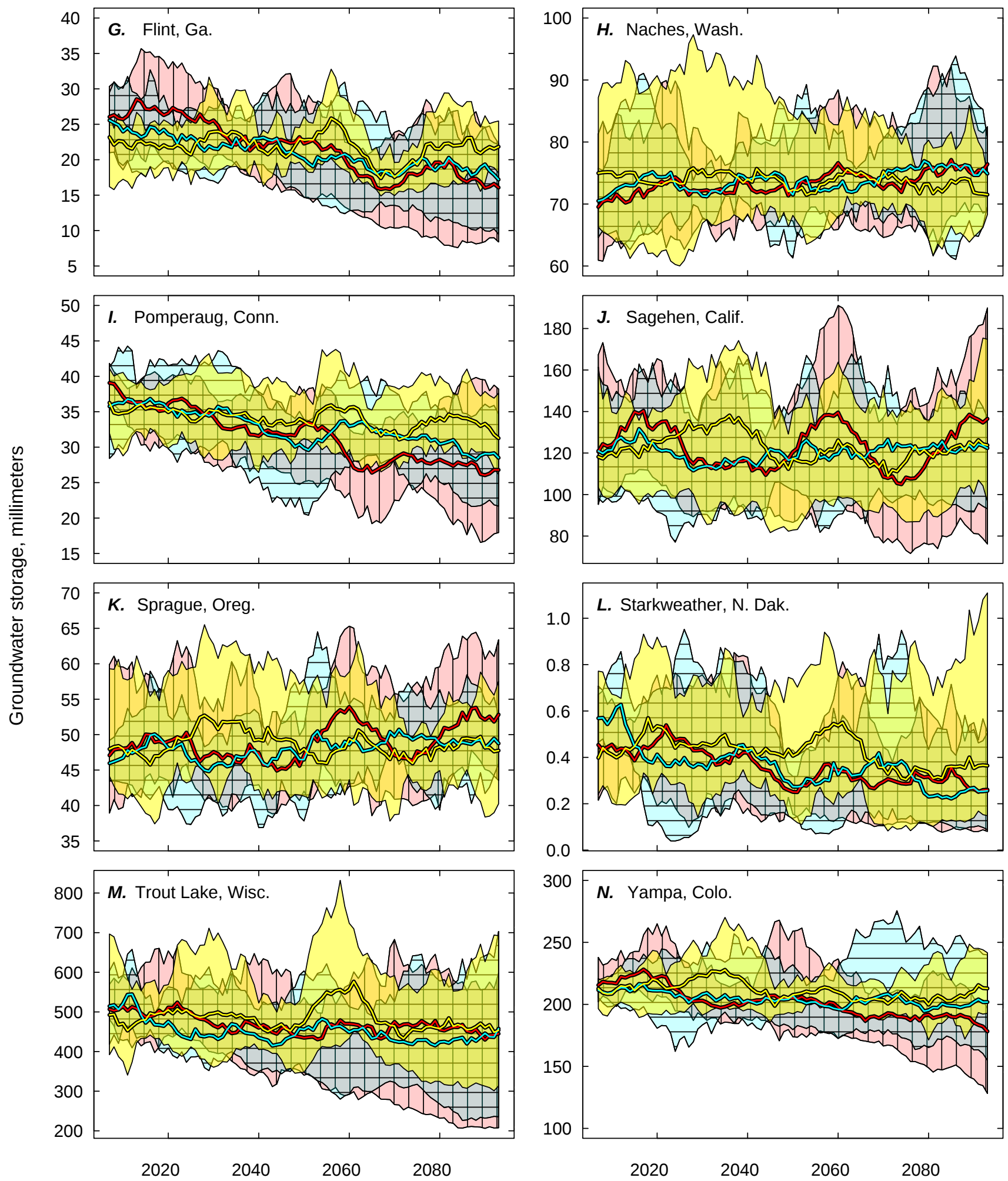

Center of 11-year window

Figure 28. Projected range in 11-year moving mean daily groundwater reservoir storage values by emission scenarios for the 14 basins and means based on the 5 General Circulation Models (GCM).-Continued 


\section{Mean Monthly Plots}

All mean monthly plots (figs. 29-46) show by month the mean daily values for baseline (red line, 1989-1999) and the range in PRMS projections for: 2030 (green, 2025-2035), 2060 (tan, 2055-2065), and 2090 (blue, 2085-2095). The range of values indicated by the boxplots illustrates the degree of uncertainty associated with the magnitude of projected changes on a monthly basis for the five GCMs and three scenarios. Each of these plots is described, basin by basin, in the following sections of this report.

Changes in the timing of peak flow are evident in projected mean monthly hydrographs (fig. 47) for baseline conditions (red dashed line, 1989-1999) and projections of 2030 (green line, 2025-2035), 2060 (tan line, 2055-2065), and 2090 (2085-2095) for the 14 PRMS applications. The timing of peak flow remains unchanged in cold weather basins (for example, April in the Starkweather projections) to shifts of several months for others (for example, May to March in the Sagehen projections). In many of the basins, projections of streamflow indicate a decrease in the effect of snowmelt and an increase in the effect of evapotranspiration, though the uncertainty is large.

Table 5 shows the change (slope) and $\mathrm{R}_{\mathrm{a}}^{2}$ for selected output variables from the PRMS projections. The slope indicates the amount of change in the selected variable by year; blue colored values indicates a significant negative trend and red colored values indicates a significant positive trend $(\mathrm{p}<0.05)$ accounting for lag-1 autocorrelation on the degrees of freedom (Lettenmaier, 1976; McCabe and Wolock, 1997). The $\mathrm{R}^{2}$ a value gives an indication of the variability in the central tendency of the trend.

\section{Precipitation Runoff Modeling System Projections for Black Earth Creek, Wisconsin}

The Black Earth Creek basin is located in northwest Dane County, Wisconsin. At USGS streamflow-gaging station 05406500 , the basin has a drainage area of $118 \mathrm{~km}^{2}$ (table 1). The basin was simulated with a fully-coupled groundwater/ surface-water model (GSFLOW; Markstrom and others, 2008). Only the results from the PRMS portion of the GSFLOW application are presented here. The Black Earth Creek basin application contains 780 HRUs with elevations that range from 718 to $1,551 \mathrm{~m}$ (table 1$)$.

Mean monthly baseline conditions for the Black Earth Creek basin are shown in figures 5 and 6. Mean monthly minimum temperatures range from just below $-12{ }^{\circ} \mathrm{C}$ during January to just below $16{ }^{\circ} \mathrm{C}$ during July. Mean monthly maximum temperatures range from approximately $-2{ }^{\circ} \mathrm{C}$ during January to above $27^{\circ} \mathrm{C}$ during July. Mean monthly precipitation ranges from $1.8 \mathrm{~mm} /$ day (during December and February) to almost $6.0 \mathrm{~mm}$ /day (during July). Because of freezing temperatures during the winter months, precipitation falls as snow and accumulates throughout the winter, with peak mean monthly runoff occurring during March because of snowmelt.

The Black Earth Creek basin encompasses both glaciated and unglaciated settings. The basin contains a trout stream located near an urbanizing fringe of the state capital, Madison. As a result of the conversions from agricultural to residential and commercial land uses, long-term evaluation of the effect of urbanization on the base flow and stormflow is desired. Urbanization may increase both stormflow (Steuer and Hunt, 2001) and nonpoint source loads of nutrients, pesticides, and sediments. Increased surface flows reduce the amount of water that would normally recharge to the groundwater system (Hunt and Steuer, 2001); thus, urbanization can result in a reduction of groundwater flows into streams.

\section{Black Earth Creek Input Variables}

Changes in annual mean precipitation vary in the PRMS projections of the Black Earth Creek basin (fig. 10A). The large range in the precipitation projections indicate a high level of uncertainty with no significant overall trend (table $5 A$ ). Seasonal variability is apparent also in these precipitation projections (fig. 29A).

All PRMS projections indicate steady increases in temperature (figs. $11 A, 12 A, 30 A, 31 A$, and tables $5 B$ and $5 C$ ), with associated uncertainties increasing with time. The projected changes of both maximum and minimum daily temperatures are smallest for the $\mathrm{B} 1$ scenario and largest for the A2 scenario (tables $5 B$ and $5 C$ ).

All projections indicate steady increases in annual mean evapotranspiration (fig. $13 A$ and table $5 D$ ). High variability in seasonal evapotranspiration is projected, with increases in all months, except August (fig. 32A).

All PRMS projections indicate steady increases in the length of the growing season (mid-April to mid-October) (fig. $14 A$ and table $5 E$ ). This increase is because of the projected increase of annual temperature (figs. $11 A$ and $12 A$ and tables $5 B$ and $5 C$ ). The projected changes in the length of the growing season are smallest for the B1 scenario and largest for the A2 scenario (table $5 E$ ).

\section{Black Earth Creek Streamflow Variables}

The PRMS projections indicate a decrease in annual mean streamflow for the A1B and A2 scenarios (fig. 15A and table $5 F$ ), though the uncertainties associated with these projections are large. High variability (indicating uncertainty) in the seasonal timing of streamflow is projected, particularly in March (fig. 33A). Specifically, the PRMS simulation of baseline conditions (red line, fig. 33A) indicates that peak streamflow occurs in March, while the PRMS projections indicate that, by the end of the 21 st century, the projected month of peak streamflow will no longer be discernible (fig. 33A). 

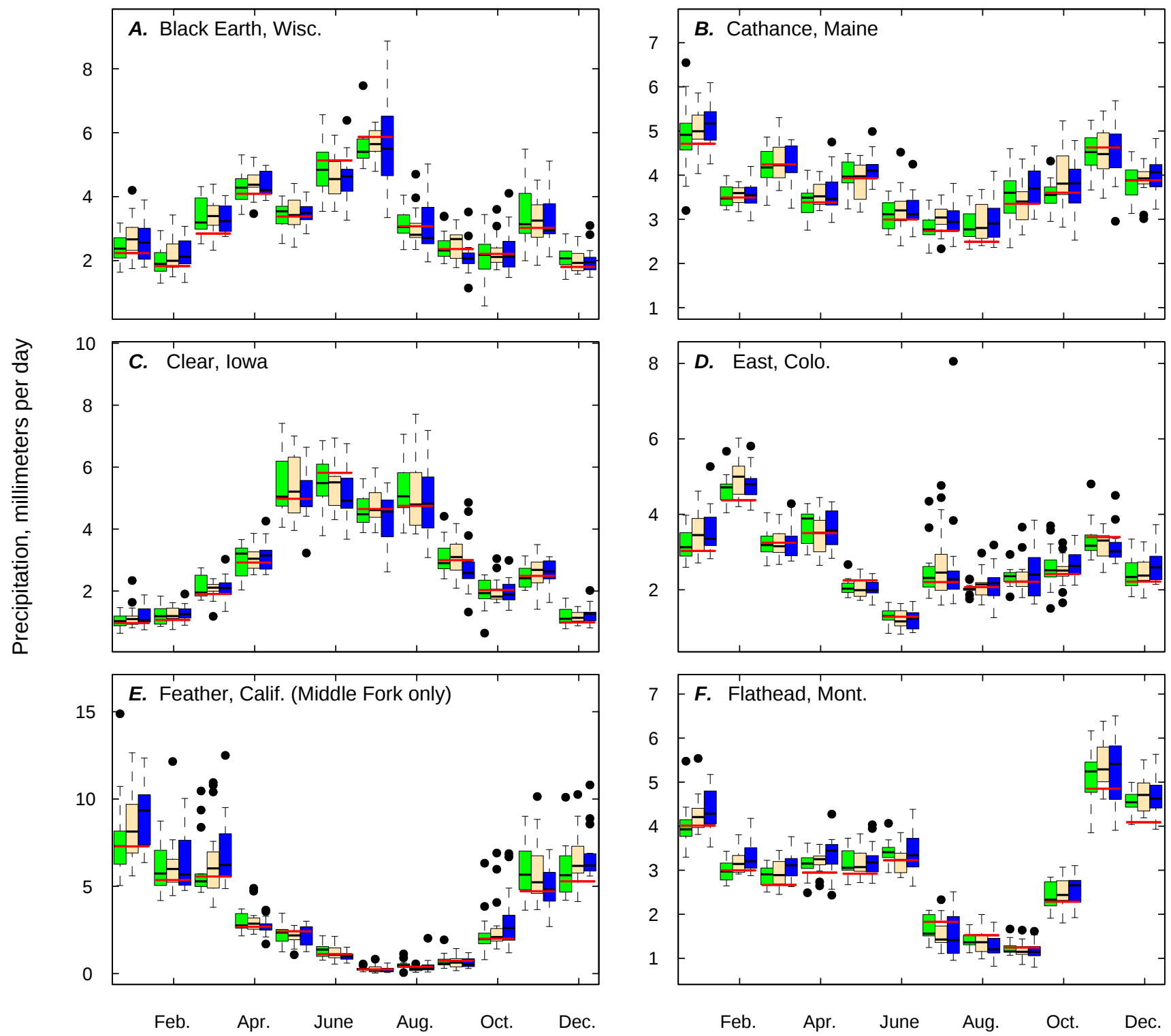

Month

\section{EXPLANATION}

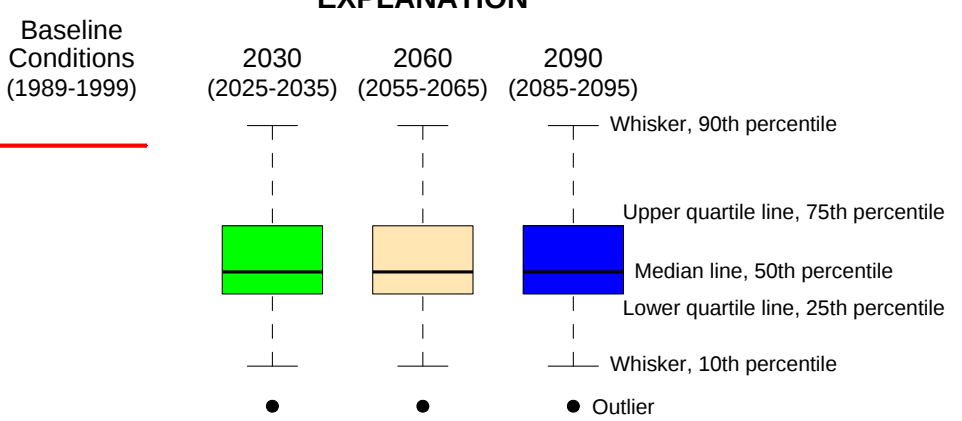

Figure 29. Mean daily precipitation values by month for baseline conditions and projected range $(2030,2060$, and 2090$)$ using the 5 general circulation models and 3 emission scenarios for the 14 basins. 


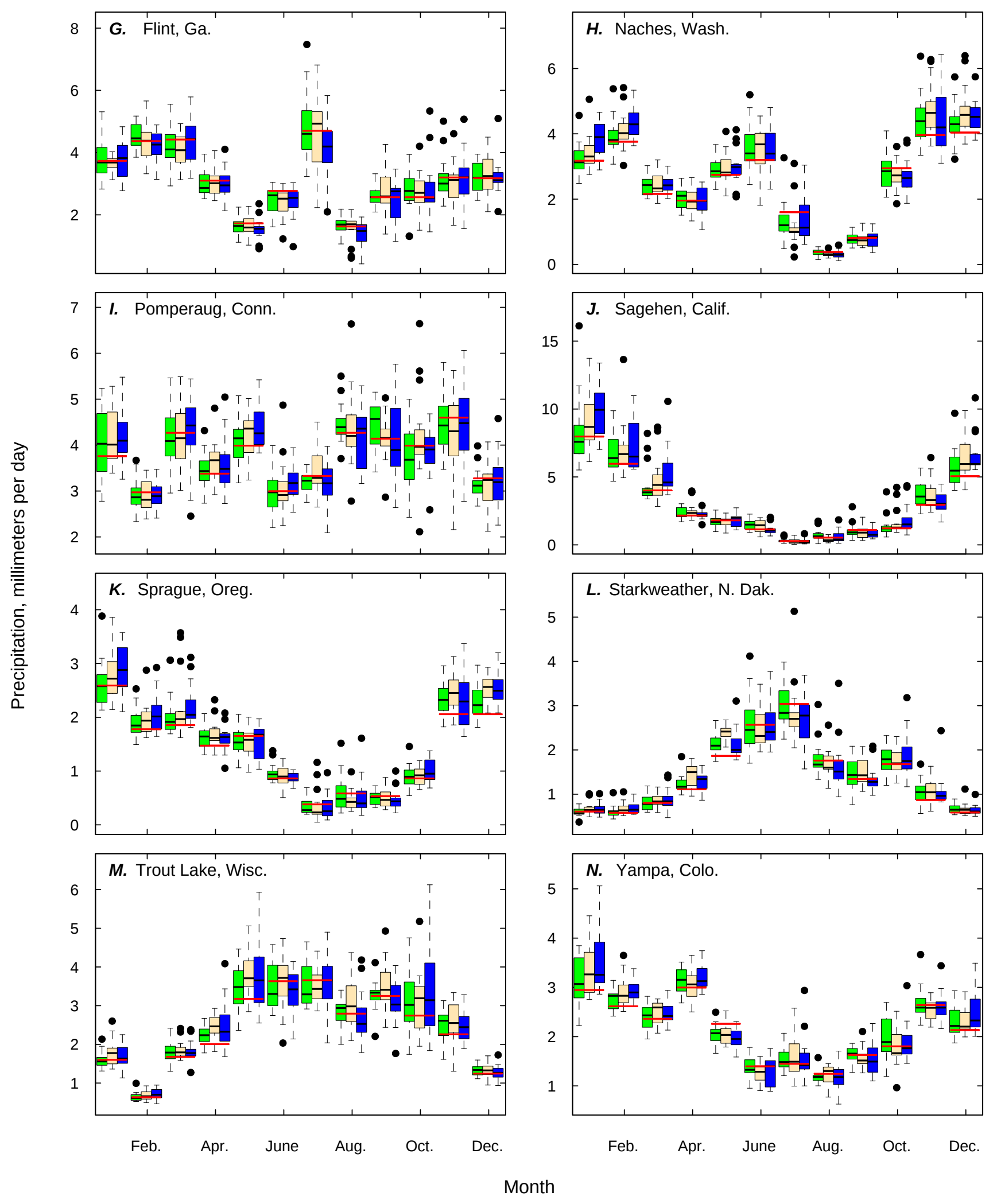

Figure 29. Mean daily precipitation values by month for baseline conditions and projected range $(2030,2060$, and 2090$)$ using the 5 general circulation models and 3 emission scenarios for the 14 basins.-Continued 

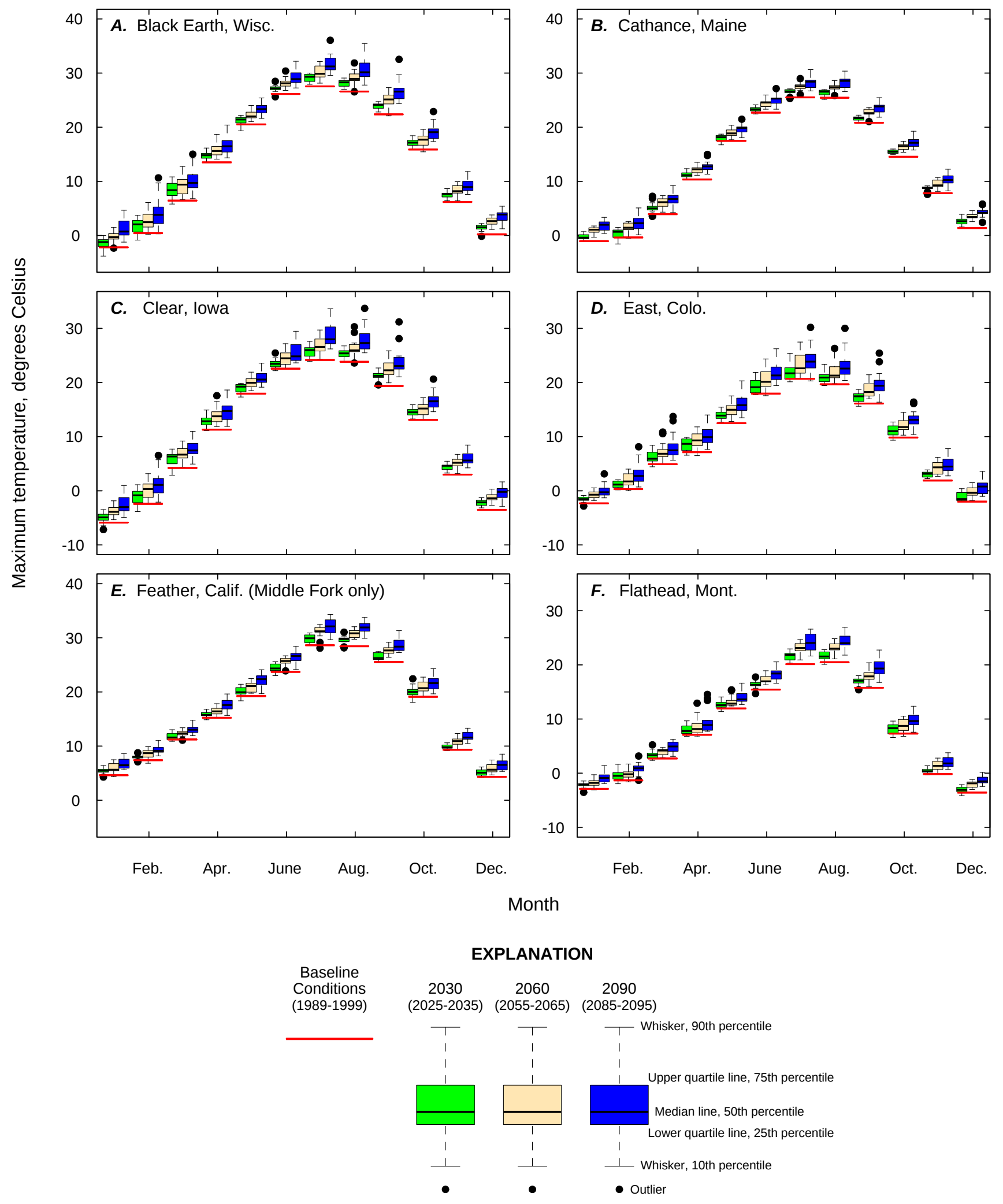

Figure 30. Mean daily maximum temperature values by month for baseline conditions and projected range (2030, 2060, and 2090) using the 5 general circulation models and 3 emission scenarios for the 14 basins. 


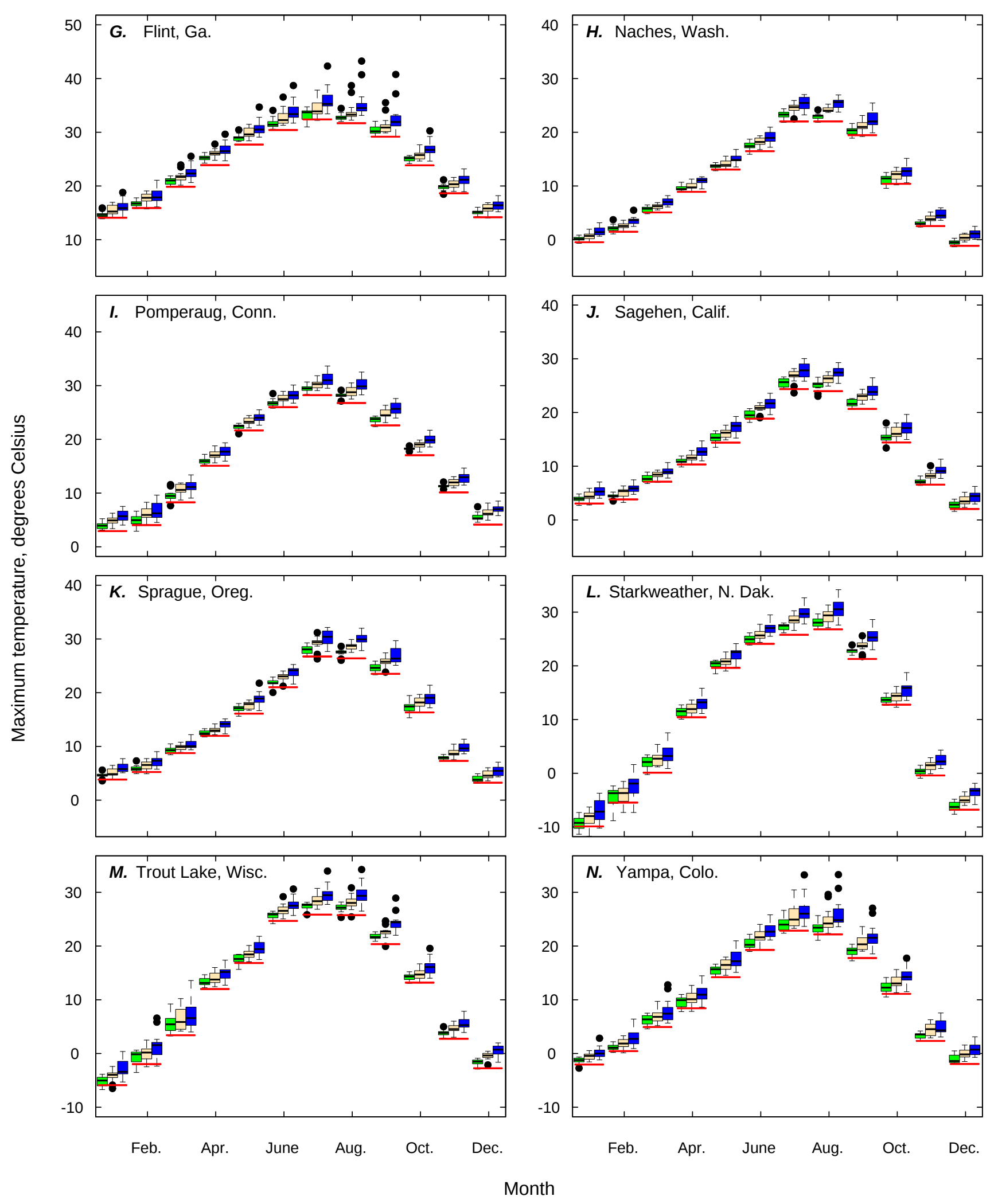

Figure 30. Mean daily maximum temperature values by month for baseline conditions and projected range $(2030,2060$, and 2090$)$ using the 5 general circulation models and 3 emission scenarios for the 14 basins.-Continued 

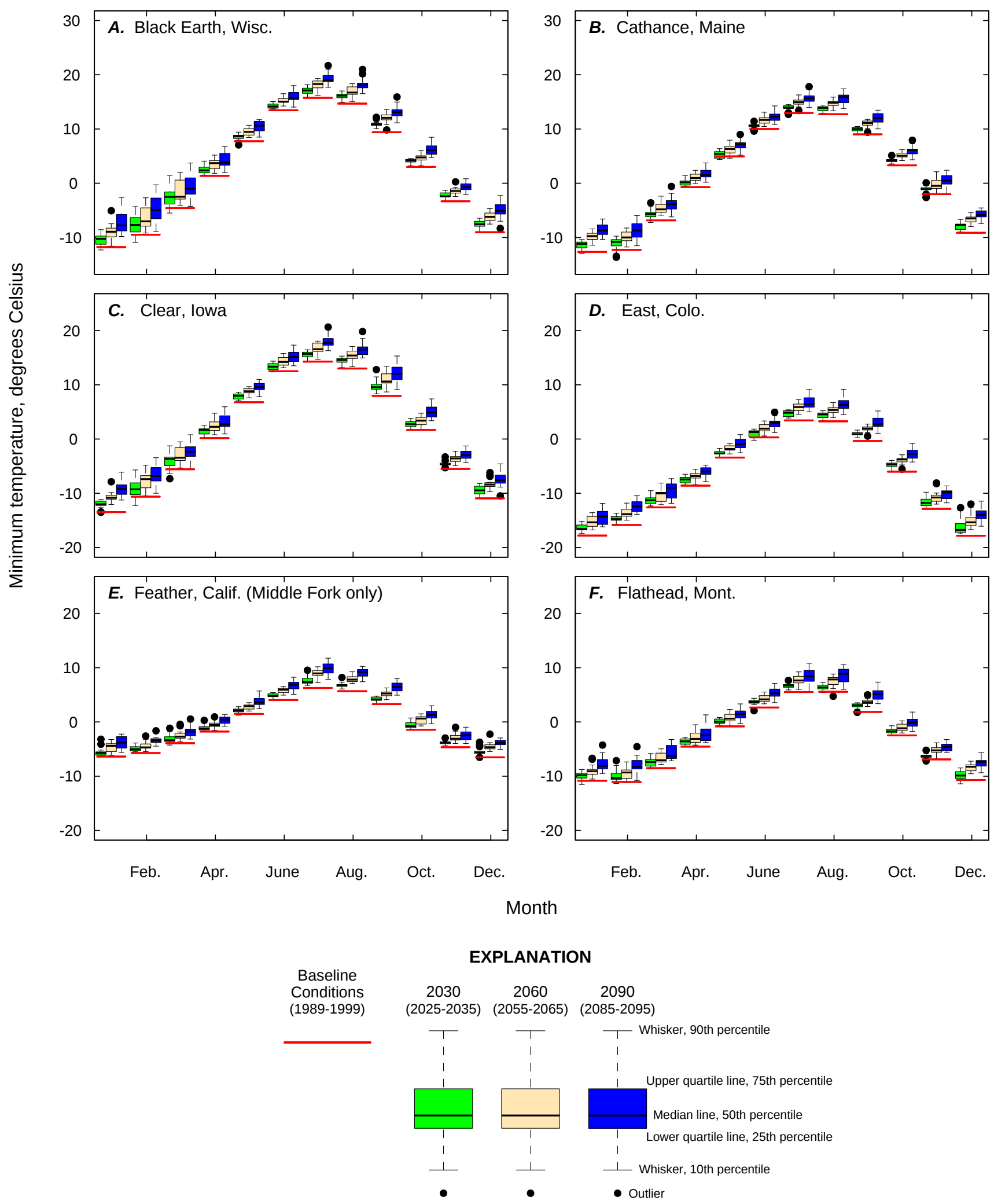

Figure 31. Mean daily minimum temperature values by month for baseline conditions and projected range $(2030,2060$, and 2090) using the 5 general circulation models and 3 emission scenarios for the 14 basins. 


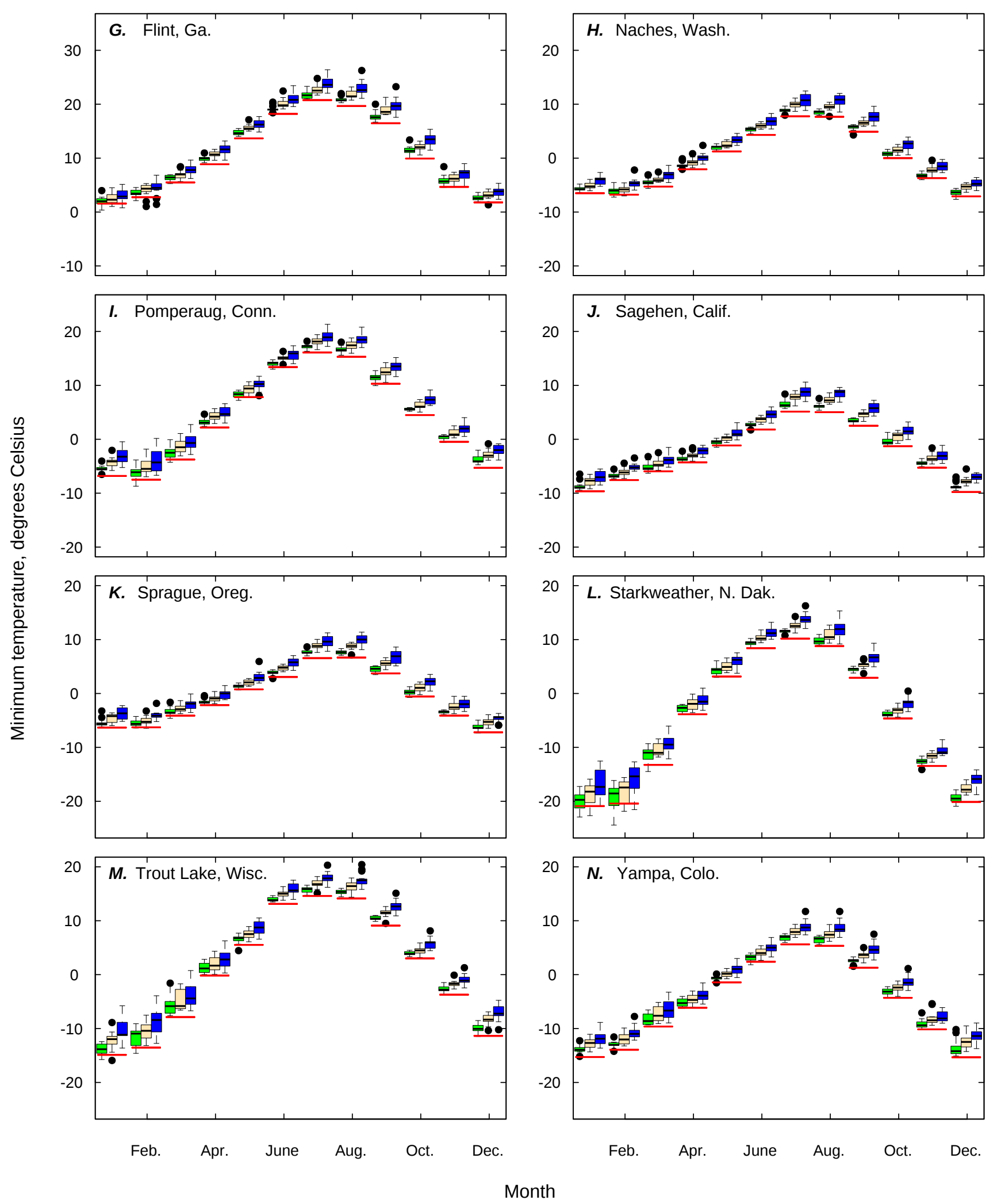

Figure 31. Mean daily minimum temperature values by month for baseline conditions and projected range (2030, 2060, and 2090) using the 5 general circulation models and 3 emission scenarios for the 14 basins.-Continued 

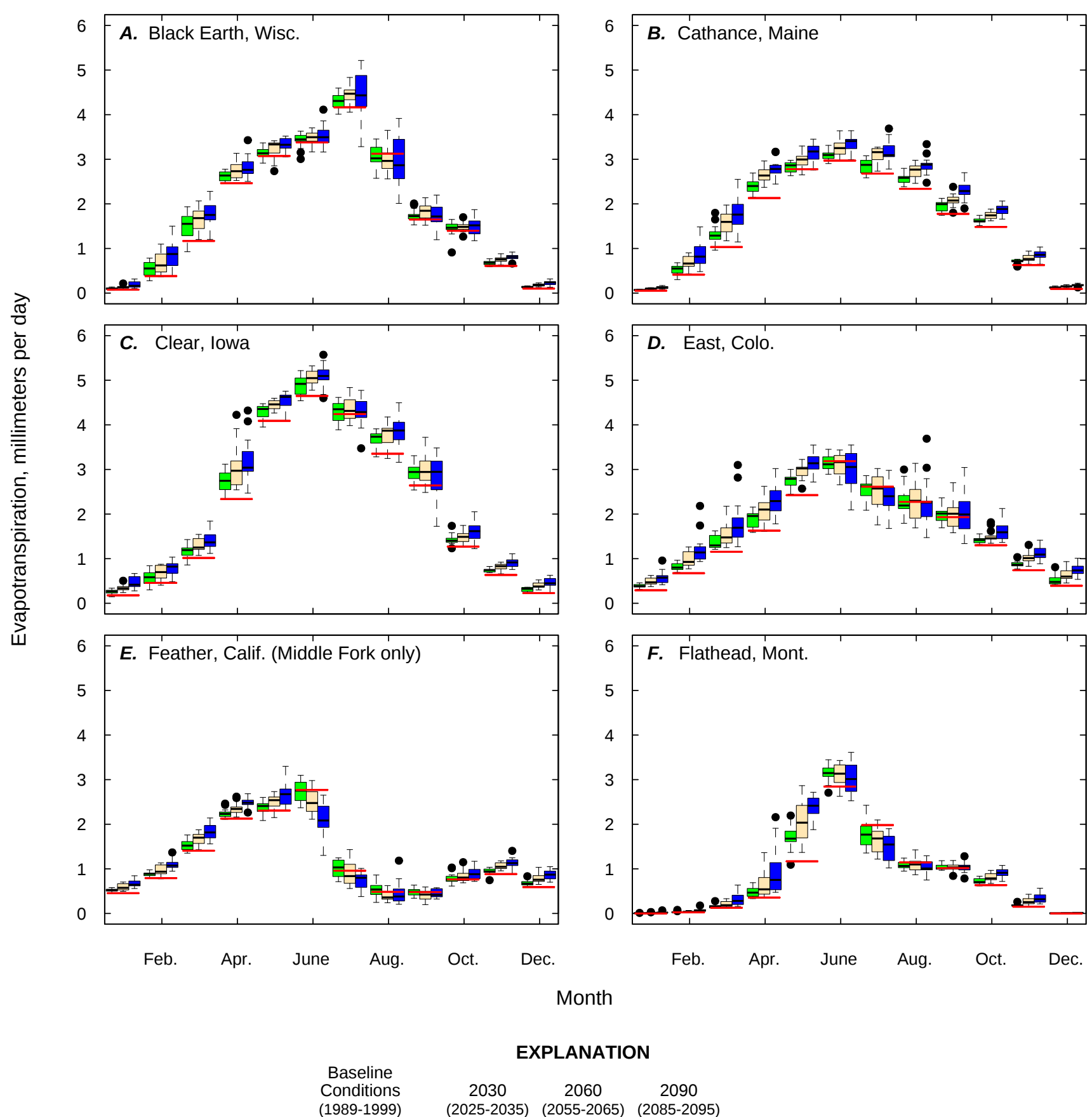

EXPLANATION (1989-1999)

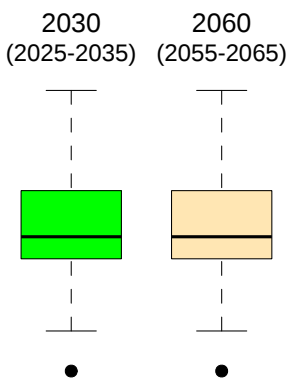

2090
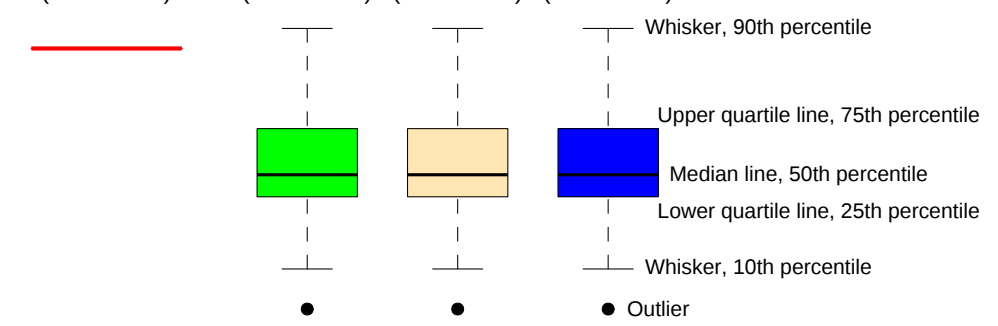

Figure 32. Mean daily evapotransipration values by month for baseline conditions and projected range $(2030,2060$, and 2090) using the 5 general circulation models and 3 emission scenarios for the 14 basins. 


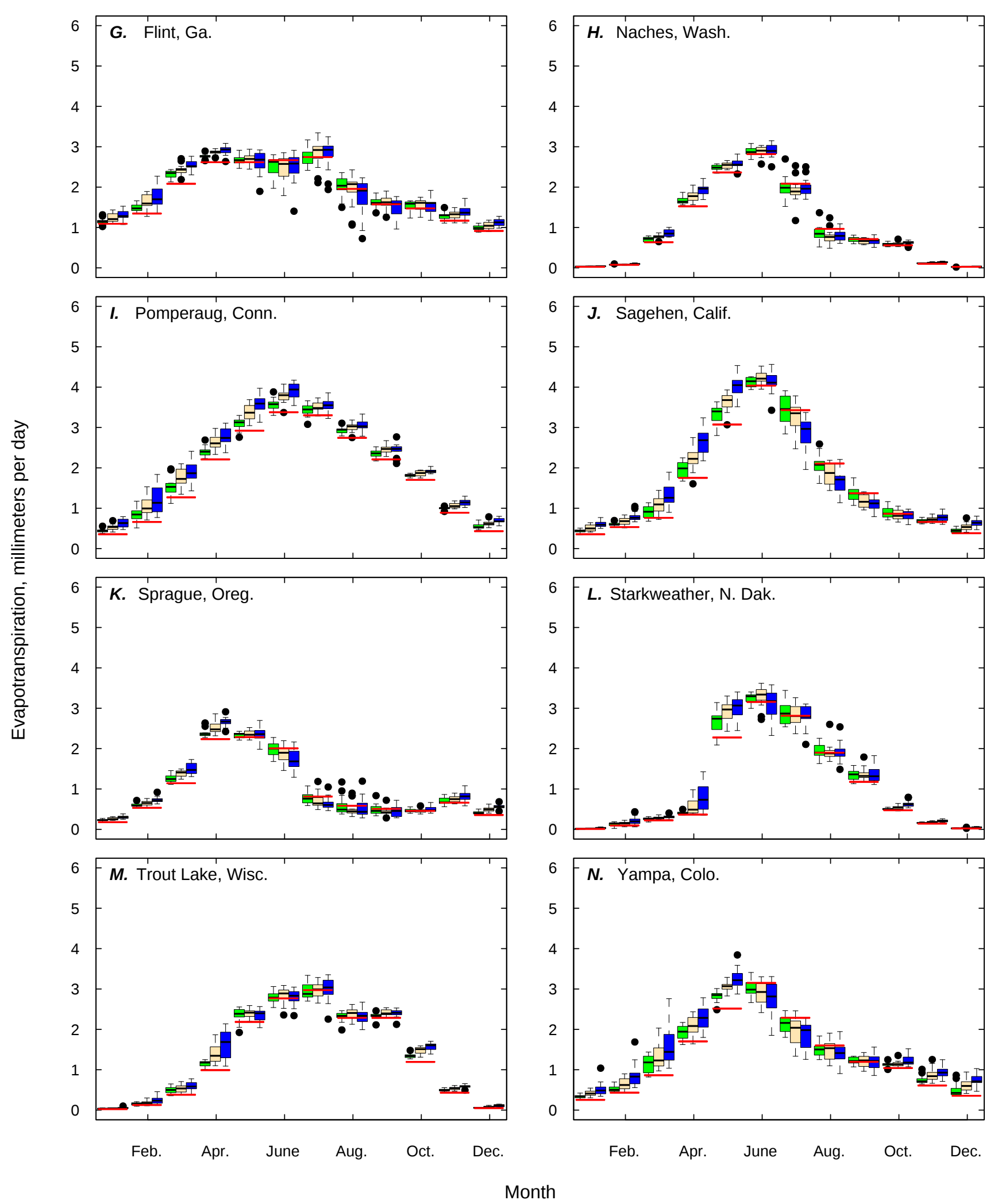

Figure 32. Mean daily evapotransipration values by month for baseline conditions and projected range $(2030,2060$, and 2090) using the 5 general circulation models and 3 emission scenarios for the 14 basins.-Continued 

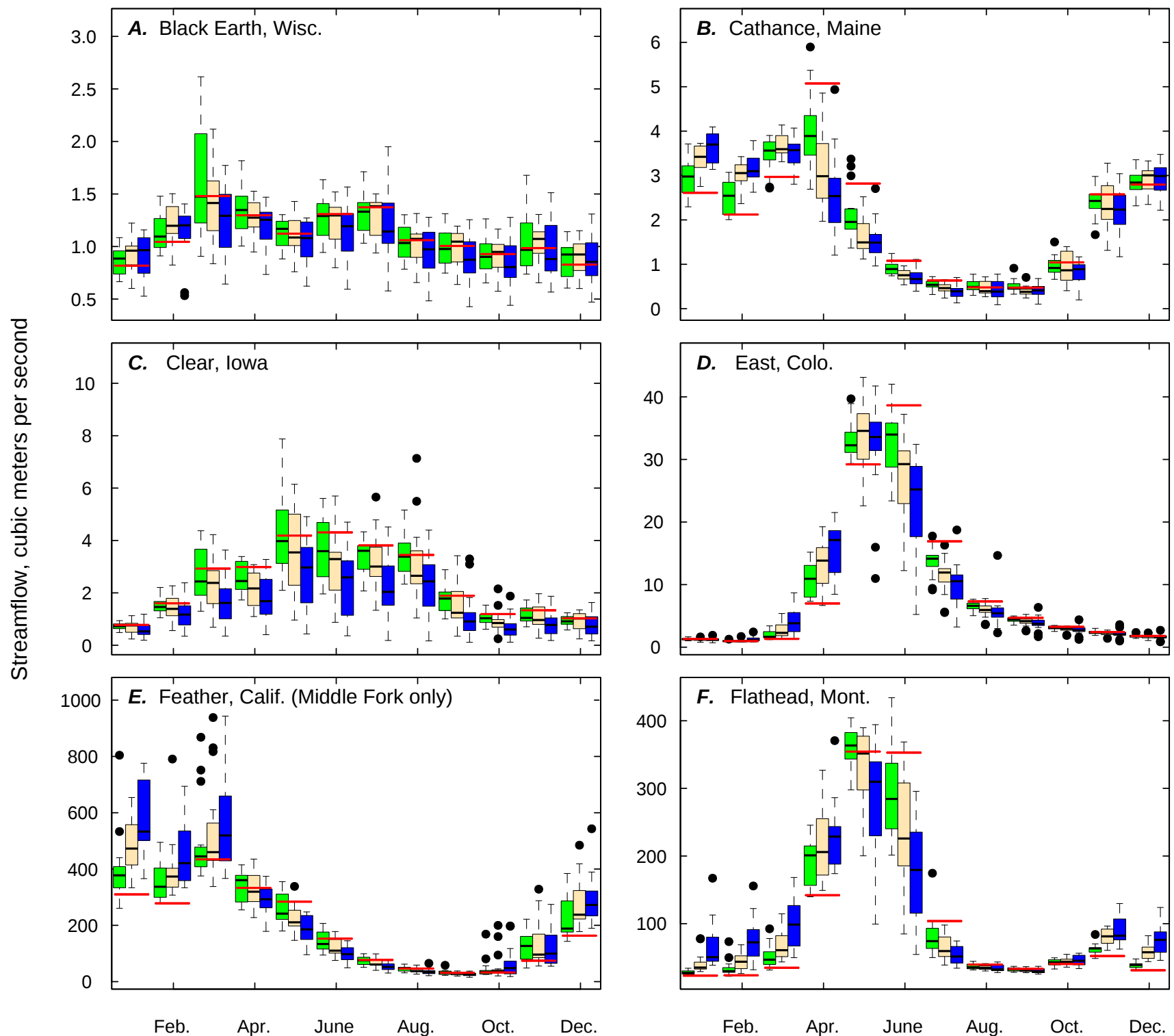

Month

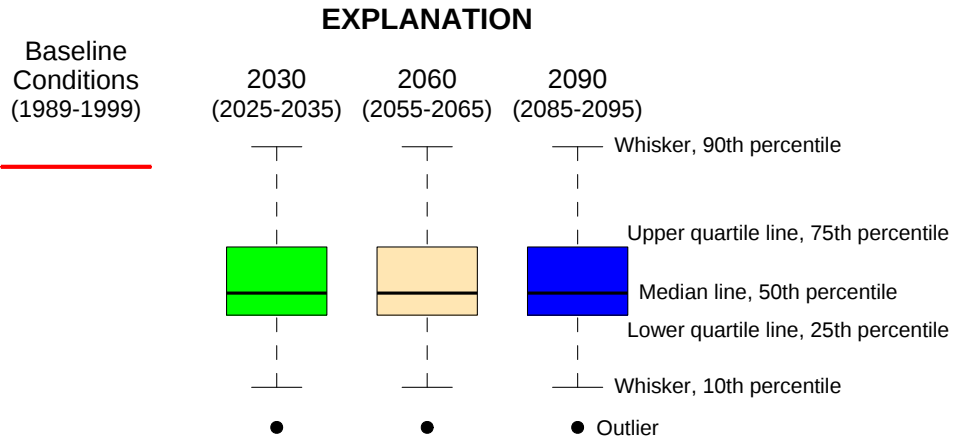

Figure 33. Mean daily streamflow values by month for baseline conditions and projected range $(2030,2060$, and 2090) using the 5 general circulation models and 3 emission scenarios for the 14 basins. 


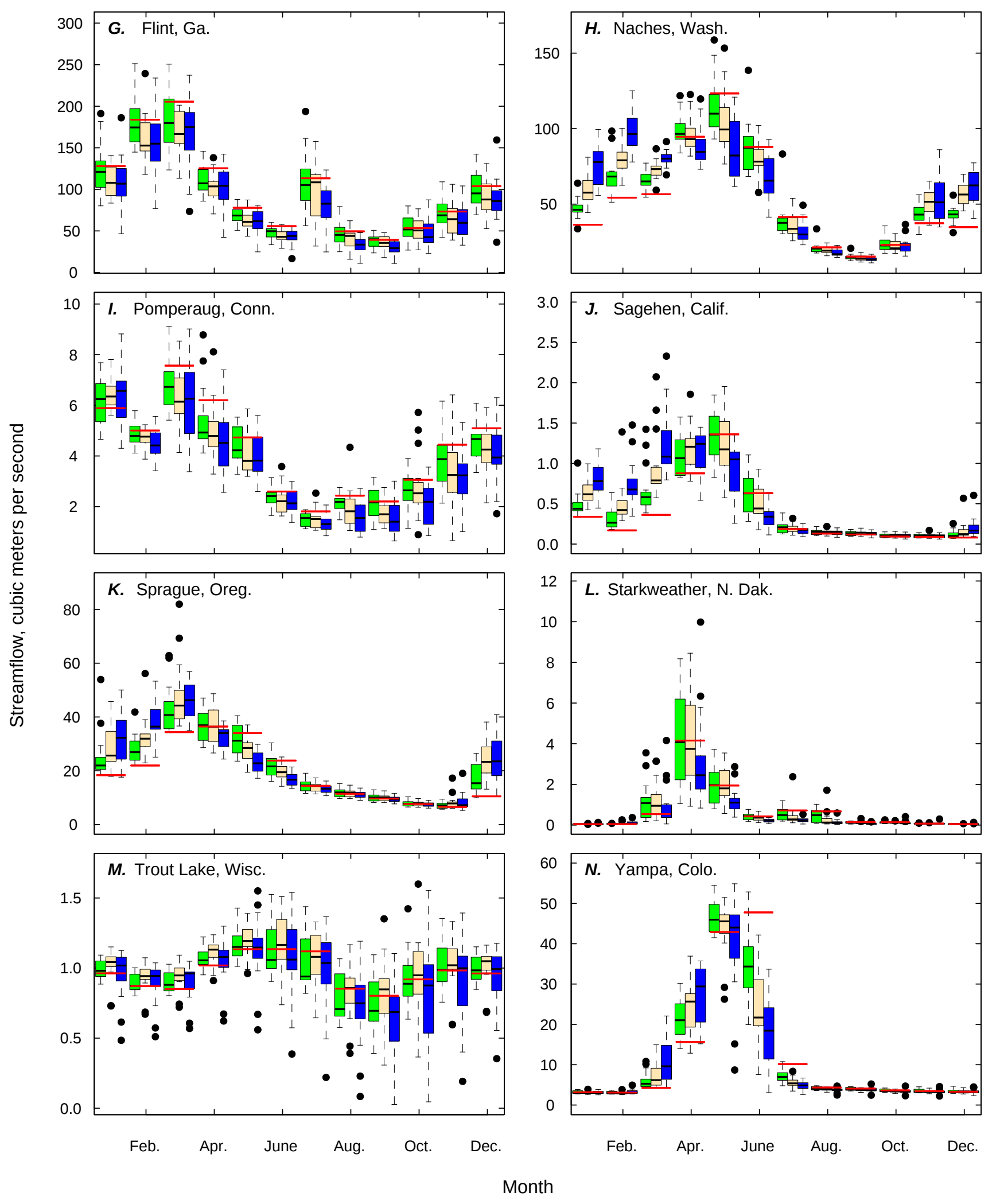

Figure 33. Mean daily streamflow values by month for baseline conditions and projected range (2030, 2060, and 2090) using the 5 general circulation models and 3 emission scenarios for the 14 basins.-Continued 

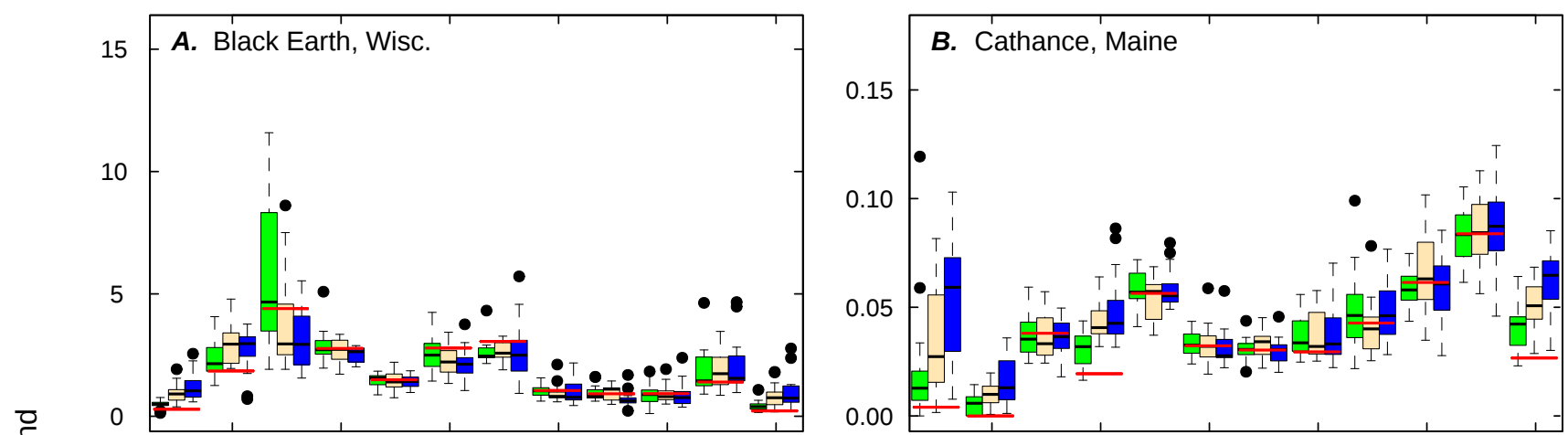

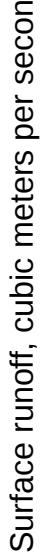
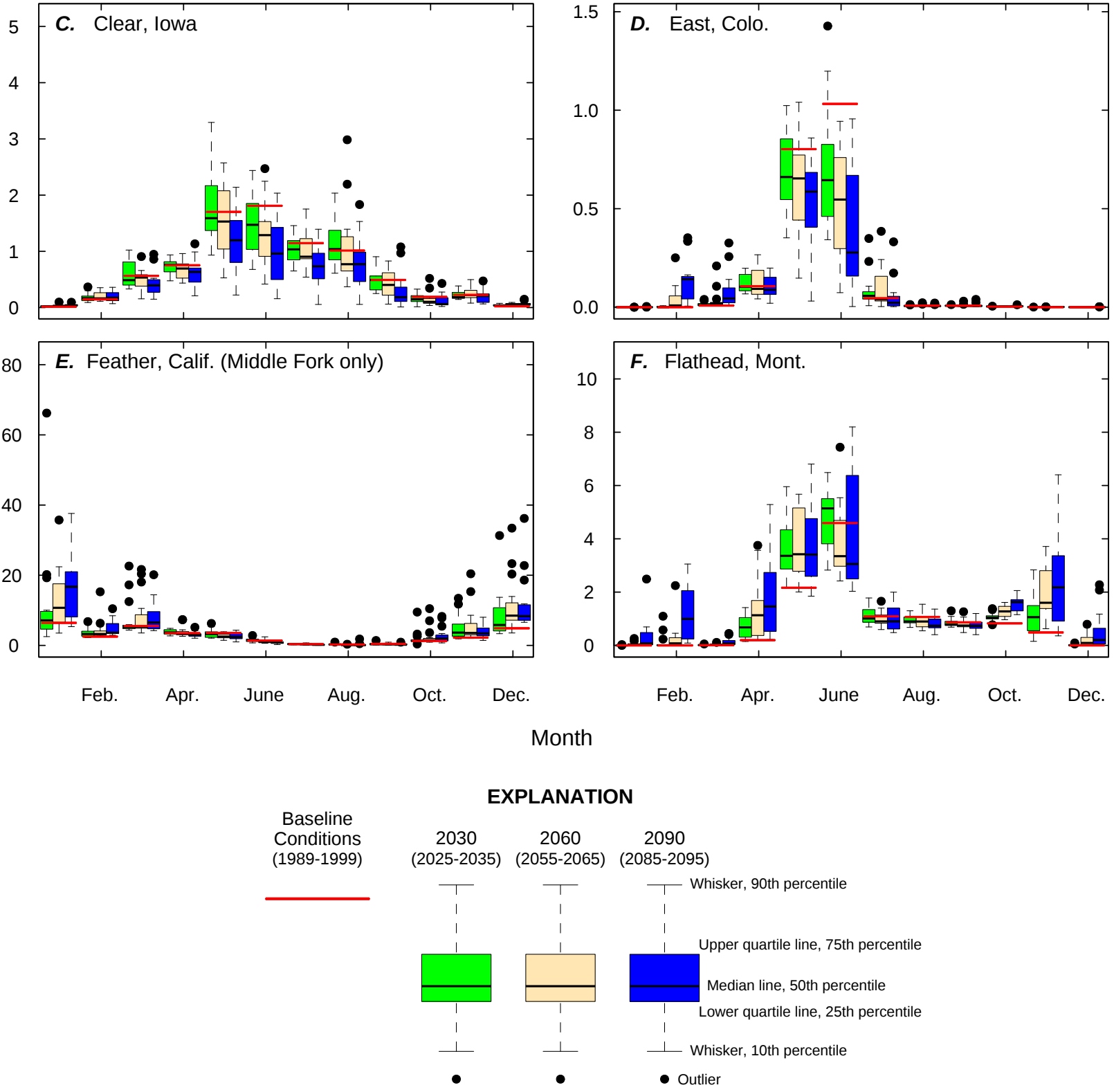

Figure 34. Mean daily surface runoff values by month for baseline conditions and projected range (2030, 2060, and 2090) using the 5 general circulation models and 3 emission scenarios for the 14 basins. 

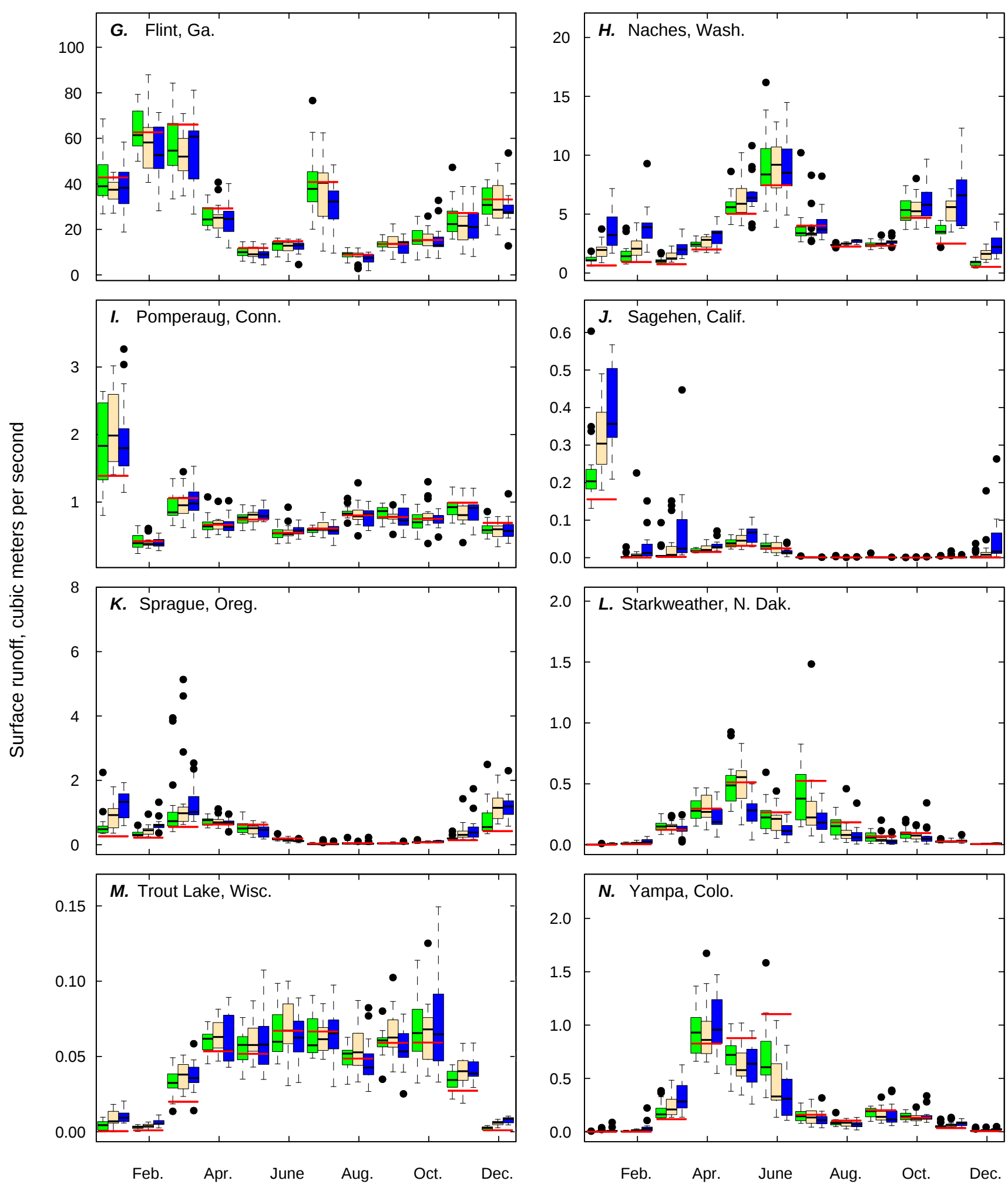

Month

Figure 34. Mean daily surface runoff values by month for baseline conditions and projected range $(2030,2060$, and 2090) using the 5 general circulation models and 3 emission scenarios for the 14 basins.-Continued 

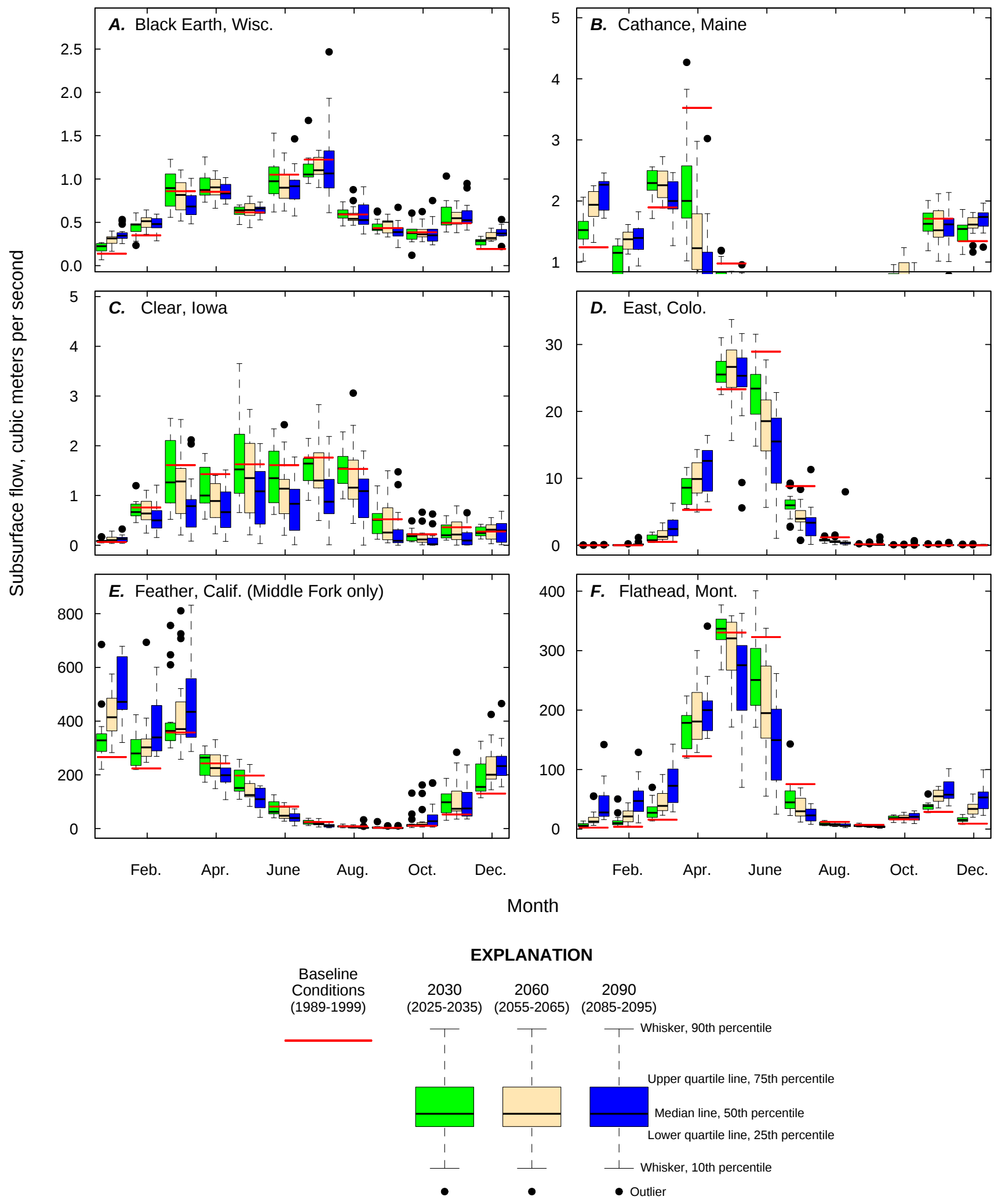

Figure 35. Mean daily subsurface flow values by month for baseline conditions and projected range $(2030,2060$, and 2090) using the 5 general circulation models and 3 emission scenarios for the 14 basins. 


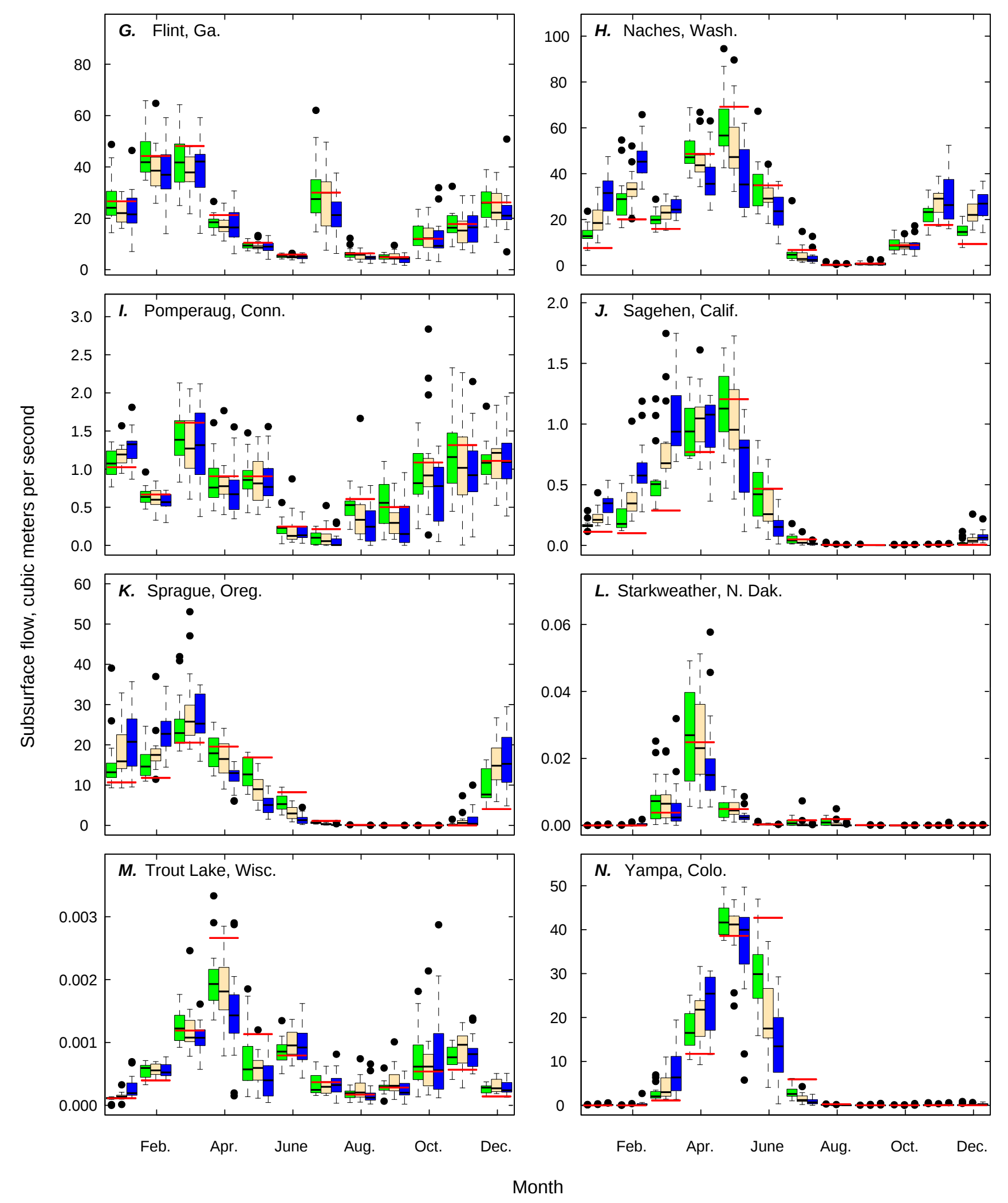

Figure 35. Mean daily subsurface flow values by month for baseline conditions and projected range $(2030,2060$, and 2090) using the 5 general circulation models and 3 emission scenarios for the 14 basins. - Continued 

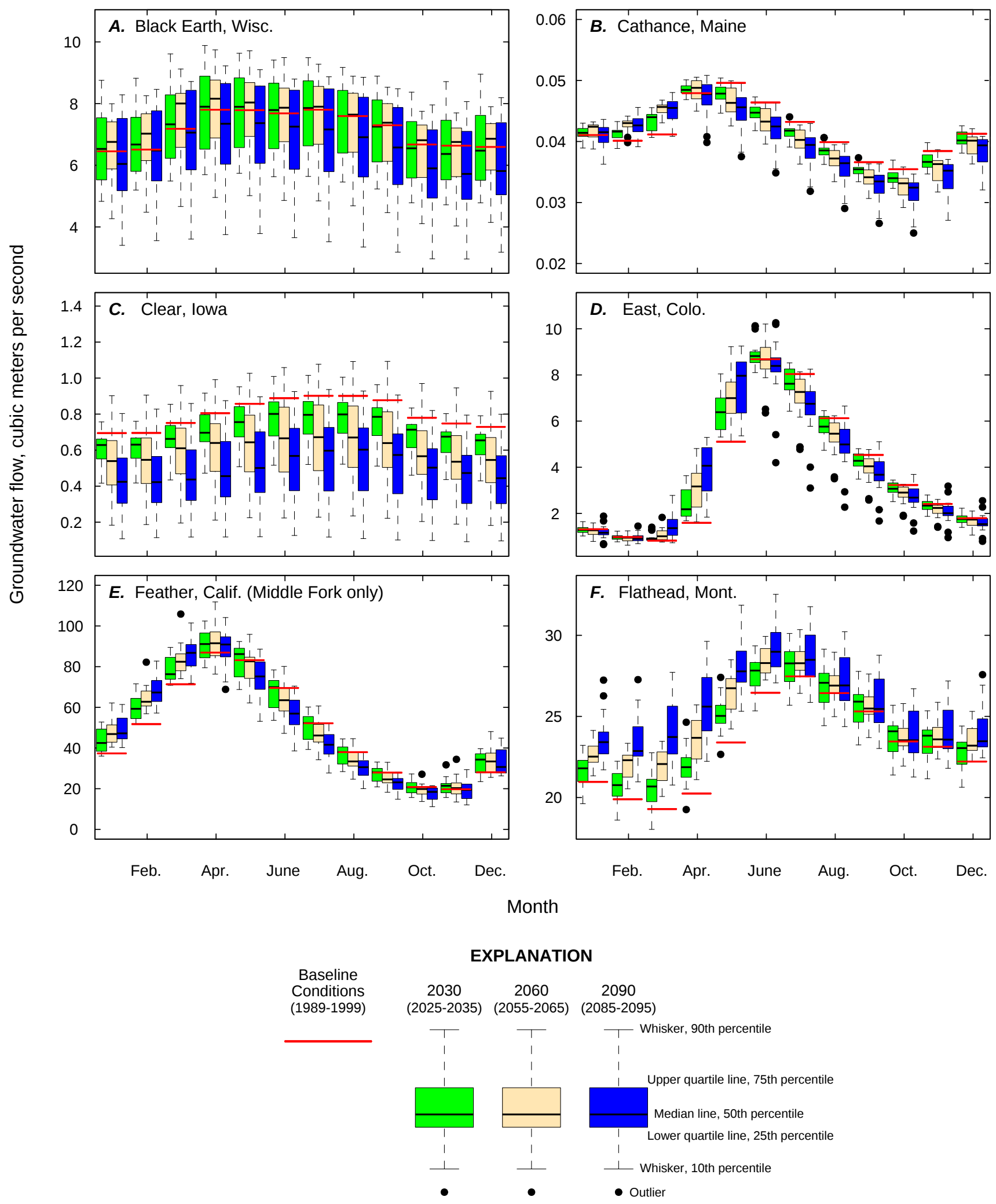

Figure 36. Mean daily groundwater flow values by month for baseline conditions and projected range (2030, 2060, and 2090) using the 5 general circulation models and 3 emission scenarios for the 14 basins. 


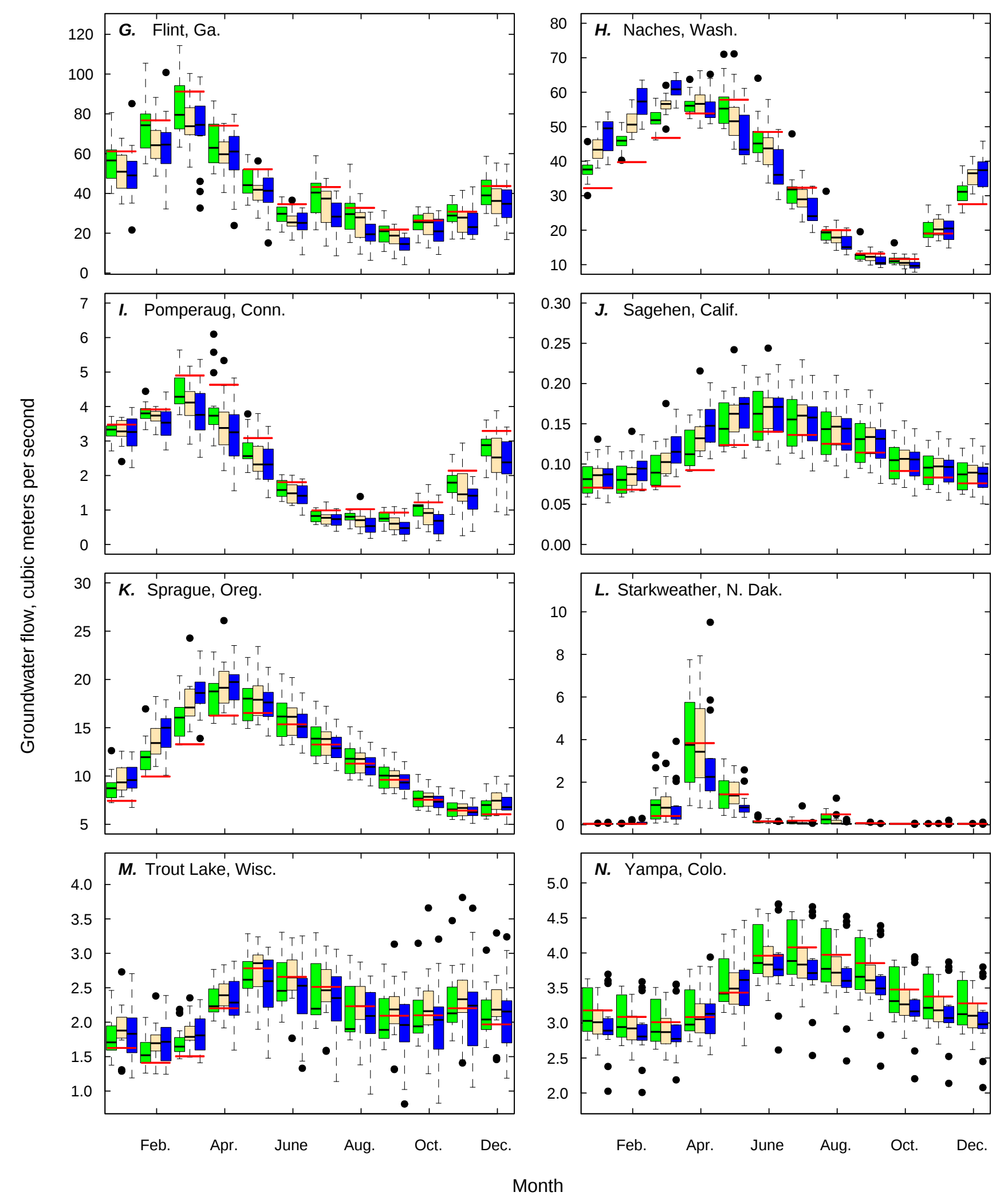

Figure 36. Mean daily groundwater flow values by month for baseline conditions and projected range (2030, 2060, and 2090) using the 5 general circulation models and 3 emission scenarios for the 14 basins. - Continued 

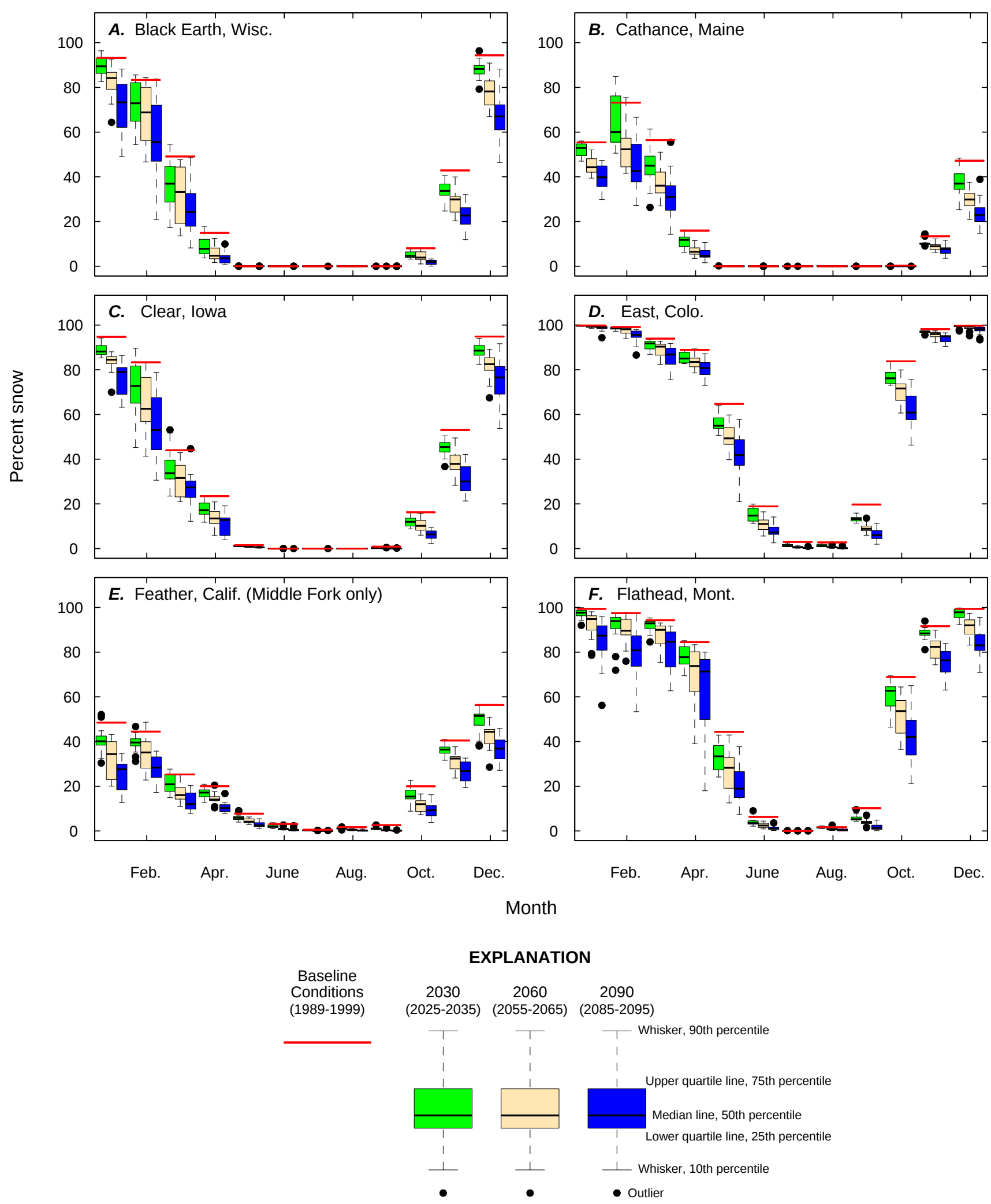

Figure 37. Mean daily percent of precipitation that falls as snow by month for baseline conditions and projected range (2030, 2060, and 2090) using the 5 general circulation models and 3 emission scenarios for the 14 basins. 

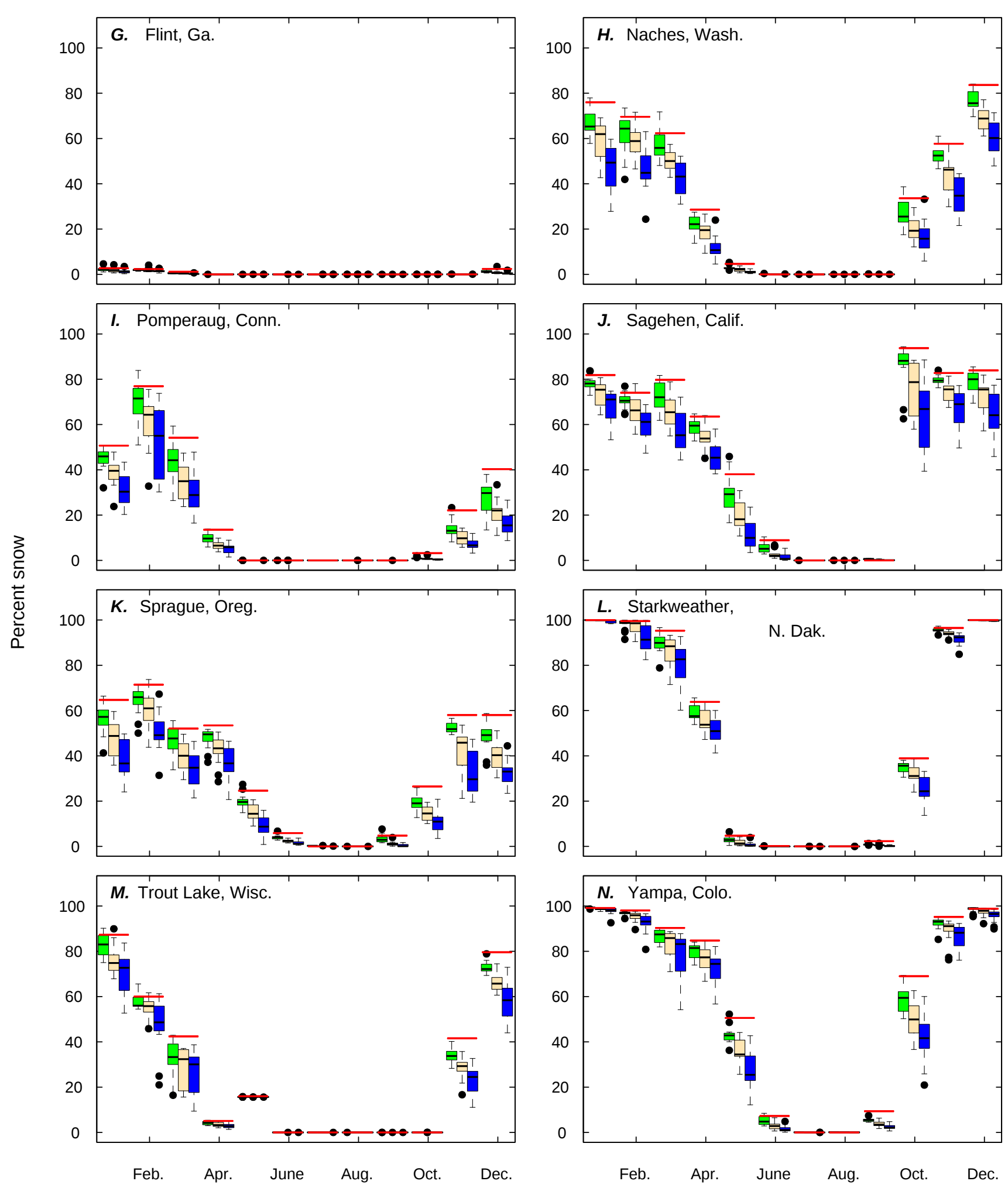

Month

Figure 37. Mean daily percent of precipitation that falls as snow by month for baseline conditions and projected range (2030, 2060, and 2090) using the 5 general circulation models and 3 emission scenarios for the 14 basins. - Continued 


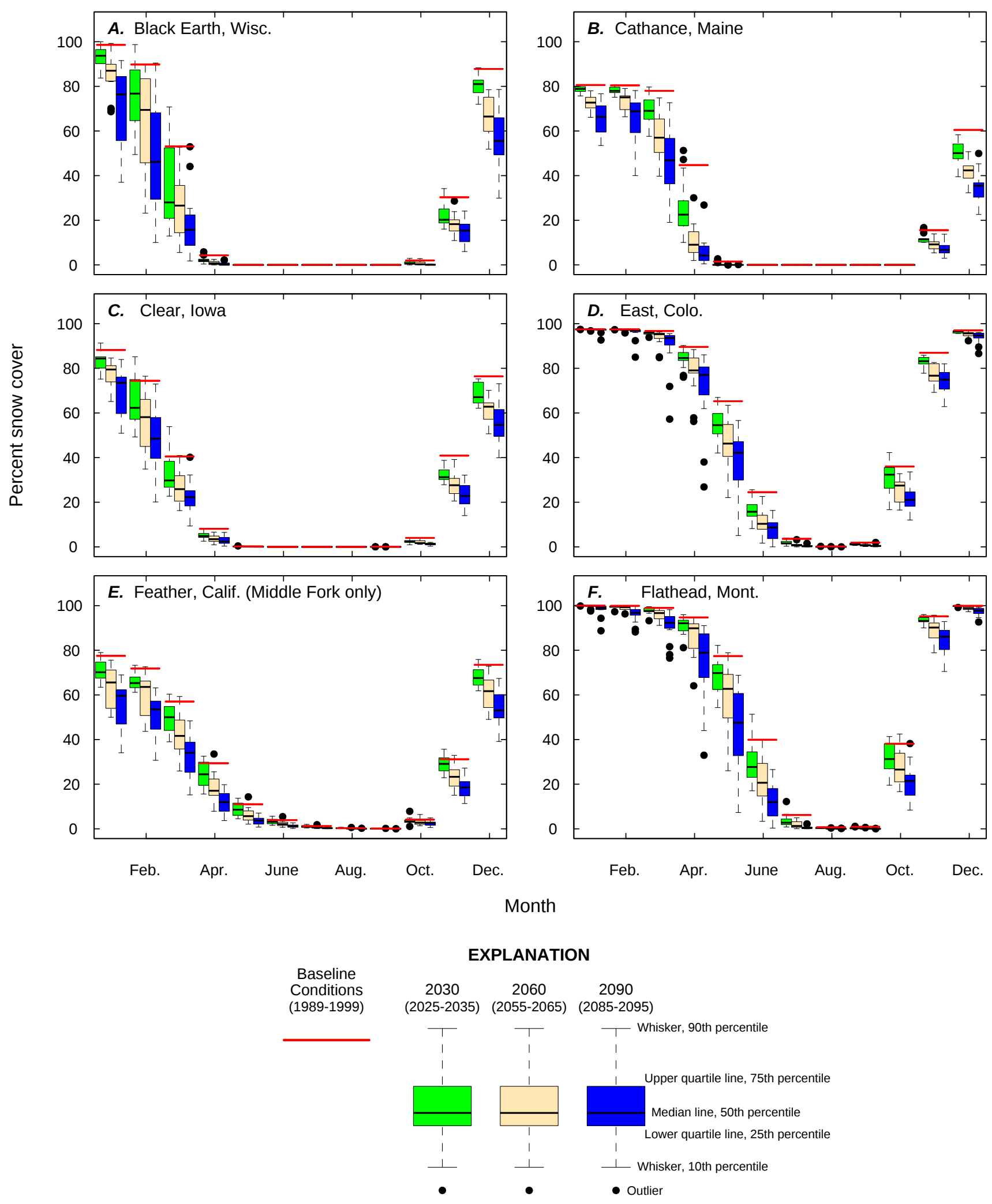

Figure 38. Mean daily percent of area covered by snow by month for baseline conditions and projected range (2030, 2060, and 2090) using the 5 general circulation models and 3 emission scenarios for the 14 basins. 

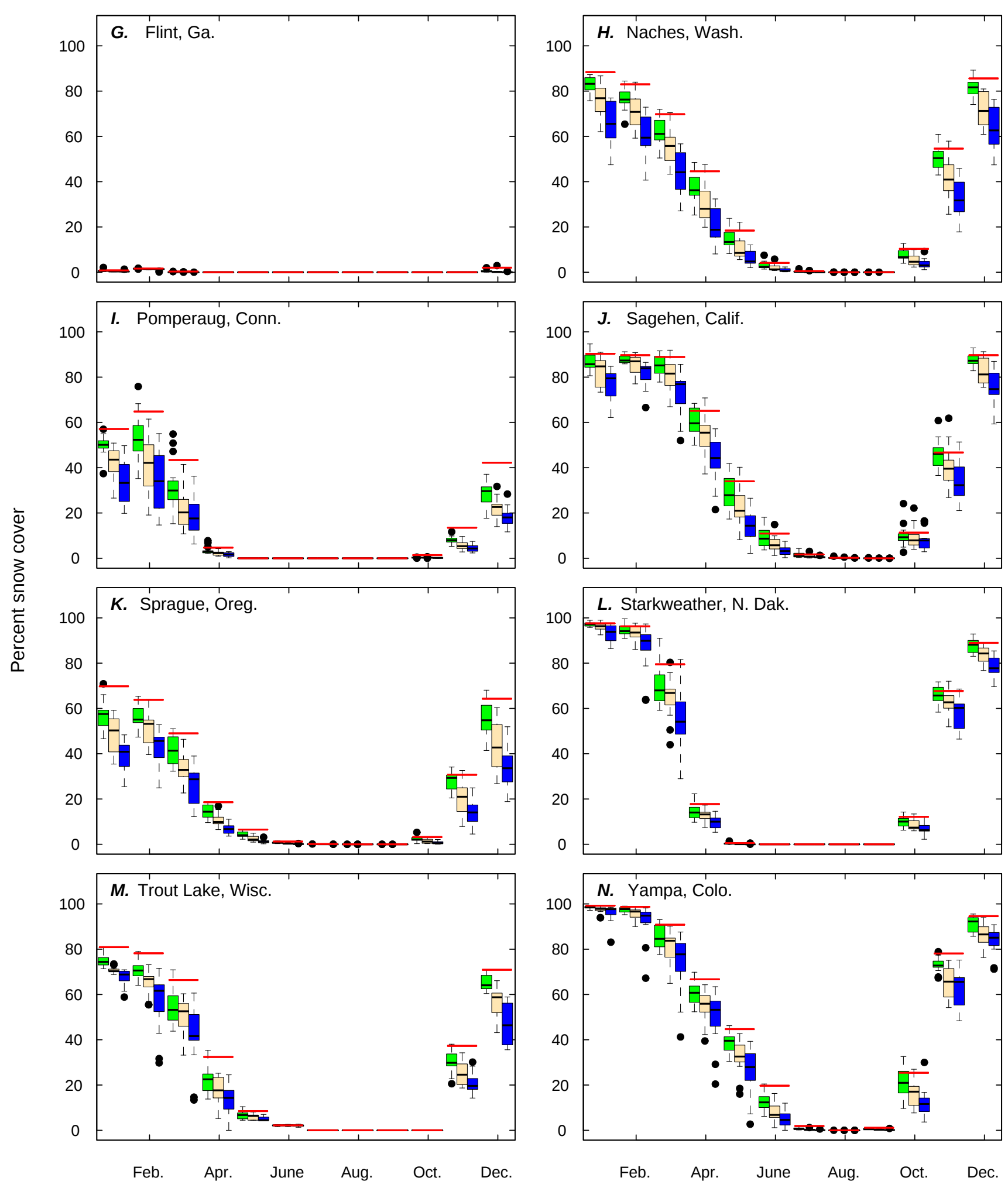

Month

Figure 38. Mean daily percent of area covered by snow by month for baseline conditions and projected range (2030, 2060, and 2090) using the 5 general circulation models and 3 emission scenarios for the 14 basins.-Continued 

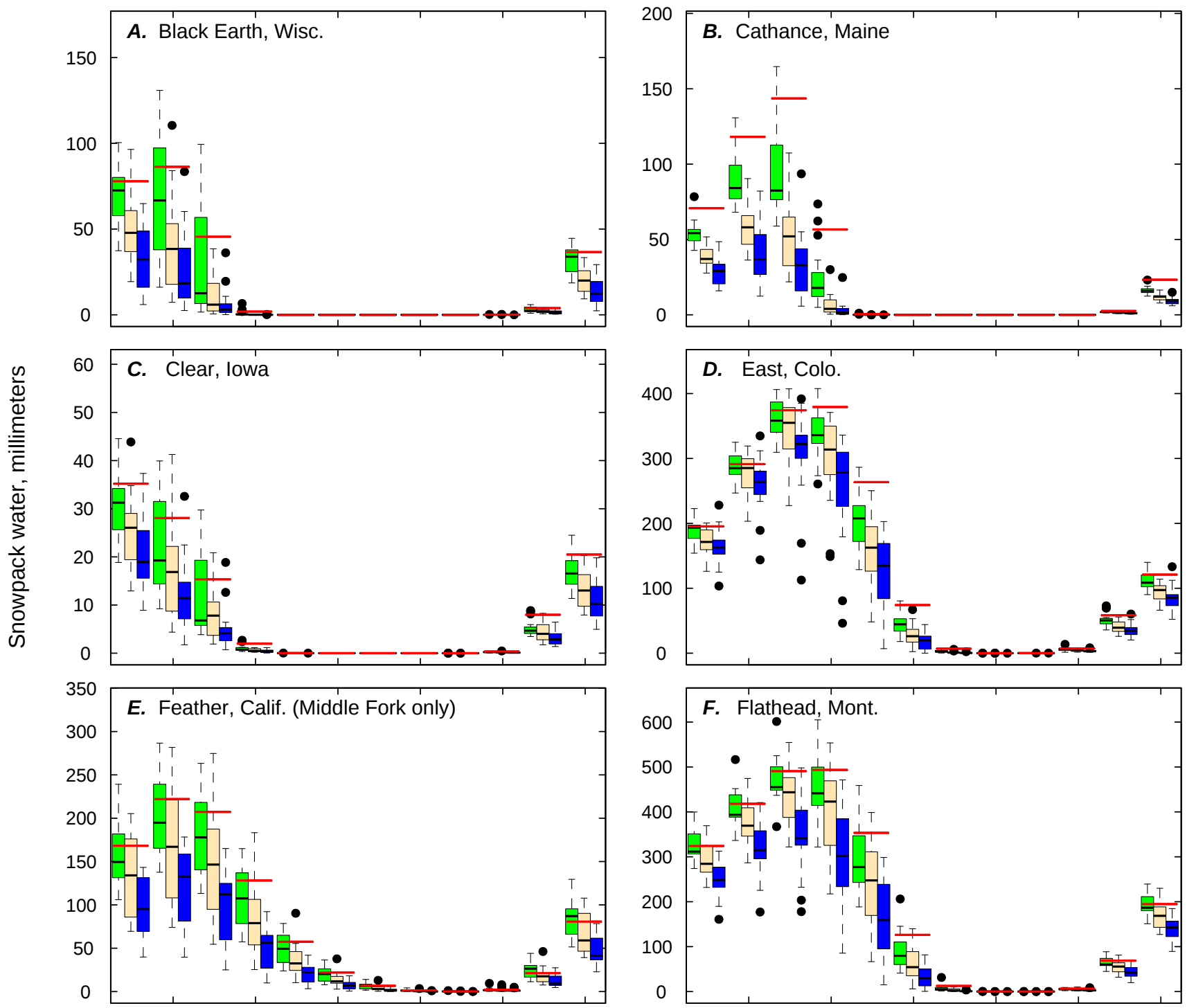

Feb. Apr. June Aug. Oct. Dec.

Feb. Apr. June Aug. Oct. Dec.

Month

EXPLANATION
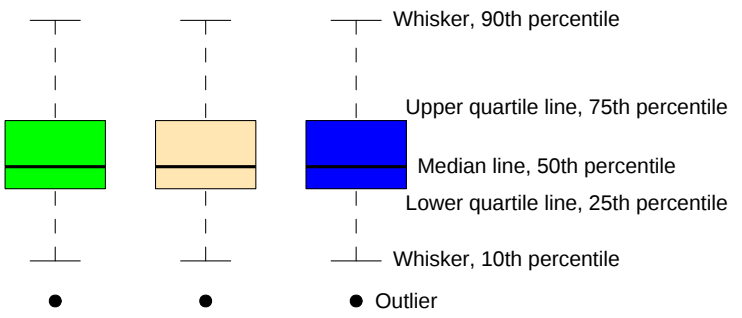

Figure 39. Mean daily snowpack water equivalent by month for baseline conditions and projected range (2030, 2060, and 2090) using the 5 general circulation models and 3 emission scenarios for the 14 basins. 

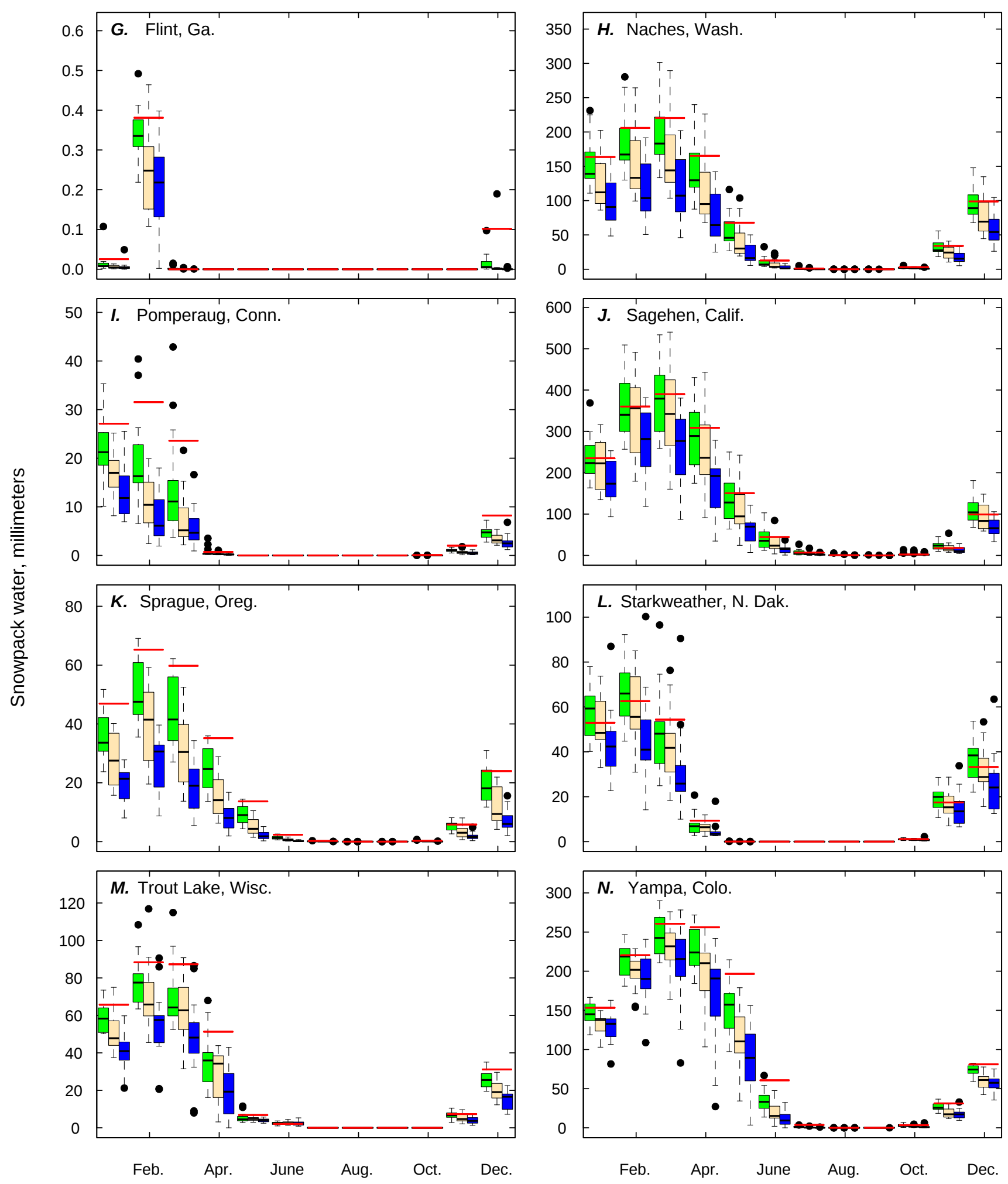

Month

Figure 39. Mean daily snowpack water equivalent by month for baseline conditions and projected range (2030, 2060, and 2090) using the 5 general circulation models and 3 emission scenarios for the 14 basins.-Continued 

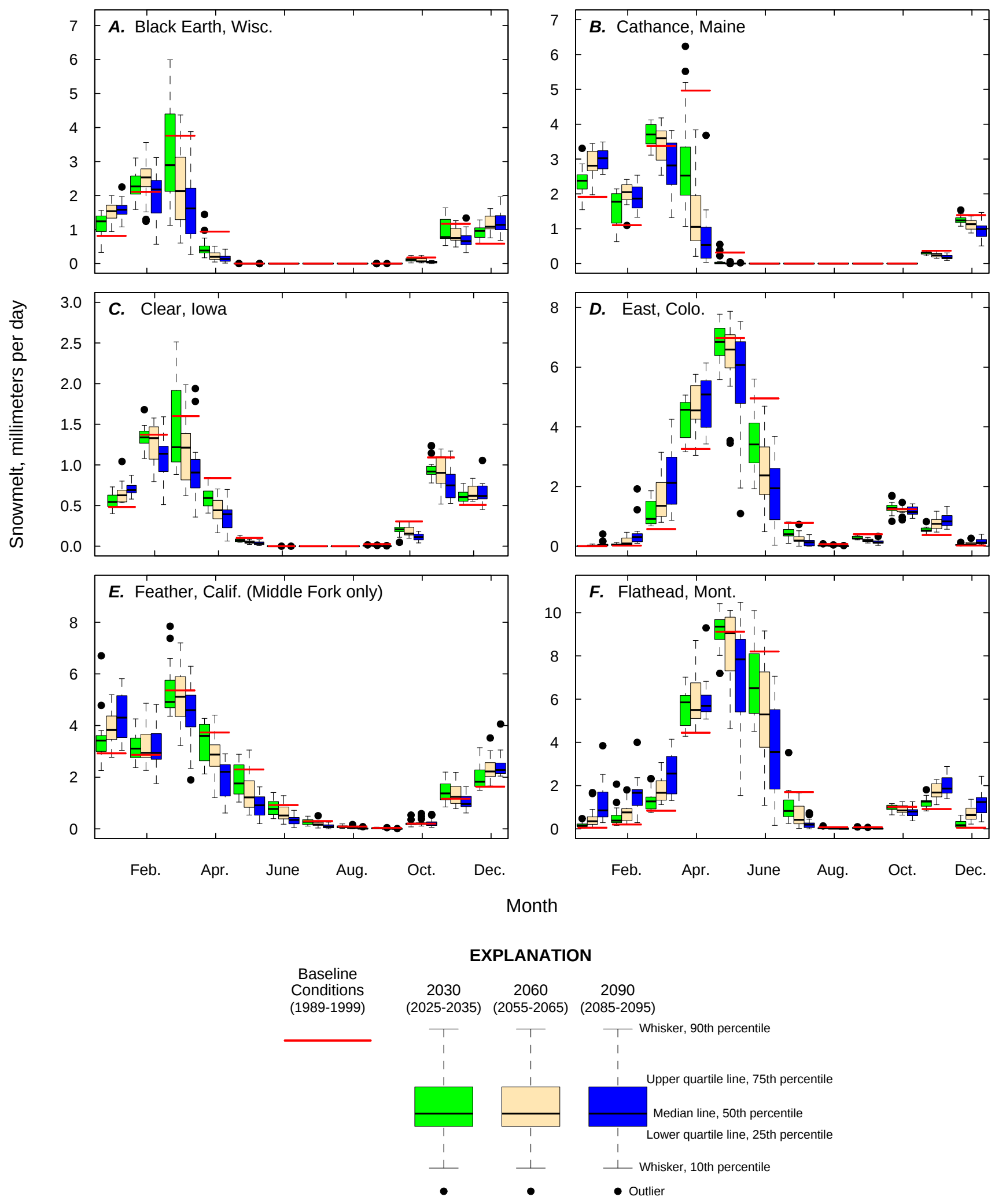

Figure 40. Mean daily snowmelt values by month for baseline conditions and projected range $(2030,2060$, and 2090) using the 5 general circulation models and 3 emission scenarios for the 14 basins. 

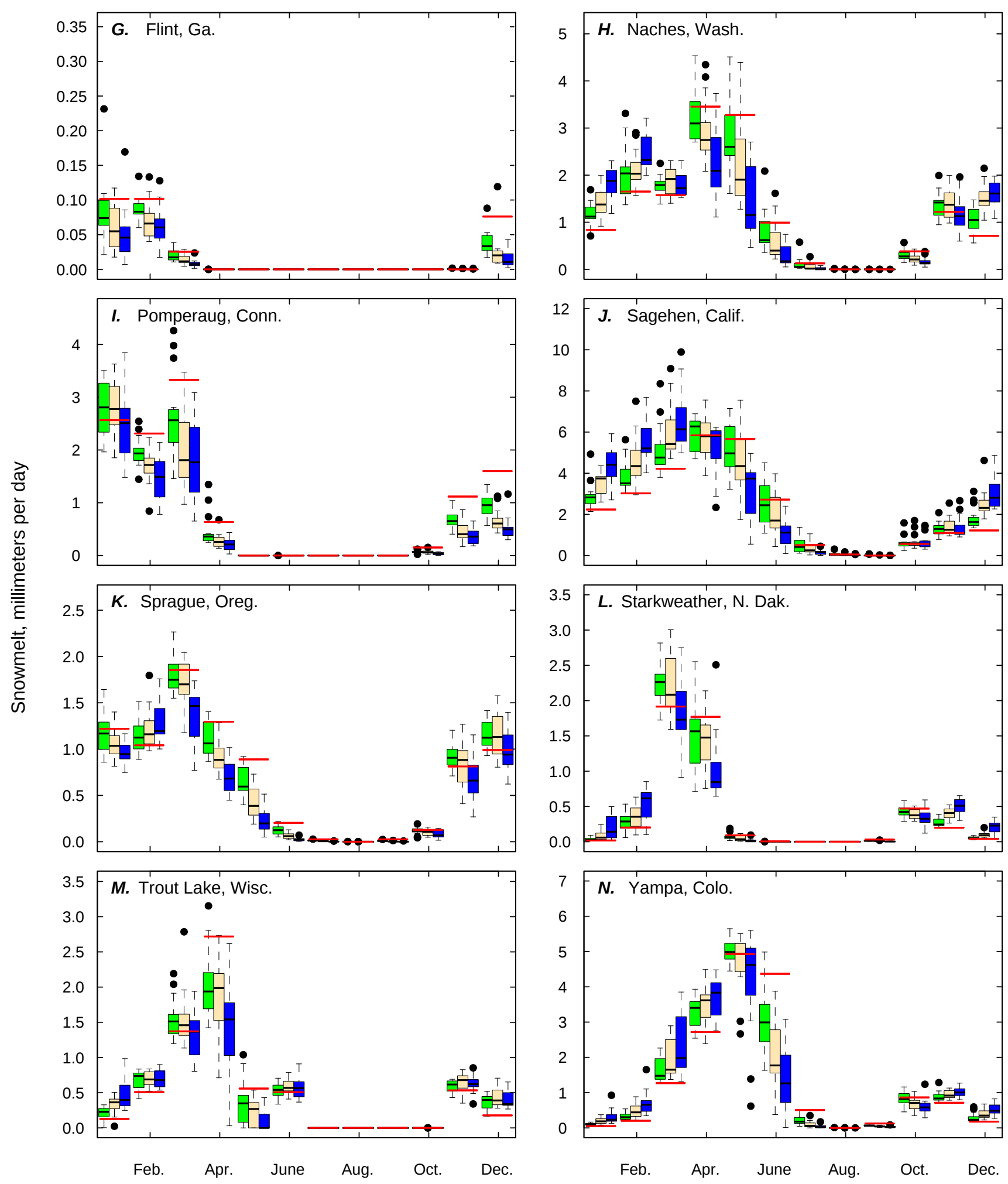

Month

Figure 40. Mean daily snowmelt values by month for baseline conditions and projected range $(2030,2060$, and 2090) using the 5 general circulation models and 3 emission scenarios for the 14 basins.-Continued 

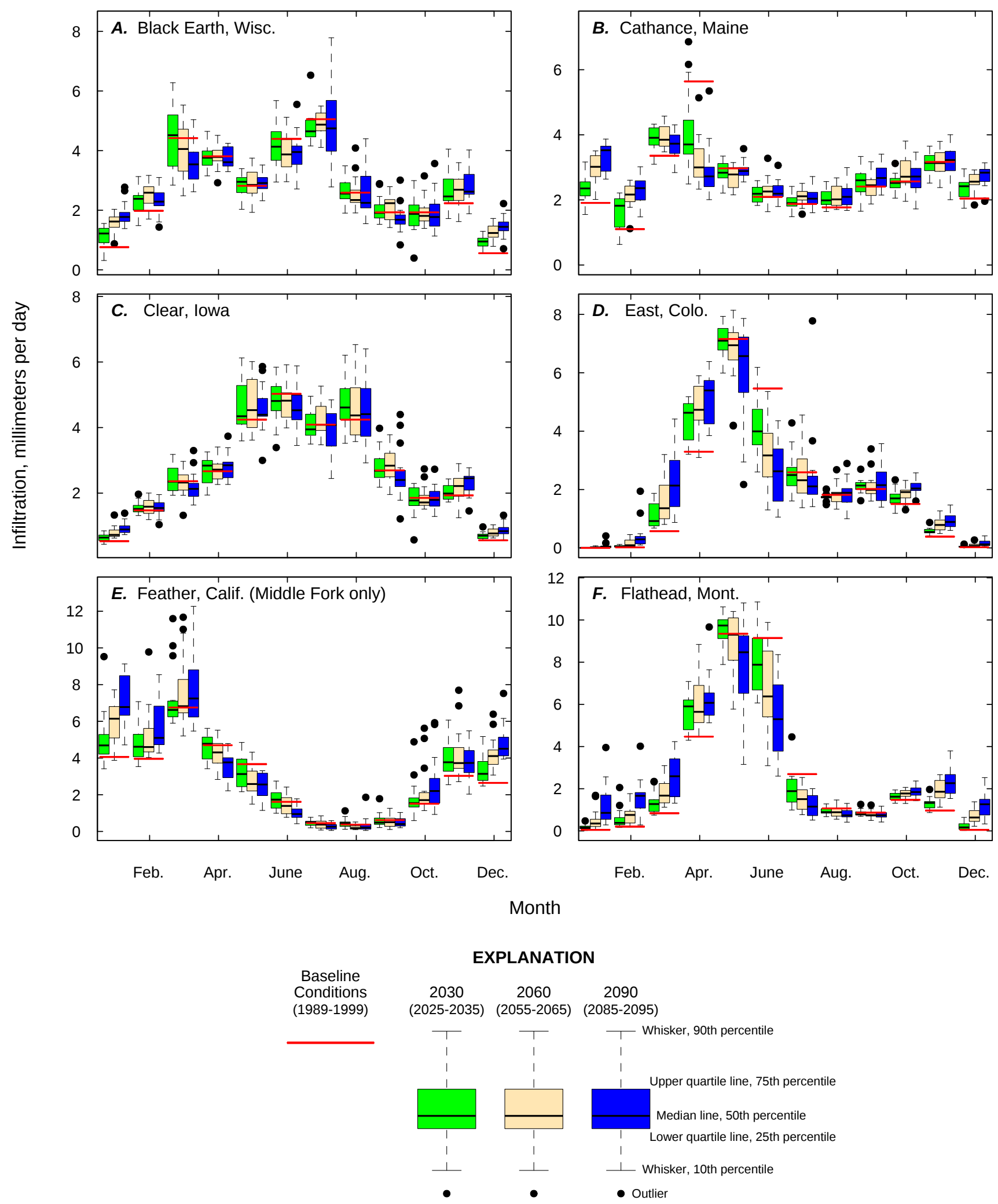

Figure 41. Mean daily infiltration values by month for baseline conditions and projected range $(2030,2060$, and 2090) using the 5 general circulation models and 3 emission scenarios for the 14 basins. 

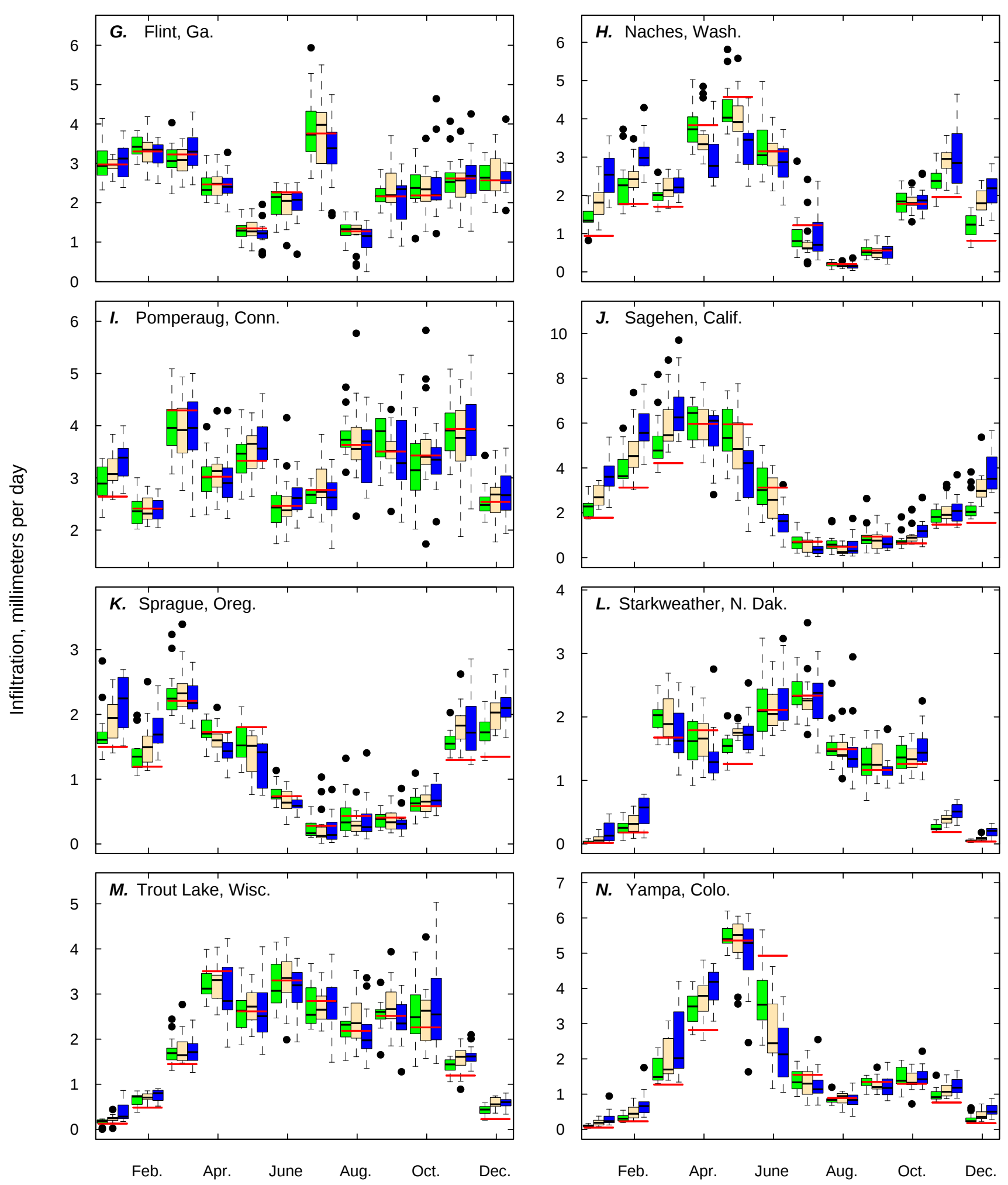

Month

Figure 41. Mean daily infiltration values by month for baseline conditions and projected range $(2030,2060$, and 2090) using the 5 general circulation models and 3 emission scenarios for the 14 basins.-Continued 

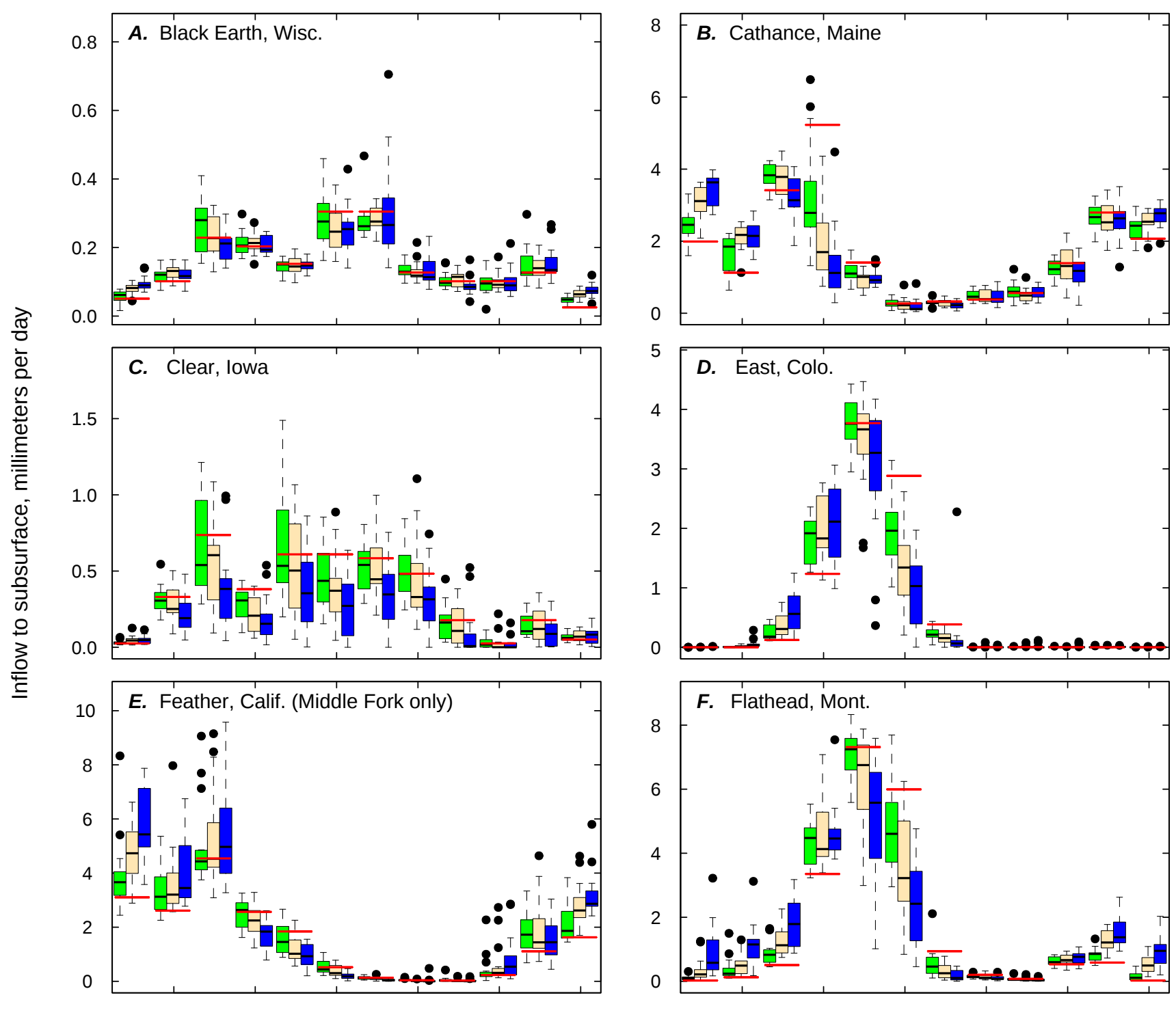

Feb. Apr. June Aug. Oct. Dec.

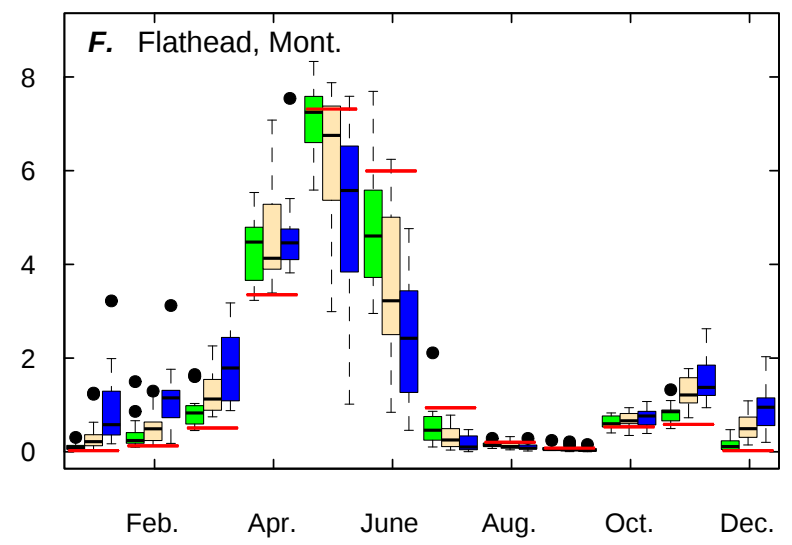

Month

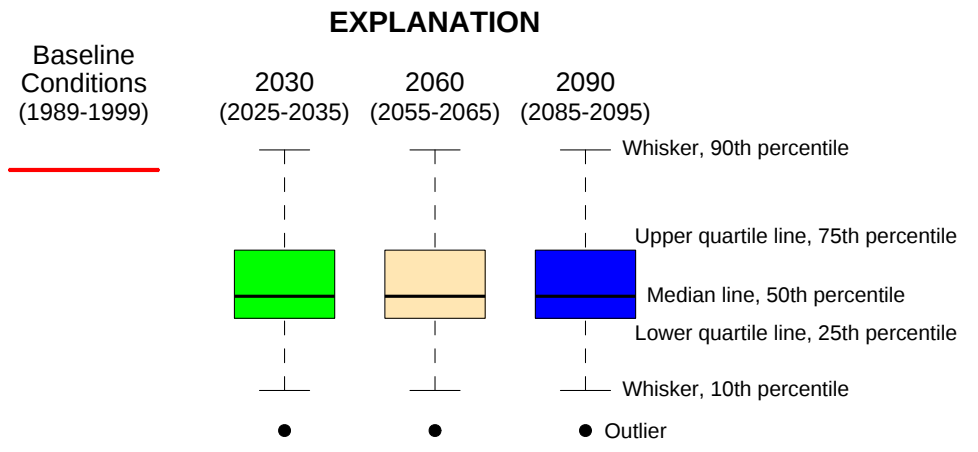

Figure 42. Mean daily subsurface reservoir inflow values by month for baseline conditions and projected range (2030, 2060, and 2090) using the 5 general circulation models and 3 emission scenarios for the 14 basins. 

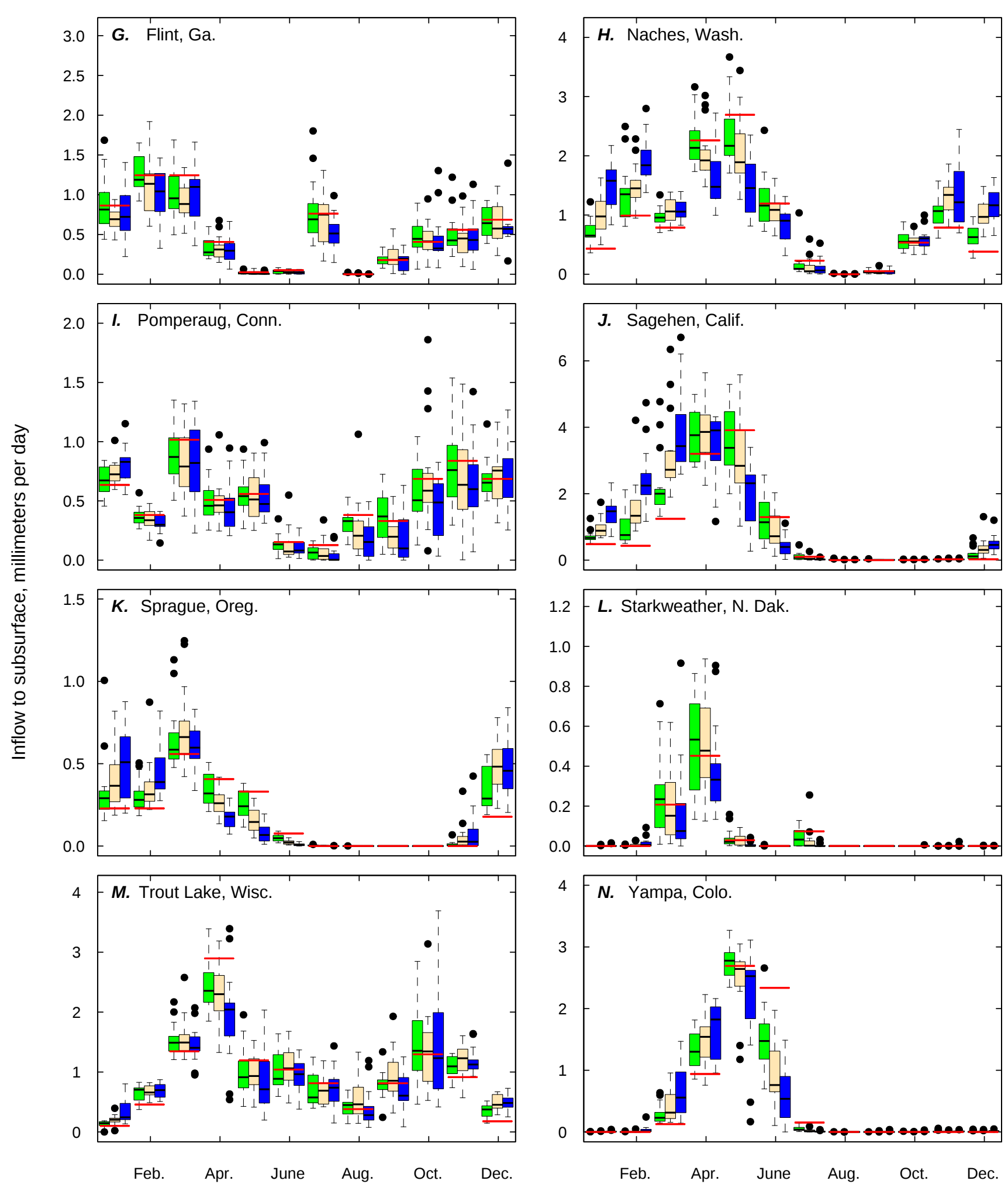

Month

Figure 42. Mean daily subsurface reservoir inflow values by month for baseline conditions and projected range (2030, 2060, and 2090) using the 5 general circulation models and 3 emission scenarios for the 14 basins.-Continued 

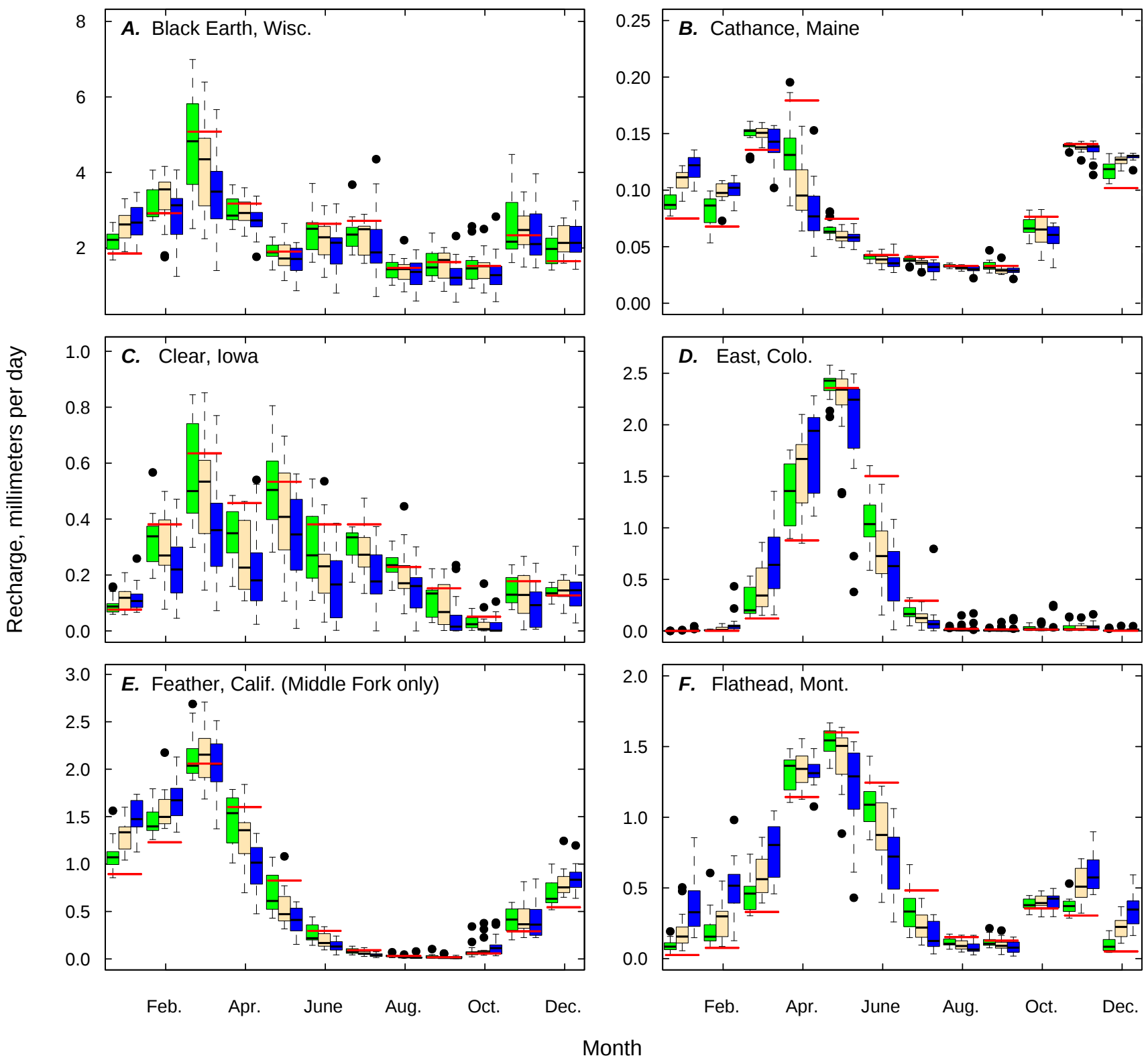

Month

EXPLANATION

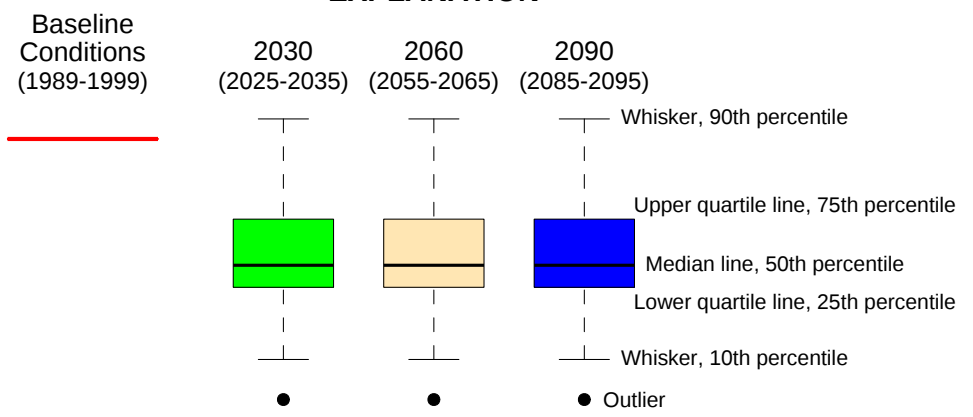

Figure 43. Mean daily groundwater reservoir recharge values by month for baseline conditions and projected range (2030, 2060, and 2090) using the 5 general circulation models and 3 emission scenarios for the 14 basins. 

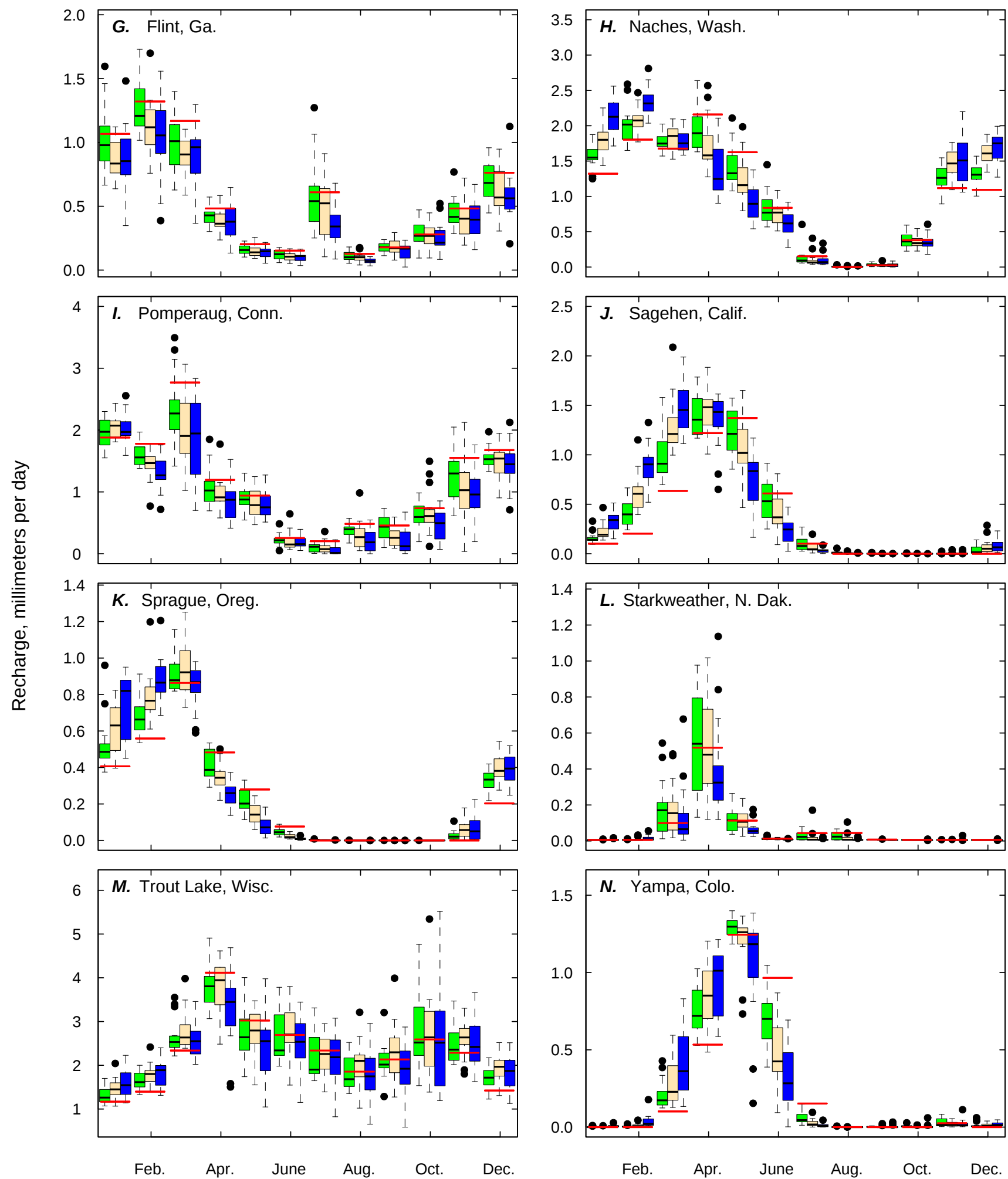

Month

Figure 43. Mean daily groundwater reservoir recharge values by month for baseline conditions and projected range (2030, 2060, and 2090) using the 5 general circulation models and 3 emission scenarios for the 14 basins.-Continued 

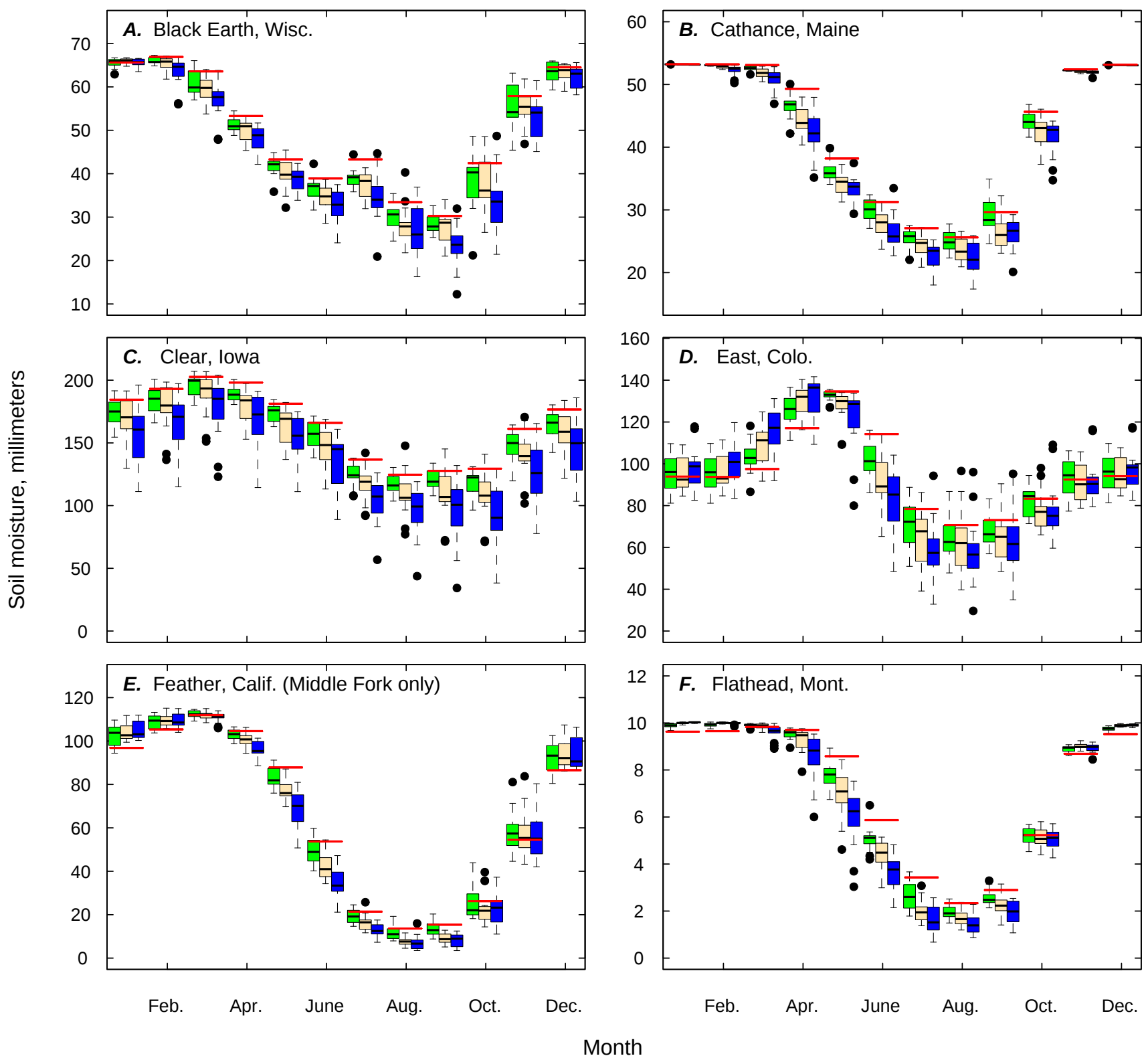

Month

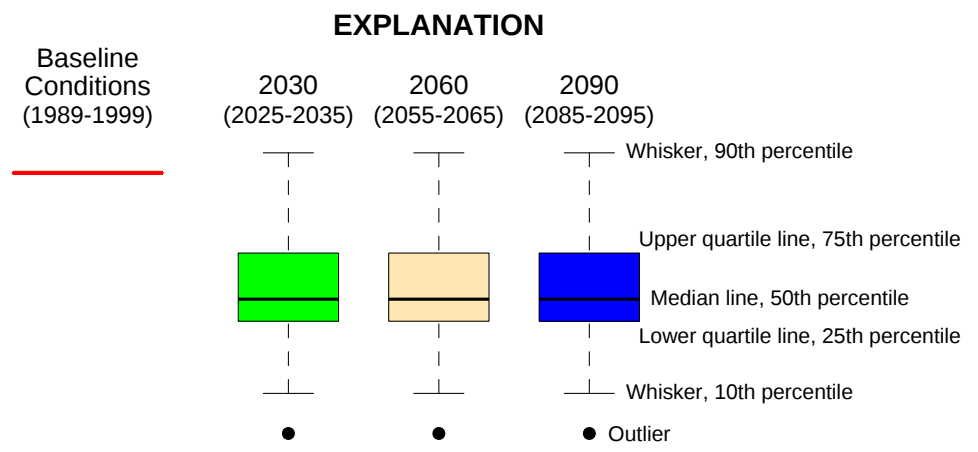

Figure 44. Mean daily soil moisture storage values by month for baseline conditions and projected range (2030, 2060, and 2090) using the 5 general circulation models and 3 emission scenarios for the 14 basins. 

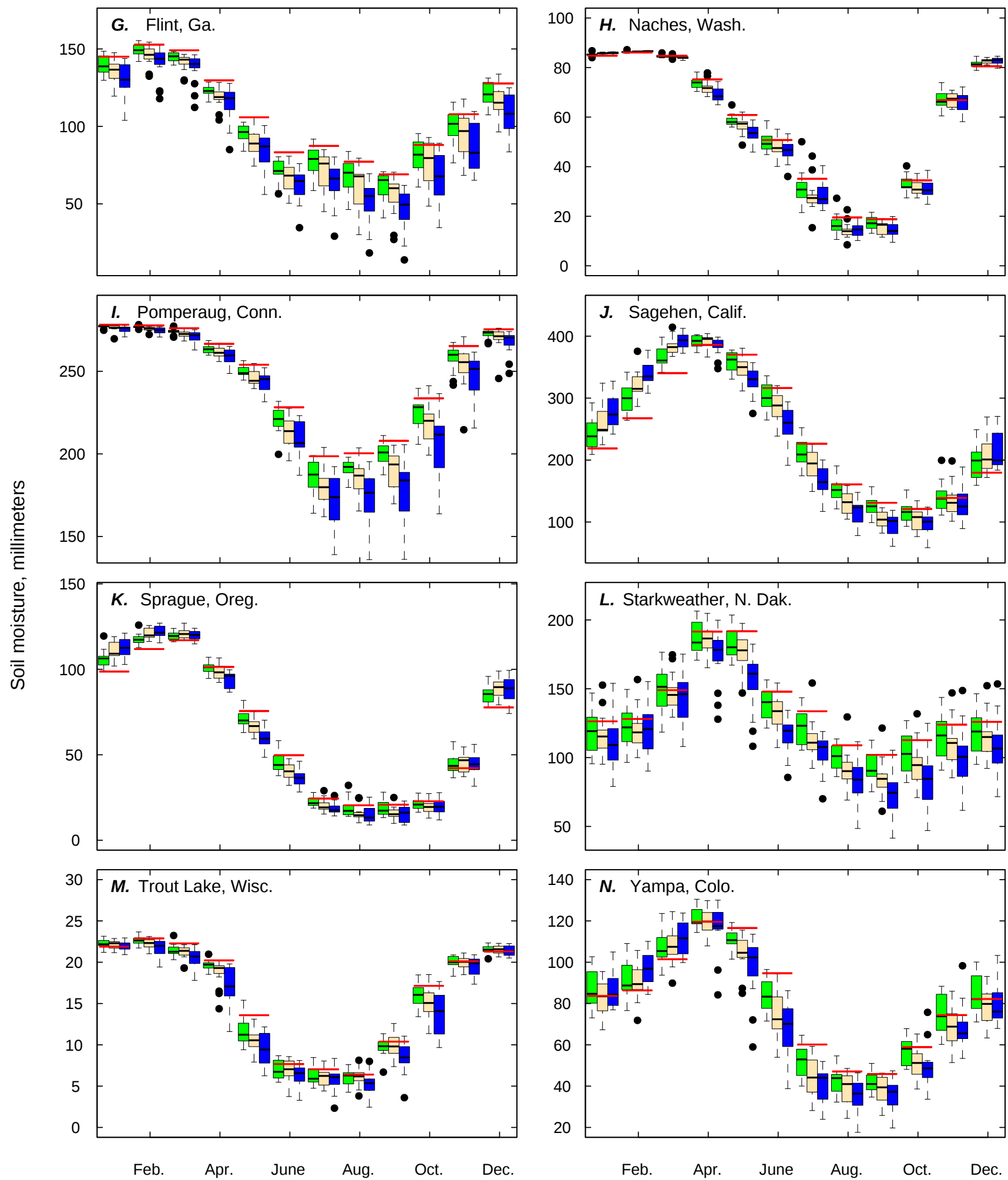

Month

Figure 44. Mean daily soil moisture storage values by month for baseline conditions and projected range (2030, 2060, and 2090) using the 5 general circulation models and 3 emission scenarios for the 14 basins.-Continued 

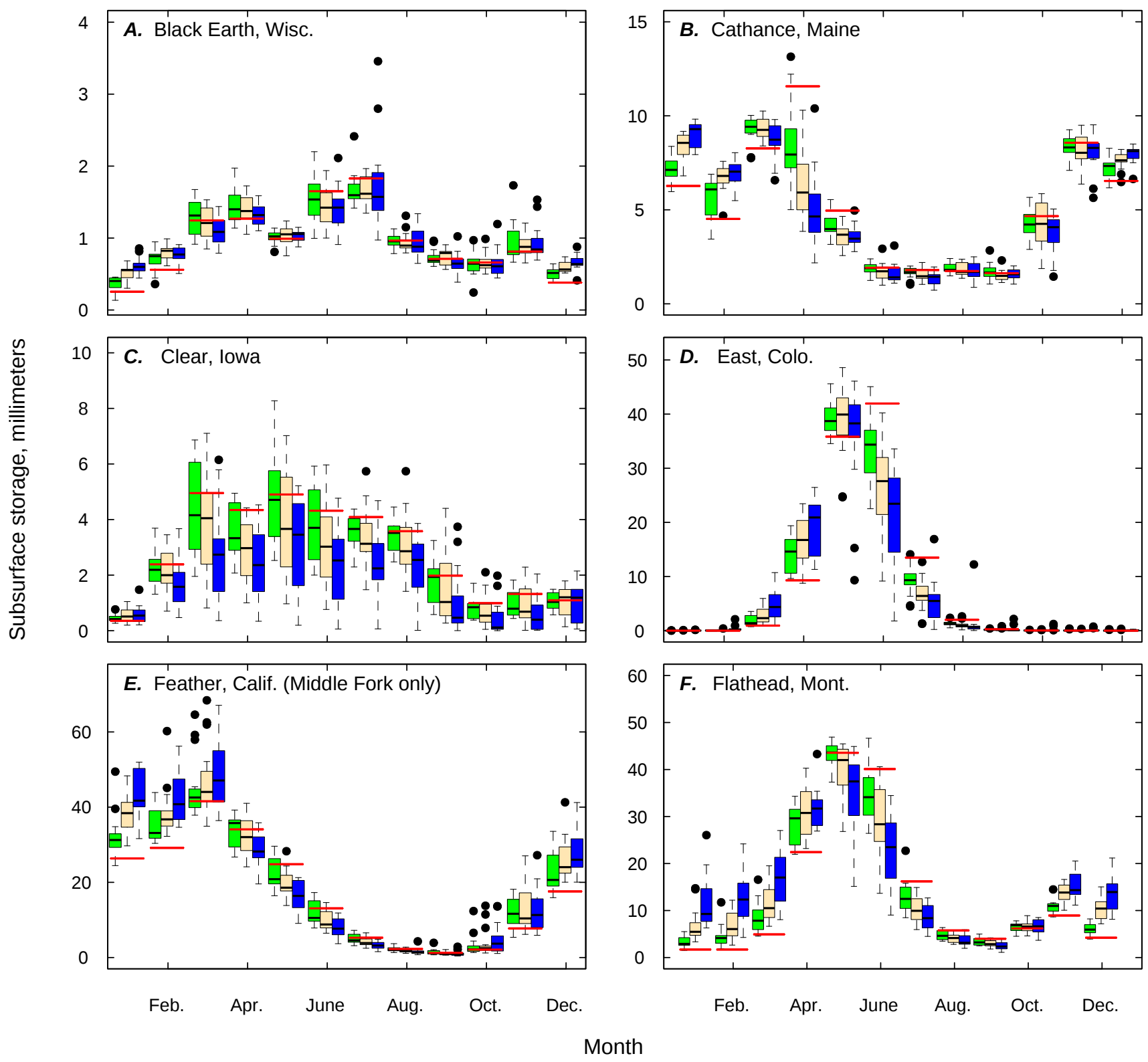

EXPLANATION
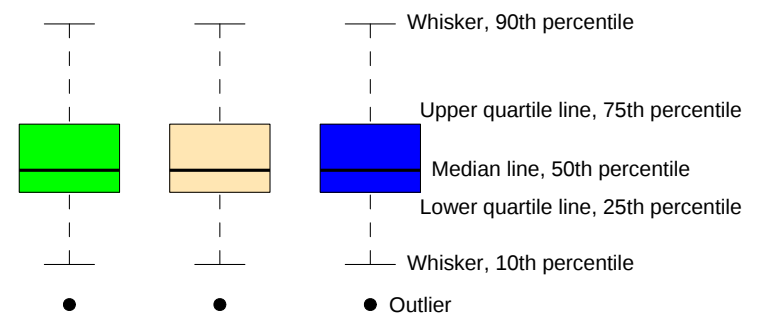

Figure 45. Mean daily subsurface reservoir storage values by month for baseline conditions and projected range (2030, 2060, and 2090) using the 5 general circulation models and 3 emission scenarios for the 14 basins. 


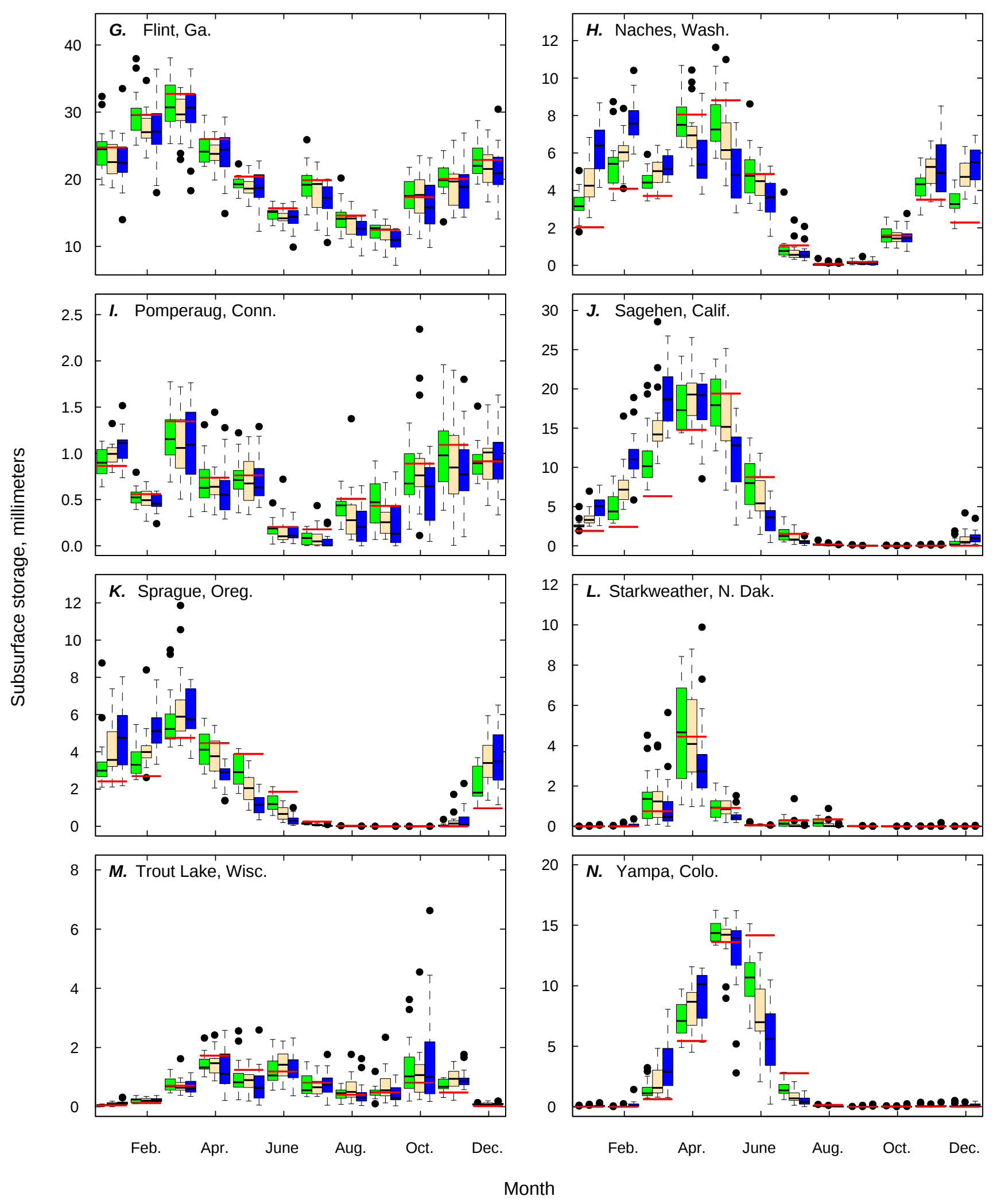

Figure 45. Mean daily subsurface reservoir storage values by month for baseline conditions and projected range (2030, 2060, and 2090) using the 5 general circulation models and 3 emission scenarios for the 14 basins. - Continued 

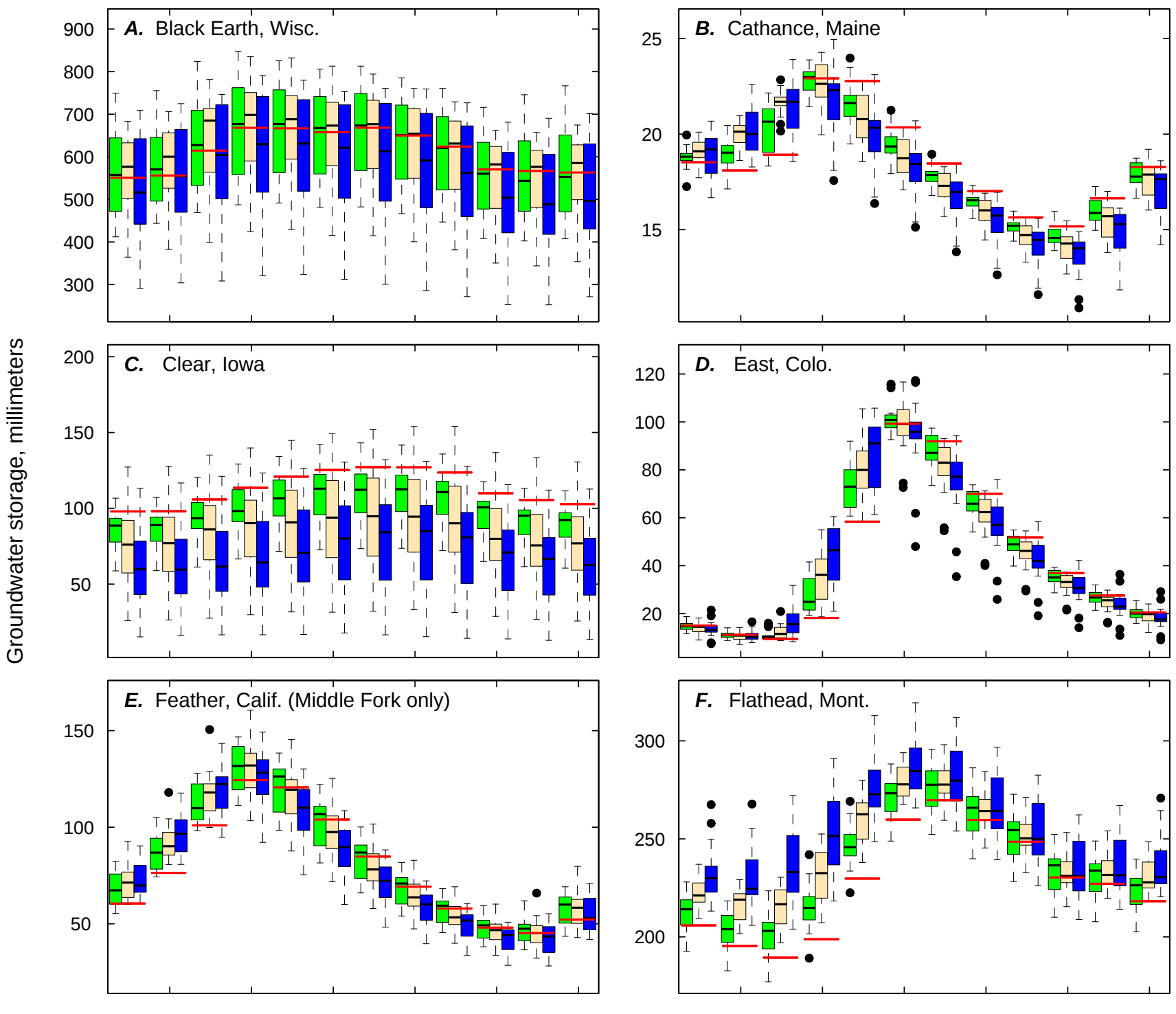

Feb. Apr. June Aug. Oct. Dec.

Feb. Apr. June Aug. Oct. Dec.

Month

EXPLANATION

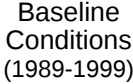

$\begin{array}{ccc}2030 & 2060 & 2090 \\ (2025-2035) & (2055-2065) & (2085-2095)\end{array}$
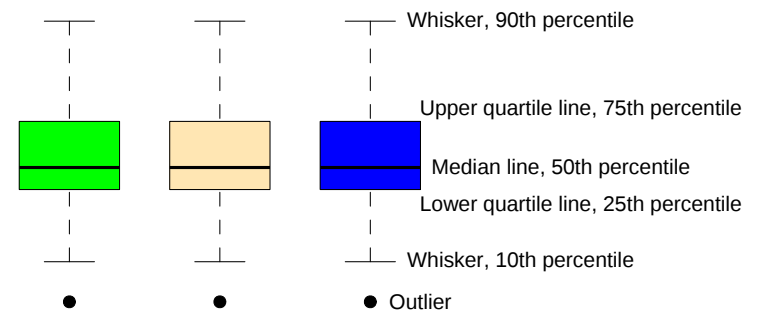

Figure 46. Mean daily groundwater reservoir storage values by month for baseline conditions and projected range (2030, 2060, and 2090) using the 5 general circulation models and 3 emission scenarios for the 14 basins. 

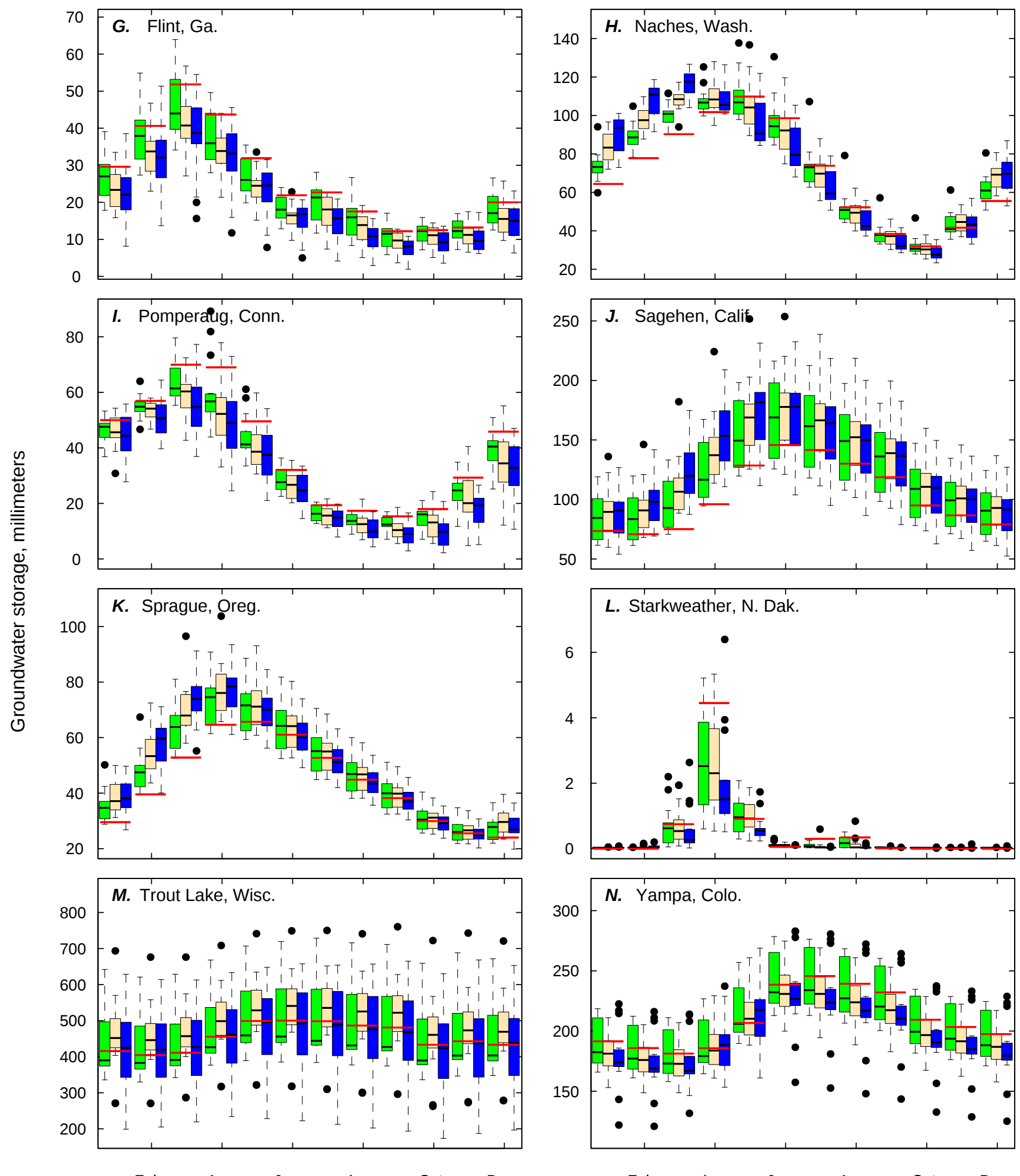

Feb. Apr. June Aug. Oct. Dec.

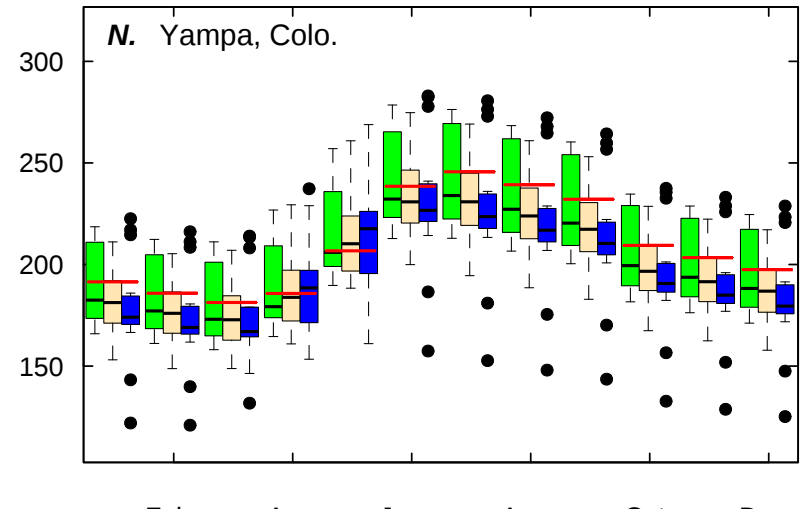

Month

Figure 46. Mean daily groundwater reservoir storage values by month for baseline conditions and projected range (2030, 2060, and 2090) using the 5 general circulation models and 3 emission scenarios for the 14 basins. - Continued 

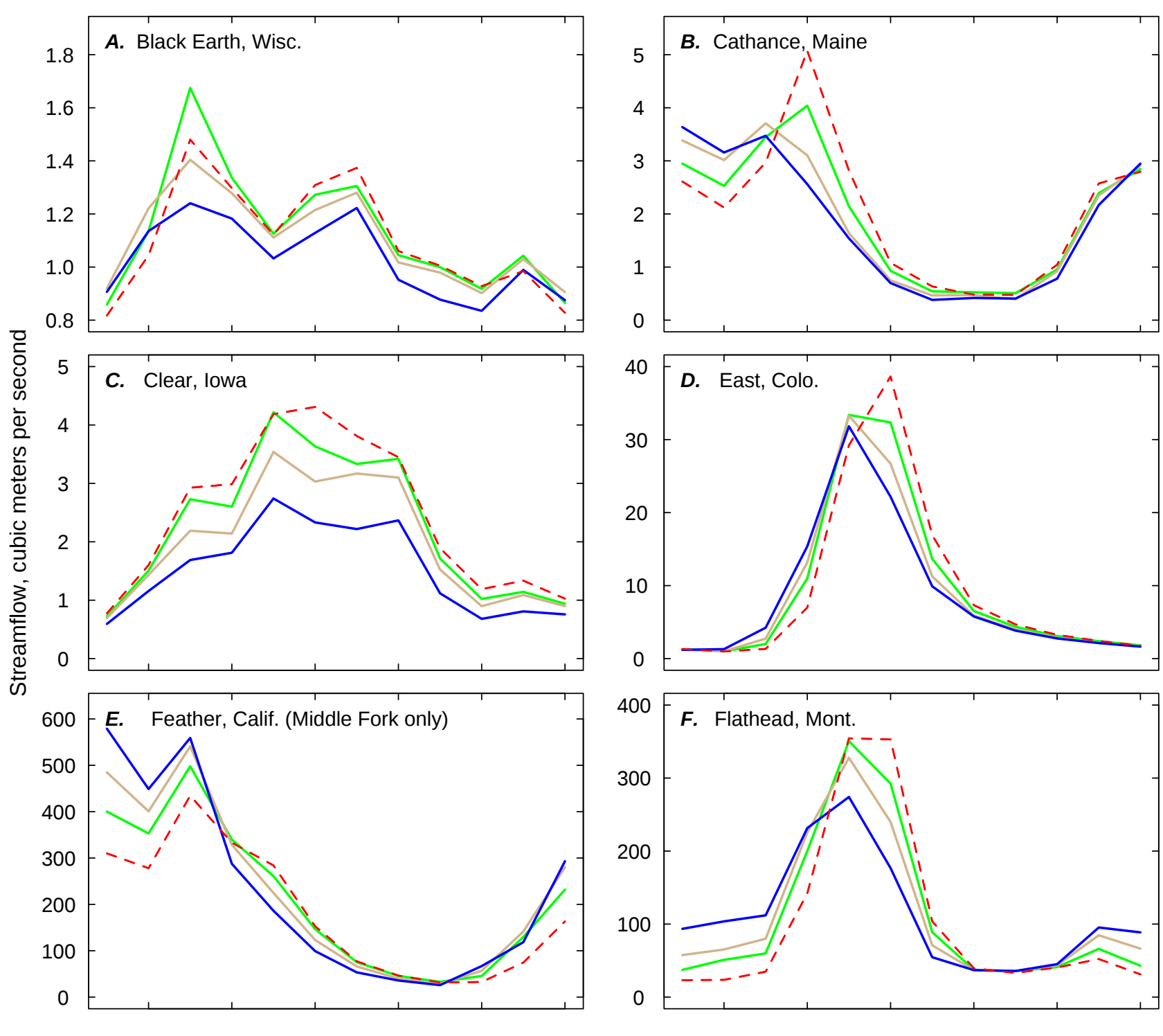

Feb. Apr. June Aug. Oct. Dec.

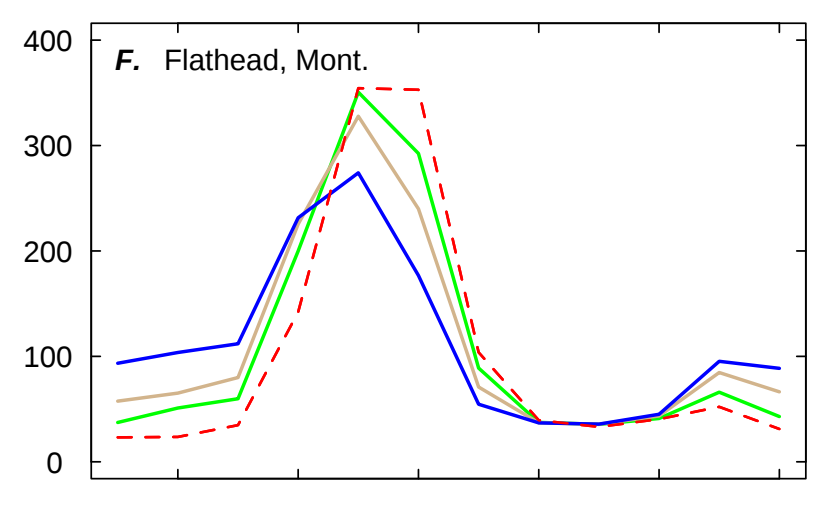

Month

EXPLANATION

- - Baseline Conditions (1989-1999)

— $2030(2025-2035)$

- $2060(2055-2065)$

- $2090(2085-2095)$

Figure 47. Mean monthly hydrographs for baseline conditions and projected conditions (2030, 2060, and 2090) using 5 general circulation models and 3 emission scenarios for the 14 basins. 

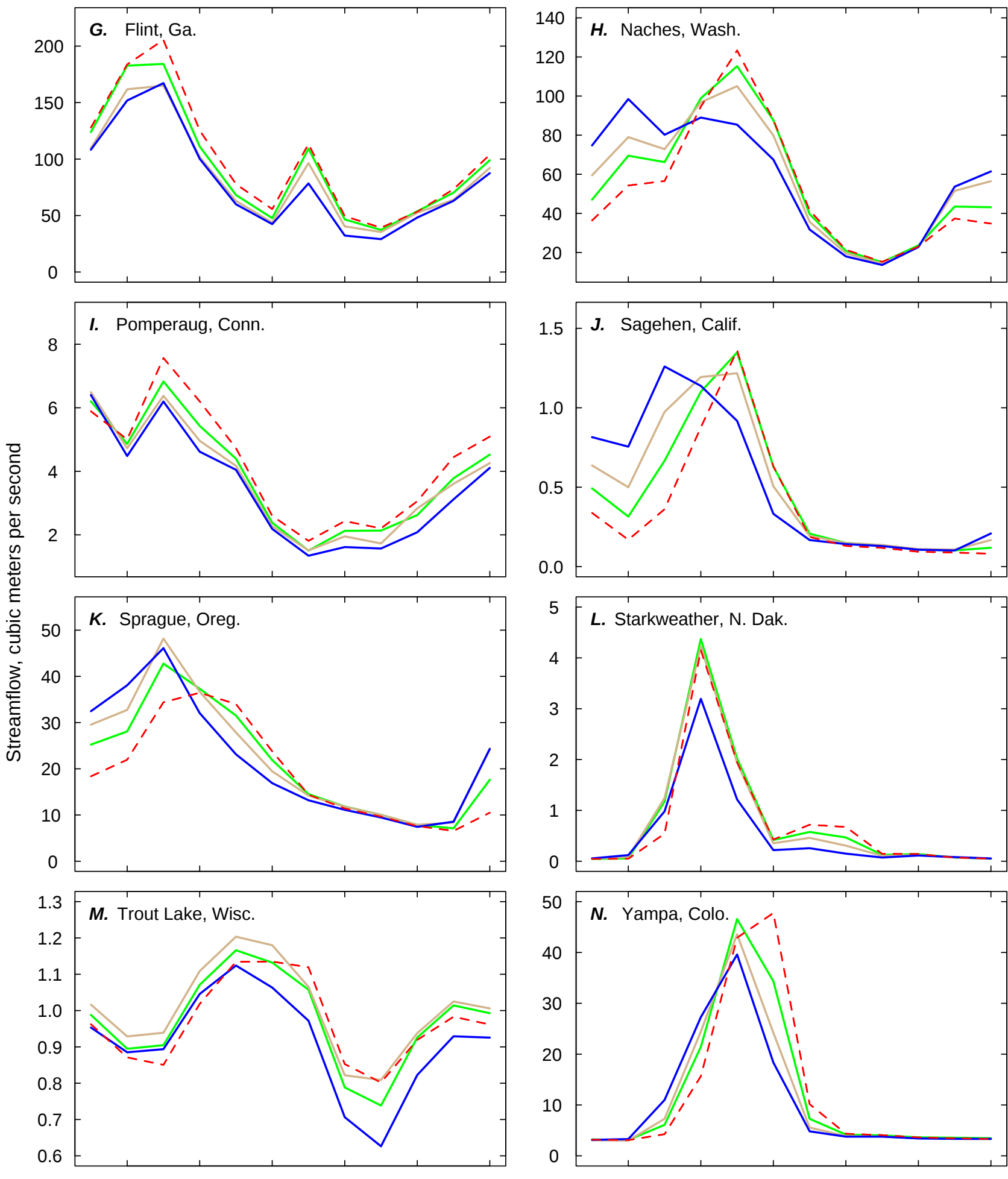

Feb. Apr. June Aug. Oct. Dec.
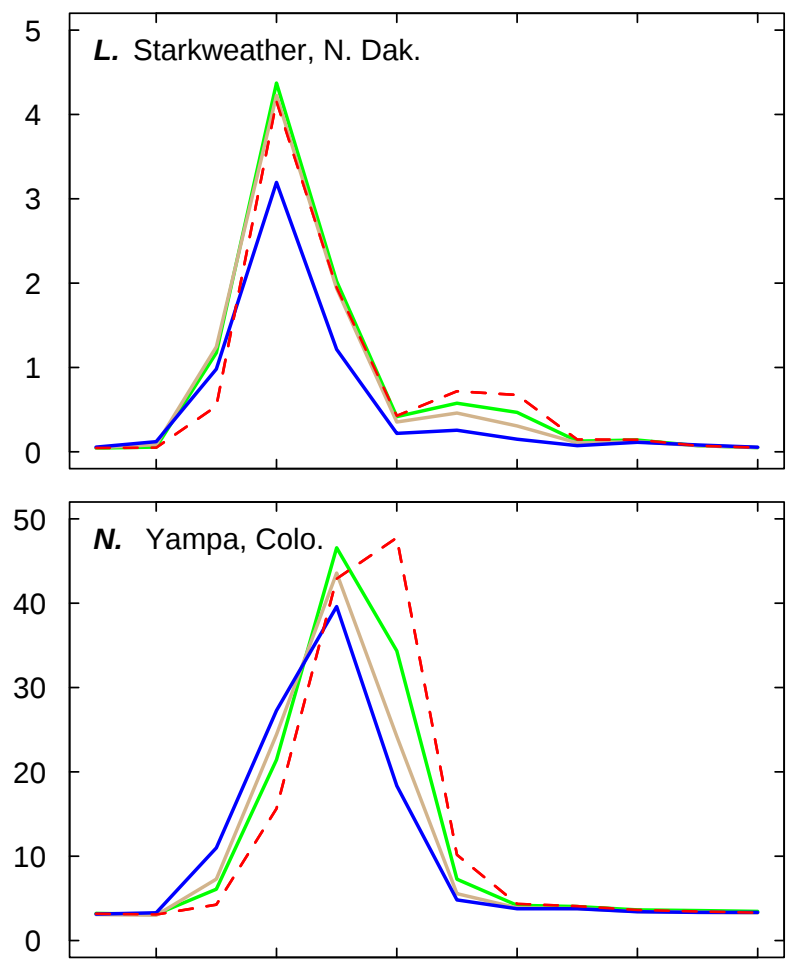

Feb. Apr. June Aug. Oct. Dec.

Figure 47. Mean monthly hydrographs for baseline conditions and projected conditions (2030, 2060, and 2090) using 5 general circulation models and 3 emission scenarios for the 14 basins.-Continued 
Table 5. Projected change by year (slope) and adjusted $R^{2}\left(R_{a}^{2}\right)$ based on the central tendencies of the five General Circulation Models for the three carbon emission scenarios by basin for selected Precipitation Runoff Modeling System output variables.

[Blue shading indicates a significant negative trend and red shading indicates a significant positive trend $(\mathrm{p}<0.05)$ accounting for lag- 1 autocorrelation]

\begin{tabular}{|c|c|c|c|c|c|c|}
\hline \multirow{3}{*}{ Basin } & \multicolumn{6}{|c|}{ A) Precipitation (millimeters): Area-weighted adjusted precipitation for basin } \\
\hline & \multicolumn{2}{|c|}{ Emission scenario A1B } & \multicolumn{2}{|c|}{ Emission scenario A2 } & \multicolumn{2}{|c|}{ Emission scenario B1 } \\
\hline & slope & $\mathbf{R}_{\mathrm{a}}^{2}$ & slope & $\mathbf{R}_{\mathrm{a}}^{2}$ & slope & $\mathbf{R}^{2}{ }_{a}$ \\
\hline Black Earth & 0.0009 & 0.21 & -0.0007 & 0.06 & -0.0003 & 0.00 \\
\hline Cathance & 0.0019 & 0.56 & 0.0019 & 0.58 & 0.0016 & 0.40 \\
\hline Clear & 0.0008 & 0.14 & -0.0018 & 0.25 & 0.0006 & 0.02 \\
\hline East & 0.0013 & 0.50 & -0.0007 & 0.11 & 0.0011 & 0.31 \\
\hline Feather & 0.0021 & 0.38 & 0.0018 & 0.04 & 0.0003 & -0.01 \\
\hline Flathead & 0.0040 & 0.87 & 0.0049 & 0.69 & 0.0022 & 0.51 \\
\hline Flint & -0.0014 & 0.35 & -0.0047 & 0.72 & 0.0008 & 0.04 \\
\hline Naches & 0.0018 & 0.49 & 0.0029 & 0.77 & 0.0002 & 0.00 \\
\hline Pomperaug & 0.0019 & 0.38 & 0.0002 & -0.00 & 0.0024 & 0.57 \\
\hline Sagehen & 0.0031 & 0.60 & 0.0033 & 0.16 & 0.0009 & 0.03 \\
\hline Sprague & 0.0009 & 0.51 & 0.0015 & 0.43 & 0.0005 & 0.10 \\
\hline Starkweather & -0.0006 & 0.11 & 0.0004 & 0.08 & 0.0000 & -0.01 \\
\hline Trout Lake & 0.0004 & 0.02 & 0.0008 & 0.20 & 0.0007 & 0.05 \\
\hline Yampa & 0.0011 & 0.56 & -0.0001 & -0.01 & 0.0004 & 0.10 \\
\hline
\end{tabular}

(B) Maximum temperature (degrees celsius): Basin area-weighted daily maximum temperature

\begin{tabular}{|c|c|c|c|c|c|c|}
\hline \multirow{2}{*}{ Basin } & \multicolumn{2}{|c|}{ Emission scenario A1B } & \multicolumn{2}{|c|}{ Emission scenario A2 } & \multicolumn{2}{|c|}{ Emission scenario B1 } \\
\hline & slope & $\mathbf{R}_{\mathrm{a}}^{2}$ & slope & $\mathbf{R}_{\mathrm{a}}^{2}$ & slope & $\mathbf{R}_{\mathrm{a}}^{2}$ \\
\hline Black Earth & 0.040 & 1.00 & 0.049 & 0.99 & 0.024 & 0.97 \\
\hline Cathance & 0.033 & 0.99 & 0.038 & 0.98 & 0.018 & 0.98 \\
\hline Clear & 0.041 & 0.99 & 0.051 & 0.99 & 0.023 & 0.96 \\
\hline East & 0.037 & 0.99 & 0.049 & 0.99 & 0.022 & 0.95 \\
\hline Feather & 0.030 & 0.98 & 0.038 & 0.99 & 0.023 & 0.98 \\
\hline Flathead & 0.031 & 0.98 & 0.040 & 0.99 & 0.024 & 0.98 \\
\hline Flint & 0.034 & 0.99 & 0.043 & 0.98 & 0.018 & 0.95 \\
\hline Naches & 0.028 & 0.97 & 0.033 & 0.97 & 0.023 & 0.99 \\
\hline Pomperaug & 0.032 & 1.00 & 0.039 & 0.99 & 0.017 & 0.99 \\
\hline Sagehen & 0.031 & 0.98 & 0.040 & 0.98 & 0.024 & 0.98 \\
\hline Sprague & 0.030 & 0.97 & 0.037 & 0.98 & 0.024 & 0.99 \\
\hline Starkweather & 0.040 & 0.99 & 0.046 & 0.98 & 0.026 & 0.96 \\
\hline Trout Lake & 0.039 & 0.99 & 0.047 & 0.99 & 0.023 & 0.97 \\
\hline Yampa & 0.035 & 0.99 & 0.047 & 0.99 & 0.023 & 0.97 \\
\hline
\end{tabular}

(C) Minimum temperature (degrees celsius): Basin area-weighted daily minimum temperature

\begin{tabular}{|c|c|c|c|c|c|c|}
\hline \multirow{2}{*}{ Basin } & \multicolumn{2}{|c|}{ Emission scenario A1B } & \multicolumn{2}{|c|}{ Emission scenario A2 } & \multicolumn{2}{|c|}{ Emission scenario B1 } \\
\hline & slope & $\mathbf{R}_{\mathrm{a}}^{2}$ & slope & $\mathbf{R}_{\mathrm{a}}^{2}$ & slope & $\mathbf{R}^{2}$ \\
\hline Black Earth & 0.04 & 1.00 & 0.048 & 0.99 & 0.024 & 0.97 \\
\hline Cathance & 0.035 & 0.99 & 0.041 & 0.98 & 0.020 & 0.98 \\
\hline Clear & 0.039 & 0.99 & 0.046 & 0.99 & 0.022 & 0.96 \\
\hline East & 0.03 & 0.98 & 0.040 & 0.98 & 0.022 & 0.98 \\
\hline
\end{tabular}


Table 5. Projected change by year (slope) and adjusted $R^{2}\left(R_{a}^{2}\right)$ based on the central tendencies of the five General Circulation Models for the three carbon emission scenarios by basin for selected Precipitation Runoff Modeling System output variables. - Continued

[Blue shading indicates a significant negative trend and red shading indicates a significant positive trend $(\mathrm{p}<0.05)$ accounting for lag-1 autocorrelation]

\begin{tabular}{|c|c|c|c|c|c|c|}
\hline \multicolumn{7}{|c|}{ (C) Minimum temperature (degrees celsius): Basin area-weighted daily minimum temperature-Continued } \\
\hline \multirow{2}{*}{ Basin } & \multicolumn{2}{|c|}{ Emission scenario A1B } & \multicolumn{2}{|c|}{ Emission scenario A2 } & \multicolumn{2}{|c|}{ Emission scenario B1 } \\
\hline & slope & $\mathbf{R}_{a}^{2}$ & slope & $\mathbf{R}_{\mathrm{a}}^{2}$ & slope & $\mathbf{R}_{\mathrm{a}}^{2}$ \\
\hline Feather & 0.030 & 0.99 & 0.036 & 0.98 & 0.022 & 0.99 \\
\hline Flathead & 0.033 & 0.99 & 0.040 & 0.98 & 0.024 & 0.98 \\
\hline Flint & 0.030 & 1.00 & 0.034 & 0.98 & 0.017 & 0.99 \\
\hline Naches & 0.029 & 0.98 & 0.034 & 0.98 & 0.021 & 0.99 \\
\hline Pomperaug & 0.034 & 1.00 & 0.040 & 0.99 & 0.019 & 0.99 \\
\hline Sagehen & 0.031 & 0.99 & 0.037 & 0.98 & 0.023 & 0.99 \\
\hline Sprague & 0.030 & 0.99 & 0.036 & 0.98 & 0.022 & 0.99 \\
\hline Starkweather & 0.042 & 0.99 & 0.049 & 0.98 & 0.028 & 0.97 \\
\hline Trout Lake & 0.041 & 1.00 & 0.048 & 0.99 & 0.026 & 0.97 \\
\hline Yampa & 0.033 & 0.99 & 0.042 & 0.99 & 0.022 & 0.98 \\
\hline
\end{tabular}

\begin{tabular}{|c|c|c|c|c|c|c|}
\hline \multicolumn{7}{|c|}{ (D) Actual evapotranspiration (millimeters): Evapotranspiration on basin } \\
\hline \multirow{2}{*}{ Basin } & \multicolumn{2}{|c|}{ Emission scenario A1B } & \multicolumn{2}{|c|}{ Emission scenario A2 } & \multicolumn{2}{|c|}{ Emission scenario B1 } \\
\hline & slope & $\mathbf{R}^{2}$ & slope & $\mathbf{R}_{\mathrm{a}}^{2}$ & slope & $\mathbf{R}_{\mathrm{a}}^{2}$ \\
\hline Black Earth & 0.0027 & 0.92 & 0.0029 & 0.93 & 0.0018 & 0.69 \\
\hline Cathance & 0.0049 & 0.99 & 0.0058 & 0.98 & 0.0029 & 0.98 \\
\hline Clear & 0.0044 & 0.97 & 0.0042 & 0.94 & 0.0029 & 0.89 \\
\hline East & 0.0031 & 0.98 & 0.0034 & 0.91 & 0.0025 & 0.92 \\
\hline Feather & 0.0012 & 0.91 & 0.0013 & 0.76 & 0.0010 & 0.69 \\
\hline Flathead & 0.0028 & 0.97 & 0.0035 & 0.94 & 0.0023 & 0.94 \\
\hline Flint & 0.0013 & 0.75 & 0.0008 & 0.54 & 0.0012 & 0.70 \\
\hline Naches & 0.0005 & 0.38 & 0.0010 & 0.77 & 0.0006 & 0.61 \\
\hline Pomperaug & 0.0045 & 0.99 & 0.0053 & 0.99 & 0.0029 & 0.99 \\
\hline Sagehen & 0.0020 & 0.94 & 0.0021 & 0.84 & 0.0013 & 0.82 \\
\hline Sprague & 0.0007 & 0.58 & 0.0011 & 0.65 & 0.0007 & 0.49 \\
\hline Starkweather & 0.0012 & 0.75 & 0.0018 & 0.88 & 0.001 & 0.66 \\
\hline Trout Lake & 0.0018 & 0.93 & 0.0021 & 0.95 & 0.0013 & 0.82 \\
\hline Yampa & 0.0024 & 0.97 & 0.0026 & 0.91 & 0.0017 & 0.96 \\
\hline \multicolumn{7}{|c|}{ (E) Growing season (days): Length of growing season } \\
\hline \multirow{2}{*}{ Basin } & \multicolumn{2}{|c|}{ Emission scenario A1B } & \multicolumn{2}{|c|}{ Emission scenario A2 } & \multicolumn{2}{|c|}{ Emission scenario B1 } \\
\hline & slope & $\mathbf{R}^{2}$ & slope & $\mathbf{R}_{a}^{2}$ & slope & $\mathbf{R}^{2}$ \\
\hline Black Earth & 0.3057 & 0.97 & 0.3536 & 0.98 & 0.1747 & 0.96 \\
\hline Cathance & 0.3569 & 0.99 & 0.4008 & 0.97 & 0.2148 & 0.97 \\
\hline Clear & 0.3095 & 0.99 & 0.3546 & 0.98 & 0.1597 & 0.95 \\
\hline East & 0.5515 & 0.97 & 0.5849 & 0.99 & 0.3173 & 0.97 \\
\hline Feather & 0.6285 & 0.98 & 0.7145 & 0.99 & 0.4385 & 0.99 \\
\hline Flathead & 0.4506 & 0.98 & 0.5746 & 0.98 & 0.3720 & 0.97 \\
\hline Flint & 0.3221 & 0.97 & 0.3207 & 0.95 & 0.1359 & 0.85 \\
\hline Naches & 0.4343 & 0.99 & 0.5173 & 0.98 & 0.2974 & 0.99 \\
\hline
\end{tabular}


Table 5. Projected change by year (slope) and adjusted $R^{2}\left(R^{2}\right)$ based on the central tendencies of the five General Circulation Models for the three carbon emission scenarios by basin for selected Precipitation Runoff Modeling System output variables.-Continued

[Blue shading indicates a significant negative trend and red shading indicates a significant positive trend $(\mathrm{p}<0.05)$ accounting for lag- 1 autocorrelation]

\begin{tabular}{|c|c|c|c|c|c|c|}
\hline \multicolumn{7}{|c|}{ (E) Growing season (days): Length of growing season-Continued } \\
\hline \multirow{2}{*}{ Basin } & \multicolumn{2}{|c|}{ Emission scenario A1B } & \multicolumn{2}{|c|}{ Emission scenario A2 } & \multicolumn{2}{|c|}{ Emission scenario B1 } \\
\hline & slope & $\mathbf{R}^{2}$ & slope & $\mathbf{R}^{2}$ & slope & $\mathbf{R}^{2}$ \\
\hline Pomperaug & 0.4049 & 0.97 & 0.4248 & 0.99 & 0.2300 & 0.98 \\
\hline Sagehen & 0.7947 & 0.95 & 0.8562 & 0.99 & 0.5801 & 0.98 \\
\hline Sprague & 0.6852 & 0.96 & 0.7669 & 0.99 & 0.5400 & 0.98 \\
\hline Starkweather & 0.2533 & 0.99 & 0.3093 & 0.98 & 0.1780 & 0.97 \\
\hline Trout Lake & 0.3995 & 0.98 & 0.4699 & 0.98 & 0.2378 & 0.94 \\
\hline Yampa & 0.4625 & 0.97 & 0.5116 & 1.00 & 0.2786 & 0.97 \\
\hline \multicolumn{7}{|c|}{ ( $F$ Streamflow (cubic meters per second): Streamflow from basin } \\
\hline \multirow{2}{*}{ Basin } & \multicolumn{2}{|c|}{ Emission scenario A1B } & \multicolumn{2}{|c|}{ Emission scenario A2 } & \multicolumn{2}{|c|}{ Emission scenario B1 } \\
\hline & slope & $\mathbf{R}^{2}$ & slope & $\mathbf{R}_{a}^{2}$ & slope & $\mathbf{R}^{2}$ \\
\hline Black Earth & -0.0014 & 0.59 & -0.0028 & 0.75 & -0.0016 & 0.49 \\
\hline Cathance & -0.0029 & 0.78 & -0.0038 & 0.84 & -0.0012 & 0.35 \\
\hline Clear & -0.0101 & 0.73 & -0.0169 & 0.86 & -0.0065 & 0.48 \\
\hline East & -0.0150 & 0.70 & -0.0347 & 0.91 & -0.0118 & 0.51 \\
\hline Feather & 0.1132 & 0.16 & 0.0820 & 0.00 & -0.0378 & -0.00 \\
\hline Flathead & 0.0547 & 0.41 & 0.0676 & 0.22 & -0.0010 & -0.01 \\
\hline Flint & -0.2162 & 0.76 & -0.4359 & 0.83 & -0.0373 & 0.02 \\
\hline Naches & 0.0561 & 0.59 & 0.0789 & 0.79 & -0.0023 & -0.01 \\
\hline Pomperaug & -0.0061 & 0.59 & -0.0116 & 0.82 & -0.0012 & 0.05 \\
\hline Sagehen & 0.0004 & 0.23 & 0.0005 & 0.04 & -0.0001 & -0.01 \\
\hline Sprague & 0.0107 & 0.15 & 0.0225 & 0.15 & -0.0128 & 0.10 \\
\hline Starkweather & -0.0056 & 0.66 & -0.0047 & 0.75 & -0.0031 & 0.37 \\
\hline Trout Lake & -0.0015 & 0.61 & -0.0014 & 0.74 & -0.0004 & 0.04 \\
\hline Yampa & -0.0205 & 0.77 & -0.0415 & 0.89 & -0.0211 & 0.67 \\
\hline
\end{tabular}

\begin{tabular}{|c|c|c|c|c|c|c|}
\hline \multirow{3}{*}{ Basin } & \multicolumn{6}{|c|}{ Surface runoff (cubic meters per second): Surface runoff from basin } \\
\hline & \multicolumn{2}{|c|}{ Emission scenario A1B } & \multicolumn{2}{|c|}{ Emission scenario A2 } & \multicolumn{2}{|c|}{ Emission scenario B1 } \\
\hline & slope & $\mathbf{R}_{a}^{2}$ & slope & $\mathbf{R}_{\mathrm{a}}^{2}$ & slope & $\mathbf{R}_{\mathrm{a}}^{2}$ \\
\hline Black Earth & -0.00186 & 0.29 & -0.00424 & 0.55 & -0.00260 & 0.38 \\
\hline Cathance & 0.00013 & 0.79 & 0.00014 & 0.78 & 0.00007 & 0.67 \\
\hline Clear & -0.00213 & 0.64 & -0.00396 & 0.79 & -0.00125 & 0.26 \\
\hline East & -0.00038 & 0.38 & -0.00120 & 0.84 & -0.00050 & 0.57 \\
\hline Feather & 0.00450 & 0.15 & 0.00810 & 0.07 & 0.00074 & -0.01 \\
\hline Flathead & 0.02048 & 0.87 & 0.02764 & 0.76 & 0.01043 & 0.73 \\
\hline Flint & -0.05164 & 0.73 & -0.11173 & 0.82 & -0.00588 & -0.00 \\
\hline Naches & 0.01745 & 0.91 & 0.02563 & 0.93 & 0.01146 & 0.91 \\
\hline Pomperaug & 0.00051 & 0.24 & -0.00030 & 0.08 & 0.00048 & 0.30 \\
\hline Sagehen & 0.00027 & 0.90 & 0.00044 & 0.66 & 0.00022 & 0.75 \\
\hline Sprague & 0.00182 & 0.83 & 0.00277 & 0.67 & 0.00099 & 0.38 \\
\hline Starkweather & -0.00141 & 0.73 & -0.00112 & 0.85 & -0.00084 & 0.47 \\
\hline
\end{tabular}


Table 5. Projected change by year (slope) and adjusted $R^{2}\left(R^{2}\right)$ based on the central tendencies of the five General Circulation Models for the three carbon emission scenarios by basin for selected Precipitation Runoff Modeling System output variables.-Continued

[Blue shading indicates a significant negative trend and red shading indicates a significant positive trend $(\mathrm{p}<0.05)$ accounting for lag-1 autocorrelation]

\begin{tabular}{|c|c|c|c|c|c|c|}
\hline \multirow{3}{*}{ Basin } & \multicolumn{6}{|c|}{ Surface runoff (cubic meters per second): Surface runoff from basin-Continued } \\
\hline & \multicolumn{2}{|c|}{ Emission scenario A1B } & \multicolumn{2}{|c|}{ Emission scenario A2 } & \multicolumn{2}{|c|}{ Emission scenario B1 } \\
\hline & slope & $\mathbf{R}_{\mathrm{a}}^{2}$ & slope & $\mathbf{R}_{\mathrm{a}}^{2}$ & slope & $\mathbf{R}_{\mathrm{a}}^{2}$ \\
\hline Trout Lake & 0.00004 & 0.37 & 0.00004 & 0.62 & 0.00003 & 0.15 \\
\hline Yampa & -0.00044 & 0.37 & -0.00118 & 0.68 & -0.00066 & 0.61 \\
\hline \multicolumn{7}{|c|}{ flow from } \\
\hline \multirow{2}{*}{ Basin } & \multicolumn{2}{|c|}{ Emission scenario A1B } & \multicolumn{2}{|c|}{ Emission scenario A2 } & \multicolumn{2}{|c|}{ Emission scenario B1 } \\
\hline & slope & $\mathbf{R}_{\mathrm{a}}^{2}$ & slope & $\mathbf{R}_{\mathrm{a}}^{2}$ & slope & $\mathbf{R}_{\mathrm{a}}^{2}$ \\
\hline Black Earth & 0.00022 & 0.15 & -0.00027 & 0.13 & -0.00024 & 0.09 \\
\hline Cathance & -0.00137 & 0.76 & -0.00177 & 0.83 & -0.00059 & 0.32 \\
\hline Clear & -0.00448 & 0.71 & -0.00745 & 0.84 & -0.00311 & 0.53 \\
\hline East & -0.01231 & 0.78 & -0.02649 & 0.92 & -0.01065 & 0.66 \\
\hline Feather & 0.15873 & 0.37 & 0.14958 & 0.06 & 0.01897 & -0.01 \\
\hline Flathead & -0.00625 & 0.00 & -0.00338 & -0.01 & -0.03355 & 0.23 \\
\hline Flint & -0.04200 & 0.66 & -0.09640 & 0.79 & -0.00282 & -0.01 \\
\hline Naches & 0.02159 & 0.41 & 0.03062 & 0.63 & -0.01020 & 0.22 \\
\hline Pomperaug & -0.00103 & 0.32 & -0.00230 & 0.66 & 0.00026 & 0.02 \\
\hline Sagehen & 0.00012 & 0.04 & 0.00007 & -0.01 & -0.00020 & 0.05 \\
\hline Sprague & 0.00125 & -0.00 & 0.00872 & 0.07 & -0.01045 & 0.22 \\
\hline Starkweather & -0.00002 & 0.59 & -0.00002 & 0.62 & -0.00001 & 0.30 \\
\hline Trout Lake & -0.00000 & 0.54 & -0.00000 & 0.67 & -0.00000 & 0.46 \\
\hline Yampa & -0.01766 & 0.81 & -0.03324 & 0.90 & -0.01784 & 0.73 \\
\hline \multicolumn{7}{|c|}{ (I) Groundwater flow (cubic meters per second): Groundwater flow from basin } \\
\hline \multirow{2}{*}{ Basin } & \multicolumn{2}{|c|}{ Emission scenario A1B } & \multicolumn{2}{|c|}{ Emission scenario A2 } & \multicolumn{2}{|c|}{ Emission scenario B1 } \\
\hline & slope & $\mathbf{R}^{2}$ & slope & $\mathbf{R}_{\mathrm{a}}^{2}$ & slope & $\mathbf{R}^{2}$ \\
\hline Black Earth & -0.00960 & 0.61 & -0.01894 & 0.79 & -0.01076 & 0.48 \\
\hline Cathance & -0.00004 & 0.90 & -0.00005 & 0.82 & -0.00001 & 0.37 \\
\hline Clear & -0.00349 & 0.80 & -0.00550 & 0.91 & -0.00217 & 0.57 \\
\hline East & -0.00232 & 0.37 & -0.00698 & 0.81 & -0.00063 & 0.02 \\
\hline Feather & -0.04999 & 0.59 & -0.07566 & 0.43 & -0.05747 & 0.52 \\
\hline Flathead & 0.04074 & 0.88 & 0.04375 & 0.69 & 0.02210 & 0.56 \\
\hline Flint & -0.12264 & 0.81 & -0.22784 & 0.86 & -0.02873 & 0.06 \\
\hline Naches & 0.02027 & 0.46 & 0.02671 & 0.67 & -0.00580 & 0.08 \\
\hline Pomperaug & -0.00554 & 0.79 & -0.00895 & 0.89 & -0.00193 & 0.37 \\
\hline Sagehen & 0.00002 & 0.01 & -0.00003 & -0.01 & -0.00008 & 0.10 \\
\hline Sprague & 0.00765 & 0.29 & 0.01102 & 0.20 & -0.00335 & 0.03 \\
\hline Starkweather & -0.00417 & 0.61 & -0.00357 & 0.68 & -0.00222 & 0.33 \\
\hline Trout Lake & -0.00244 & 0.37 & -0.00208 & 0.42 & -0.00081 & 0.03 \\
\hline Yampa & -0.00241 & 0.54 & -0.00709 & 0.81 & -0.00260 & 0.31 \\
\hline
\end{tabular}


Table 5. Projected change by year (slope) and adjusted $R^{2}\left(R_{a}^{2}\right)$ based on the central tendencies of the five General Circulation Models for the three carbon emission scenarios by basin for selected Precipitation Runoff Modeling System output variables. - Continued

[Blue shading indicates a significant negative trend and red shading indicates a significant positive trend $(\mathrm{p}<0.05)$ accounting for lag-1 autocorrelation]

\begin{tabular}{|c|c|c|c|c|c|c|}
\hline \multirow{3}{*}{ Basin } & \multicolumn{6}{|c|}{ ( $)$ Percent snow: Percent precipitation that falls as snow for total basin } \\
\hline & \multicolumn{2}{|c|}{ Emission scenario A1B } & \multicolumn{2}{|c|}{ Emission scenario A2 } & \multicolumn{2}{|c|}{ Emission scenario B1 } \\
\hline & slope & $\mathbf{R}^{2}$ & slope & $\mathbf{R}_{a}^{2}$ & slope & $\mathbf{R}^{2}$ \\
\hline Black Earth & -0.09 & 0.92 & -0.10 & 0.95 & -0.06 & 0.70 \\
\hline Cathance & -0.12 & 0.98 & -0.13 & 0.99 & -0.07 & 0.95 \\
\hline Clear & -0.06 & 0.89 & -0.06 & 0.93 & -0.04 & 0.69 \\
\hline East & -0.09 & 0.95 & -0.10 & 0.95 & -0.07 & 0.87 \\
\hline Feather & -0.15 & 0.96 & -0.19 & 0.99 & -0.14 & 0.96 \\
\hline Flathead & -0.18 & 0.97 & -0.21 & 0.95 & -0.13 & 0.94 \\
\hline Flint & -0.01 & 0.90 & -0.00 & 0.92 & -0.00 & 0.94 \\
\hline Naches & -0.17 & 0.96 & -0.22 & 0.97 & -0.15 & 0.97 \\
\hline Pomperaug & -0.10 & 0.98 & -0.12 & 0.98 & -0.07 & 0.97 \\
\hline Sagehen & -0.17 & 0.96 & -0.23 & 0.97 & -0.14 & 0.96 \\
\hline Sprague & -0.19 & 0.98 & -0.25 & 0.98 & -0.16 & 0.97 \\
\hline Starkweather & -0.02 & 0.11 & -0.03 & 0.45 & -0.01 & 0.09 \\
\hline Trout Lake & -0.06 & 0.92 & -0.06 & 0.92 & -0.04 & 0.72 \\
\hline Yampa & -0.08 & 0.96 & -0.10 & 0.96 & -0.06 & 0.93 \\
\hline
\end{tabular}

\begin{tabular}{|c|c|c|c|c|c|c|}
\hline \multirow{3}{*}{ Basin } & \multicolumn{6}{|c|}{ Snow-covered area (percent): Average snow-covered area for total basin } \\
\hline & \multicolumn{2}{|c|}{ Emission scenario A1B } & \multicolumn{2}{|c|}{ Emission scenario A2 } & \multicolumn{2}{|c|}{ Emission scenario B1 } \\
\hline & slope & $\mathbf{R}_{\mathrm{a}}^{2}$ & slope & $\mathbf{R}_{a}^{2}$ & slope & $\mathbf{R}_{\mathrm{a}}^{2}$ \\
\hline Black Earth & -0.16 & 0.97 & -0.18 & 0.98 & -0.11 & 0.89 \\
\hline Cathance & -0.13 & 0.99 & -0.16 & 0.98 & -0.08 & 0.97 \\
\hline Clear & -0.11 & 0.97 & -0.12 & 0.98 & -0.07 & 0.88 \\
\hline East & -0.10 & 0.98 & -0.15 & 0.98 & -0.07 & 0.94 \\
\hline Feather & -0.13 & 0.97 & -0.17 & 0.97 & -0.12 & 0.95 \\
\hline Flathead & -0.14 & 0.98 & -0.18 & 0.96 & -0.11 & 0.96 \\
\hline Flint & -0.00 & 0.89 & -0.00 & 0.93 & -0.00 & 0.93 \\
\hline Naches & -0.16 & 0.97 & -0.20 & 0.97 & -0.14 & 0.98 \\
\hline Pomperaug & -0.10 & 0.98 & -0.12 & 0.98 & -0.06 & 0.97 \\
\hline Sagehen & -0.13 & 0.97 & -0.17 & 0.94 & -0.11 & 0.92 \\
\hline Sprague & -0.13 & 0.98 & -0.17 & 0.98 & -0.12 & 0.98 \\
\hline Starkweather & -0.08 & 0.96 & -0.09 & 0.96 & -0.05 & 0.88 \\
\hline Trout Lake & -0.12 & 0.98 & -0.13 & 0.98 & -0.08 & 0.90 \\
\hline Yampa & -0.10 & 0.98 & -0.16 & 0.98 & -0.08 & 0.94 \\
\hline
\end{tabular}

\begin{tabular}{|c|c|c|c|c|c|c|}
\hline \multirow{2}{*}{ Basin } & \multicolumn{2}{|c|}{ Emission scenario A1B } & \multicolumn{2}{|c|}{ Emission scenario A2 } & \multicolumn{2}{|c|}{ Emission scenario B1 } \\
\hline & slope & $\mathbf{R}^{2}$ & slope & $\mathbf{R}^{2}{ }_{a}$ & slope & $\mathbf{R}^{2}$ \\
\hline Black Earth & -0.19 & 0.86 & -0.23 & 0.90 & -0.16 & 0.73 \\
\hline Cathance & -0.28 & 0.95 & -0.29 & 0.98 & -0.17 & 0.94 \\
\hline Clear & -0.06 & 0.82 & -0.07 & 0.90 & -0.04 & 0.70 \\
\hline East & -0.47 & 0.93 & -0.77 & 0.96 & -0.38 & 0.82 \\
\hline
\end{tabular}


Table 5. Projected change by year (slope) and adjusted $R^{2}\left(R^{2}\right)$ based on the central tendencies of the five General Circulation Models for the three carbon emission scenarios by basin for selected Precipitation Runoff Modeling System output variables.-Continued

[Blue shading indicates a significant negative trend and red shading indicates a significant positive trend $(\mathrm{p}<0.05)$ accounting for lag-1 autocorrelation]

\begin{tabular}{|c|c|c|c|c|c|c|}
\hline \multicolumn{7}{|c|}{ (L) Snowpack water equivalent (millimeters): Average snowpack water equivalent for total basin-Continued } \\
\hline \multirow{2}{*}{ Basin } & \multicolumn{2}{|c|}{ Emission scenario A1B } & \multicolumn{2}{|c|}{ Emission scenario A2 } & \multicolumn{2}{|c|}{ Emission scenario B1 } \\
\hline & slope & $\mathbf{R}_{\mathrm{a}}^{2}$ & slope & $\mathbf{R}_{\mathrm{a}}^{2}$ & slope & $\mathbf{R}_{\mathrm{a}}^{2}$ \\
\hline Feather & -0.54 & 0.92 & -0.6 & 0.88 & -0.53 & 0.87 \\
\hline Flathead & -1.21 & 0.95 & -1.45 & 0.95 & -1.04 & 0.92 \\
\hline Flint & -0.00 & 0.90 & -0.00 & 0.92 & -0.00 & 0.89 \\
\hline Naches & -0.46 & 0.91 & -0.58 & 0.95 & -0.51 & 0.97 \\
\hline Pomperaug & -0.06 & 0.91 & -0.06 & 0.97 & -0.03 & 0.88 \\
\hline Sagehen & -0.79 & 0.88 & -1.04 & 0.77 & -0.79 & 0.80 \\
\hline Sprague & -0.16 & 0.95 & -0.19 & 0.96 & -0.15 & 0.96 \\
\hline Starkweather & -0.10 & 0.84 & -0.11 & 0.82 & -0.07 & 0.67 \\
\hline Trout Lake & -0.17 & 0.91 & -0.18 & 0.92 & -0.12 & 0.80 \\
\hline Yampa & -0.34 & 0.93 & -0.54 & 0.96 & -0.32 & 0.87 \\
\hline
\end{tabular}

(M) Snowmelt (millimeters): Average snowmelt for total basin

\begin{tabular}{|c|c|c|c|c|c|c|}
\hline \multirow{2}{*}{ Basin } & \multicolumn{2}{|c|}{ Emission scenario A1B } & \multicolumn{2}{|c|}{ Emission scenario A2 } & \multicolumn{2}{|c|}{ Emission scenario B1 } \\
\hline & slope & $\mathbf{R}_{\mathrm{a}}^{2}$ & slope & $\mathbf{R}_{\mathrm{a}}^{2}$ & slope & $\mathbf{R}^{2}$ \\
\hline Black Earth & -0.0030 & 0.89 & -0.0035 & 0.91 & -0.0021 & 0.70 \\
\hline Cathance & -0.0039 & 0.95 & -0.0047 & 0.97 & -0.0021 & 0.93 \\
\hline Clear & -0.0017 & 0.86 & -0.0021 & 0.93 & -0.0012 & 0.74 \\
\hline East & -0.0014 & 0.69 & -0.0031 & 0.86 & -0.0012 & 0.52 \\
\hline Feather & -0.0052 & 0.84 & -0.0074 & 0.71 & -0.0052 & 0.72 \\
\hline Flathead & -0.0008 & 0.30 & -0.0010 & 0.17 & -0.0010 & 0.18 \\
\hline Flint & -0.0002 & 0.90 & -0.0002 & 0.96 & -0.0001 & 0.94 \\
\hline Naches & -0.0014 & 0.57 & -0.0020 & 0.70 & -0.0022 & 0.87 \\
\hline Pomperaug & -0.0040 & 0.96 & -0.0053 & 0.98 & -0.0025 & 0.94 \\
\hline Sagehen & 0.0004 & 0.01 & -0.0005 & -0.01 & -0.0011 & 0.07 \\
\hline Sprague & -0.0025 & 0.97 & -0.0032 & 0.94 & -0.0022 & 0.89 \\
\hline Starkweather & -0.0004 & 0.29 & -0.0003 & 0.30 & -0.0002 & 0.11 \\
\hline Trout Lake & -0.0012 & 0.80 & -0.0014 & 0.77 & -0.0009 & 0.61 \\
\hline Yampa & -0.0010 & 0.64 & -0.0023 & 0.82 & -0.0011 & 0.59 \\
\hline
\end{tabular}

\begin{tabular}{|c|c|c|c|c|c|c|}
\hline \multicolumn{7}{|c|}{ (M) Infiltration (millimeters) } \\
\hline \multirow{2}{*}{ Basin } & \multicolumn{2}{|c|}{ Emission scenario A1B } & \multicolumn{2}{|c|}{ Emission scenario A2 } & \multicolumn{2}{|c|}{ Emission scenario B1 } \\
\hline & slope & $\mathbf{R}_{\mathrm{a}}^{2}$ & slope & $\mathbf{R}_{\mathrm{a}}^{2}$ & slope & $\mathbf{R}_{\mathrm{a}}^{2}$ \\
\hline Black Earth & 0.0011 & 0.32 & -0.0002 & -0.00 & 0.0001 & -0.01 \\
\hline Cathance & 0.0016 & 0.63 & 0.0017 & 0.65 & 0.0013 & 0.43 \\
\hline Clear & 0.0015 & 0.48 & -0.0006 & 0.04 & 0.0010 & 0.13 \\
\hline East & 0.0009 & 0.34 & -0.0010 & 0.25 & 0.0007 & 0.18 \\
\hline Feather & 0.0022 & 0.43 & 0.0019 & 0.06 & 0.0005 & 0.00 \\
\hline Flathead & 0.0030 & 0.82 & 0.0037 & 0.62 & 0.0016 & 0.40 \\
\hline Flint & -0.0007 & 0.19 & -0.0031 & 0.67 & 0.0008 & 0.09 \\
\hline Naches & 0.0026 & 0.74 & 0.0037 & 0.87 & 0.0010 & 0.39 \\
\hline
\end{tabular}


Table 5. Projected change by year (slope) and adjusted $R^{2}\left(R_{a}^{2}\right)$ based on the central tendencies of the five General Circulation Models for the three carbon emission scenarios by basin for selected Precipitation Runoff Modeling System output variables.-Continued

[Blue shading indicates a significant negative trend and red shading indicates a significant positive trend $(\mathrm{p}<0.05)$ accounting for lag- 1 autocorrelation]

\begin{tabular}{|c|c|c|c|c|c|c|}
\hline \multicolumn{7}{|c|}{ (M) Infiltration (millimeters)—Continued } \\
\hline \multirow{2}{*}{ Basin } & \multicolumn{2}{|c|}{ Emission scenario A1B } & \multicolumn{2}{|c|}{ Emission scenario A2 } & \multicolumn{2}{|c|}{ Emission scenario B1 } \\
\hline & slope & $\mathbf{R}_{a}^{2}$ & slope & $\mathbf{R}_{\mathrm{a}}^{2}$ & slope & $\mathbf{R}_{\mathrm{a}}^{2}$ \\
\hline Pomperaug & 0.0016 & 0.40 & 0.0004 & 0.02 & 0.0022 & 0.59 \\
\hline Sagehen & 0.0023 & 0.51 & 0.0021 & 0.09 & 0.0003 & -0.00 \\
\hline Sprague & 0.0008 & 0.53 & 0.0014 & 0.45 & 0.0005 & 0.14 \\
\hline Starkweather & 0.0006 & 0.30 & 0.0014 & 0.73 & 0.0007 & 0.31 \\
\hline Trout Lake & 0.0002 & 0.00 & 0.0006 & 0.14 & 0.0006 & 0.06 \\
\hline Yampa & 0.0005 & 0.23 & -0.0007 & 0.20 & -0.0000 & -0.01 \\
\hline
\end{tabular}


Table 5. Projected change by year (slope) and adjusted $R^{2}\left(R^{2}\right)$ based on the central tendencies of the five General Circulation Models for the three carbon emission scenarios by basin for selected Precipitation Runoff Modeling System output variables. - Continued

[Blue shading indicates a significant negative trend and red shading indicates a significant positive trend $(\mathrm{p}<0.05)$ accounting for lag- 1 autocorrelation]

\begin{tabular}{|c|c|c|c|c|c|c|}
\hline \multicolumn{7}{|c|}{ (P) Groundwater reservoir recharge-Continued } \\
\hline \multirow{2}{*}{ Basin } & \multicolumn{2}{|c|}{ Emission scenario A1B } & \multicolumn{2}{|c|}{ Emission scenario A2 } & \multicolumn{2}{|c|}{ Emission scenario B1 } \\
\hline & slope & $\mathbf{R}_{\mathrm{a}}^{2}$ & slope & $\mathbf{R}_{\mathrm{a}}^{2}$ & slope & $\mathbf{R}_{\mathrm{a}}^{2}$ \\
\hline Trout Lake & -0.0028 & 0.38 & -0.0025 & 0.44 & -0.0011 & 0.04 \\
\hline Yampa & -0.0002 & 0.66 & -0.0006 & 0.83 & -0.0002 & 0.38 \\
\hline \multicolumn{7}{|c|}{ (Q) Soil moisture } \\
\hline \multirow{2}{*}{ Basin } & \multicolumn{2}{|c|}{ Emission scenario A1B } & \multicolumn{2}{|c|}{ Emission scenario A2 } & \multicolumn{2}{|c|}{ Emission scenario B1 } \\
\hline & slope & $\mathbf{R}^{2}$ & slope & $\mathbf{R}^{2}$ & slope & $\mathbf{R}^{2}$ \\
\hline Black Earth & -0.0549 & 0.93 & -0.0785 & 0.95 & -0.0326 & 0.66 \\
\hline Cathance & -0.0405 & 0.98 & -0.0456 & 0.93 & -0.0204 & 0.96 \\
\hline Clear & -0.3386 & 0.93 & -0.5071 & 0.95 & -0.1537 & 0.55 \\
\hline East & -0.0725 & 0.72 & -0.1258 & 0.82 & -0.0113 & 0.03 \\
\hline Feather & -0.0710 & 0.89 & -0.0908 & 0.83 & -0.0564 & 0.69 \\
\hline Flathead & -0.0456 & 0.69 & -0.0760 & 0.86 & -0.0322 & 0.38 \\
\hline Flint & -0.2076 & 0.95 & -0.2995 & 0.97 & -0.0902 & 0.56 \\
\hline Naches & -0.0344 & 0.69 & -0.0325 & 0.81 & -0.0343 & 0.86 \\
\hline Pomperaug & -0.1650 & 0.95 & -0.2205 & 0.93 & -0.0534 & 0.64 \\
\hline Sagehen & -0.1596 & 0.68 & -0.2340 & 0.51 & -0.1792 & 0.53 \\
\hline Sprague & -0.0315 & 0.56 & -0.0333 & 0.48 & -0.0289 & 0.37 \\
\hline Starkweather & -0.3260 & 0.82 & -0.3400 & 0.93 & -0.2087 & 0.63 \\
\hline Trout Lake & -0.0217 & 0.95 & -0.0227 & 0.97 & -0.0106 & 0.67 \\
\hline Yampa & -0.0852 & 0.84 & -0.1596 & 0.90 & -0.0476 & 0.63 \\
\hline
\end{tabular}

\begin{tabular}{|c|c|c|c|c|c|c|}
\hline \multicolumn{7}{|c|}{ (R) Subsurface reservoir storage } \\
\hline \multirow{2}{*}{ Basin } & \multicolumn{2}{|c|}{ Emission scenario A1B } & \multicolumn{2}{|c|}{ Emission scenario A2 } & \multicolumn{2}{|c|}{ Emission scenario B1 } \\
\hline & slope & $\mathbf{R}_{\mathrm{a}}^{2}$ & slope & $\mathbf{R}_{\mathrm{a}}^{2}$ & slope & $\mathbf{R}^{2}$ \\
\hline Black Earth & 0.0005 & 0.26 & -0.0002 & 0.06 & -0.0002 & 0.04 \\
\hline Cathance & -0.0040 & 0.79 & -0.0056 & 0.76 & -0.0011 & 0.13 \\
\hline Clear & -0.0120 & 0.74 & -0.0204 & 0.88 & -0.0077 & 0.53 \\
\hline East & -0.0172 & 0.77 & -0.0367 & 0.93 & -0.0143 & 0.65 \\
\hline Feather & 0.0059 & 0.09 & 0.0018 & -0.01 & -0.0027 & -0.00 \\
\hline Flathead & 0.0080 & 0.87 & 0.0087 & 0.66 & 0.0044 & 0.52 \\
\hline Flint & -0.0223 & 0.67 & -0.0508 & 0.83 & 0.0003 & -0.01 \\
\hline Naches & 0.0050 & 0.68 & 0.0068 & 0.82 & 0.0008 & 0.06 \\
\hline Pomperaug & -0.0008 & 0.32 & -0.0019 & 0.66 & 0.0002 & 0.02 \\
\hline Sagehen & 0.0023 & 0.07 & 0.0010 & -0.01 & -0.0029 & 0.04 \\
\hline Sprague & 0.0002 & -0.01 & 0.0018 & 0.06 & -0.0024 & 0.24 \\
\hline Starkweather & -0.0044 & 0.60 & -0.0038 & 0.66 & -0.0024 & 0.32 \\
\hline Trout Lake & -0.0001 & -0.01 & -0.0005 & 0.07 & -0.0004 & 0.02 \\
\hline Yampa & -0.0054 & 0.81 & -0.0099 & 0.90 & -0.0052 & 0.71 \\
\hline
\end{tabular}


Table 5. Projected change by year (slope) and adjusted $R^{2}\left(R_{a}^{2}\right)$ based on the central tendencies of the five General Circulation Models for the three carbon emission scenarios by basin for selected Precipitation Runoff Modeling System output variables. - Continued

[Blue shading indicates a significant negative trend and red shading indicates a significant positive trend $(\mathrm{p}<0.05)$ accounting for lag- 1 autocorrelation]

\begin{tabular}{|c|c|c|c|c|c|c|}
\hline \multicolumn{7}{|c|}{ (S) Groundwater reservoir storage } \\
\hline \multirow{2}{*}{ Basin } & \multicolumn{2}{|c|}{ Emission scenario A1B } & \multicolumn{2}{|c|}{ Emission scenario A2 } & \multicolumn{2}{|c|}{ Emission scenario B1 } \\
\hline & slope & $\mathbf{R}^{2}$ & slope & $\mathbf{R}^{2}{ }_{a}$ & slope & $\mathbf{R}^{2}$ \\
\hline Black Earth & -0.8165 & 0.61 & -1.6218 & 0.79 & -0.9220 & 0.47 \\
\hline Cathance & -0.0149 & 0.81 & -0.0214 & 0.79 & -0.0048 & 0.23 \\
\hline Clear & -0.4921 & 0.80 & -0.7756 & 0.91 & -0.3054 & 0.57 \\
\hline East & -0.0265 & 0.36 & -0.0798 & 0.81 & -0.0072 & 0.02 \\
\hline Feather & -0.1055 & 0.68 & -0.1568 & 0.53 & -0.1169 & 0.61 \\
\hline Flathead & 0.7227 & 0.88 & 0.7760 & 0.69 & 0.3923 & 0.56 \\
\hline Flint & -0.0781 & 0.83 & -0.1400 & 0.86 & -0.0197 & 0.08 \\
\hline Naches & 0.0385 & 0.37 & 0.0519 & 0.60 & -0.0203 & 0.19 \\
\hline Pomperaug & -0.0835 & 0.78 & -0.1365 & 0.89 & -0.0288 & 0.34 \\
\hline Sagehen & 0.0250 & 0.01 & -0.0309 & -0.01 & -0.0875 & 0.10 \\
\hline Sprague & 0.0304 & 0.29 & 0.0438 & 0.20 & -0.0133 & 0.03 \\
\hline Starkweather & -0.0028 & 0.61 & -0.0024 & 0.68 & -0.0015 & 0.33 \\
\hline Trout Lake & -0.6985 & 0.38 & -0.6133 & 0.44 & -0.2613 & 0.04 \\
\hline Yampa & -0.1453 & 0.54 & -0.4269 & 0.81 & -0.1565 & 0.31 \\
\hline
\end{tabular}

The PRMS projections indicate minimal changes in annual mean surface runoff and subsurface flow (figs. $16 A$ and $17 A$ ) with no significant trends (table $5 G$ and $5 H$ ). High variability (indicating uncertainty) in the seasonal timing of these variables is projected (figs. $34 A$ and $35 A$ ), with decreasing flows in March, June, and July, and increasing flows in December through February. Groundwater flow is the dominant component of streamflow and has a similar seasonal pattern (figs. $15 \mathrm{~A}$ and $18 A$, table $5 F$ and $5 I$ ). High variability in the seasonal timing of groundwater flow also is projected (fig. $36 A$ ).

\section{Black Earth Creek Snow Variables}

Because of increases in temperatures, the PRMS projections indicate that the annual mean percentage of precipitation that falls as snow (fig. 19A), percentage of are covered by snow (fig. 20A), snowpack water equivalent (fig. 21A), and snowmelt (fig. 22A) will decrease (tables $5 J-5 M$ ). Projected warmer temperatures will: (1) result in less snowfall, which will result in less snow available to melt in the spring; (2) decrease the amount of precipitation that falls as snow, percentage of area covered by snow, and snowpack water equivalent in every month (figs. 37A-39A); and (3) increase the snowmelt in December and January, leaving less snow to melt in March and April (fig. 40A).

\section{Black Earth Creek Soil Moisture Variables}

The PRMS projections of infiltration (figs. $23 A$ and $41 A$, respectively) are similar to those of precipitation (figs. $10 \mathrm{~A}$ and 29A). The large range in the infiltration projections indicates a high level of uncertainty with no significant overall trend (table $5 N$ ). High variability in seasonal infiltration is also projected (fig. 41A), with large increases projected for the months of November through February and large decreases projected for the months of March and June.

Projected changes in the inflow to the subsurface reservoir (fig. 24A) and recharge to the groundwater reservoir (fig. 25A) are similar to the changes seen in the subsurface (fig. 17A) and groundwater (fig. 18A) flow components, respectively. The projections show no significant trends in inflow to the subsurface reservoir (table 5O). The large range in the projections of annual mean recharge indicates a high level of uncertainty, with decreases projected for the A1B and A2 scenarios (table $5 P$ ). High variability in seasonal recharge is projected (figs. $42 A$ and $43 A$ ).

There is a decrease in the projected annual mean soil moisture (fig. $26 A$ and table 5Q). High variability in seasonal timing of soil moisture is projected (fig. $44 A$ ), with decreases in nearly every month. The largest decreases occur during the growing season months. 
The PRMS projections indicate that the storage in the subsurface (fig. 27A) and the groundwater reservoirs fig. $28 \mathrm{~A}$ ) reach equilibrium quickly, resulting in simulated values similar to the inflows (see tables $5 O$ and $5 P ; 5 R$ and $5 S$, respectively). High variability in seasonal timing of subsurface and groundwater storage is projected (figs. $45 A$ and $46 A$ ).

\section{Discussion of Black Earth Creek Projections}

In the Black Earth Creek Basin, the PRMS projections indicate an overall decrease in snowmelt and increase in evapotranspiration in the basin, although the large range of values indicate a large degree of uncertainty in these trends. Annual mean streamflow may not change substantially; however, the seasonal timing of flows, such as reduced spring runoff, and local conditions, such as soil moisture, may be affected. This could affect in-stream water quality and temperature. This study did not consider future changes in land use or the demand for water from irrigation or urbanization in the basin. The interaction of land use and climate change may affect the watershed hydrology in ways that were not accounted for by this study.

\section{Precipitation Runoff Modeling System Projections for Cathance Stream, Maine}

The Cathance Stream basin is a tributary to the Dennys River Basin in Washington County, eastern Maine, on the coast of the Atlantic Ocean. At USGS streamflow-gaging station 01021230 the basin has a drainage area of $85 \mathrm{~km}^{2}$ (table 1). The initial PRMS application was developed by Dudley (2008). The PRMS application contains 85 HRUs with elevations that range from 46 to $174 \mathrm{~m}$ (table 1 ).

Mean monthly baseline conditions in the Cathance Stream Basin are shown in figures 5 and 6 . Mean monthly minimum temperatures range from just above $-13{ }^{\circ} \mathrm{C}$ during January to just below $13{ }^{\circ} \mathrm{C}$ during July and August. Mean monthly maximum temperatures range from $-1{ }^{\circ} \mathrm{C}$ during January to above $25^{\circ} \mathrm{C}$ during July and August. On a mean monthly basis, precipitation ranges from $2.5 \mathrm{~mm} /$ day (during August) to $4.7 \mathrm{~mm} /$ day (during January). Because of freezing temperatures during the winter months (December, Janurary, and Feburary), precipitation falls as snow and accumulates throughout the winter, with peak mean monthly streamflow occurring during April because of snowmelt.

The Cathance Stream Basin is rural and its rolling topography is predominantly forested with wetlands, lakes, and ponds, some blueberry agriculture fields, clear cuts, partial cuts, regenerating forest, and light residential development. The Dennys River and its tributary, Cathance Stream, are important habitat for wild Atlantic salmon. Wild Atlantic salmon populations are protected under the U.S. Endangered Species Act of 1973 and are the subject of a comprehensive recovery program (Dudley, 2008). The USGS, in cooperation with the Maine Department of Marine Resources Bureau of Sea Run Fisheries and Habitat, began a study in 2004 to characterize the quantity, variability, and timing of streamflow in the Dennys River (Dudley, 2008). The study included the development and evaluation of a distributed-parameter watershed model (PRMS). The watershed modeling work supports several tasks directed at developing water-use management plans for Atlantic salmon rivers and development of comprehensive flow monitoring in those basins. Improved water-resources information supports Atlantic salmon protection efforts.

\section{Cathance Stream Input Variables}

Changes in annual mean precipitation vary in the PRMS projections of the Cathance Stream Basin (fig. 10B), with similar increases in the central tendencies for the A1B and A2 scenarios (table $5 A$ ). Seasonal variability is apparent also in these precipitation projections (fig. 29B), with the largest projected increases in January, July, and August.

All PRMS projections indicate steady increases in temperature (figs. $11 B, 12 B, 30 B$, and $31 B$ and tables $5 B$ and $5 C$ ), with associated uncertainties increasing with time. The projected changes of both maximum and minimum daily temperatures are smallest for the $\mathrm{B} 1$ scenario (tables $5 B$ and $5 C$ ).

All projections indicate steady increases in annual mean evapotranspiration (fig. $13 B$ and table $5 D$ ). High variability in seasonal evapotranspiration is projected, with increases in all months (fig. 32B).

All PRMS projections indicate steady increases in the length of the growing season (fig. $14 B$ and table $5 E$ ). This increase is because of the projected increase of annual temperature (figs. $11 B$ and $12 B$ and tables $5 B$ and $5 C$ ). The projected changes in the length of the growing season are smallest for the $\mathrm{B} 1$ scenario (table $5 E$ ).

\section{Cathance Stream Streamflow Variables}

The PRMS projections indicate a decrease in annual mean streamflow for the A1B and A2 scenarios (fig. $15 B$ and table $5 F$ ), though the uncertainties associated with these projections are large. Large increases in seasonal streamflow are projected from January through March, whereas large decreases are projected from April through June. The PRMS simulation of baseline conditions (red line, fig. 33B) indicate that peak streamflow occurs in April, whereas the PRMS projections indicate that, by the end of the 21 st century, the peak of streamflow could occur as early as January (figs. 33B). High variability (indicating uncertainty) is projected in the seasonal timing of streamflow in all but the summer months.

The PRMS projections indicate increases in annual mean surface runoff for all scenarios (fig. $16 B$ and table $5 G$ ). Seasonal projections indicate that the increases in surface runoff are because of increased surface runoff in December, January, February, and April (fig. 34B). Projections of subsurface and groundwater flow indicate the same decreasing pattern as the 
annual mean streamflow (figs. $15 B, 17 B$ and $18 B$, and tables $5 F, 5 H$ and $5 I$ ). Projected decreases in April subsurface flow (fig. $35 B$ ) leads to an overall decrease in the annual mean subsurface flow (fig. 25B). Monthly decreases in groundwater are projected in May through December, whereas increases are projected from January through March (fig. 36B).

\section{Cathance Stream Snow Variables}

Because of increases in temperatures, the PRMS projections indicate that the annual mean percentage of precipitation that falls as snow (fig. 19B), percentage of area covered by snow (fig. 20B), snowpack water equivalent (fig. 21B), and snowmelt (fig. 22B) will decrease (tables $5 J-5 M$ ). Projected warmer temperatures will: (1) result in less snowfall, which will result in less snow available to melt in the spring;

(2) decrease the amount of precipitation that falls as snow, percentage of area covered by snow, and snowpack water equivalent in every month (figs. $37 B-39 B$ ); and (3) increase the snowmelt in January and February, leaving less snow to melt in April (fig. 40B).

\section{Cathance Stream Soil Moisture Variables}

The PRMS projections of infiltration (figs. $23 B$ and $41 B$ ) are similar to those of precipitation (figs. $10 B$ and 29B). The large range in the infiltration projections indicates a high level of uncertainty with an increasing trend for the A1B and A2 scenarios (table $5 N$ ). Seasonal infiltration is projected to decrease during April (fig. $41 B$ ) because of the decrease in snowmelt in that month (fig. 40B). The overall increase in infiltration is because of the increase in precipitation.

Projected changes in the inflow to the subsurface reservoir (fig. 24B) and recharge to the groundwater reservoir (fig. 25B) are similar to the changes seen in the subsurface (fig. 17B) and groundwater (fig. 18B) flow components, respectively. The projections show a negative trend in the inflows to the subsurface reservoirs and recharge for the A1B and A2 scenarios (figs. $24 B$ and $25 B$ and tables $5 O$ and $5 P$ ). High variability in seasonal recharge is projected (figs. $42 B$ and $43 B$ ).

There is a decrease in the projected annual mean soil moisture (fig. $26 B$ and table $5 Q$ ). High variability in seasonal timing of soil moisture is projected (fig. $44 B$ ), with decreases in nearly every month. The largest decreases occur during the growing season months.

The PRMS projections indicate that the storage in the subsurface (fig. 27B) and the groundwater reservoirs (fig. 28B) reach equilibrium quickly, resulting in simulated values similar to the inflows (see tables $5 O$ and $5 P$; $5 R$ and $5 S$, respectively). High variability in seasonal timing of subsurface and groundwater storage is projected (figs. $45 B$ and $46 B$ ).

\section{Discussion of Cathance Stream Projections}

The Cathance Stream and other coastal river basins in Maine are important habitat for a variety of aquatic animals including endangered Atlantic salmon. The broader-scale consequences of climate change on the flow regime of the rivers in Maine, like Cathance Stream, likely will affect ecosystems. The ecological implications of changes in the timing of winterspring streamflows in Maine are not well understood and possibly could affect Atlantic salmon survival rates. If the peak spring migration of juvenile salmon from freshwater rivers (which is controlled by photoperiod, temperature, and flow) becomes out of phase with optimal environmental conditions in rivers, estuaries, or the ocean, salmon survival could drop substantially (McCormick and others, 1998). Changes in the timing of spring river flows may affect fresh-water mixing in estuarine ecosystems. Earlier snowmelt and increases in summer evapotranspiration rates could shorten the annual periods of standing water used by amphibians for breeding in forested depressional wetlands (vernal pools).

\section{Precipitation Runoff Modeling System Projections for Clear Creek, lowa}

The Clear Creek Basin is located in east-central Iowa, includes parts of Iowa and Johnson Counties, and is a tributary to the Iowa River. At USGS streamflow-gaging station 05454300 , the basin has a drainage area of $254 \mathrm{~km}^{2}$. The PRMS application contains 75 HRUs with elevations that range from 205 to 261 meters (table 1).

Mean monthly baseline conditions for the Clear Creek basin are shown in figures 5 and 6 . Mean monthly minimum temperatures range from $-13.5^{\circ} \mathrm{C}$ during January to above $14{ }^{\circ} \mathrm{C}$ during July. Mean monthly maximum temperatures range from approximately $-6{ }^{\circ} \mathrm{C}$ during January to above $24{ }^{\circ} \mathrm{C}$ during July. On a mean monthly basis, precipitation ranges from approximately $1.0 \mathrm{~mm} /$ day (from December through February) to almost $6.0 \mathrm{~mm} /$ day (during June). Because of freezing temperatures during the winter months, precipitation falls as snow and accumulates throughout the winter. The majority of annual mean streamflow occurs during spring and summer, with the peak monthly streamflow occurring during May and June.

The topography of the Clear Creek Basin is characterized by uplands dissected by tributary streams (Schwob, 1964). The Clear Creek Basin has a wide and broad flood plain, with a meandering channel except along reaches that have been straightened (Barnes and Eash, 1990). Land use is predominantly agricultural with a growing urban population in Johnson County, Iowa. The Iowa Department of Natural Resources and the Natural Resources Conservation Service (NRCS) have created the Clear Creek Watershed Enhancement Project (Iowa Department of Natural Resources, 2011). The goal of this project is to restore Clear Creek to natural conditions. 


\section{Clear Creek Input Variables}

Changes in annual mean precipitation vary in the PRMS projections of the Clear Creek basin (fig. 10C). The large range in the precipitation projections indicates a large amount of uncertainty with no apparent overall trend (table $5 A$ ). Seasonal variability also is apparent in these precipitation projections (fig. 29C), with the lowest precipitation amounts (September through April) having minimal changes and low variability. Months with the highest projected precipitation amounts (May through August) have both increasing and decreasing precipitation, but with much larger uncertainty.

All PRMS projections indicate steady increases in temperature (figs. $11 C, 12 C, 30 C$, and $31 C$, and tables $5 B$ and $5 C$ ), with associated uncertainties increasing with time. The projected changes of both maximum and minimum daily temperatures are smallest for the $\mathrm{B} 1$ scenario (tables $5 B$ and $5 C$ ).

All projections indicate steady increases in annual mean evapotranspiration (figs. $13 C$ and table $5 D$ ). High variability in seasonal evapotranspiration is projected, with increases in all months, except July (fig. 32C).

All PRMS projections indicate steady increases in the length of the growing season (fig. $14 C$ and table $5 E$ ). This increase is because of the projected increase of annual temperature (figs. $11 C$ and $12 C$ and tables $5 B$ and $5 C$ ). The projected changes in the length of the growing season are smallest for the B1 scenario (table 5E).

\section{Clear Creek Streamflow Variables}

The PRMS projections indicate a decrease in annual mean streamflow for the A1B and A2 scenarios (fig. $15 C$ and table $5 F$ ), though the uncertainties associated with these projections are large. High variability (indicating uncertainty) in the seasonal timing of streamflow is projected, particularly from March through August. Specifically, the PRMS simulation of baseline conditions (red line, fig. 33C) indicate that peak streamflow occurs in June. Whereas the PRMS projections indicate that, by the end of the 21 st century, the projected month of peak streamflow will be May (fig. 33C).

The PRMS projections indicate decreases in all three components of flow (figs. $16 C-18 C$ and tables $5 G-5 I$ ). High variability (indicating uncertainty) in the seasonal timing of these variables is projected $(34 C-36 C)$, with the largest decreases in surface runoff in May and June, the largest decreases in subsurface flows in May through August, and groundwater flow shows relatively consistent decreases in every month.

\section{Clear Creek Snow Variables}

Because of increases in temperature, the PRMS projections indicate that the annual mean percentage of precipitation that falls as snow (fig. 19C), percentage of area covered by snow (fig. 20C), snowpack water equivalent (fig. 21C), and snowmelt (fig. $22 C$ ) will decrease (tables $5 J-5 M$ ). Projected warmer temperatures will: (1) result in less snowfall, which will result in less snow available to melt in the spring; (2) decrease the amount of precipitation that falls as snow, percentage of area covered by snow, and snowpack water equivalent in every month (figs. 37C-39C); and (3) increase the snowmelt in December and January, with large decreases in November, March, and April by the end of the 21st century (fig. 40C).

\section{Clear Creek Soil Moisture Variables}

The PRMS projections of infiltration (fig. $23 C$ and $41 C$ ) are similar to those of precipitation (fig. $10 C$ and $29 C$ ). The large range in the infiltration projections indicates a high level of uncertainty with no significant overall trend (table $5 N$ ). High variability in seasonal infiltration also is projected (fig. 41C).

Projected changes in the inflow to the subsurface reservoir (fig. 24C) and recharge to the groundwater reservoir (fig. 25C) are similar to the changes seen in the subsurface (fig. 17C) and groundwater (fig. 18C) flow components, respectively. The projections show decreases in the inflows to the subsurface reservoirs and recharge (tables $5 O$ and $5 P$ ). High variability in seasonal recharge is projected (figs. $42 C$ and $43 C$ ).

There is a decrease in the projected annual mean soil moisture (fig. 26C) for scenarios A1B and A2 (table 5Q). High variability in seasonal timing of soil moisture is projected (fig. 44C), with decreases in nearly every month.

The PRMS projections indicate that the storage in the subsurface (fig. 27C) and the groundwater reservoirs (fig. 28C) reach equilibrium quickly, resulting in simulated values similar to the inflows (see tables $5 O$ and $5 P$; $5 R$ and $5 S$, respectively). High variability in seasonal timing of subsurface and groundwater storage is projected (figs. $45 C$ and $46 C$ ).

\section{Discussion of Clear Creek Projections}

In the Clear Creek Basin, agricultural water consumption and population growth will result in increasing water demand. The broader-scale effects of climate change on the flow regime of the Clear Creek Basin indicate a slight overall drying of the basin as a consequence of increased evapotranspiration, but the uncertainty associated with the magnitude of this drying is large.

These results did not consider potential future population growth and land-use changes. They also do not answer the question of whether the potentially adverse effects because of climate change can be mitigated with careful land-use planning in the Clear Creek Basin.

The combined effects of climate change and urbanization in the Clear Creek Basin may alter both the quantity and timing of streamflow and has the potential to change the conditions of water quality that supports biological diversity in aquatic communities. 


\section{Precipitation Runoff Modeling System Projections for East River, Colorado}

The East River Basin at Almont, Colorado is part of the Gunnison River Basin, and an important tributary of the Colorado River. The Gunnison River contributes approximately 40 percent of the streamflow of the Colorado River at the Utah/Colorado State line (Spahr and others, 1999), and the East River accounts for approximately 25 percent of the streamflow of the Gunnison River (Ugland and others, 1991). At USGS streamflow-gaging station 09112500, the basin has a drainage area of $748 \mathrm{~km}^{2}$. The basin has been simulated with the PRMS model by Hay and others (1993) and McCabe and Hay (1995). This application contains 71 HRUs with elevations that range from 2,583 to 3,796 meters (table 1).

Mean monthly baseline conditions for the East River Basin are shown in figures 5 and 6 . Mean monthly minimum temperatures range from just below $-18{ }^{\circ} \mathrm{C}$ during December and January to just below $3.5^{\circ} \mathrm{C}$ during July and August. Mean monthly maximum temperatures range from approximately $-2{ }^{\circ} \mathrm{C}$ during December and January to above $20^{\circ} \mathrm{C}$ during July. On a mean monthly basis, precipitation ranges from $1.3 \mathrm{~mm} /$ day (during June) to $4.4 \mathrm{~mm} /$ day (during February). Because of freezing temperatures during the winter months, precipitation falls as snow and accumulates throughout the winter. The majority of annual mean streamflow occurs during May through July, with the peak monthly streamflow occurring during June.

Current (2002) and projected total water demand in the Gunnison River Basin is about equal to the native supply (Colorado Water Conservation Board, 2002a). The East River Basin is representative of many snowmelt dominated, highelevation basins in Colorado that supply much of the water to downstream users. Because of its importance as a source of water to the Colorado River, the U.S. Geological Survey conducted studies (Leavesley and others, 1992; Hay and others, 1993; McCabe and Hay, 1994; and McCabe and Hay, 1995) of the effects of potential climate change on the water resources of the East River Basin.

Tourism that results from abundant local recreational options is the largest source of revenue in the region (Gunnison Country Chamber of Commerce, 2009). Many of these recreational activities, such as fishing, whitewater boating, snowmobiling, and skiing, are directly dependent on the basin's water resources. The Crested Butte ski area falls within the East River Basin and has a base elevation of 2,856 meters and top elevation of 3,707 meters. The ski area typically receives more than 7 meters of snowfall, and operates from late November to early April.

\section{East River Input Variables}

Changes in annual mean precipitation vary in the PRMS projections of the East River Basin (fig.10D). The large range in the precipitation projections indicates a high level of uncertainty with a slight increase in the central tendencies shown for the significant A1B scenario (table $5 A$ ). Seasonal variability also is apparent in the projections with increasing precipitation in December through February and decreasing precipitation in May and November (fig. 29D).

All PRMS projections indicate steady increases in temperature (figs. $11 D, 12 D, 30 D, 31 D$, and tables $5 B$ and $5 C$ ), with associated uncertainties increasing with time. The projected changes of both maximum and minimum daily temperatures are smallest for the $\mathrm{B} 1$ scenario (tables $5 B$ and $5 C$ ).

All projections indicate an overall increase in annual mean evapotranspiration (fig. $13 D$ and table $5 D$ ). High variability in seasonal evapotranspiration is projected, with large increases from October through May followed by greater uncertainty from June through September (fig. 32D).

All PRMS projections indicate steady increases in the length of the growing season (fig. $14 D$ and table $5 E$ ). This increase is because of the projected increase of annual temperature (figs. $11 D$ and $12 D$ and tables $5 B$ and $5 C$ ). The projected changes in the length of the growing season are smallest for the $\mathrm{B} 1$ scenario (table $5 E$ ).

\section{East River Streamflow Variables}

The PRMS projections indicate a decrease in annual mean streamflow (fig. $15 D$ and table $5 F$ ), though the uncertainties associated with these streamflow projections are large. High variability (indicating uncertainty) in the seasonal timing of streamflow is projected, particularly during the snowmelt months (fig. 33D). Streamflow is projected to increase from March through May and decrease in June through August (fig. $33 D$ ). By 2060, peak timing of streamflow is projected to shift from June to May.

The PRMS projections indicate an overall decrease in surface runoff and subsurface flow (tables $5 G$ and $5 H$ ) with a high degree of uncertainty (figs. $16 D$ and $17 D$ ) for most scenarios. Groundwater flow is projected to decrease (for the A2 emission scenario only; fig. $18 D$ and table 5I). By the end of the 21 st century, the projected month of peak surface runoff and subsurface flow shifts from June to May, while the groundwater peak remains in June (figs. $34 D-36 D$ ).

\section{East River Snow Variables}

Because of increases in temperatures, the PRMS projections indicate that the annual mean percentage of precipitation that falls as snow (fig. 19D), percentage of area covered by snow (fig. 20D), snowpack water equivalent (fig. 21D), and snowmelt (fig. 22D) will decrease (tables $5 J-5 M$ ). The large range in the seasonal projections (figs. $37 D-40 D$ ) indicates a high degree of uncertainty associated with the projected changes during the snow accumulation and melt season. The largest projected decreases in the percent of precipitation that falls as snow and percentage of area covered by snow are seen in the transition spring and fall months. The PRMS simulation of 
baseline conditions (red line, fig. 39) indicates that the timing of maximum snowpack water equivalent occurs in March and April. The PRMS projections indicate by the end of the 21 st century, this will shift to March. Also projected are substantial increases in snowmelt during March and April, followed by large decreases in May, and especially June (fig. 40).

\section{East River Soil Moisture Variables}

The PRMS projections of infiltration (figs. $23 D$ and $41 D$ ) are similar to those seen in the precipitation plots (fig. $10 D$ and $29 D$ ). The large range in the infiltration projections indicates a high level of uncertainty with no significant overall trend (table $5 N$ ). High variability in seasonal infiltration also is projected (fig. 41D), with large increases during the snow accumulation months followed by large decreases during the snowmelt months.

Projected changes in the inflow to the subsurface reservoir (fig. 24D) and recharge to the groundwater reservoir (fig. 25D) are similar to the changes seen in the subsurface (fig. 17D) and groundwater (fig. 18D) flow components, respectively. The projections show an overall negative annual mean trend in the inflows to the subsurface reservoirs for all scenarios (tables 50 ). The large range in the projections of annual mean recharge indicates a high level of uncertainty, with decreases projected for the A2 scenario (table $5 P$ ). High variability in seasonal recharge is projected (figs. $42 D$ and $43 D$ ).

There is a slight decrease in annual mean soil moisture for A1B and A2 scenarios (fig. $26 D$ and table $5 Q$ ). High variability in seasonal timing of soil moisture is projected (fig. 44A), with decreases projected from June through September and substantial increases projected in March and April.

The PRMS projections indicate that the storage in the subsurface (fig. 27D) and the groundwater reservoirs (fig. 28D) reached equilibrium quickly, resulting in their annual mean storage values following the same trends as their inflows (tables $5 O$ and $5 P$; and $5 R$, and $5 S$, respectively). High variability in seasonal timing of subsurface and groundwater storage is projected (figs. $45 D$ and $46 D$ ).

\section{Discussion of East River Projections}

Streamflow in the East River Basin is under increasing demand from water users and recreationalists within the basin. Decreases in streamflow resulting from future changes in climate may add to the stress that this basin will experience as a result of projected increases in domestic and industrial water use (Colorado Water Conservation Board, 2006a). The effects of climate change in the East River Basin may also result in earlier snowmelt resulting in earlier spring runoff and affecting the conditions that support recreational activities such as skiing.

\section{Precipitation Runoff Modeling System Projections for Feather River, California}

The Feather River Basin is located in northern California. The basin has a drainage area of $9,324 \mathrm{~km}^{2}$ at the basin outlet reservoir, Lake Oroville. The basin was simulated with the PRMS model by Koczot and others (2005). The PRMS application, which consists of 8 subbasins, contains 324 HRUs with elevations that range from 325 to 2,212 meters (table 1).

The Feather River Basin is a valuable hydrologic resource for California (Koczot and others, 2005). The basin is a major contributor to the California State Water Project, which distributes water throughout California for domestic use, irrigation, and hydropower production. The outlet reservoir, Lake Oroville, holds 8 percent of the state's reservoir capacity and plays an important role in flood management, water quality, and the health of fisheries, affecting areas downstream at least as far south as the Sacramento/San Joaquin River Delta. The climate is Mediterranean, with warm dry summers and cool wet winters. Spring snowmelt from the basin is relied upon to meet the State Water Project's summer water demands.

The Feather River Basin is sensitive to slight changes in temperature which affect the formation and melting of snow. The basin includes large areas that are at or near the seasonal snow line (1,676 meters elevation), and winter rain or rain-on-snow occurrences are common. This basin has been recognized as one of the first in California anticipated to be affected by climate-induced change to snowpack, which will have relatively large effects on the timing and quantity of streamflow (Freeman, 2008).

Mean monthly baseline conditions for the Feather River Basin are shown in figures 5 and 6 . Mean monthly minimum temperatures range from $-6.5^{\circ} \mathrm{C}$ during December and January to $6.3{ }^{\circ} \mathrm{C}$ during July. Mean monthly maximum temperatures range from above $4{ }^{\circ} \mathrm{C}$ during December and January to above $28^{\circ} \mathrm{C}$ during July and August. On a mean monthly basis, precipitation ranges from less than $0.25 \mathrm{~mm} /$ day (during July) to above $7 \mathrm{~mm}$ /day (during January). Because of winter freezing temperatures in the highest elevations of the basin and near freezing temperatures in mid-elevations of the basin, precipitation falls as snow on higher elevations and as a mixture of rain and snow on mid-elevations; precipitation falls as rain below 1,000 meters. Snow accumulates and melts in this basin throughout the winter, with maximum snowpack accumulation historically occurring by April 1 (Koczot and others, 2005). Coresponding to winter precipitation, the majority of mean annual streamflow occurs during the winter and spring months, with the peak monthly streamflow occurring from March to as late as May (Koczot and others, 2005)

Existing PRMS forecast applications focus on seasonal (3 to 9 months) and medium-range (one week to one month) streamflows (Koczot and others, 2005). Currently (2005), in the Feather River Basin, the California Department of Water Resources makes seasonal and medium-range forecasts of total streamflow into Lake Oroville, and hydroelectric power 
operators use their own suite of statistical models to manage power generation within the basin. The National Oceanic and Atmospheric Administration California-Nevada River Forecasting Center also employs the National Weather Service River Forecasting System for flood and water-supply forecasting for the Feather River Basin. Agricultural, fishery, logging, and local user groups may benefit from improved forecasts of long-term climatological trends. Improved understanding of how the Feather River Basin responds to changing climatic conditions will help water managers safeguard this resource.

\section{Feather River Input Variables}

Changes in annual mean precipitation in the PRMS projections of the Feather River Basin are not significant, but highly variable (fig. 10E). The large range in the precipitation projections indicates a large amount of uncertainty in the GCM scenarios used in this study with no significant overall trend (table $5 \mathrm{~A}$ ). Seasonal variability also is apparent in these precipitation projections with the largest amount in the winter months (fig. 29E).

All PRMS projections indicate steady increases in temperature (figs. $11 E, 12 E, 30 E, 31 E$, and tables $5 B$ and $5 C$ ), with associated uncertainties increasing with time. The projected changes of both maximum and minimum daily temperatures are smallest for the B1 scenario (tables $5 B$ and $5 C$ ).

All projections indicate steady increases in annual mean evapotranspiration (fig. $13 E$ table $5 D$ ). High variability in seasonal evapotranspiration is projected, with increases projected from October through May, followed by large projected decreases in the central tendencies in June and July (fig. 32E).

All PRMS projections indicate steady increases in the length of the growing season (fig. $14 E$ and table $5 E$ ). This increase is because of the projected increase of annual temperature (figs. $11 E$ and $12 E$ and tables $5 \mathrm{~B}$ and $5 \mathrm{C}$ ). The projected changes in the length of the growing season are smallest for the $\mathrm{B} 1$ scenario and largest for the A2 scenario (table $5 E$ ).

\section{Feather River Streamflow Variables}

The PRMS projections indicate both increases and decreases in annual mean streamflow with no significant trend (fig. $15 E$ and table $5 F$ ), though the uncertainties associated with these projections are large. High variability (indicating uncertainty) in the seasonal timing of streamflow is projected, especially in the winter months, with minimal changes shown for the summer months (fig. 33E). Streamflow is projected to increase from November through March and decrease in May and June. By the end of the 21 st century peak monthly streamflow is projected to shift from March to possibly as early as January.

The PRMS projections indicate variable changes in annual mean surface runoff and subsurface flow (figs. $16 \mathrm{~A}$ and $17 A$ ) with no significant trends (table $5 G$ and $5 H$ ), while the annual mean groundwater flow is projected to decrease for the A1B scenario (fig. $18 E$ and table $5 I$ ). High variability (indicating uncertainty) in the seasonal timing of these variables is projected (figs. $34 E, 35 E$, and $36 E$ ). Surface runoff is projected to increase in December and January by the end of the 21 st century. Subsurface flow is projected to increase December through March and decrease April through June, with the timing of the timing shifting from March to possibly January (fig. 35E). Groundwater flow is projected to increase December through April, followed by a decrease May through October (fig. 36E).

\section{Feather River Snow Variables}

Because of increases in temperatures, the PRMS projections indicate that the annual mean percentage of precipitation that falls as snow (fig. 19E), percentage of area covered by snow (fig. 20E), snowpack water equivalent (fig. 21E), and snowmelt (fig. $22 E$ ) will decrease (tables $5 J-5 M$ ). On a monthly basis, the central tendencies of the five GCMs and three emission scenarios indicate decreases in all months, with the exception of snowmelt (figs. $37 E-40 E$ ). Because of projected warmer temperatures, snowmelt is projected to increase December and January and decrease March through June.

\section{Feather River Soil Moisture Variables}

The PRMS projections of infiltration (figs. $23 E$ and $41 E$ ) are similar to those seen in the precipitation plots (figs. $10 E$ and 29E). The large range in the infiltration projections indicates a high level of uncertainty with no significant overall trend, with the exception of a slight increase in the A1B scenario (table $5 N$ ). High variability in seasonal infiltration also is projected (fig. 41E), with increases during snow accumulation season followed by decreases in snowmelt season.

Changes in the inflow to the subsurface reservoir (fig. 24E) and recharge to the groundwater reservoir (fig. 25E) are similar to the changes seen in the subsurface (fig. 17E) and groundwater (fig. 18E) flow components, respectively. The projections show decreases in the recharge to the groundwater reservoirs for the A1B scenario only (table $5 P$ ) with a high level of uncertainty.

There is a decrease in the projected annual mean soil moisture (fig. $26 E$ and table $5 Q$ ). High variability in seasonal timing of soil moisture is projected (fig. $44 E$ ), with increases projected during the winter months followed by decreases from April through September.

The PRMS projections indicate that the storage in the subsurface (fig. 27E) and the groundwater reservoirs (fig. 28E) reach equilibrium quickly, resulting in simulated values similar to the inflows (see tables $5 O$ and $5 P ; 5 R$ and $5 S$, respectively). High variability in seasonal timing of subsurface and groundwater storage is projected (figs. $45 E$ and $46 E$ ). 


\section{Discussion of Feather River Projections}

For the Feather River Basin, projections indicate that basin temperatures likely are to increase over the next century, and precipitation likely is to fall on the basin in cycles of wetter and drier decadal oscillations. Because large areas of this basin straddle the seasonal snowline, slight changes in temperature will affect precipitation form. The projections also indicate that the cumulative climatic effects on the basin will likely produce more winter runoff, earlier peak streamflow, and less spring snowmelt. The broader-scale effects of climate change on the flow regime of the Feather River project no significant overall trend in annual mean streamflow in the basin, but the uncertainty associated with this is large. These results did not consider many of the important feedback mechanisms which act between the land surface and the atmosphere, such as the relation between evaporation and relative humidity.

The effects of climate change in Feather River Basin may alter both the quantity and timing of streamflow as has been discussed by Dettinger and Cayan (1995). This could potentially change the conditions that affect: water availability in summer for the California State Water Project; winter high flows; and water quality and quantity for fisheries.

\section{Precipitation Runoff Modeling System Projections for South Fork Flathead River, Montana}

The South Fork of the Flathead River Basin is located on the west side of the Continental Divide in northwestern Montana. The South Fork Flathead River flows into the Flathead River and ultimately into the Clark Fork of the Columbia River. At USGS streamflow-gaging station 12362500 , the basin has a drainage area of $4,307 \mathrm{~km}^{2}$. The basin was simulated with the PRMS model by Chase (2011). The PRMS application for this basin contains 106 HRUs with elevations that range from 1,045 to 2,078 meters (table 1).

Mean monthly baseline conditions for the South Fork Flathead River Basin are shown in figures 5 and 6. Mean monthly minimum temperatures range from approximately $-11^{\circ} \mathrm{C}$ during December, January, and February to just below $6.0^{\circ} \mathrm{C}$ during July and August. Mean monthly maximum temperatures range from $-3.6{ }^{\circ} \mathrm{C}$ during December to $21^{\circ} \mathrm{C}$ during August. On a mean monthly basis, precipitation ranges from $1.9 \mathrm{~mm} /$ day (during August) to $5.5 \mathrm{~mm} /$ day (during November). Because of freezing temperatures during the winter months, most precipitation falls as snow and accumulates throughout the winter. The majority of annual mean streamflow occurs during April through July, with the peak monthly streamflow occurring during May or June.

The South Fork Flathead River Basin mostly is undeveloped and covered with forests, which have been affected by wildfires and mountain pine beetles during the 1998-2008 drought. Hungry Horse Reservoir, on the lower end of the
South Fork Flathead River, stores water behind Hungry Horse Dam. Hungry Horse Dam is operated by the Bureau of Reclamation for power generation, flood control, recreation, and flow augmentation for endangered species. Releases from Hungry Horse Dam must meet minimum flow requirements below Hungry Horse Dam and on the main stem Flathead River at Columbia Falls for bull trout, and must provide spring and summer flow augmentation for salmon and steelhead in the Columbia River (Mary Mellema, Bureau of Reclamation, written commun., 2010). These uses together with potential future uses of Hungry Horse storage water pose many challenges to water resources planners and managers.

This PRMS application is used to simulate runoff in the South Fork Flathead basin for forecasting inflow to Hungry Horse Reservoir.

\section{Flathead River Input Variables}

Changes in annual mean precipitation vary in the PRMS projections of the South Fork Flathead River (fig. 10F), with an overall increase in the central tendencies projected for the A1B and A2 scenarios (table 5A). The large range in the precipitation projections indicates a large amount of uncertainty. The high variability in the precipitation projections are demonstrated in the monthly plot, with a tendency towards increasing precipitation by the end of the 21 st century in all but the summer months (fig. 29F).

All PRMS projections indicate steady increases in temperature (figs. $11 F, 12 F, 30 F, 31 F$, and tables $5 B$ and $5 C$ ), with associated uncertainties increasing with time. The projected changes of both maximum and minimum daily temperatures are smallest for the $\mathrm{B} 1$ scenario (tables $5 B$ and $5 C$ ).

All projections indicate steady increases in annual mean evapotranspiration (fig. $13 F$ and table $5 D$ ). High variability in seasonal evapotranspiration is projected, with projected increases in all months except July through September. In July through September evapotranspiration is limited by the decreases in precipitation (figs. $29 F$ and $32 F$ ).

All PRMS projections indicate steady increases in the length of the growing season (fig. $14 F$ and table $5 E$ ). This increase is because of the projected increase of annual temperature (figs. $11 F$ and $12 F$ and tables $5 B$ and $5 C$ ). The projected changes in the length of the growing season are smallest for the B1 scenario (table $5 E$ ).

\section{Flathead River Streamflow Variables}

Though the USGS streamflow-gaging station 12362500 is downstream from Hungry Horse Reservoir, natural streamflows (without the effect of storage in the reservoir) were simulated in PRMS. The PRMS projections indicate an increase in annual mean streamflow for the A1B (fig. $15 F$ and table $5 F$ ), though the uncertainties associated with these projections are large. High variability (indicating uncertainty) in the seasonal timing of streamflow is projected, particularly during the months of 
April, May, and June (fig. 33F). By the end of the 21st century, streamflow is projected to increase from November through April and decrease in May through July. The PRMS simulation of baseline conditions (red line, fig. $33 F$ ) indicate that peak streamflow occurs in May and June, whereas the PRMS projections indicate that, by the year 2030, the projected month of peak streamflow will shift to May.

In general, the PRMS projections indicate increases in surface runoff and groundwater flow (figs. $16 F$ and $18 F$ and tables $5 G$ and $5 I$ ). Streamflow is dominated by the subsurface flow component which projects no significant trend (table $5 H$ ). High variability (indicating uncertainty) in the seasonal timing of these variables is projected (figs. $34 F$ and $35 F$ ), with large increases in surface runoff during November, February, April and May by the end of the 21st century. Projections of subsurface flow indicate increases during November through April followed by large decreases during May through July (fig. $35 F$ ), with groundwater flow increasing in all months (fig. 36F).

\section{Flathead River Snow Variables}

Because of the increase in temperatures, the PRMS projections indicate that the annual mean percentage of precipitation that falls as snow (fig. 19F), percentage of area covered by snow (fig. 20F), and snowpack water equivalent (fig. $21 F$ ) will decrease (tables $5 J-5 L$ ). The projections show no significant trend for annual mean snowmelt (fig. $22 F$ and table $5 M$ ). Warmer temperatures will result in less snowfall and increased snowmelt November through April, so that less snow is available to melt in May, June, and July (fig. 40F).

\section{Flathead River Soil Moisture Variables}

The PRMS projections of infiltration (figs. $23 F$ and $41 F$ ) are similar to those of precipitation (figs. $10 F$ and $29 F$ ). The large range in the infiltration projections indicates a high level of uncertainty with a positive trend in the A1B scenario (table $5 N$ ). High variability in seasonal infiltration also is projected (fig. $41 F$ ), with large increases projected from October through April and large decreases projected for June and July.

Projected changes in the inflow to the subsurface reservoir shows no significant trend (fig. $24 \mathrm{~F}$ and table $5 O$ ), though projected mean monthly inflow to the subsurface reservoir is projected to increase November through April and decrease May through July (fig. 42F). A significant positive trend in groundwater reservoir recharge is projected for the $\mathrm{A} 1 \mathrm{~B}$ and $\mathrm{A} 2$ scenarios (fig. $25 F$ and table $5 P$ ). High variability in seasonal recharge is projected (fig. $43 F$ ).

There is a decrease in the projected annual mean soil moisture for the A1B and A2 scenarios (fig. $26 F$ and table $5 Q$ ). High variability in seasonal timing of soil moisture is projected (fig. 44A), with substantial decreases projected from May through October and substantial increases projected in February and March.
The PRMS projections indicate that storage in the subsurface reservoirs (fig. $27 F$ and table $5 R$ ) and the groundwater reservoirs (fig. $28 F$ and table $5 S$ ) both significantly increase. High variability in seasonal timing of subsurface and groundwater storage is projected (figs. $45 F$ and $46 F$ ).

\section{Discussion of Flathead River Results}

Hungry Horse Reservoir, on the South Fork Flathead River, is an important component in the Columbia River system of reservoirs operated by the Bureau of Reclamation. Even as demand for the water stored in the reservoir is increasing, climate projections indicate that the quantity and timing of streamflow entering the reservoir could be changing. PRMS projections indicate that flows could increase in the winter and early spring and decrease in late spring and through the summer. Uncertainty associated with the magnitude of these changes in streamflow is large. These results did not consider potential future land-cover dynamics, such as forest fire or pine beetle damage. The combined effects of climate change and land-cover changes in the South Fork Flathead River Basin could affect water available for use in Montana and in downstream states.

\section{Precipitation Runoff Modeling System Projections for Flint River, Georgia}

The Flint River Basin is located in Macon County Georgia, above Montezuma. Downstream from Montezuma, the Flint River joins the Chattahoochee River and ultimately drains into the Gulf of Mexico. At USGS streamflow-gaging station 02349500 , the basin has a drainage area of $7511 \mathrm{~km}^{2}$. The basin was simulated with the PRMS model by Viger and others (2010). The PRMS application contains 128 HRUs with elevations that range from 90 to 286 meters (table 1).

Mean monthly baseline conditions in the Flint River Basin are shown in figures 5 and 6 . Mean monthly minimum temperatures range from just below $2.0^{\circ} \mathrm{C}$ during December and January to almost $21^{\circ} \mathrm{C}$ during July. Mean monthly maximum temperatures range from approximately $14.0^{\circ} \mathrm{C}$ during December and January to over $32^{\circ} \mathrm{C}$ during July. On a mean monthly basis precipitation is highly variable, with ranges from below $2.0 \mathrm{~mm} /$ day (during May and August) to more than $4.0 \mathrm{~mm} /$ day (during February, March, and July). The majority of annual mean streamflow occurs during February and March.

The upper portion of the Flint River flows unimpeded by major impoundments for about 320 river kilometers and provides habitat for biologically diverse communities that have been lost in the impounded reaches of many other rivers in the eastern United States. River shoal habitats in the upper Flint support a variety of native fishes, mussels, and aquatic plants. The upper Flint River Basin supplies water to a growing population in the Atlanta metropolitan area and is a major recreational resource for the region (Gregory and others, 
2006). Urban growth in the headwaters, which encompass a portion of the Atlanta metropolitan area, and increasing demands for offstream water use will affect future flow regimes in the upper Flint River.

The USGS selected "Water availability for ecological needs in the Upper Flint River Basin, Georgia" as a national priority science thrust program starting in 2006 (Gregory and others, 2006). The Flint River Science project is part of a federally funded program to address key national science priorities including landslides/debris flows, fire science, integrated landscape monitoring, and water availability. The fundamental purpose of this project is to advance the science needed to specify the hydrologic conditions necessary to support flowing-water ecosystems; information that is critical for management of this water resource.

\section{Flint River Input Variables}

Changes in annual mean precipitation vary in the PRMS projections of the upper Flint River Basin (fig. 10G), with two of three scenarios having significant decreases in mean annual precipitation (table $5 A$ ). Seasonal variability also is apparent in these precipitation projections (fig. 29G).

All PRMS projections indicate steady increases in temperature (figs. $11 G, 12 G, 30 G, 31 G$, and tables $5 B$ and $5 C$ ), with associated uncertainties increasing with time. The projected changes of both maximum and minimum daily temperatures are smallest for the B1 scenario (tables $5 B$ and $5 C$ ).

All projections indicate steady increases in annual mean evapotranspiration (table $5 D$ ), with a large amount of uncertainty, especially in the A2 and A1B scenarios by the end of the 21 st century (fig. 13G). High variability in seasonal evapotranspiration is projected, with increases in evapotranspiration during October through April and July (fig. 32G).

All PRMS projections indicate steady increases in the length of the growing season (fig $14 G$ and table $5 E$ ). This increase is because of the projected increase of annual temperature (figs. $11 G$ and $12 G$ and tables $5 B$ and $5 C$ ). The projected changes in the length of the growing season are smallest for the B1 scenario (table $5 E$ ).

\section{Flint River Streamflow Variables}

The PRMS projections indicate a decrease in annual mean streamflow and corresponding flow components for all but the $\mathrm{B} 1$ scenarios (figs. $15 G-18 G$ and tables $5 F-5 I$ ), though the uncertainties associated with these projections are large. High variability (indicating uncertainty) in the seasonal timing of streamflow is projected. Increased flows in July are because of increased precipitation in both the baseline conditions and the projections (fig. $33 G$ ).

\section{Flint River Snow Variables}

The Flint River Basin receives a small amount of snow. Projections of the snow related variables (figs. 19G-22G and $37 G-40 G$ ) are difficult to interpret because of the small amounts of snow present (simulations indicate that less than 1 percent of the basin is snow covered in January).

\section{Flint River Soil Moisture Variables}

The PRMS projections of infiltration (figs $23 G$ and $41 G$ ) are similar to those of precipitation (figs. $10 G$ and $29 G$ ). The large range in the infiltration projections indicates a high level of uncertainty with a significant overall negative trend for the A2 scenario (table $5 N$ ). High variability in seasonal infiltration also is projected (fig. $41 G$ ).

Projected changes in the inflow to the subsurface reservoir (fig. 24G) and recharge to the groundwater reservoir (fig. 25G) are similar to the changes seen in the subsurface (fig. 17G) and groundwater (fig. 18G) flow components, respectively. The projections show decreases in annual mean inflows to the subsurface reservoirs and recharge for all but the B1 scenario (tables $5 O$ and $5 P$ ). High variability in seasonal recharge is projected (figs. $42 G$ and $43 G$ ).

There is a significant decrease in the trends in annual mean soil moisture (fig. $26 G$ and table $5 Q$ ) for the A1B and A2 scenarios, though the uncertainties are large and increase with time (fig. 26G). High variability in seasonal timing of soil moisture is projected (fig. $44 G$ ), with decreases in every month.

The PRMS projections indicate that the storage in the subsurface (fig. 27G) and the groundwater reservoirs (fig. 28G) reached equilibrium quickly, resulting in simulated values similar to the inflows (tables $5 O$ and $5 P$ compared to tables $5 R$ and $5 S$ ). High variability in seasonal timing of subsurface and groundwater storage is projected (figs. $45 G$ and $46 G)$.

\section{Discussion of Flint River Results}

In the upper Flint River watershed, increasing demand for water from the steady growth of the Atlanta metropolitan area has the potential to alter streamflow throughout the watershed. Increased development, combined with severe droughts in the area, has resulted in shortages and restrictions on the limited surface-water supplies.

The broader-scale effect of climate change on the flow regime of the Flint River indicates a slight drying of the watershed, but the variability associated with the magnitude of this projected drying is large. These results did not consider potential future land-cover dynamics. They also do not answer the question of whether the potentially adverse effects because of climate change, combined with the added urbanization stresses, can be mitigated with careful land-use planning in the Flint River Basin. 
The combined effects of decreased precipitation (particularly during the summer months) and urbanization in the Flint River may alter both the quantity and timing of streamflow. This has the potential to change the conditions that support biological diversity in aquatic communities.

\section{Precipitation Runoff Modeling System Projections for Naches River, Washington}

The Naches River Basin is a tributary to the Yakima River Basin in Washington. Much of the Naches River Basin lies on the east-side slopes of the Cascade Mountains. At USGS streamflow-gaging station 12494000 , the basin has a drainage area of $2,437 \mathrm{~km}^{2}$. The basin was simulated with the PRMS model by Mastin and Vaccaro (2002). The PRMS application contains 363 HRUs with elevations that range from 562 to 1,650 meters (table 1).

Mean monthly baseline conditions in the Naches River Basin are shown in figures 5 and 6 . Mean monthly minimum temperatures range from below $-7.0^{\circ} \mathrm{C}$ during December to above $7.5^{\circ} \mathrm{C}$ during July and August. Mean monthly maximum temperatures range from below -1.0 during December to $22^{\circ} \mathrm{C}$ during July and August. On a mean monthly basis, precipitation ranges from less than $0.4 \mathrm{~mm} /$ day (during August) to more than $4.0 \mathrm{~mm} /$ day (during December). Because of freezing temperatures during the winter months, precipitation falls as snow and accumulates throughout the winter. The majority of annual mean streamflow occurs during April through June, with the peak monthly streamflow occurring during May.

Agriculture is the principal economic activity in the Yakima River Basin with about $200 \mathrm{~km}^{2}$ in the low-lying semiarid-to-arid parts of the basin. Agriculture in the basin depends on irrigation with a demand of about 3,200 million cubic-meters of water that is mostly supplied with surface water. Five principle reservoirs in the upper portions of the basin with a capacity of 1,300 million cubic-meters supplement flows in the rivers to supply irrigators and provide adequate in streamflows for anadromous fish habitat (Mastin and Vaccaro, 2002). Sufficient water to meet the demands of the basin in any one year is dependent highly on an adequate spring snowpack.

\section{Naches River Input Variables}

Changes in annual mean precipitation vary in the PRMS projections of the Naches River Basin (fig. 10H) The large range in the precipitation projections indicates a high level of uncertainty with a trend towards increasing precipitation by the latter half of the 21st century for the A2 and A1B scenarios and (table 5A). Seasonal variability also is apparent in these precipitation projections with increases during the winter months and the largest decreases during July (fig. 29H).

All PRMS projections indicate steady increases in temperature (figs. $11 \mathrm{H}, 12 \mathrm{H}, 30 \mathrm{H}, 31 \mathrm{H}$, and tables $5 \mathrm{~B}$ and $5 C$ ), with associated uncertainties increasing with time. The projected changes of both maximum and minimum daily temperatures are smallest for the B1 scenario (tables $5 B$ and $5 C$ ).

All projections indicate steady increases in annual mean evapotranspiration for the $\mathrm{A} 2$ and $\mathrm{B} 1$ scenarios (fig. $13 \mathrm{H}$ and table $5 D$ ). High variability in seasonal evapotranspiration is projected, with the increases in March through April, and the decreases in July and August (fig. 32A).

All PRMS projections indicate steady increases in the length of the growing season (fig $14 H$ and table $5 E$ ). This increase is because of the projected increase of annual temperature (figs. $11 \mathrm{H}$ and $12 \mathrm{H}$ and tables $5 \mathrm{~B}$ and $5 \mathrm{C}$ ). The projected changes in the length of the growing season are smallest for the $\mathrm{B} 1$ scenario and largest for the $\mathrm{A} 2$ scenario (table $5 E$ ).

\section{Naches River Streamflow Variables}

The PRMS projections indicate a slight increase in annual mean streamflow for the A1B and A2 scenarios (fig. $15 \mathrm{H}$ and table $5 F$ ), though the uncertainties associated with all of these projections are large. High variability (indicating uncertainty) in the seasonal timing of streamflow is projected, with flows increasing in November through March and decreasing in May through July (fig. $33 H$ ). The PRMS simulation of baseline conditions (red line, fig. $33 H$ ) indicate that peak streamflow occurs in May. The PRMS projections indicate that, by the end of the 21 st century, the projected month of peak streamflow occurring as early as February.

The PRMS projections indicate an increase in annual mean surface runoff for all scenarios (fig. $16 G$ and table $5 G$ ), while subsurface flow will increase for the A2 scenario and a decrease for the $\mathrm{B} 1$ scenario (fig. $17 \mathrm{G}$ and table $5 \mathrm{H}$ ). Groundwater flow will increase for the A1B and A2 scenarios (fig. $18 \mathrm{H}$ and table $5 I$ ). High variability (indicating uncertainty) in the seasonal timing of these variables is projected with surface runoff projected to increase from October through June (fig. 24H). Subsurface flow will increase during November through March and decrease during April through July. The PRMS simulation of baseline conditions (red line, fig. $33 H$ ) indicate that peak streamflow occurs in May, while the PRMS projections indicate that this may shift to February. Groundwater flow will increase from December through March, followed by a decrease from May through August (fig. 36H).

\section{Naches River Snow Variables}

Because of increases in temperatures, the PRMS projections indicate that the annual mean percentage of precipitation that falls as snow (fig. 19H), percentage of area covered by snow (fig. 20H), snowpack water equivalent (fig. $21 H$ ), and snowmelt (fig. $22 H$ ) will decrease (tables $5 J-5 M$ ). Seasonal projections indicate decreases in the percent of precipitation that falls as snow, percentage of area covered by snow, and snowpack water equivalent during all snow accumulation and melt months (figs. $37 H-39 H$ ). Snowmelt is projected to 
increase during December through March, followed by large decreases during April and May and smaller decreases in June (fig. 40H).

\section{Naches River Soil Moisture Variables}

The PRMS projections of infiltration (figs. $23 \mathrm{H}$ and $41 \mathrm{H}$ ) are similar to those of precipitation (figs. $10 H$ and $29 H$ ). The large range in the infiltration projections indicates a high level of uncertainty with a positive trend (table $5 N$ ). High variability in seasonal infiltration also is projected (fig. $H$ ), with large increases projected November through February and decreases in July.

Projected changes in the inflow to the subsurface reservoir (fig. 24H) and recharge to the groundwater reservoir (fig. $25 H$ ) are similar to the changes seen in the subsurface (fig. 17H) and groundwater (fig. 18H) flow components, respectively. The projections show increases for inflow to the subsurface reservoir for the $\mathrm{A} 1 \mathrm{~B}$ and $\mathrm{A} 2$ emissions (table $5 O$ and $5 P$ ). High variability in seasonal recharge is projected (figs. $42 \mathrm{H}$ and $43 H$ ).

There is a decrease in the projected annual mean soil moisture (fig. $26 H$ and table $5 Q$ ). High variability in seasonal timing of soil moisture is projected (fig. $44 A$ ), with increases in winter months, because of melting snow, and decreases during April through October.

The PRMS projections indicate that the storage in the subsurface (fig. 27H) and the groundwater reservoirs (fig. $28 H$ ) reach equilibrium quickly, resulting in simulated values similar to the inflows (see tables $5 O$ and $5 P ; 5 R$ and $5 S$, respectively). High variability in seasonal timing of subsurface and groundwater storage is projected (figs. $45 \mathrm{H}$ and $46 \mathrm{H}$ ).

\section{Discussion of Naches River Results}

The PRMS projections show seasonal changes in snow and rain dynamics for the Naches River Basin. Projections indicate that increases in air temperature will result in increased winter runoff because the form of the precipitation will change from snow to rain. When precipitation falls as rain, it becomes streamflow more quickly than if it had fallen as snow and accumulated in the snowpack. Also, more rain and less snow means less runoff in the late spring and summer. This has implications for water managers who rely on the snowmelt from the spring snowpack to replenish reservoirs and provide early season irrigation. Whereas projections indicate an increase in total annual runoff, runoff during the spring is less, and therefore, water managers will need to store more winter runoff to meet the irrigation and in-stream flow demands. The effects of climate change in the Naches River basin may alter the timing of streamflow and has the potential to change the conditions that support biological diversity in aquatic communities.

\section{Precipitation Runoff Modeling System Projections for Pomperaug River, Connecticut}

The Pomperaug River Basin is located in western Connecticut. The river flows into the Housatonic River which is a tributary to the Long Island Sound. At USGS streamflowgaging station 01204000 , the basin has a drainage area of $194 \mathrm{~km}^{2}$. The basin was simulate by Bjerklie and others (2009). The PRMS application contains 55 HRUs with elevations that range from 63 to 332 meters (table 1).

Mean monthly baseline conditions in the Pomperaug River Basin are shown in figures 5 and 6. Mean monthly minimum temperatures range from approximately $-7.5^{\circ} \mathrm{C}$ during February to just above $16.0^{\circ} \mathrm{C}$ during July. Mean monthly maximum temperatures range from just below $3.0^{\circ} \mathrm{C}$ during January to above $28.0^{\circ} \mathrm{C}$ during July. On a mean monthly basis precipitation is highly variable, with ranges from less than $3.4 \mathrm{~mm} /$ day (during February, June, July, and December) to more than $4.25 \mathrm{~mm} /$ day (during March, August, and November). Because of freezing temperatures during the winter months, precipitation falls as snow and accumulates throughout the winter. The majority of annual mean streamflow occurs during the winter and spring, with the peak monthly streamflow occurring during March.

The basin supports significant areas of groundwater withdrawal from wells completed in stratified glacial deposits, and numerous individual domestic wells completed in bedrock. Water withdrawals for commercial and industrial use are almost entirely from groundwater; however, withdrawals for agricultural use come mostly from surface water. Portions of eight towns are included within the basin boundaries. Land use and land cover in the basin has changed over the last century from primarily agriculture to primarily forest with an increasing, but still relatively small, percentage of urban and residential use (Bjerklie and others, 2009).

In recent years, increased use of surface-water and groundwater supplies in the Pomperaug River Basin has created concern that insufficient flows remain for future development, aquatic habitat, and recreational use. In response, the USGS, in cooperation with the Pomperaug River Watershed Coalition developed a PRMS application for the Pomperaug River as part of a study to evaluate the potential effects of land-use change and water management strategies on streamflow, in-stream habitat, and groundwater availability in the Pomperaug River Basin. Although the basin is rural, the population increased by 15 percent during the last decade as a result of suburban sprawl (Bjerklie and others, 2009). Increases in population and development can lead to changes in land use and land cover that causes change in the distribution of runoff 
and groundwater recharge. Unless these cumulative effects are considered when allocating the water resources, in-stream flow losses and degradation of water quality and ecosystems can occur. Because of uncertainty about the quantity of water available for future use, the effects of new applications for water diversion are poorly understood.

\section{Pomperaug River Input Variables}

Changes in annual mean precipitation vary in the PRMS projections of the Pomperaug River Basin (fig. 10I). The large range in the precipitation projections indicates a high level of uncertainty with a significant positive trend for the B1 scenario (table $5 A$ ). Seasonal variability also is apparent in these precipitation projections (figure 29I).

All PRMS projections indicate steady increases in temperature (figs. $11 I, 12 I, 30 I$, and $31 I$ and tables $5 B$ and $5 C$ ), with associated uncertainties increasing with time. The projected changes of both maximum and minimum daily temperatures are smallest for the $\mathrm{B} 1$ scenario (tables $5 B$ and $5 C$ ).

All projections indicate steady increases in annual mean evapotranspiration (fig. $13 I$ and table $5 D$ ). High variability in seasonal evapotranspiration is projected with increases in all months (figure 32I).

All PRMS projections indicate steady increases in the length of the growing season (fig. $14 I$ and table $5 E$ ). This increase is because of the projected increase of annual temperature (figs. $11 I$ and $12 I$ and tables $5 B$ and $5 C$ ). The projected changes in the length of the growing season are smallest for the $\mathrm{B} 1$ scenario (table $5 E$ ).

\section{Pomperaug River Streamflow Variables}

The PRMS projections indicate a decrease in annual mean streamflow for the A2 scenario (fig. $15 I$ and table $5 F$ ), though the uncertainties associated with these streamflow projections are large. High variability (indicating uncertainty) in the seasonal timing of streamflow is projected, with a decrease in all months with the exception of January (fig. 33I).

The PRMS projections of surface runoff vary (fig. 16I) with no significant trend (table $5 G$ ). With the exception of increases in January, the changes are minimal (fig. 34I). Subsurface and groundwater flow decrease over time (tables $5 F$, $5 H$, and $5 I$ ). High variability (indicating uncertainty) in the seasonal timing of these variables is projected with decreases in all months for the groundwater flow (figure 36I).

\section{Pomperaug River Snow Variables}

Because of the increase in temperatures, the PRMS projections indicate that the annual mean percentage of precipitation that falls as snow (fig. 19I), percentage of area covered by snow (fig. 20I), snowpack water equivalent (fig. 21I), and snowmelt (fig. 22I) will decrease (tables $5 J-5 M$ ). Projected warmer temperatures will: (1) result in less snowfall, which will result in less snow available to melt in the spring; (2) decrease the amount of precipitation that falls as snow, percentage of area covered by snow, and snowpack water equivalent in every month (figs. 37I-39I); and (3) increase the snowmelt in January (fig. 40A), which is consistent with the projections of monthly streamflow (fig. 33I) and surface runoff (fig. 34I).

\section{Pomperaug River Soil Moisture Variables}

The PRMS projections of infiltration (figs. 23I and 41I) are similar to those of precipitation (figs. $10 I$ and 29I). The large range in the infiltration projections indicates a high level of uncertainty with a positive trend for the B1 scenario (table $5 N$ ). High variability in seasonal infiltration also is projected (fig. 41I).

Projected changes in the inflow to the subsurface reservoir (fig. 24I) and recharge to the groundwater reservoir (fig. 25I) are similar to the changes seen in the subsurface (fig. 17I) and groundwater (fig. 18I) flow components, respectively. The projections show no significant trends in the inflows to the subsurface reservoirs (table 5O). The large range in the projections of annual mean recharge indicates a high level of uncertainty, with decreases projected for the A1B and A2 scenarios (table $5 P$ ). High variability in seasonal recharge is projected (figs. $42 A$ and $43 A$ ).

There is a decrease in the projected annual mean soil moisture (fig. $26 I$ and table $5 Q$ ). High variability in seasonal timing of soil moisture is projected (fig. 44I), with decreases in nearly every month. The largest decreases occur during the summer months when potential evapotranspiration demand is highest.

The PRMS projections indicate that the storage in the subsurface (fig. 27I) and the groundwater reservoirs (fig. 28I) reach equilibrium quickly, resulting in simulated values similar to the inflows (see tables $5 O$ and $5 P ; 5 R$ and $5 S$, respectively). High variability in seasonal timing of subsurface and groundwater storage is projected (figs. $45 I$ and $46 I$ ).

\section{Discussion of Pomperaug River Results}

In the Pomperaug River Basin, increasing demand for groundwater from steady population growth has the potential to reduce groundwater base flow to streams throughout the watershed. Increasing stress on groundwater and base flow directly may affect the capacity to supply high quality groundwater to residents and at the same time not be able to preserve adequate base flow to streams for aquatic habitat. The broaderscale effects of climate change on the flow regime of the Pomperaug River indicate an overall slight drying of the basin with a somewhat larger reduction in groundwater relative to streamflow, however the uncertainty associated with the magnitude of this drying is large. These results did not consider potential future population and land-use changes. The results also do not answer the question of whether the potentially 
adverse effects because of climate change can be mitigated with careful basinwide land-use planning. The combined effects of climate change and urbanization in the watershed may alter both the quantity and timing of streamflow and has the potential to change the conditions that support biological diversity in aquatic communities.

\section{Precipitation Runoff Modeling System Projections for Sagehen Creek, California}

The Sagehen Creek Basin is located on the east slope of the northern Sierra Nevada and is a tributary to the Truckee River in California. At USGS streamflow-gaging station 10343500 , the basin has a drainage area of $27 \mathrm{~km}^{2}$. The basin was simulated with a fully coupled groundwater/surface-water model (Markstrom and others, 2008). The PRMS portion of the GSFLOW application contains 128 HRUs with elevations that range from 1,941 to 2,589 meters (table 1).

Mean monthly baseline conditions in the Sagehen Creek basin are shown in figures 5 and 6 . Mean monthly minimum temperatures range from less than $-9.5^{\circ} \mathrm{C}$ during December and February to just above $5.0^{\circ} \mathrm{C}$ during July and August. Mean monthly maximum temperatures range from $2.0^{\circ} \mathrm{C}$ during December to over $24.0^{\circ} \mathrm{C}$ during July and August. On a mean monthly basis, precipitation ranges from less than $0.25 \mathrm{~mm} /$ day (during July) to almost $8.0 \mathrm{~mm}$ /day (during January). Because of freezing temperatures during the winter months, precipitation falls as snow and accumulates throughout the winter. The majority of annual mean streamflow occurs from April through June, with the peak monthly streamflow occurring during May.

\section{Sagehen Creek Input Variables}

Changes in annual mean precipitation vary in the PRMS projections of the Sagehen Creek Basin (fig. 10J). The large range in the precipitation projections indicates a high level of uncertainty with a significant positive trend for the A1B scenario (table $5 A$ ). Seasonal variability also is apparent in these precipitation projections (fig. 29J), with the largest potential increases and uncertainties in precipitation in the winter months.

All PRMS projections indicate steady increases in temperature (figs. $11 \mathrm{~J}, 12 \mathrm{~J}, 30 \mathrm{~J}, 31 \mathrm{~J}$, and tables $5 \mathrm{~B}$ and $5 \mathrm{C}$ ), with associated uncertainties increasing with time. The projected changes of both maximum and minimum daily temperatures are smallest for the $\mathrm{B} 1$ scenario (tables $5 B$ and $5 C$ ).

All projections indicate steady increases in annual mean evapotranspiration (fig. $13 \mathrm{~J}$ and table $5 \mathrm{D}$ ). High variability in seasonal evapotranspiration is projected, with increases during December through May and decreases during July through September (fig. 32J).

All PRMS projections indicate steady increases in the length of the growing season (fig. $14 J$ and table 5E). This increase is because of the projected increase of annual temperature (figs. $11 \mathrm{~J}$ and $12 \mathrm{~J}$ and tables $5 \mathrm{~B}$ and $5 \mathrm{C}$ ). The projected changes in the length of the growing season are smallest for the B1 scenario (table $5 E$ ).

\section{Sagehen Creek Streamflow Variables}

The PRMS projections indicate no significant overall trend in annual mean streamflow (fig. $15 \mathrm{~J}$ and table $5 F$ ), though the uncertainties associated with these projections are large. High variability (indicating uncertainty) in the seasonal timing of streamflow is projected, with increases during January through April, and decreases during May and June. The PRMS simulation of baseline conditions (red line, fig. 33A) indicate that peak streamflow occurs in May, while the PRMS projections indicate that, by the end of the 21 st century, peak streamflow will occur in April.

The PRMS projections indicate a positive trend in annual mean surface runoff for the A1B and B1 scenarios (fig. $16 \mathrm{~J}$ and table $5 G$ ), whereas the subsurface and groundwater flow (figs. $17 \mathrm{~J}$ and $18 J$ ) have no trend (tables $5 H-5 I$ ).

High variability (indicating uncertainty) in the seasonal timing of these variables is projected (figs. $34 A$ and $35 A$ ), with increases in January surface runoff (fig. 34J). Subsurface flow is the dominant component of streamflow and has a similar seasonal pattern (figs. $15 \mathrm{~J}$ and $18 \mathrm{~J}$, table $5 F$ and $5 H$ ). The month of peak subsurface flow is projected to shift from May to April. High variability in the seasonal timing of groundwater flow also is projected (fig. 36J).

\section{Sagehen Creek Snow Variables}

Because of the increase in temperatures the PRMS projections indicate that the annual mean percentage of precipitation that falls as snow (fig. 19J), percentage of area covered by snow (fig. 20J), and snowpack water equivalent (fig. 21J) will decrease (tables $5 J-5 L$ ) with the exception of the A2 scenario for snowpack water equivalent (no significant trend). Projected warmer temperatures will: (1) result in less snowfall, which will result in less snow available to melt in the spring; (2) decrease the amount of precipitation that falls as snow, percentage of area covered by snow, and snowpack water equivalent in every month (figs. 37J-39J); and (3) increase the snowmelt during November through March, leaving less snow to melt during May and June (fig. 40J).

\section{Sagehen Creek Soil Moisture Variables}

The PRMS projections of infiltration (figs. $23 J$ and $41 J$ ) are similar to those of precipitation (figs. $10 \mathrm{~J}$ and 29J). The large range in the infiltration projections indicates a high level of uncertainty with a positive trend for the A1B scenario (table $5 N$ ). High variability in seasonal infiltration also is projected (fig. 41J), with projected increases during the snow accumulation season. 
Projected changes in the inflow to the subsurface reservoir (fig. 24J) and recharge to the groundwater reservoir (fig. $25 J$ ) are similar to the changes seen in the subsurface (fig. 17J) and groundwater (fig. 18J) flow components, respectively. The projections show no significant trends in inflow to these reservoirs (tables $5 O$ and $5 P$ ). High variability in seasonal recharge is projected (figs. $42 J$ and $43 J$ ).

There is a decrease in the projected annual mean soil moisture for the A1B scenario (fig. $26 J$ and table 5Q). High variability in seasonal timing of soil moisture is projected (fig. 44J), with increases during December through March and decreases during May through October.

The PRMS projections indicate that the storage in the subsurface (fig. 27J) and the groundwater reservoirs (fig. 28J) reach equilibrium quickly, resulting in simulated values similar to the inflows (see tables $5 O$ and $5 P ; 5 R$ and $5 S$, respectively). High variability in seasonal timing of subsurface and groundwater storage is projected (figs. $45 \mathrm{~J}$ and $46 J$ ).

\section{Discussion of Sagehen Creek Results}

In northern Nevada and central California increased development, combined with severe droughts, have resulted in shortages and restrictions on limited surface-water supplies. The broader-scale effects of climate change on the flow regime and water-balance components of Sagehen Creek indicate a shift in timing of streamflow from May to April with no overall discernible trend in annual flows. The uncertainties associated with the projections are large. These results did not consider many of the important feedback mechanisms which act between the land surface and the atmosphere.

\section{Precipitation Runoff Modeling System Projections for Sprague River, Oregon}

The Sprague River Basin is located in the northeastern headwaters of the Klamath River in Oregon. At USGS streamflow-gaging station 11501000 , the basin has a drainage area of $4,053 \mathrm{~km}^{2}$. The basin was simulated with the PRMS model by Hay and others (2009). The PRMS application contains 102 HRUs with elevations that range from 1,316 to 2,203 meters (table 1).

Mean monthly baseline conditions in the Sprague River basin are shown in figures 5 and 6 . Mean monthly minimum temperatures range from less than $-7.0^{\circ} \mathrm{C}$ during December to above $6.5^{\circ} \mathrm{C}$ during July and August. Mean monthly maximum temperatures range from $3.2^{\circ} \mathrm{C}$ during December to over $26.0^{\circ} \mathrm{C}$ during July and August. On a mean monthly basis, precipitation ranges from less than $0.4 \mathrm{~mm} /$ day (during July) to almost $2.6 \mathrm{~mm} /$ day (during January). Because of freezing temperatures during the winter months, precipitation falls as snow and accumulates throughout the winter. The majority of annual mean streamflow occurs in spring, with the peak monthly streamflow occurring during April.
The Sprague River flows to the west draining inactive volcanoes, rims, scarps, buttes, and fault-block mountains along the northern, eastern, and southern basin boundaries. Lower elevation benches and tablelands are used as rangeland and bottomlands along the main stream and major tributaries are used for irrigated agriculture. Conifer forests, which cover approximately 80 percent of the basin area, are predominant on the slopes of buttes and mountains. The Sprague River Basin supplies approximately 25 percent of total inflow to the Upper Klamath Lake. Demand for water from the lake has increased in recent years in response to needs such as irrigated agriculture, minimum downstream flow for threatened Coho salmon, water supply for nearby wildlife refuges, hydropower, and a minimum lake level for habitat and water-quality protection of two endangered sucker species (Risley and others, 2005).

\section{Sprague River Input Variables}

Changes in annual mean precipitation vary in the PRMS projections of the Sprague River Basin (fig. 10K). The large range in the precipitation projections indicates a high level of uncertainty with a significant positive trend for the A1B scenario (table $5 A$ ). Seasonal variability also is apparent in these precipitation projections with increases in precipitation during the winter months (fig. 29K).

All PRMS projections indicate steady increases in temperature (figs. $11 \mathrm{~K}, 12 \mathrm{~K}, 30 \mathrm{~K}, 31 \mathrm{~K}$, and tables $5 \mathrm{~B}$ and $5 \mathrm{C}$ ), with associated uncertainties increasing with time. The projected changes of both maximum and minimum daily temperatures are smallest for the $\mathrm{B} 1$ scenario (tables $5 B$ and $5 C$ ). Projections for the A1B scenario indicate steady increases in annual mean evapotranspiration (fig. $13 K$ and table $5 D$ ). High variability in seasonal evapotranspiration is projected, with increases projected from November through April, followed by decreases in June through September (fig. 32K).

All PRMS projections indicate steady increases in the length of the growing season (fig. $14 K$ and table $5 E$ ). This increase is because of the projected increase of annual temperature (figs. $11 \mathrm{~K}$ and $12 \mathrm{~K}$ and tables $5 \mathrm{~B}$ and $5 \mathrm{C}$ ). The projected changes in the length of the growing season are smallest for the B1 scenario (table $5 E$ ).

\section{Sprague River Streamflow Variables}

The PRMS projections indicate no significant trend in annual mean streamflow (fig. $15 K$ and table $5 F$ ), though the uncertainties associated with these projections are large. The large range in the streamflow projections indicates a large amount of uncertainty. High variability (indicating uncertainty) in the seasonal timing of streamflow is projected, with increases during December through March and decreases from April through June (fig. 33K). The PRMS simulation of baseline conditions (red line, fig. $33 \mathrm{~K}$ ) indicates that peak streamflow occurs in April, whereas the PRMS projections indicate 
that, by the end of the 21 st century, the projected month of peak streamflow will be March.

The PRMS projections indicate increases in the surface runoff for the A1B and A2 scenarios (fig. $16 K$ and table $5 G$ ), whereas there is no trend in the subsurface and groundwater flow (figs. $17 \mathrm{~K}$ and $18 \mathrm{~K}$ and tables $5 \mathrm{H}$ and $5 \mathrm{I}$ ). High variability (indicating uncertainty) in the seasonal timing of these variables is projected (figs. $34 K-36 K$ ), with increases in surface runoff and subsurface flow during December through March, decreases in subsurface flow during April through June, and increases in groundwater flow during December through May.

\section{Sprague River Snow Variables}

Because of increases in temperatures, the PRMS projections indicate that the annual mean percentage of precipitation that falls as snow (fig. $19 \mathrm{~K}$ ), percentage of area covered by snow (fig. 20K), snowpack water equivalent (fig. $21 K$ ), and snowmelt (fig. $22 K$ ) will decrease (tables $5 J-5 M$ ). Seasonally, precipitation that falls as snow (fig. $37 \mathrm{~K}$ ), percentage of area covered by snow (fig. $38 \mathrm{~K}$ ), and snowpack water equivalent (fig $39 K$ ) are all projected to decrease during the snow accumulation and melt seasons. The projections also indicate that snowmelt (fig. 40K) will increases in February and decreases during November, January, and March through June by the end of the 21 st century. Warmer temperatures will result in less snowfall resulting in less snow available to melt in the spring.

\section{Sprague River Soil Moisture Variables}

The PRMS projections of infiltration (figs. $23 K$ and $41 K$ ) are similar to those of precipitation (figs. $10 A$ and 29A). The large range in the infiltration projections indicates a high level of uncertainty with a significant increase in infiltration for the A1B scenario (table $5 N$ ). High variability in seasonal infiltration also is projected (fig. $41 \mathrm{~K}$ ), with increases in infiltration during snow accumulation season followed by decreases in the snowmelt season.

Projected changes in the inflow to the subsurface reservoir (fig. 24K) and recharge to the groundwater reservoir (fig. $25 K$ ) are similar to the changes seen in the subsurface (fig. 17K) and groundwater (fig. 18K) flow components, respectively. The projections show no significant trends in inflow to these reservoirs (tables $5 O$ and $5 P$ ). High variability in seasonal recharge is projected (figs. $42 K$ and $43 K$ ).

There is a decrease in the projected annual mean soil moisture for the A1B scenario (fig. $26 K$ and table $5 Q$ ) though the uncertainties associated with these projections are large. High variability in seasonal timing of soil moisture is projected (fig. $44 K$ ), with increases during December through March, followed by decreases during April through September.

The PRMS projections indicate that the storage in the subsurface (fig. 27K) and the groundwater reservoirs (fig. $28 K$ ) reach equilibrium quickly, resulting in simulated values similar to the inflows (see tables $5 O$ and $5 P ; 5 R$ and $5 S$, respectively). High variability in seasonal timing of subsurface and groundwater storage is projected (figs. $45 K$ and $46 K$ ).

\section{Discussion of Sprague River Results}

Supplying approximately 25 percent of inflow to the Upper Klamath Lake, the Sprague River Basin is vital to environmental and human water needs within the Klamath River Basin. As water demands increase, the reliability of flows from headwater basins like the Sprague becomes increasingly critical in water-management decisions. The broader scale effects of climate change on the flow regime of the Sprague River indicate increased annual high flows earlier in the spring as overall basin storage decreases. However, the uncertainty associated with these changes is large. It is apparent that with significant changes in seasonal patterns of inflow to the Upper Klamath Lake, one or a combination of the following measures may be necessary: (1) modification of the operation of the lake as a storage reservoir, (2) creation of additional storage capacity to meet water demands, and (3) reprioritization of water deliveries for environmental and human needs.

\section{Precipitation Runoff Modeling System Projections for Starkweather Coulee, North Dakota}

The Starkweather Coulee Basin is a major basin within the Devils Lake Basin in northeastern North Dakota. At USGS streamflow-gaging station 05056239, the basin has a drainage area of $543 \mathrm{~km}^{2}$ of which about $259 \mathrm{~km}^{2}$ probably does not contribute to streamflow (Vining, 2002). The basin was simulated with the PRMS model by Vining (2002). The PRMS application contains 50 HRUs with elevations that range from 446 to 491 meters (table 1).

Mean monthly baseline conditions in the Starkweather Coulee basin are shown in figures 5 and 6 . Mean monthly minimum temperatures range from less than $-20.0^{\circ} \mathrm{C}$ during December, January, and February to above $10.0^{\circ} \mathrm{C}$ during July. Mean monthly maximum temperatures range from just above $-10.0^{\circ} \mathrm{C}$ during January to almost $27.0^{\circ} \mathrm{C}$ during August. On a mean monthly basis, precipitation ranges from approximately $0.6 \mathrm{~mm} /$ day (December, January, and February) to over $3.0 \mathrm{~mm} /$ day (during July). Because of freezing temperatures during the fall and winter months, precipitation falls as snow and accumulates throughout the winter. The majority of annual mean streamflow occurs during April and May, with the peak monthly streamflow occurring during April.

The topography of the basin is mostly level to slightly rolling in the south, somewhat more rolling in the central, and mostly level again in the north, with predominately loam to silty clay soils throughout the basin. Thousands of small depressions and wetlands exist on the surface. Many of the original depressions and wetlands were drained years ago and currently are being farmed. The majority of the land in 
the basin is used in production agriculture, although some land areas are used as pasture or are enrolled in conservation programs (Vining, 2002).

The region around the Devils Lake Basin has experienced intermittent flooding conditions since the summer of 1993 during which copious amounts of precipitation filled many lakes, wetlands, and depressions. The low-relief topography of the region and the lack of a prominent outlet from Devils Lake means that precipitation and runoff water remains within the basin. Millions of dollars have been spent protecting infrastructure around Devils Lake from rising waters (Vining, 2002). Alternatives have been proposed for stabilizing basin water levels including the re-establishment and expansion of wetlands and depressions in the upper basin, including Starkweather Coulee basin, to store runoff water. Increases in the amount of surface-water storage would likely decrease runoff to Devils Lake, but if the surface-water storage capacity is exceeded, then the wetlands and depressions likely will discharge most of the runoff water received.

\section{Starkweather Coulee Input Variables}

Changes in annual mean precipitation vary in the PRMS projections of the Starkweather Coulee Basin (fig. 10L). The large range in the precipitation projections indicates a high level of uncertainty with no significant overall trend (table $5 A$ ). Seasonal variability also is apparent in these precipitation projections (fig. 29L).

All PRMS projections indicate steady increases in temperature (figs. $11 \mathrm{~L}, 12 \mathrm{~L}, 30 \mathrm{~L}, 31 \mathrm{~L}$, and tables $5 B$ and $5 \mathrm{C}$ ), with associated uncertainties increasing with time. The projected changes of both maximum and minimum daily temperatures are smallest for the $\mathrm{B} 1$ scenario (tables $5 B$ and $5 C$ ).

All projections indicate steady increases in annual mean evapotranspiration (fig. $13 \mathrm{~L}$ and table $5 D$ ). High variability in seasonal evapotranspiration is projected, with large increases during April and May (fig. 32L).

All PRMS projections indicate steady increases in the length of the growing season (fig. $14 L$ and table $5 E$ ). This increase is because of the projected increase of annual temperature (figs. $11 L$ and $12 L$ and tables $5 B$ and $5 C$ ). The projected changes in the length of the growing season are smallest for the B1 scenario (table $5 E$ ).

\section{Starkweather Coulee Streamflow Variables}

The PRMS projections indicate a decrease in annual mean streamflow for scenarios A1B and A2 (fig. $15 \mathrm{~L}$ and table $5 F$ ), though the uncertainties associated with these projections are large. High variability (indicating uncertainty) in the seasonal timing of streamflow is projected, particularly in April (fig. 33L). Projections indicate little or no streamflow during September through February, because of subfreezing temperatures in the basin, with decreases in flow during April and May.
The PRMS projections indicate decreases in surface runoff, subsurface and groundwater flow for the A1B and A2 scenarios (figs. $16 L-18 L$ and tables $5 G-5 I$ ). High variability (indicating uncertainty) in the seasonal timing of these variables is projected (figs. $34 L-36 L$ ), with the largest decreases in surface flow during April through August. Subsurface and groundwater flow are the dominant components of streamflow and have a similar seasonal pattern (figs. $15 \mathrm{~L}, 17 \mathrm{~L}$ and $18 \mathrm{~L}$, tables $5 F, 5 G$ and $5 I$ ) with the largest decreases in April.

\section{Starkweather Coulee Snow Variables}

The PRMS projections indicate no significant trend in the annual mean percentage of precipitation that falls as snow (fig. $19 L$ and table 5J). Seasonal projections indicate little change in precipitation form (fig. $37 L$ ) is expected during December and January because of the cold temperatures (figs. $11 \mathrm{~L}$ and $12 \mathrm{~L}$ ), with decreases in the percent of precipitation that falls as snow in all other snowfall months. Because of increases in temperatures, the PRMS projections indicate that the percentage of area covered by snow (fig. 20L) and snowpack water equivalent (fig. $21 \mathrm{~L}$ ) will decrease (tables $5 J$ and $5 L$ ), with high seasonal variability in these values (figs. $38 L$ and $39 L$ ) and decreases during November through March. PRMS projections also indicate no significant trend in annual mean snowmelt (fig. $22 L$ and table $5 M$ ), with increases during November through February and large decreases during March and April.

\section{Starkweather Coulee Soil Moisture Variables}

The PRMS projections of infiltration indicate an increase for the A2 emission scenario (fig. $23 L$ and table $5 N$ ). High variability in seasonal infiltration also is projected (fig. $41 \mathrm{~L}$ ), with increases during October through February and May and decreases during April and August.

Projected changes in the inflow to the subsurface reservoir (fig. 24L) and recharge to the groundwater reservoir (fig. $25 L$ ) are similar to the changes seen in the subsurface (fig. 17L) and groundwater (fig. 18L) flow components, respectively. The large range in the projections indicates a high level of uncertainty, with decreases projected in the inflows to the subsurface reservoirs and recharge for the A1B and A2 scenarios (tables $5 O$ and $5 P$ ). High variability in seasonal recharge is projected (figs. $42 L$ and $43 L$ ).

There is a decrease in the projected annual mean soil moisture for the A1B and A2 scenarios (fig. 26L and table 5Q), with the large uncertainties associated with these projections. High variability in seasonal timing of soil moisture is projected (fig. $44 L$ ), with decreases projected for all months except March.

The PRMS projections indicate that the storage in the subsurface (fig. 27L) and the groundwater reservoirs (fig. 28L) reach equilibrium quickly, resulting in simulated values similar to the inflows (see tables $5 \mathrm{O}$ and 5P; $5 \mathrm{R}$ and 5S, 
respectively). High variability in seasonal timing of subsurface and groundwater storage is projected (figs. $45 \mathrm{~L}$ and $46 \mathrm{~L}$ ).

\section{Discussion of Starkweather Coulee Results}

In the Starkweather Coulee Basin, continued above-normal precipitation along with drainage of wetlands and depressions could allow intermittent flooding conditions to occur. Additional drainage downstream could increase Devils Lake water levels causing additional damage to regional infrastructures and requiring additional spending on protective measures.

The broader-scale effects of climate change on streamflow and water storage in Starkweather Coulee Basin indicate the possibility of an overall slight drying of the basin, but the uncertainty associated with this drying is large. Alternating flood and drought conditions, which occurred in the past, are also possible. The results did not consider potential future land-cover dynamics. However, land-cover dynamics in the basin would likely be limited to the type of agriculture and drainage practiced on the landscape.

\section{Precipitation Runoff Modeling System Projections for Trout Lake, Wisconsin}

The Trout Lake Basin is located in the Northern Highlands district in north-central Wisconsin, in an area with many lakes. At USGS streamflow-gaging station 05357245, the basin has a drainage area of $120 \mathrm{~km}^{2}$. The basin was simulated with a fully coupled groundwater/surface-water model (GSFLOW; Markstrom and others, 2008). The PRMS portion of the application contains 146 HRUs with elevations that range from 491 to 522 meters (table 1).

Mean monthly baseline conditions in the Trout Lake Basin are shown in figures 5 and 6 . Mean monthly minimum temperatures range from approximately $-15.0^{\circ} \mathrm{C}$ during January to more than $14.5^{\circ} \mathrm{C}$ during July. Mean monthly maximum temperatures range from just below $-6.0^{\circ} \mathrm{C}$ during January to almost $26.0^{\circ} \mathrm{C}$ during July and August. On a mean monthly basis, precipitation ranges from approximately $0.6 \mathrm{~mm} /$ day (during February) to more than $3.6 \mathrm{~mm} /$ day (during June and July). Because streamflow is dominated by groundwater, there is not a large amount of variability in the mean monthly distribution of streamflow.

The aquifer consists of 40-60 m of unconsolidated Pleistocene glacial sediments mostly comprised of glacial outwash sands and gravel. In this area, streamflow is dominated by groundwater contributions; however, surface runoff can occur during intense rainfall periods and spring snowmelt. Surface runoff also occurs locally in low-lying areas near streams and lakes where the unsaturated zone is thin. The Trout Lake basin (which includes Trout Lake and all four of the basins that flow into the lake) has been the focus of previous regional groundwater modeling studies including a two-dimensional analytic element screening model and three-dimensional, finite-difference models. See Walker and Bullen (2000) for additional descriptions of the setting and Pint (2002) and Hunt and others $(2005 ; 2008)$ for more description of previous modeling efforts.

The Trout Lake Basin is one of five research basins in the U.S. Geological Survey's Water, Energy and Biogeochemical Budgets program, and is collocated with the National Science Foundation funded North Temperate Lakes Long Term Ecological Research site (Magnuson and others, 1984). A major focus of the Trout Lake program is the development of a hydrologic model to allow predictions of hydrologic and biogeochemical response to future conditions including land use and climate change.

\section{Trout Lake Input Variables}

Changes in annual mean precipitation vary in the PRMS projections of the Trout Lake Basin (fig. 10M). The large range in the precipitation projections indicates a high level of uncertainty with no significant overall trend (table $5 A$ ). Seasonal variability also is apparent in these precipitation projections, especially from May through October (fig. 29M).

All PRMS projections indicate steady increases in temperature (figs. $11 \mathrm{M}, 12 \mathrm{M}, 30 \mathrm{M}, 31 \mathrm{M}$, and tables $5 \mathrm{~B}$ and $5 C$ ), with associated uncertainties increasing with time. The projected changes of both maximum and minimum daily temperatures are smallest for the B1 scenario and largest for the A2 (tables $5 B$ and $5 C$ ).

All projections indicate steady increases in annual mean evapotranspiration (fig. $13 M$ and table $5 D$ ). High variability in seasonal evapotranspiration is projected, with increases in all months, especially April (fig. 32M).

All PRMS projections indicate steady increases in the length of the growing season (fig. $14 M$ and table $5 E$ ). This increase is because of the projected increase of annual temperature (figs. $11 M$ and $12 M$ and tables $5 B$ and $5 C$ ). The projected changes in the length of the growing season are smallest for the $\mathrm{B} 1$ scenario and largest for the $\mathrm{A} 2$ scenario (table $5 E$ ).

\section{Trout Lake Streamflow Variables}

The PRMS projections indicate a decrease in annual mean streamflow for the A1B and A2 scenarios (fig. $15 \mathrm{M}$ and table $5 F$ ), though the uncertainties associated with these projections are large. High variability (indicating uncertainty) in the seasonal timing of streamflow is projected, particularly during June through December (fig. 33M).

The PRMS projections indicate increases in surface runoff on an annual mean basis for the A2 scenario (fig. 16M and table $5 G$ ). High variability (indicating uncertainty) in the seasonal timing of these variables is projected (fig. 34M). The projections indicate minimal changes in subsurface flow on an annual mean basis (fig. $17 \mathrm{M}$ and table $5 \mathrm{H}$ ), the largest seasonal decreases occurring in April and May (fig. 35M). The PRMS projections indicate no significant trend in groundwater 
flow (fig. $18 M$ and table $5 I$ ). High variability (indicating uncertainty) in the seasonal timing of groundwater flow is projected (fig. 36L).

\section{Trout Lake Snow Variables}

Because of increases in temperatures, the PRMS projections indicate that the annual mean percentage of precipitation that falls as snow (fig. 19M), percentage of area covered by snow (fig. 20M), snowpack water equivalent (fig. 21M), and snowmelt (fig. 22M) will decrease, with the exception of the B1 emission scenario for snowmelt (tables $5 J-5 M$ ). Projected warmer temperatures will: (1) result in less snowfall, which will result in less snow available to melt in the spring; (2) decrease the amount of precipitation that falls as snow, percentage of area covered by snow, and snowpack water equivalent in every month (figs. 37A-39A); and (3) increase the snowmelt in November through March, leaving less snow to melt in April and May (fig. 40M).

\section{Trout Lake Soil Moisture Variables}

The PRMS projections of infiltration (figs. $23 M$ and $41 M$ ) are similar to those of precipitation (figs. 10M and 29M). The large range in the infiltration projections indicates a high level of uncertainty with no significant overall trend (table $5 N$ ). High variability in seasonal infiltration also is projected (fig. $41 M$ ).

Projected changes in the inflow to the subsurface reservoir (fig. 24M) and recharge to the groundwater reservoir (fig. $25 M$ ) are similar to the changes seen in the subsurface (fig. 17M) and groundwater (fig. 18M) flow components, respectively. The projections show slight decreases in inflows to the subsurface reservoirs and recharge on an annual mean basis (tables $5 O$ and $5 P$ ). High variability in seasonal recharge is projected (figs. $42 M$ and $43 M$ ), with large decreases in inflows to the subsurface reservoirs and groundwater recharge during April through May.

There is a decrease in the projected annual mean soil moisture (fig. $26 M$ and table $5 Q$ ). High variability in seasonal timing of soil moisture is projected (fig. $44 A$ ), with decreases in all but the coldest months.

The PRMS projections indicate that the storage in the subsurface (fig. 27M) and the groundwater reservoirs (fig. 28M) reach equilibrium quickly, resulting in simulated values similar to the inflows (see tables $5 O$ and $5 P ; 5 R$ and $5 S$, respectively). High variability in seasonal timing of subsurface and groundwater storage is projected (figs. $45 M$ and $46 M$ ).

\section{Discussion of Trout Lake Results}

The snow-component results suggest a shorter snowcovered season, with smaller snowpack volumes and a tendency for mid-winter melts. The snow-covered season will begin later and end earlier. This has implications for winter recreation, and could potentially affect phenological responses, with corresponding changes in the ecosystem. The recharge results suggest a shift in the timing of the recharge. The current conditions (water years 1988 through 1999) result in a hydrologic regime characterized by a buildup of water in the snowpack, and a large spring recharge occurrence before losses through transpiration begin. The projections indicate a flattening of the seasonal recharge response, with more prominent recharge pulses during the growing season and late fall. The flattening of the recharge dynamic of this northern temperate hydrologic system could result in a more southern lake-stream watershed. This change also potentially could affect the seasonal nature of water budgets to lakes and the seasonal distribution of streamflow, which are both dependent on groundwater levels. As with the snow-covered response, a shift in the timing of recharge could alter phenological responses with associated ecosystem changes.

The soil moisture results indicate a reduction of soil moisture, which could potentially change the overall vegetation in the system. This has obvious ecosystem implications, and potentially could result in a changed and less diverse plant assemblage. Further, the system likely would be more prone to fires, which dramatically could alter the hydrologic response after a fire.

One of the principle concerns in the Trout Lake area is the fate of hydrologic budgets of area lakes and resulting lake levels. This has wide ranging implications for property values, recreational use of the lakes, the hard-water/soft-water status and trophic state of the lakes, and the biotic response within the lakes. Because of the precipitation rates being relatively higher than basinwide evapotranspiration rates, flat terrain, and coarse aquifer sediments, groundwater has a strong effect on the hydrologic system in the watershed. Therefore, a more sophisticated representation of the groundwater system would likely provide a more representative view of the response of the basin hydrology to change. A coupled groundwater-surface water model (GSFLOW; Markstrom and others, 2008) can be used to predict the response of the full hydrologic system, including groundwater and lake levels, which in turn will allow a more complete assessment of the response of the system to climate and land-use change.

\section{Precipitation Runoff Modeling System Projections for Yampa River, Colorado}

The Yampa River Basin at Steamboat Springs, Colorado is part of the Green River Basin, and an important tributary of the Colorado River. At USGS streamflow-gaging station 09239500 , the basin has a drainage area of $1,471 \mathrm{~km}^{2}$. The basin was simulated with PRMS by Hay and others (2006b; 2006c). The PRMS model contains 68 HRUs with elevations that range from 2,124 to 3,504 meters (table 1).

Mean monthly baseline conditions in the Yampa River basin are shown in figures 5 and 6 . Mean monthly minimum temperatures range from below $-15.0^{\circ} \mathrm{C}$ during December and January to above $5.5^{\circ} \mathrm{C}$ during July. Mean monthly 
maximum temperatures range from below $-2.0^{\circ} \mathrm{C}$ during January to almost $23.0^{\circ} \mathrm{C}$ during July. On a mean monthly basis, precipitation ranges from less than $1.25 \mathrm{~mm} /$ day (during August) to $3.0 \mathrm{~mm} /$ day (during April). Because of freezing temperatures during the winter months, precipitation falls as snow and accumulates throughout the winter. The majority of annual mean streamflow occurs during May and June, with the peak monthly streamflow occurring during June.

The Yampa River at Steamboat Springs, Colorado was included in the Hydro-Climatic Data Network, indicating that the streamflow records prior to 1987 (when the Stagecoach Reservoir was completed) for this streamflow-gaging station relatively are "unaffected by artificial diversions, storage, or other works of man in or on the natural stream channels or in the watershed" (Slack and Landwehr, 1992). The Yampa River Basin is one of only a few river basins in Colorado where current and projected total water demand is less than the native supply (Colorado Water Conservation Board, 2002). Because of its importance as a source of water to the Colorado River, the U.S. Geological Survey conducted studies (Hay and others, 2006b; Hay and others, 2006c) of the effects of potential climate change on the water resources of the Yampa River Basin.

Tourism that results from abundant local recreational options is the largest source of revenue in the region (Steamboat on the Move, 2009), but agriculture also is important. Many of the recreational activities, such as fishing, whitewater boating, snowmobiling, and skiing, are dependent directly on the basins water resources. The Steamboat Ski area falls within the Yampa River Basin and has a base elevation of 2,203 meters and top elevation of 2,768 meters. The ski area typically receives more than 8 meters of snowfall, and operates from late November to early April.

\section{Yampa River Input Variables}

Changes in annual mean precipitation vary in the PRMS projections of the Yampa River Basin (fig. 10N). The large range in the precipitation projections indicates a high level of uncertainty with a positive significant trend for the A1B scenario (table $5 A$ ). Seasonal variability also is apparent in these precipitation projections, with increasing precipitation during December through February and decreasing precipitation in May (fig. 29N).

All PRMS projections indicate steady increases in temperature (figs. $11 N, 12 N, 30 N, 31 N$, and tables $5 B$ and $5 C$ ), with associated uncertainties increasing with time. The projected changes of both maximum and minimum daily temperatures are smallest for the $\mathrm{B} 1$ scenario (tables $5 B$ and $5 C$ ).

All projections indicate steady increases in annual mean evapotranspiration (fig. $13 N$ and table $5 D$ ). High variability in seasonal evapotranspiration is projected, with increases during October through May and decreases during June through August.

All PRMS projections indicate steady increases in the length of the growing season (fig. $14 N$ and table $5 E$ ). This increase is because of the projected increase of annual temperature (figs. $11 N$ and $12 N$ and tables $5 B$ and $5 C$ ). The projected changes in the length of the growing season are smallest for the B1 scenario (table $5 E$ ).

\section{Yampa River Streamflow Variables}

The PRMS projections indicate a decrease in annual mean streamflow (fig. $15 N$ and table $5 F$ ), though the uncertainties associated with these projections are large. High variability (indicating uncertainty) in the seasonal timing of streamflow is projected, with increases during March through April, decreases during June through July, and minimal change during August through February. The PRMS simulation of baseline conditions (red line, fig. 33N) indicate that peak streamflow occurs in June, whereas the PRMS projections indicate that, by as early as 2030, the projected month of peak streamflow will be May.

The PRMS projections indicate decreases in surface runoff for the B1 scenario (fig. $16 N$ and table $5 G$ ), in subsurface flow for all three scenarios (fig. $17 \mathrm{~N}$ and table $5 \mathrm{H}$ ), and in groundwater flow for the A1B and A2 scenarios (fig. 18N and table 5I). High variability (indicating uncertainty) in the seasonal timing of these variables is projected. By the end of the 21 st century, peak timing is projected to shift from June to April for surface runoff, from June to May for subsurface flow, and from July to possibly June for groundwater flow.

\section{Yampa River Snow Variables}

Because of increases in temperatures, the PRMS projections indicate that the annual mean percentage of precipitation that falls as snow (fig. 19N), percentage of area covered by snow (fig. 20N), snowpack water equivalent (fig. 21N), and snowmelt (fig. 22N) will decrease (tables 5J-5M). Seasonally, these variables have a high degree of uncertainty during the snow accumulation and melt months (figs. $37 N-40 N$ ). Projected warmer temperatures result in a decrease in the percent of precipitation that falls as snow, percentage of area covered by snow, and snowpack water equivalent. The largest projected decreases in the percent of precipitation that falls as snow and percentage of area covered by snow are seen in the spring and fall transition months. The PRMS simulation shows maximum snowpack water equivalent for baseline conditions (red line, fig. 33N) occurring in March and April, whereas the PRMS projections indicate that the snowpack water equivalent maximums will shift to March by the end of the 21 st century. Projections also indicate increases in snowmelt during March and April and decreases in June. Despite this, there is no change in the peak timing of snowmelt (May) projected (fig. $40 \mathrm{~N}$ ). Warmer temperatures also will result in less snowfall so that less snow is available to melt during May through July. 


\section{Yampa River Soil Moisture Variables}

The PRMS projections of infiltration (figs. $23 N$ and $41 N$ ) are similar to those of precipitation (figs. $10 N$ and $29 N$ ). The large range in the infiltration projections indicates a high level of uncertainty with no significant overall trend (table $5 N$ ). High variability in seasonal infiltration also is projected (fig. $41 N$ ), with large increases during March and April followed by large decrease during June.

Projected changes in the inflow to the subsurface reservoir (fig. $24 N$ ) and recharge to the groundwater reservoir (fig. 25N) are similar to the changes seen in the subsurface (fig. 17N) and groundwater (fig. 18N) flow components, respectively. The projections show significant negative trends in inflow to the subsurface reservoir for scenarios A1B and A2 (table 5O). The large range in the projections of annual mean recharge indicates a high level of uncertainty, especially during the snow accumulation and melt seasons.

There is a decrease in the projected annual mean soil moisture (fig. $26 \mathrm{~A}$ and table $5 Q$ ). High variability in seasonal timing of soil moisture is projected (fig. $44 N$ ), with decreases during June through September and increases during March and April.

The PRMS projections indicate that the storage in the subsurface (fig. $27 N$ ) and the groundwater reservoirs (fig. $28 N$ ) reach equilibrium quickly, resulting in simulated values similar to the inflows (see tables $5 O$ and $5 P$; $5 R$ and $5 S$, respectively). High variability in seasonal timing of subsurface and groundwater storage is projected (figs. $45 A$ and $46 A$ ).

\section{Discussion of Yampa River Results}

Streamflow in the Yampa River Basin is under increasing demand from water users and energy companies in the southwestern United States, and recreationalists within the basin. Potential decreases in streamflow resulting from future changes in climate may add to the stress that this basin will experience as a result of projected increases in domestic and industrial water use (Colorado Water Conservation Board, 2006b). The effects of climate change in the Yampa River Basin may also result in earlier snowmelt resulting in earlier spring runoff and affecting the conditions that support recreational activities such as skiing.

\section{Integrated Watershed-Scale Response to Climate Change for Selected Basins Across the United States}

Intercomparisons between the PRMS projections made for the 14 basins were difficult to make because the PRMS applications were set up in different ways for different purposes. For example, how the HRUs were delineated, selection of input parameters related to routing and soil moisture computations, and differences in how the measured climate data was distributed to the HRUs resulted in simulated results that were difficult to compare.

In addition to this report, the results of this study have been summarized and evaluated in 10 different publications. Results produced by this study have been evaluated in the following publications (table 1):

1. Battaglin and others (2011) identifies the potential effects of future climate on hydrologic conditions for two Colorado basins, the East River at Almont and the Yampa River at Steamboat Springs, and for two ski areas within those basins. All Precipitation Runoff Modeling System projections of the scenarios indicate decreases in basin mean snow-covered area and snowpack water equivalent, with uncertainty around the projected decreases increasing with time. However, when examined on a monthly basis, the changes are most dramatic during fall and spring and less important during winter. Presumably, ski area locations are picked because of a tendency to receive snow and retain snowpack relative to the surrounding area. This effect of ski area location within the basin was examined by comparing simulations of March snow-covered area and snowpack water equivalent for the entire basin with simulations for the portion of the basin that represents the ski area in the PRMS applications. These projections indicate only small changes in March snow-covered area at both ski areas for the three scenarios until around 2050. After 2050 , larger decreases are projected, but also there is large uncertainty. Results from this modeling effort show that there is a wide range of possible outcomes for projected snowpack conditions in Colorado. The results also highlight the differences between projections for entire basins and projections for particular locations within those basins.

2. Bjerklie and others (2011) developed a regional watershed model using geographic information systembased parameters for watersheds contributing to Long Island Sound, including the Connecticut River Basin. The study region covers approximately 15,800 square miles, extending from a moderate coastal climate zone in the south to a mountainous northern New England climate zone dominated by snowmelt in the north. The input data, including daily precipitation and maximum and minimum daily temperature for 47 years (1961-2007), indicate that precipitation and temperature have been increasing across the modeled area. Although both maximum and minimum daily temperature have been increasing, minimum temperature has increased more than maximum temperature. The Precipitation Runoff Modeling System simulation indicates that there is an upward trend in groundwater recharge across most of the modeled region. The trend in simulated snowfall generally is not significant across the region, except in the extreme 
southeast part of Connecticut and in parts of central Massachusetts where it has been downward.

3. Christiansen and others (2011) examine trends in the total length (annual), as well as changes in the timing of onset (spring) and the end (fall) of the growing season. The results showed an increase in the annual growing season length in all 14 basins of this study, averaging 27 to 47 days for the 3 scenarios. The change in the spring and fall growing season onset and end varied across the 14 basins, with larger increases in seasonal change occurring in the mountainous regions, and smaller increases occurring in the midwest, northeast, and southeast regions.

4. Hay and others (2011) present an overview of this study, details of the methodology, results from the 14 basin simulations, and interpretation of these results. A key finding is that the hydrological response of the different geographical regions of the United States to potential climate change may be different, depending on the dominant physical processes of that particular region. Also considered is the tremendous amount of uncertainty present in the climate emission scenarios and how this uncertainty propagates through the hydrologic simulations. This report concludes with a discussion of the lessons learned and potential for future work.

5. Koczot and others (2011) evaluate the projected changes in temperature and precipitation from several climate change emission scenarios are applied using three different baseline conditions, each corresponding to measured temperature and precipitation data from specified historical periods during the 20th century. Differences and similarities between projections of hydrologic components (that is, snowpack formation and melt, evapotranspiration, and streamflow) are examined and results indicate that the selection of a specific time period used for baseline conditions has a substantial effect on some, but not all, hydrologic variables. This effect seems to be amplified in hydrologic variables which accumulate over time, for instance actual evapotranspiration and soil-moisture content. Projections also indicate that to account for uncertainty related to the selection of baseline conditions, a range of different baseline conditions need to be considered.

6. Mastin and others (2011) find a future of declining spring snowpack in the 8 snowmelt dominated basins of the 14. Snow-covered area and snow-water equivalent were used to compare the spring snowpack for current conditions (2006) with three time periods in the future $(2030,2060$, and 2090) using the three scenarios. Distributed snow-water equivalent and snow-covered area values were evaluated by elevation zones. The change in the spring snowpack over time was greater than the change among scenarios suggesting that even for a globally reduced carbon emission scenario, large decreases in snowwater equivalent likely are to occur.

7. Milly and Dunne (2011) analyze the effects of hydrologic adjustment on the projections of runoff change associated with projected 21st-century climate change. Results in a case study including 3 climate models and 10 river basins in the contiguous United States found that relative (that is, fractional or percentage) runoff change computed with hydrologic adjustment more often than not was less positive (or, equivalently, more negative) than what was projected by the climate models. The dominant contributor to this decrease in runoff was a ubiquitous change in runoff (median -11 percent) caused by the hydrologic model's apparent amplification of the climate-modelimplied growth in potential evapotranspiration.

8. Risley and others (2011b) used projected daily streamflow and energy output from the Precipitation Runoff Modeling System applications to compute a range of statistics. With a side-by-side comparison of the statistical analyses for the 14 basins, regional climatic and hydrologic trends over the 21 st century could be identified. Low-flow statistics (95-percent exceedance, 7-day mean annual minimum, and summer mean monthly streamflow) decreased for almost all basins. Annual maximum daily streamflow also decreased in all the basins except for all four basins in California and the Pacific Northwest. An analysis of the supply of available energy and water for the basins indicated that ratios of evaporation to precipitation and potential evapotranspiration to precipitation for most of the basins will increase. Probability density functions were developed to assess the uncertainty and multimodality in the effect of climate change on mean annual streamflow variability. Probability density functions for two basins in the upper Midwest were more dispersed and skewed than for all the other basins. For most of the 14 basins, the probability density shape did not change over the 21 st century.

9. Viger and others (2011) examine the projected effects of long-term urbanization and climate change on the freshwater resources of the Flint River basin. Projections of urbanization through 2050 derived for the Flint River basin by the FOREcasting SCEnarios (FORE-SCE, Sohl and Sayler, 2008) landcover change model also were used as input to the PRMS application. Comparison of the central tendency of streamflow simulated based on the three climate-change scenarios showed a slight decrease in overall streamflow relative to simulations under 
current conditions (water years 1988 through 1999), mostly caused by decreases in the surface-runoff and groundwater components. The addition of information about forecasted urbanization of land surfaces to the hydrologic simulation mitigated the decreases in streamflow, mainly by increasing surface runoff.

10. Walker and others (2011a) fitted empirical orthogonal functions to the Precipitation Runoff Modeling System model output driven by the ensemble of climate projections, and provided a basis for randomly (but representatively) generating realizations of hydrologic response to future climates. For each realization, the 1.5-year flood was calculated to represent a flow important for sediment transport and channel geomorphology. The empirical probability density function of the 1.5-year flood was estimated using the results across the realizations, for each basin. Nine of the 14 basins studied showed clear temporal shifts in the probability density functions of the 1.5 -year flood projected into the 21st century. In the Western United States, where the annual peak discharges are heavily influenced by snowmelt, three basins show at least a 10 percent increase in the 1.5 -year flood in the 21 st century; the remaining two basins demonstrate increases in the 1.5-year flood, but the temporal shifts in the probability density functions and the percent changes are not as distinct. Four basins in the Eastern Rockies/Central United States show at least a 10 percent decrease in the 1.5-year flood; the remaining two basins demonstrate decreases in the 1.5-year flood, but the temporal shifts in the probability density function and the percent changes are not as distinct. Two basins in the eastern United States show at least a 10 percent decrease in the 1.5 -year flood; the remaining basin shows little or no change in the 1.5 -year flood.

\section{Summary}

The simulated hydrologic response of different climate change emission scenarios for the 21 st century were evaluated in 14 basins from different hydroclimatic regions across the United States using the Precipitation Runoff Modeling System, a process-based, distributed-parameter watershed model. This study involved five major steps: (1) setup, calibrate, and evaluate the Precipitation Runoff Modeling System (PRMS) model in 14 basins across the United States by local USGS personnel; (2) acquire selected simulated carbon emission scenarios from the World Climate Research Programme's Coupled Model Intercomparison Project; (3) statistical downscaling of these scenarios to create PRMS input files which reflect the future climatic conditions of these scenarios; (4) generate PRMS projections for the carbon emission scenarios for the 14 basins; and (5) analyze the simulated hydrologic response.
All climate change emission scenarios evaluated with PRMS show a steady increase in maximum and minimum temperatures progressing through the 21 st century. This generally results in projections of earlier spring snowmelt and increases in evapotranspiration, if soil moisture is available. If these projected increases in temperature hold true, then the largest changes in the timing of streamflow will occur in the snowmelt-dominated basins with winter temperatures close to the freezing point. This has long been recognized that an increase in winter temperature initially resulting in less snow (change of form from snow to rain) and eventually earlier snowmelt. The PRMS projections for the three emission scenarios indicate that streamflow could increase in the winter and early spring and decrease in late spring and through the summer for many of the basins; however, uncertainty associated with the magnitude of these changes in streamflow is large. Basins in which precipitation form (rain or snow) is sensitive to the air temperature are the most sensitive to changes in temperature and precipitation. This is consistent with the findings of previous work: warmer temperatures at mid-elevation mountainous regions show decreasing snowpack and earlier melt despite the increase in precipitation, whereas high-elevation regions that remain well below freezing during winter show little effects.

A change in timing and volume of snowmelt has large implications for water managers who rely on the melt from the spring snowpack to replenish reservoirs and provide early season irrigation; earlier snowmelt may lead to increased water scarcity. Even when the annual streamflow shows a positive trend into the $21^{\text {st }}$ Century, spring streamflow from snowmelt is projected to decrease, and therefore, water managers may need to store more winter streamflow to meet the irrigation and instream flow demands. Increasing temperatures and population will invariably lead to increasing water demands, making water-management decisions increasingly difficult due to the uncertainty in the quantity and timing of the spring snowmelt.

The ecological implications of changes in the timing of and volume of snowmelt are not well understood. The PRMS projections indicate changes in the timing of peak flows due to snowmelt in all but the coldest basins, which may affect fresh-water mixing in estuarine ecosystems and increase the length of the summer drought that characterizes much of western North America. A shorter snow-covered season, with smaller snowpack volumes, and a tendency for mid-winter melts has implications for winter recreation, but could also affect phenological responses, with corresponding changes in the ecosystem. Earlier snowmelt and increases in evapotranspiration rates may result in drier forests and more wildfires and threaten fish and amphibian habitat. Projected reductions in soil moisture could lead to changes in overall vegetation. This has ecological implications and could result in a changed and less diverse plant assemblage. Further, the basins could be more prone to wildfires.

This study did not consider future population growth and land-use changes. It is possible that changes in land cover can 
affect climate at the regional and local scales. The methodologies for adequate simulation of changes in urban systems, agricultural systems, ecosystem disturbance regimes, and soil effects are not yet well developed. The combined effects of climate change and urbanization may alter both the quantity and timing of streamflow and can change the conditions of water quality that support biological diversity in aquatic communities. Also not addressed, is whether the adverse effects of climate change can be mitigated with careful landuse planning.

In many of the basins, projected decreases in soil moisture may increase agricultural water consumption, resulting in an increase in overall water demand. A reduction in soil moisture will cause drier conditions in the root zone likely causing increased irrigation groundwater withdrawals to maintain current agricultural production levels. Such simulations are beyond the scope of the methods used in this study, as simulating effects of increased irrigation requires a coupled groundwater-surface water model.

When evaluating the projections developed for the 14 basins, it was apparent that the consistent application of the hydrology model in each basin would lead to more comparable results in inter-regional studies of this type. Of particular benefit, would be a hydrologic modeling structure which would help address the issues of (1) differing temporal and spatial scales and resolutions, (2) evolving data availability and needs, (3) differing calibration methods and purpose, and (4) internal and external institutional constraints. Future research, including the development of a national hydrologic modeling structure with consistent formulation, would enhance this type of climate change study.

\section{Acknowledgments}

The work described in this report was supported through the USGS Global Change Research and Development Program and the USGS National Research Program. The initial development of the 14 Precipitation Runoff Modeling System basin applications was supported through Wisconsin Focus on Energy, Maine Department of Marine Resources Bureau of Sea Run Fisheries and Habitat, Iowa Department of Natural Resources, California Department of Water Resources Cooperative Snow Surveys Program, Bureau of Reclamation, USGS Southeast Regional Assessment Program, USGS Watershed and River Systems Management Program, Pomperaug River Watershed Coalition, O\&G Industries, Naugatuck Valley Council of Governments, and the North Dakota State Water Commission.

The technical reviewers of this report were R. Dwight Atkinson, U.S. Environmental Protection Agency, Kenneth R. Odom, USGS, and Mark Ayers, USGS (Emeritus). We appreciate their thorough reviews and comments that improved greatly the quality of this report.

\section{References Cited}

Antolik, M.S., 2000, An overview of the National Weather Service's centralized statistical quantitative precipitation forecasts: Journal of Hydrology, p. 306-337.

Arnell, N.W., 2003a, Effects of IPCC SRES emissions scenarios on river runoff: a global perspective: Hydrology and Earth System Sciences, v. 7, p. 619-641.

Arnell, N.W., 2003b, Relative effects of multi-decadal climatic variability and changes in the mean and variability of climate due to global warming: future streamflows in Britain: Journal of Hydrology, v. 270, p. 195-213.

Arnell, N.W., and Reynard, N.S., 1996, The effects of climate change due to global warming on river flows in Great Britain: Journal of Hydrology, v. 183, p. 397-424.

Barnes, K.K., and Eash, D.A., 1990, Flood of June 17, 1990, in the Clear Creek Basin, east-central Iowa: U.S. Geological Survey Open-File Report 94-78, 16 p.

Battaglin, W.A., Hay, L.E., and Markstrom, S.L., 2011, Simulating the potential effects of climate change in two Colorado Basins and at two Colorado ski areas: Earth Interactions, v. 15, p. 1-23.

Bjerklie, D.M., Trimbley, T.J., and Viger, R.J., 2011, Simulated watershed-scale snowfall and groundwater recharge trends from 1961-2007 and projected to the end of this century based on selected climate-change scenarios for basins draining to Long Island Sound: Earth Interactions, p. 1-35.

Blöschl, Günter, and Montanari, Alberto, 2010, Climate change impacts-Throwing the dice?: Hydrological Processes, v. 24, p. 374-381.

Boorman, D.B., and Sefton, C.E.M., 1997, Recognizing the uncertainty in quantification of the effects of climate change on hydrological response: Climatic Change, v. 35, p. 415-434.

Buytaert, Wouter, C'elleri, Rolando, and Timbe, Luis, 2009, Predicting climate change impacts on water resources in the tropical Andes: the effects of GCM uncertainty: Geophysical Research Letters, v. 36, p. 1-11.

Chase, K.J., 2011, Development of a precipitation-runoff model to simulate unregulated streamflow in the South Fork Flathead River Basin, Montana: U.S. Geological Survey Scientific Investigations Report 2011-5095, 39 p.

Christiansen, D.E., Markstrom, S.L., and Hay, L.E., 2011, Impacts of climate change on growing season in the United States: Earth Interactions, p. 1-17. 
Colorado Water Conservation Board, 2002a, Gunnison River basin water use, growth and water demand projections, 2 p., accessed January 2009, at http://cwcb.state.co.us/Home/ RiverBasinFacts/BasinFactSheets.htm.

Colorado Water Conservation Board, 2002b, Yampa/White River basin water use, growth and water demand projections, 2 p., accessed January 2009, at http://cwcb.state.co.us/ Home/RiverBasinFacts/BasinFactSheets.htm.

Colorado Water Conservation Board, 2006a, Statewide water supply initiative fact sheet: Gunnison Basin, 2 p., accessed January 2009, at http://cwcb.state.co.us/Home/RiverBasinFacts/BasinFactSheets.htm.

Colorado Water Conservation Board, 2006b, Statewide water supply initiative fact sheet: Yampa/White/Green Basin, 2 p., accessed January 2009, at http://cwcb.state.co.us/Home/ RiverBasinFacts/BasinFactSheets.htm.

Dettinger, M.D. and Cayan, D.R., 1995, Large-scale atmospheric forcing of recent trends toward early snowmelt runoff in California: Journal of Climate, v. 8, p. 606-623.

Diaz-Nieto, Jacqueline, and Wilby, R.L., 2005, A comparison of statistical downscaling and climate change factor methods: Impacts on low flows in the River Thames, United Kingdom: Climatic Change, v. 69, p. 245-268.

Donahue, R.J., McVicar, T.R., and Roderick, M.L., 2010, Assessing the ability of potential evaporation formulations to capture the dynamics in evaporative demand within a changing climate: Journal of Hydrology, v. 386, p. 186-197.

Draper, David, 1995, Assessment and propagation of model uncertainty: Journal of the Royal Statistical Society Series B-Methodological, v. 57, p. 45-97.

Duan, Q.A., Gupta, V.K., and Sorooshian, Soroosh, 1993, A shuffled complex evolution approach for effective and efficient global minimization: Journal of Optimization Theory and Its Applications, v. 76, n. 3, p. 501-521.

Duan, Q.A., Sorooshian, Soroosh, and Gupta, V.K., 1992, Effective and efficient global optimization for conceptual rainfall-runoff models: Water Resources Research, v. 28, no. 4, p. 1015-1031.

Duan, Q.A., Sorooshian, Soroosh, and Gupta, V.K., 1994, Optimal use of the SCE-UA global optimization method for calibrating watershed models: Journal of Hydrology, v. 158, p. $265-284$.

Dudley, R.W., 2008, Simulation of the quantity, variability, and timing of streamflow in the Dennys River Basin, Maine, by use of a precipitation-runoff watershed model: U.S. Geological Survey Scientific Investigations Report 2008$5100,44 \mathrm{p}$.
Eckhardt, Klaus, and Ulbrich, Uwe, 2003, Potential impacts of climate change on groundwater recharge and streamflow in a central European low mountain range: Journal of Hydrology, v. 284, p. 244-252.

Farnsworth, R.K., Thompson, E.S., and Peck, E.L., 1982, Evaporation atlas for the contiguous 48 United States: NOAA Technical Report NWS 33, Washington, D.C., U.S. Department of Commerce, $26 \mathrm{p}$.

Fealy, Rowan, and Sweeney, John, 2008, Statistical downscaling of temperature, radiation and potential evapotranspiration to produce a multiple GCM ensemble mean for a selection of sites in Ireland: Irish Geography, v. 41, no. 1, p. 1-27.

Fowler, H.J., Blenkinsop, Stephen, and Tebaldi, Claudia, 2007, Review. Linking climate change modelling to impacts studies: recent advances in downscaling techniques for hydrological modeling: International Journal of Climatology, v. 27, p. $1547-1578$.

Freeman, G.J., 2008, Runoff impacts of climate change on northern California's watersheds as influenced by geology and elevation - a mountain hydroelectric system perspective: Proceedings of the Western Snow Conference, April 14-17, 2008, Hood River, Oregon, Omnipress, v. 76, p. 23-34.

Giorgi, Filippo, Hewitson, Bruce, Christensen, J.H., Hulme, Michael, von Storch, Hans, Whetton, P.H., Jones, R.N., Mearns, L.O., and Fu, C.B., 2001, Regional climate information-Evaluation and projections: In Climate Change 2001, in Houghton, J.T., Ding, Yihui., Griggs, D.J., Noguer, M., van der Linden, P.J., Dai, X., Maskell, K., and Johnson, C.A., eds., The Scientific Basis, Contribution of Working Group I to the Third Assessment Report of the Intergovernmental Panel on Climate Change: Cambridge, United Kingdom, Cambridge University Press, p. 583-638.

Gregory, M.B., Freeman, M.C., and Hughes, W.B., 2006, Water availability for ecological needs in the Upper Flint River Basin, Georgia: U.S. Geological Survey Fact Sheet 2006-3114, 4 p.

Gunnison Country Chamber of Commerce, 2009, About Gunnison, accessed January 2009, at http://www.gunnison-co.com/

Hall, N.D., Stuntz, B.B., and Abrams, R.H., 2008, Climate change and freshwater resources: Natural Resources and Environment, v. 22, no. 3, p. 30-35.

Hay, L.E., Battaglin, W.A., Parker, R.S., and Leavesley, G.H., 1993, Modeling the effects of climate change on water resources in the Gunnison River basin, Colorado: Chapter 16, in Goodchild, M.F., Parks, B.O., and Steyaert, L.T., eds., Environmental modeling with GIS: Oxford, Oxford University Press, p. 173-181. 
Hay, L.E., Clark, M.P. Pagowski, M., Leavesley, G.H., and Gutowski, Jr., W.J., 2006a, One-way coupling of an atmospheric and a hydrologic model in Colorado: Journal of Hydrometeorology, v. 7, no. 4, p. 569-589.

Hay, L.E., Leavesley, G.H., and Clark, M.P., 2006b, Use of remotely-sensed snow covered area in watershed model calibration for the Sprague River, Oregon: Joint 8th Federal Interagency Sedimentation Conference and 3rd Federal Interagency Hydrologic Modeling Conference, April 2-6, 2006, Reno, Nevada.

Hay, L.E., Leavesley, G.H., Clark, M.P., Markstrom, S.L., Viger, R.J., and Umemoto, Makiko, 2006c, Step-wise, multiple-objective calibration of a hydrologic model for a snowmelt-dominated basin: Journal of American Water Resources, v. 42, no. 4, p. 877-890.

Hay, L. E., Markstrom, S. L., and Ward-Garrison, C.D., 2011, Watershed-scale response to climate change through the 21st century for selected basins across the United States: Earth Interactions, v. 15, p. 1-37.

Hay, L.E. and McCabe, G.J., 2010, Hydrologic effects of climate change in the Yukon River Basin: Climatic Change, v. 100 , p. 509-523.

Hay, L.E., McCabe, G.J., Clark, M.P., Risley, J.C., 2009, Reducing streamflow forecast uncertainty: Application and qualitative assessment of the upper Klamath River basin, Oregon: Journal of the American Water Resources Association, v. 45 , no. 3 , p. 580-596.

Hay, L.E. and Umemoto, Makiko, 2006, Multiple-objective stepwise calibration using Luca: U.S. Geological Survey Open-File Report 2006-1323, 25 p.

Hay, L.E., Wilby, R.L., and Leavesley, G.H., 2000, A comparison of delta change and downscaled carbon emission scenarios for three mountainous basins in the United States: Journal of American Water Resources, v. 36, no. 2, p. 387-397.

Helsel, D.R. and Hirsch, R.M., 2002, Statistical methods in water resources: U.S. Geological Survey Techniques of Water Resources Investigations, Book 4, chapter A3. U.S. Geological Survey. 522 p.

Hunt, R.J., and Steuer, J.J., 2001, Evaluating the effects of urbanization and land-use planning using ground-water and surface-water models: U.S. Geological Survey Fact Sheet $102-01,4$ p.

Hunt, R.J., Strand, Mac, and Walker, J.F., 2006, Measuring groundwater-surface water interaction and its effect on wetland stream benthic productivity, Trout Lake watershed, northern Wisconsin, USA: Journal of Hydrology v. 320, no. 3-4, p. 370-384.
Hunt, R.J., Walker, J.F., and Doherty, John, 2008, Using GSFLOW to simulate climate change in a northern temperate climate, in MODFLOW and more 2008: Ground water and public policy, Proceedings of the 9th International Conference of the International Ground Water Modeling Center: Golden, Colo., Colorado School of Mines, p. 109-113.

Ikeda, Kyoko, Rasmussen, R.M., Liu, Changhai, Gochis, David, Yates, David, Chen, Fei, Tewari, Mukul, Barlage, M.J., Dudhia, Jimy, Miller, Kathy, Arsenault, Kristi, Grubišić, Vanda, Thompson, Greg, and Guttman, Ethan, 2010, Simulation of seasonal snowfall over Colorado: Atmospheric Research, v. 97, p. 462-477.

Iowa Department of Natural Resources, 2011, Clear Creek watershed enhancement project, accessed June 2011, at http://www.iowadnr.gov/Environment/WaterQuality/ WatershedImprovement.aspx.

Gunnison Country Chamber of Commerce, 2009, About Gunnison, accessed January 2009, at http://www.gunnisonco.com/

Intergovernmental Panel on Climate Change, 2001, Climate change 2001: impacts, adaptation, vulnerability: Cambridge and New York, Cambridge University Press, 1,032 p.

Intergovernmental Panel on Climate Change, 2007, Summary for policymakers, in Climate change 2007-The physical science basis, contributions of working group 1 to the fourth assessment report of the Intergovernmental Panel on Climate Change: Cambridge and New York, Cambridge University Press, $18 \mathrm{p}$.

Jensen, M.E., Rob, D.C.N., and Franzoy, C.E., 1970, Scheduling irrigations using climate-crop-soil data: Journal of the Irrigation and Drainage Division, American Society of Civil Engineers, v. 96, no. IR1, p. 25-38.

Khan, M.S., Coulibaly, Paulin, and Dibike, Y.B., 2006, Uncertainty analysis of statistical downscaling methods: Journal of Hydrology, v. 319, p. 357-382.

Kingston, D.G., Todd, M.C., Taylor, R.G., Thompson, J.R., and Arnell, N.W., 2009, Uncertainty in the estimation of potential evapotranspiration under climate change: Geophysical Research Letters, v. 36, p. 1-6.

Koczot, K.M., Jeton, A.E., McGurk, B.J., and Dettinger, M.D., 2005, Precipitation-runoff processes in the Feather River Basin, northeastern California, with prospects for streamflow predictability, water years 1971-97: U.S. Geological Survey Scientific Investigations Report 2004-5202, 82 p.

Koczot, K.M., Markstrom, S.L., and Hay, L.E., 2011, Effects of baseline conditions on the hydrologic effects of climate change: Earth Interactions, p. 1-23. 
Leavesley, G.H., Branson, M.D., and Hay, L.E., 1992, Using coupled atmospheric and hydrologic models to investigate the effects of climate change in mountainous regions, in Herrmann, Raymond, ed., Managing water resources during global change: Reno, Nevada, American Water Resources Association, 28th Annual conference and Symposium, p. 691-700.

Leavesley, G.H., Lichty, R.W., Troutman, B.M., and Saindon, L.G., 1983, Precipitation-runoff modeling system-User's manual: U.S. Geological Survey Water-Resources Investigation Report 83-4238, 207 p.

Lettenmaier, D.P., 1976, Detection of trends in water quality data from records with dependent observations: Water Resources Research, v. 12, p. 1037-1046.

Leung, L.R., Mearns, L.O., Giorgi, Filippo, and Wilby, R.L., 2003, Workshop on regional climate research: Needs and opportunities: Bulletin of the American Meteorological Society, v. 84, p. 89-95.

Magnuson, J.J., Bowser, C.J., and Kratz, T.K., 1984, Longterm ecological research (LTER) on north temperate lakes of the United States: Verhandlungen Internationale Vereinigung Limnologie, v. 22, p. 533-535.

Markstrom, S.L., and Hay, L.E, 2009, Integrated watershed scale response to climate change for selected basins across the United States: Water Resources Impact, v. 11, no. 2, p. $8-10$.

Markstrom, S.L., Niswonger, R.G., Regan, R.S., Prudic, D.E., and Barlow, P.M., 2008, GSFLOW-Coupled ground-water and surface-water flow model based on the integration of the Precipitation-Runoff Modeling System (PRMS) and the Modular Ground-Water Flow Model (MODFLOW-2005): U.S. Geological Survey Techniques and Methods 6-D1, 240 p.

Mastin, M.C., Chase, K.J., and Dudley, R.W., 2011, Changes in spring snowpack for selected basins in the United States for different climate-change scenarios: Earth Interactions, v. 15 , p. $1-18$.

Mastin, M.C., and Vaccaro J.J., 2002, Watershed models for decision support in the Yakima River Basin, Washington: U.S. Geological Survey Open-File Report 2002-404, 46 p.

McCabe, G.J., and Hay, L.E., 1994, Hydrologic effects of hypothetical climate change in the East River Basin, Colorado:, Jackson Hole, Wyoming, AWRA Annual Summer Symposium, Effects of Human-Induced Changes on Hydrologic Systems, June 26-29, 1994, p. 163-172.

McCabe, G.J., and Hay, L.E., 1995, Hydrological effects of hypothetical climate change in the East River Basin, Colorado, USA: Hydrological Sciences Journal, v. 40, no. 3, $16 \mathrm{p}$.
McCabe, G.J., and Wolock, D.M., 1997, Climate change and the detection of trends in annual runoff: Climate Research, v. 8 , p. $129-134$.

McCormick, S.D., Hansen, L.P., Quinn, T.P., and Saunders, R.L., 1998, Movement, migration, and smolting of Atlantic salmon (Salmo salar): Canadian Journal of Fisheries and Aquatic Science, v. 55 (Suppl. 1), p. 77-92.

Milly, P.C.D., and Dunne, K.A., 2011, On the hydrologic adjustment of climate-model projections: the potential pitfall of potential evapotranspiration: Earth Interactions, v. 15 , p. $1-14$.

Murphy J.M., Sexton, D.M.H., Barnett, D.N., Jones, G.S., Webb, M.J., Collins, Mat, and Stainforth, D.A., 2004, Quantification of modelling uncertainties in a large ensemble of climate change simulations: Nature, v. 430, p. 768-72.

Pilling, C.G., and Jones, J.A.A., 1999, High resolution equilibrium and transient climate change scenario implications for British runoff: Hydrological Processes, v. 13, no. 17, p. 2877-2895.

Pint, C.D., 2002, A groundwater flow model of the Trout Lake Basin, Wisconsin: calibration and lake capture zone analysis: Madison, Department of Geology and Geophysics, University of Wisconsin-Madison, M.S. thesis, p. 123.

Prudhomme, Christel, and Davies, Helen, 2009, Assessing uncertainties in climate change impact analyses on the river flow regimes in the UK. Part 1: baseline climate: Climatic Change, v. 93, p. 177-195.

Prudhomme, Christel, Reynard, N.S., and Crooks, Sue, 2002, Downscaling of global climate models for flood frequency analysis: where are we now?: Hydrological Processes, v. 16, no. 6 , p. $1137-1150$.

Raftery, A.E., Gneiting, Tilmann, Balabdaoui, Fadoua, and Polakowski, Michael, 2005, Using Bayesian model averaging to calibrate forecast ensembles: Monthly Weather Review, v. 133, p. 1155-1174.

Risley, J.C., Gannett, M.W., Lea, J.K., and Roehl, E.A., Jr., 2001, An analysis of statistical methods for seasonal flow forecasting in the Upper Klamath River Basin of Oregon and California: U.S. Geological Survey Scientific Investigations Report 2005-5177, $44 \mathrm{p}$.

Risley, J.C., Moradkhani, Hamid, Hay, L.E., and Markstrom, S.L., 2011, Statistical trends in watershed scale response to climate change in selected basins across the United States: Earth Interactions, v. 15, p. 1-26.

Roderick, M.L., Hobbins, M.T., and Farquhar, G.D., 2009, Pan evaporation trends and the terrestrial water balance. II. Energy balance and interpretation: Geography Compass, v. 3 , no. 2 , p. $761-780$. 
Schwob, H.H., 1964, Water resources of the English River, Olds Mans Creek, and Clear Creek basins in Iowa: U.S. Geological Survey Open-File Report 64-141, 57 p.

Slack, J.R., and Landwehr, J.M., 1992, Hydro-climatic data network (HCDN); a U.S. Geological Survey streamflow dataset for the United States for the study of climatic variations, 1874-1988: U.S. Geological Survey Open-File Report 92-129, 193 p.

Sohl, T.L, and Sayler, K.L., 2008, Using the FORE-SCE model to project land-cover change in the southeastern United States: Ecological Modelling, v. 219, no. 1-2, p. $49-65$.

Spahr, N.E., Boulger, R.W., and Szmajter, R.J., 1999, Water quality at basic fixed sites in the Upper Colorado River basin National Water-Quality Assessment study unit, October 1995-September 1998: U.S. Geological Survey Water-Resources Investigations Report 99-4223, 63 p.

Stainforth, D.A., Downing, T.E., Washington, Richard, Lopez, Ana, and New, M.G., 2007, Issues in the interpretation of climate model ensembles to inform decisions: Philosophical Transactions of the Royal Society A, v. 365, p. 2163-2177.

Steamboat on the Move, 2009. 2008: Business and the economy, accessed January 2009, http://www.steamboatonthemove.com/.

Steuer, J.J., and Hunt, R.J., 2001, Use of a watershedmodeling approach to assess hydrologic effects of urbanization, North Fork Pheasant Branch basin near Middleton, Wisconsin: U.S. Geological Survey Water-Resources Investigations Report 2001-4113, 49 p.

Stewart, I. T., 2009, Changes in snowpack and snowmelt runoff for key mountain regions: Hydrological Processes v. 23, no. 1, p. 78-94.

Szilagyi, Jozsef, 2001, Modeled areal evapotranspiration trends over the conterminous United States: Journal of Irrigation and Drainage Engineering, v. 127, no. 4, p. 196-200.

Szilagyi, Jozsef, Katul, G.G., and Parlange, M.B., 2001, Evapotranspiration intensifies over the conterminous United States: Journal of Water Resources Planning and Management, v. 127 , no. 6 , p. 354-362.

Tebaldi, Claudia, Smith, R.L., Nychka, D.W., and Mearns, L.O., 2005, Quantifying uncertainty in projections of regional climate change: a Bayesian approach to the analysis of multimodel ensembles: Journal of Climate, v. 18, p. 1524-1540.
Ugland, R.C., Cochran, B.J., Kretschman, R.G., Wilson, E.A., and Bennett, J.D., 1991, Water resources data, Colorado, water wear 1990, Volume 2. Colorado River Basin: U.S. Geological Survey Water-Data Report CO-90-2, 403 p.

Urban, N.M., and Keller, Klaus, 2009, Complementary observational constraints on climate sensitivity: Geophysical Research Letters, v. 36, L04708.

Viger, R.J., Hay, L.E., Jones, J.W., and Buell, G.R., 2010, Accounting for large numbers of small water bodies in the application of the Precipitation-Runoff Modeling System in the Flint River Basin, Georgia: U.S. Geological Survey Open-File Report 2010-5062, 37 p.

Viger, R.J., Hay, L.E., Markstrom, S.L., Jones, J.W. and Buell, G.R., 2011, Hydrologic effects of urbanization and climate change on the Flint River Basin, Georgia: Earth Interactions, v. 15, p. 1-25.

Vining, K.C., 2002, Simulation of streamflow and wetland storage, Starkweather Coulee Subbasin, North Dakota, water years 1981-98: U.S. Geological Survey WaterResources Investigations Report 02-4113, 28 p.

Walker, J.F., and Bullen, T.D., 2000, Trout Lake, Wisconsin: A water, energy, and biogeochemical budgets program site: U.S. Geological Survey Fact Sheet 161-99, p. 4.

Walker, J.F., Hay, L.E., Markstrom, S.L., and Dettinger, M.D., 2011, Characterizing climate-change impacts on the 1.5-year flood flow in selected basins across the United States: a probabilistic approach: Earth Interactions, v. 15, p. $1-16$.

Walter, M.T., Wilks, D.S., Parlange, J-Yves, and Schneider, R.L., 2004, Increasing evapotranspiration from the conterminous United States: Journal of Hydrometeorology, v. 5, p. 405-408.

Wilby, R.L., Charles, S.P., Zorita, Eduard, Timbal, Bertrand, Whetton P.H., and Mearns, L.O., 2004, Guidelines for use of climate scenarios developed from statistical downscaling methods, supporting material of the Intergovernmental Panel on Climate Change: Data Distribution Centre, Task Group on Data and Scenario Support for Impacts and Climate Analysis, Intergovenrnmental Panel on Climate Change, p. 27.

Wilby, R.L., Hay, L.E., and Leavesley, G. H., 1999, A comparison of downscaled and raw GCM output: implications for carbon emission scenarios in the San Juan River basin, Colorado: Journal of Hydrology, v. 225, p. 67-91.

Wilks, D.S., 1995, Statistical methods in the atmospheric sciences: An introduction: San Diego, Academic Press, 467 p. 
Appendix 


\section{Appendix. Documentation of New PRMS Modules}

\section{Introduction}

This appendix describes the inputs and outputs, equations, computations, references, assumptions, and limitations of the new PRMS modules that were developed for this study. Each described module is encoded as a Fortran 90 source code file.

\section{Styles and Formats}

The following font styles and formats are used in this Appendix:

- Module variables are identified 12-point, italic, Times New Roman font.

- Module parameters and dimensions are identified 12-point, bold, Times New Roman font.

- Constants are identified using upper case 12-point, bold, Times New Roman font.

- Module names are identified in 12-point, Courier font.

\section{Transpiration Period Modules}

The period of active transpiration is determined for each HRU by one of two user-specified options. These options are described below.

\section{transp_frost_prms}

The first option for determination of the period of active transpiration, or growing season length, (module transp_frost_prms) uses the killing frost approach (Christiansen and others, 2011). The growing season length can be defined as the time between the last and first freezing air temperatures (U.S. Department of Agriculture, National Agricultural Statistics Service, 1999) and has been used in numerous studies (Wang 1963; Brinkman, 1979; Cooter and LeDuc,1995; Kunkel and others, 2004). This module defines the growing season length as the period between the last killing frost in the spring and the first killing frost in the fall (U.S. Army Corps of Engineers, 1987).

The user specifies the solar dates of the last killing frost of the spring and the first killing frost of the fall for each HRU. The period of active transpiration are the time steps between these dates. This can be determined by using the frost date_prms module (described below in section "Preprocess Module: frost date prms"), saving HRU temperatures in the Statvar Output File, and computing the average solar date for the last killing frost of the spring and the first of the fall. The input parameters used to determine period of active transpiration are defined in table A1-1. The computed variables are defined in table A1-2.

Table A1-1. Input parameters to module transp_frost_prms.

[HRU: hydrologic response unit; nhru: number of HRUs; nmonths: number of months in a year]

\begin{tabular}{lcccccc}
\hline \multicolumn{1}{c}{ Parameter name } & Description & $\begin{array}{c}\text { Dimension } \\
\text { variable }\end{array}$ & Units & $\begin{array}{c}\text { Type } \\
\text { Range }\end{array}$ & $\begin{array}{c}\text { Default } \\
\text { value }\end{array}$ \\
\hline Spring_frost & $\begin{array}{c}\text { The solar date (number of days after winter } \\
\text { solsitce) of the last killing frost of the spring }\end{array}$ & nhru & $\begin{array}{r}\text { solar day } \\
\text { of year }\end{array}$ & integer & 1 to 366 & 111 \\
fall_frost & $\begin{array}{c}\text { The solar date (number of days after winter } \\
\text { solsitce) of the first killing frost of the fall }\end{array}$ & $\mathbf{n h r u}$ & $\begin{array}{c}\text { solar day } \\
\text { of year }\end{array}$ & integer & 1 to 366 & 264 \\
\hline
\end{tabular}

Table A1-2. Variables used in module transp_frost_prms.

[HRU: hydrologic response unit; one: a constant; nhru: number of HRUs]

\begin{tabular}{|c|c|c|c|c|}
\hline Variable name & Description & Dimension & Units & Type \\
\hline \multicolumn{5}{|c|}{ Input Variables } \\
\hline active_hrus & Number of active HRUs & ONE & none & long \\
\hline \multicolumn{5}{|c|}{ Output Variables } \\
\hline transp_on & Switch indicating whether transpiration is occurring $(0=$ no; $1=$ yes $)$ & nhru & none & long \\
\hline
\end{tabular}




\section{transp_tindex_prms}

The second option for determination of the period of active transpiration (module transp_tindex_prms) uses a temperature index approach. This module computes a temperature index, which is the sum of the daily maximum temperature for each HRU once the model reaches the transpiration starting trigger date (parameter transp_beg).
The period of active transpiration for each HRU actually begins once the temperature index reaches the temperature index threshold (parameter transp_tmax). The period of transpiration for each HRU is terminated when the simulation time step reaches the date specified by the transp_end parameter. The input parameters used to determine period of active transpiration are defined in table A1-3. The computed variables are defined in table A1-4.

Table A1-3. Input parameters to module transp_tindex_prms.

[HRU: hydrologic response unit; nhru: number of HRUs; nmonths: number of months in a year; one: a constant]

\begin{tabular}{|c|c|c|c|c|c|c|}
\hline Parameter name & Description & $\begin{array}{c}\text { Dimension } \\
\text { variable }\end{array}$ & Units & Type & Range & $\begin{array}{c}\text { Default } \\
\text { value }\end{array}$ \\
\hline hru_area & Area of each HRU & nhru & acres & float & 0.01 to $1.0 \mathrm{e} 9$ & 1 \\
\hline transp_beg & $\begin{array}{l}\text { Month to begin summing } \operatorname{tmaxf} \text { or } \\
\text { tmaxc (table A1-4) for each HRU; } \\
\text { when sum is }>=\text { to transp_tmax, } \\
\text { transpiration begins }\end{array}$ & nhru & month & long & 1 to 12 & 4 \\
\hline transp_end & $\begin{array}{l}\text { Month to stop transpiration compu- } \\
\text { tations; transpiration is computed } \\
\text { thru end of previous month }\end{array}$ & nhru & month & long & 1 to 12 & 10 \\
\hline transp_tmax & $\begin{array}{l}\text { Temperature index to determine the } \\
\text { specific date of the start of the } \\
\text { transpiration period. Subroutine } \\
\text { sums tmaxf or tmaxc (table A1-4) } \\
\text { for each HRU starting with the } \\
\text { first day of month transp } \\
\text { beg. When the sum exceeds this } \\
\text { index, transpiration begins }\end{array}$ & nhru & degrees & float & 0 to 1000 & 500 \\
\hline
\end{tabular}

Table A1-4. Variables used in module transp_tindex_prms.

[HRU: hydrologic response unit; one: a constant; nhru: number of HRUs; F, Fahrenheit]

\begin{tabular}{|c|c|c|c|c|}
\hline Variable name & Description & Dimension & Units & Type \\
\hline \multicolumn{5}{|c|}{ Input variables } \\
\hline active_hrus & Number of active HRUs & ONE & none & long \\
\hline $\begin{array}{l}\text { hru_route_or- } \\
\text { der }\end{array}$ & Routing order for HRUs & nhru & none & long \\
\hline tmaxc & HRU adjusted daily maximum temperature & nhru & degrees Celsius & float \\
\hline $\operatorname{tmaxf}$ & HRU adjusted daily maximum temperature & nhru & degrees $\mathrm{F}$ & float \\
\hline \multicolumn{5}{|c|}{ Output variables } \\
\hline$\underset{\text { on }}{\text { basin_transp }}$ & $\begin{array}{l}\text { Switch indicating whether transpiration is } \\
\text { occurring anywhere in the basin }(0=\text { no; } \\
1=\text { yes })\end{array}$ & ONE & none & long \\
\hline transp_on & $\begin{array}{l}\text { Switch indicating whether transpiration is } \\
\text { occurring }(0=\text { no; } 1=\text { yes })\end{array}$ & nhru & none & long \\
\hline
\end{tabular}




\section{Potential Evapotranspiration Modules}

\section{potet_jh_prms}

Potential evapotranspiration (PET) is computed for each HRU by one of three user-specified options. The first option (module potet jh_prms) is the modified JensenHaise formulation (Jensen and others, 1970), in which PET is computed as a function of air temperature, solar radiation, and two coefficients that can be estimated using regional air temperature, elevation, vapor pressure, and plant cover. The input parameters used to compute the potential evapotranspiration variables and are defined in table A1-5. The computed variables are defined in table A1-6. Equation symbols, used in this section of the report, which correspond directly to PRMS input or output, are defined in these two tables.

PET is calculated as:

Table A1-5. Input parameters to module potet_jh_prms.

$$
\begin{gathered}
\text { potet }_{H R U}^{m}=\mathrm{jh} \_ \text {coef }_{\text {month }}\left(\operatorname{tavg} f_{H R U}-\mathrm{jh} \_ \text {coef_hru }\right) \frac{\operatorname{swrad}_{H R U}^{m}}{2.54 \lambda_{H R U}} \\
\lambda_{H R U}=597.3-\left(0.5653 \operatorname{tavg} f_{H R U}\right)
\end{gathered}
$$

where

$$
\begin{aligned}
& \text { is the latent heat of vaporization on the } \\
& \lambda_{\text {HRU }} \quad \text { HRU for time step } m \text {, calories/gram }
\end{aligned}
$$

\begin{tabular}{|c|c|c|c|c|c|c|}
\hline $\begin{array}{c}\text { Parameter } \\
\text { name }\end{array}$ & Description & $\begin{array}{c}\text { Dimension } \\
\text { variable }\end{array}$ & Units & Type & Range & $\begin{array}{c}\text { Default } \\
\text { value }\end{array}$ \\
\hline hru_area & Area of each HRU & nhru & acres & float & 0.01 to $1.0 \mathrm{e} 9$ & 1 \\
\hline jh_coef & $\begin{array}{l}\text { Monthly air temperature } \\
\text { coefficient used in Jensen- } \\
\text { Haise potential evapo- } \\
\text { transpiration computa- } \\
\text { tions. }\end{array}$ & nmonths & $\begin{array}{c}\text { per } \\
\text { degrees }\end{array}$ & float & 0.005 to 0.06 & 0.014 \\
\hline jh_coef_hru & $\begin{array}{l}\text { Air temperature coefficient } \\
\text { used in Jensen-Haise } \\
\text { potential evapotranspira- } \\
\text { tion computations for } \\
\text { each HRU. }\end{array}$ & nhru & $\begin{array}{c}\text { per } \\
\text { degrees }\end{array}$ & float & 5 to 20 & 13 \\
\hline temp_units & $\begin{array}{l}\text { Units for measured tem- } \\
\text { perature }(0=\text { Fahrenheit; } \\
1=\text { Celsius })\end{array}$ & ONE & none & long & 0 to 1 & 0 \\
\hline
\end{tabular}

[HRU: hydrologic response unit; nhru: number of HRUs; nmonths: number of months in a year; one: a constant]

\begin{tabular}{|c|c|c|c|c|}
\hline Variable name & Description & Dimension & Units & Type \\
\hline \multicolumn{5}{|c|}{ Input variables } \\
\hline active_hrus & Number of active HRUs & ONE & none & long \\
\hline basin_area_inv & Inverse of total basin area as sum of HRU areas & ONE & $1 /$ acres & float \\
\hline hru_route_order & Routing order for HRUs & nhru & none & long \\
\hline route_on & Kinematic routing switch $(0=$ daily; $1=$ storm period $)$ & ONE & none & long \\
\hline swrad & Computed shortwave radiation for each HRU & nhru & langleys & float \\
\hline tavgc & HRU adjusted daily average temperature & nhru & degrees Celsius & float \\
\hline $\operatorname{tavgf}$ & HRU adjusted daily average temperature & nhru & degrees F & float \\
\hline tmaxc & HRU adjusted daily maximum temperature & nhru & degrees Celsius & float \\
\hline $\operatorname{tmaxf}$ & HRU adjusted daily maximum temperature & nhru & degrees $\mathrm{F}$ & float \\
\hline newday & Switch signifying the start of a new day $(0=$ no; $1=$ yes $)$ & ONE & none & long \\
\hline
\end{tabular}

Table A1-6. Variables used in module potet_jh_prms.

[HRU: hydrologic response unit; one: a constant; nhru: number of HRUs; F, Fahrenheit] 
Table A1-6. Variables used in module potet_jh_prms._Continued

[HRU: hydrologic response unit; one: a constant; nhru: number of HRUs; F, Fahrenheit]

\begin{tabular}{lcccc}
\hline \multicolumn{1}{c}{ Variable name } & Description & Dimension & Units & Type \\
\hline \multicolumn{4}{c}{ Output variables } \\
basin_potet & Basin area-weighted average of potential evapotranspiration & ONE & inches & float \\
potet & Potential evapotranspiration on an HRU & nhru & inches & float \\
\hline
\end{tabular}

\section{potet_hamon_hru_prms}

The second option (module potet hamon hru prms) for computing PET is the empirical Hamon formulation, in which PET is computed as a function of daily mean air temperature and possible hours of sunshine according to (Hamon, 1961; Murray, 1967; and Federer and Lash, 1978). The input parameters used to compute the PET variables are defined in table A1-7. The computed variables are defined in table A1-8. Equation symbols, used in this section of the report, which correspond directly to PRMS input or output, are defined in these two tables. PET is calculated as:

$$
\begin{gathered}
\text { potet }_{H R U}^{m}=\text { hamon_coef }{ }_{H R U}\left(\operatorname{sh}_{H R U}^{m}\right)^{2} \rho_{H R U} \\
\rho_{H R U}=216.7 \frac{6.108 e^{\left(\frac{17.26939^{*} \operatorname{tavgc}_{H R U}}{\operatorname{tavgc}_{H R U}+273.3}\right)}}{\operatorname{tavg}_{H R U}+273.3}
\end{gathered}
$$

where

$$
\begin{aligned}
& s h_{H R}^{m} \quad \text { is length of the daylight period, for time } \\
& \text { step } m \text {, radians per 12-hour period, and }
\end{aligned}
$$

$\rho_{H R U} \quad$ is the saturated water-vapor density (absolute humidity), grams per cubic meter.

\section{potet_pan_prms}

The third option (module potet_pan_prms) is used when pan evaporation data from one or more measurement stations are available. The station associated with each HRU is specified by parameter hru_pansta (table A1-9). PET is computed from the measured pan evaporation and a monthly coefficient. The input parameters used to compute the potential evapotranspiration variables and are defined in table A1-9. The computed variables are defined in table A1-10. Equation symbols, used in this section of the report, which correspond directly to PRMS input or output, are defined in

\begin{tabular}{|c|c|c|c|c|c|c|}
\hline Parameter name & Description & $\begin{array}{c}\text { Dimension } \\
\text { variable }\end{array}$ & Units & Type & Range & $\begin{array}{c}\text { Default } \\
\text { value }\end{array}$ \\
\hline hamon_coef & $\begin{array}{l}\text { Monthly air temperature } \\
\text { coefficient used in Hamon } \\
\text { potential evapotranspira- } \\
\text { tion computations, see } \\
\text { PRMS manual }\end{array}$ & nmonths & $\begin{array}{l}\text { inch-cubic } \\
\text { meter } \\
\text { per } \\
\text { gram }\end{array}$ & float & 0.004 to 0.008 & 0.0055 \\
\hline hru_area & Area of each HRU & nhru & acres & float & 0.01 to $1.0 \mathrm{e} 9$ & 1 \\
\hline temp_units & $\begin{array}{l}\text { Units for measured tem- } \\
\text { perature }(0=\text { Fahrenheit; } \\
1=\text { Celsius })\end{array}$ & ONE & none & long & 0 to 1 & 0 \\
\hline
\end{tabular}
these two tables. PET is calculated as:

Table A1-7. Input parameters to module potet_hamon_hru_prms.

[HRU: hydrologic response unit; nmonths: number of months in a year; nhru: number of HRUs; one: a constant; F, Fahrenheit] 
Table A1-8. Variables used in module potet_hamon_hru_prms.

[HRU: hydrologic response unit; one: a constant; nhru: number of HRUs; ndays: number of days in a year]

\begin{tabular}{|c|c|c|c|c|}
\hline Variable name & Description & Dimension & Units & Type \\
\hline active_hrus & Number of active HRUs & ONE & none & long \\
\hline basin_area_inv & $\begin{array}{l}\text { Inverse of total basin area as sum of HRU } \\
\text { areas }\end{array}$ & ONE & 1/acres & float \\
\hline hru_route_order & Routing order for HRUs & nhru & none & long \\
\hline route_on & $\begin{array}{l}\text { Kinematic routing switch }(0=\text { daily; } \\
1=\text { storm period })\end{array}$ & ONE & none & long \\
\hline soltab_sunhrs & $\begin{array}{l}\text { Hours between sunrise and sunset for each } \\
\text { HRU }\end{array}$ & $\begin{array}{l}\text { ndays, } \\
\text { nhru }\end{array}$ & hours & float \\
\hline $\operatorname{tavgc}$ & HRU adjusted daily average temperature & nhru & degrees Celsius & float \\
\hline $\operatorname{tmaxc}$ & HRU adjusted daily maximum temperature & nhru & degrees Celsius & float \\
\hline $\operatorname{tmaxf}$ & HRU adjusted daily maximum temperature & nhru & degrees Fahrenheit & float \\
\hline newday & $\begin{array}{l}\text { Switch signifying the start of a new day } \\
(0=\text { no; } 1=\text { yes })\end{array}$ & ONE & none & long \\
\hline \multicolumn{5}{|c|}{ Output variables } \\
\hline basin_potet & Basin area-weighted average of potential et & ONE & inches & float \\
\hline potet & Potential evapotranspiration on an HRU & nhru & inches & float \\
\hline
\end{tabular}

Table A1-9. Input parameters to module potet_pan_prms.

[HRU: hydrologic response unit; nmonths: number of months in a year; nhru: number of HRUs]

\begin{tabular}{|c|c|c|c|c|c|c|}
\hline Parameter name & Description & $\begin{array}{c}\text { Dimension } \\
\text { variable }\end{array}$ & Units & Type & Range & $\begin{array}{c}\text { Default } \\
\text { value }\end{array}$ \\
\hline epan_coef & Evaporation pan coefficient & nmonths & none & float & 0.2 to 3 & 1 \\
\hline hru_area & Area of each HRU & nhru & acres & float & 0.01 to $1.0 \times 10^{9}$ & 1 \\
\hline hru_pansta & $\begin{array}{l}\text { Index of pan evaporation station } \\
\text { used to compute HRU potential } \\
\text { evapotranspiration }\end{array}$ & nhru & none & long & 0 to 0 & 0 \\
\hline transp_beg & $\begin{array}{l}\text { Month to begin summing tmaxf } \\
\text { or tmaxc (table A1-4) for } \\
\text { each HRU; when sum is }>= \\
\text { to transp_tmax (table } \\
\text { A1-3), transpiration begins }\end{array}$ & nhru & month & long & 1 to 12 & 4 \\
\hline transp_end & $\begin{array}{l}\text { Month to stop transpiration } \\
\text { computations; transpiration is } \\
\text { computed thru end of previous } \\
\text { month }\end{array}$ & nhru & month & long & 1 to 12 & 10 \\
\hline transp_beg & $\begin{array}{l}\text { Month to begin summing tmaxf or } \\
\text { tmaxc (table A1-4) for each HRU; } \\
\text { when sum is }>=\text { to transp_- } \\
\text { tmax (table A1-3), transpiration } \\
\text { begins }\end{array}$ & nhru & month & long & 1 to 12 & 4 \\
\hline transp_end & $\begin{array}{l}\text { Month to stop transpiration } \\
\text { computations; transpiration is } \\
\text { computed thru end of previous } \\
\text { month }\end{array}$ & nhru & month & long & 1 to 12 & 10 \\
\hline
\end{tabular}


Table A1-10. Variables used in module potet_pan_prms.

[HRU: hydrologic response unit; one: a constant; nhru: number of HRUs; nevap: number of climate stations that measure pan evaporation]

\begin{tabular}{|c|c|c|c|c|}
\hline Variable name & Description & Dimension & Units & Type \\
\hline \multicolumn{5}{|c|}{ Input variables } \\
\hline active_hrus & Number of active HRUs & ONE & none & long \\
\hline basin_area_inv & $\begin{array}{l}\text { Inverse of total basin area as sum of HRU } \\
\text { areas }\end{array}$ & ONE & 1/acres & float \\
\hline hru_route_order & Routing order for HRUs & nhru & none & long \\
\hline pan_evap & $\begin{array}{l}\text { Measured pan evaporation at each measure- } \\
\text { ment station }\end{array}$ & nevap & inches & float \\
\hline route_on & $\begin{array}{l}\text { Kinematic routing switch }(0=\text { daily; } 1=\text { storm } \\
\text { period })\end{array}$ & ONE & none & long \\
\hline newday & $\begin{array}{l}\text { Switch signifying the start of a new day } \\
(0=\text { no; } 1=\text { yes })\end{array}$ & ONE & none & long \\
\hline \multicolumn{5}{|c|}{ Output variables } \\
\hline basin_potet & Basin area-weighted average of potential et & ONE & inches & float \\
\hline potet & Potential evapotranspiration on an HRU & nhru & inches & float \\
\hline
\end{tabular}

\section{Preprocess Module: frost_date_prms}

Determination of the mean last killing frost of the spring and the first killing frost of the fall can be done with the PRMS preprocessing module frost date_prms. This module is activated by running the PRMS executable with the -preprocess argument on the command line. For each
HRU, this module will determine the solar year dates defining the active period of transpiration for each year in the specified period of simulation. The mean values of these dates are written out to a PRMS Parameter File at both the HRU and basin resolution. The input parameters used to compute the frost date outputs and are defined in table A1-11. The computed variables are defined in table A1-12.

Table A1-11. Input parameters to module frost_date_prms.

[HRU: hydrologic response unit; nhru: number of HRUs; one: a constant]

\begin{tabular}{lccccc}
\hline \multicolumn{1}{c}{ Parameter name } & \multicolumn{1}{c}{ Description } & $\begin{array}{c}\text { Dimension } \\
\text { variable }\end{array}$ & Units & Type & $\begin{array}{c}\text { Default } \\
\text { value }\end{array}$ \\
\hline frost_temp & $\begin{array}{c}\text { Temperature of the killing } \\
\text { frost }\end{array}$ & ONE & $\begin{array}{c}\text { temperature } \\
\text { degrees }\end{array}$ & float & -10.0 to 32.0 \\
temp_units & $\begin{array}{c}\text { Units for measured tem- } \\
\text { perature }(0=\text { Fahrenheit; } \\
1=\text { Celsius })\end{array}$ & ONE & none & long & 0 or 1 \\
& Area of each HRU & nhru & acres & float & 0.01 to \\
hru_area & & & & $1.0 \times 10^{9}$ \\
\hline
\end{tabular}


Table A1-12. Variables used in module frost_date_prms.

[HRU: hydrologic response unit; one: a constant; nhru: number of HRUs]

\begin{tabular}{|c|c|c|c|c|}
\hline Variable name & Description & Dimension & Units & Type \\
\hline \multicolumn{5}{|c|}{ Input variables } \\
\hline active_hrus & Number of active HRUs & ONE & none & long \\
\hline basin_area_inv & $\begin{array}{l}\text { Inverse of total basin area as sum of HRU } \\
\text { areas }\end{array}$ & ONE & $1 /$ acres & float \\
\hline hru_route_order & Routing order for HRUs & nhru & none & long \\
\hline route_on & $\begin{array}{l}\text { Kinematic routing switch }(0=\text { daily; } 1=\text { storm } \\
\text { period) }\end{array}$ & ONE & none & long \\
\hline soltab_sunhrs & $\begin{array}{l}\text { Hours between sunrise and sunset for each } \\
\text { HRU }\end{array}$ & $\begin{array}{c}\text { ndays, } \\
\text { nhru }\end{array}$ & hours & float \\
\hline
\end{tabular}




\section{References Cited}

Brinkman, W.A.R., 1979, Growing season length as an indicator of climatic variations?: Climatic Change, v. 2, p. $127-138$.

Christiansen, D.E., Markstrom, S.L., and Hay, L.E., 2011, Impacts of climate change on growing season in the United States: Earth Interactions, v. 15, p. 1-17.

Cooter, E.J., and LeDuc, S.K., 1995, Recent frost date trends in the north-eastern USA: International Journal of Climatology, v. 15 , p. $65-67$.

Federer, A.C., and Lash, D., 1978, Brook: A hydrologic simulation model for eastern forests: Durham, New Hampshire, University of New Hampshire, Water Resources Research Center, Research Report No. 19, 84 p.

Hamon, W.R., 1961, Estimating potential evapotranspiration: Proceedings of the American Society of Civil Engineers, Journal of the Hydraulic Division, v. 87, no. HY3, p. $107-120$.
Jensen, M.E., Rob, D.C.N., and Franzoy, C.E., 1970, Scheduling irrigations using climate-crop-soil data: Journal of the Irrigation and Drainage Division, American Society of Civil Engineers, v. 96, no. IR1, p. 25-38.

Kunkel, K.D., Easterling, R., Hubbard, K., and Redmond, K., 2004, Temporal variations in frost-free season in the United States: 1895-2000: Geophysics Research. Letters, v. 31, no. L03201, doi:10.1029/2003GL018624

Murray, F.W., 1967, On the computation of saturation vapor pressure: Journal of Applied Meteorolgy, v. 6, p. 203-204.

United States Army Corps of Engineers, 1987, Corps of Engineers wetlands delineation manual: U.S. Army Corps of Engineers Technical Report Y-87-1, variously paginated.

United States Department of Agriculture National Agricultural Statistics Service, 1999, Grain, hay, potato, cotton, soy bean, and tobacco, production by state, 1998, in Famighetti, R., ed., 2000 World Almanac and Book of Facts, Mahwah, N.J.: Primedia Reference, p. 1024.

Wang, J.Y., 1963, Agricultural meteorology: Pacemaker Press, p. 693.
Publishing support provided by:

Denver Publishing Service Center

For more information concerning this publication, contact:

Chief, Branch of Regional Research, Central Region

Box 25046, Mail Stop 418

Denver, CO 80225

(303) 236-5021

Or visit the USGS National Research Program Web site at: http://water.usgs.gov/nrp/ 


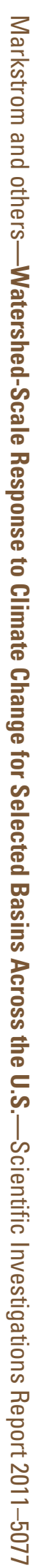

